CAMILA SOUIT

EXOESQUELETO DE MEMBRO INFERIOR COM DOIS GRAUS DE LIBERDADE ATIVOS

São Paulo

2016 
CAMILA SOUIT

EXOESQUELETO DE MEMBRO INFERIOR COM DOIS GRAUS DE LIBERDADE ATIVOS

Dissertação apresentada à Escola Politécnica da Universidade de São Paulo para obtenção do Título de Mestre em Ciências.

São Paulo

2016 
Este exemplar foi revisado e corrigido em relação à versão original, sob responsabilidade única do autor e com a anuência de seu orientador.

São Paulo, de de

Assinatura do autor:

Assinatura do orientador:

Catalogação-na-publicação

Souit, Camila

Exoesqueleto de membro inferior com dois graus de liberdade ativos / C.

Souit -- versão corr. -- São Paulo, 2016.

$152 \mathrm{p}$.

Dissertação (Mestrado) - Escola Politécnica da Universidade de São Paulo. Departamento de Engenharia Mecânica.

1.Bioengenharia 2.Exoesqueleto I.Universidade de São Paulo. Escola Politécnica. Departamento de Engenharia Mecânica II.t. 
CAMILA SOUIT

\section{EXOESQUELETO DE MEMBRO INFERIOR COM DOIS GRAUS DE LIBERDADE ATIVOS}

Dissertação apresentada à Escola Politécnica da Universidade de São Paulo para obtenção do Título de Mestre em Ciências.

Área de Concentração:

Engenharia de Controle e Automação Mecânica

Orientador:

Prof. Dr. Arturo Forner-Cordero

São Paulo

2016 


\section{AGRADECIMENTOS}

Agradeço a toda a minha família, principalmente, ao meu querido marido, Antônio, por sua dedicação e por me apoiar em todos os desafios da minha vida, incluindo esse trabalho.

Agradeço ao professor Arturo por sua orientação, paciência e confiança.

Agradeço ao meu pai, Emir, e ao Fabio por viabilizar a construção de um exoesqueleto robusto.

Agradeço a todos os alunos do laboratório, principalmente, à Dafne, por me acompanhar em todo o desenvolvimento e experimentos do trabalho. 
Faça o que puder, com o que tiver, onde estiver. (Theodore Roosevelt) 


\section{RESUMO}

Pesquisas sobre próteses ativas e exoesqueletos têm se intensificado nas últimas décadas. Seu uso para reabilitação, aumento de força ou substituição de um membro amputado já está sendo utilizado comercialmente. Porém, um dos desafios para o controle deste tipo de dispositivo é a identificação dos parâmetros das articulações humanas para que o equipamento simule o mesmo comportamento e a interface homemmáquina seja mais eficaz e confortável.

Este trabalho apresenta o desenvolvimento, construção e validação de um exoesqueleto que é um dispositivo para estudo da marcha. Em outras palavras, o exoesqueleto apresentado é capaz de medir a força de interação com o corpo humano bem como a posição angular das articulações do joelho e tornozelo durante a marcha. Com essas medições é possível calcular os parâmetros de impedâncias dessas articulações.

A revisão bibliográfica sobre exoesqueletos foi necessária para a definição dos requisitos do projeto. $\mathrm{O}$ projeto do exoesqueleto desenvolvido pela autora durante o trabalho de conclusão de curso foi revisto de acordo com os requisitos estabelecidos. Assim, o novo projeto, chamado de Protótipo II ou ExoLoLi, é capaz de suprir as deficiências do primeiro projeto e atender a todos os requisitos para ser uma ferramenta de estudo da marcha.

O ExoLoLi foi construído e experimentos preliminares foram realizados para a sua validação como ferramenta de estudo da marcha. Foi possível confirmar que o exoesqueleto faz as medições de força de interação e de posição corretamente. Também foi possível verificar que o exoesqueleto interfere no padrão natural da marcha. De qualquer forma, o exoesqueleto poderá ser usado, não apenas para o cálculo dos parâmetros de impedância, mas também para estudo de consumo energético com diferentes tipos de controle e para diferentes aplicações (como reabilitação e aumento de força), dependendo do controle programado para o seu funcionamento. 


\begin{abstract}
Research on active prosthetics and exoskeletons has been intensified in recent decades. Its use for rehabilitation, strength increase or replacement of a disabled member is already being used commercially. But one of the challenges for the control of this type of device is the identification of the human joint's parameters so the machine is able to simulate the same behavior and the man-machine interface is more effective and comfortable.

This dissertation presents the development, construction and validation of an exoskeleton which is a device for gait study. In other words, the presented exoskeleton is capable of measuring the interaction force with the human body as well as the angular position of the knee and ankle joints during gait. With these measurements it is possible to calculate the impedance parameters of these joints.

The literature review about exoskeletons was necessary to define the project requirements. The exoskeleton developed by the author to obtain the engineering degree (undergraduate paper) has been reviewed in accordance with the established requirements. So the new exoskeleton design, named as Prototype II or ExoLoLi, was able to address the weaknesses of the first project and meet all the requirements to be a gait study tool.

The ExoLoLi was built and preliminary experiments were performed to validate it as gait study tool. It was confirmed that the exoskeleton is able to measure the interaction forces and the angular position correctly. It was also observed that the exoskeleton interferes with the natural gait pattern. Nevertheless, the exoskeleton can be used not only for calculating the human impedance parameters, but also to analyze the energy consumption using different control strategies and to be used in different applications (such as rehabilitation or strength increase) depending on the programmed control for its operation.
\end{abstract}




\section{LISTA DE FIGURAS}

Figura 1: Fases de um ciclo da marcha humana. As porcentagens mostram a localização aproximada dos eventos de contato (SOUIT e MALGUEIRO, 2012) apud (HERR, 2008). 2

Figura 2: Foto do projeto concluído do exoesqueleto BLEEX (ZOSS, 2006)...... 4

Figura 3: Exoesqueleto "HAL-5" à esquerda e "E-Legs" à direita, (GUIZZO e GOLDSTEIN, 2005) e (STRICKLAND, 2012), respectivamente. 6

Figura 4: (a) LOKOMAT, adaptado de (AIM2WALK, 2014); (b) EXOKanguera, adaptado de (NOGUEIRA, SIQUEIRA, et al., 2014). 8

Figura 5: À esquerda, protótipo do Exosuit; à direita, ilustração mostrando os principais componentes do Exosuit. Adaptado de (ASBECK, DYER, et al., 2013)....... 12

Figura 6: À esquerda, protótipo do exoesqueleto semi-ativo; à direita, figura ilustrando o trabalho em paralelo com a perna humana. Adaptado de (COLLINS, WIGGIN e SAWICKI, 2015). 13

Figura 7: Exoesqueleto autônomo para redução de consumo energético. Adaptado de (MOONEY, ROUSE e HERR, 2014). 14

Figura 8: Descrição dos planos anatômicos do corpo humano. Adaptado de (HERR, 2008). 17

Figura 9: Movimentos do tornozelo. Adaptado de (OUTSIDE, 2011). 19

Figura 10: Torque nas articulações durante a marcha. Adaptado de (HERR, 2008).

Figura 11: Potência nas articulações durante a marcha. Adaptado de (HERR, 2008).

Figura 12: Explicação do princípio de funcionamento da redução harmônica. Adaptado de (HARMONICDRIVE, 2011). 25 
Figura 13: Dentes de engrenagem dificultam o caminho inverso da transmissão. Adaptado de (BACKDRIVABILITY, 2011).

Figura 14: Vista em corte do quarto módulo atuador (SOUIT, MALGUEIRO, et al., 2013).

Figura 15: Módulo atuador completo (SOUIT e MALGUEIRO, 2012). 28

Figura 16: Montagem dos apoios de fibra de carbono (SOUIT e MALGUEIRO, 2012) e (SOUIT, MALGUEIRO, et al., 2013), respectivamente. 28

Figura 17: Primeira versão do protótipo acoplado na perna (SOUIT, MALGUEIRO, et al., 2013). 28

Figura 18: Tutor de quadril (SOUIT e MALGUEIRO, 2012). 29

Figura 19: Exoesqueleto com acoplamentos no quadril, coxa e canela (SOUIT, MALGUEIRO, et al., 2013). 29

Figura 20: Comparação entre a "Caixa de redução" do joelho e do tornozelo (SOUIT e MALGUEIRO, 2012). 30

Figura 21: Montagem entre a "caixa de redução" otimizada e o harmonic drive (SOUIT e MALGUEIRO, 2012).

Figura 22: Modificação feita na "Caixa da redução" para facilitar a usinagem (SOUIT e MALGUEIRO, 2012).

Figura 23: Módulo atuador otimizado e finalizado (SOUIT e MALGUEIRO, 2012) e (SOUIT, MALGUEIRO, et al., 2013), respectivamente.

Figura 24: Detalhes da peça "Apoio Motor" (SOUIT e MALGUEIRO, 2012). . 32

Figura 25: Montagem entre o "Apoio Motor" e o "sistema de segurança" (SOUIT e MALGUEIRO, 2012). 33

Figura 26: Tutor plástico para fratura da tíbia, fabricado pela Dilepé. Adaptado de (MÉDICO, 2012) 
Figura 28: Representação do quadrilátero articulado (SOUIT, MALGUEIRO, et al., 2013).

Figura 29: Montagem completa do módulo do tornozelo (SOUIT e MALGUEIRO, 2012).

Figura 30: Protótipo I do exoesqueleto completo. 36

Figura 31: Vista em corte do modulo atuador do protótipo I. 38

Figura 32: Sentido da força axial gerada pelo Harmonic Drive em funcionamento. Adaptado de (HARMONICDRIVE, 2015)

Figura 33: Apoio do Flexspline. 39

Figura 34: Vista em corte do modelo 3D novo módulo atuador... 40

Figura 35: Vista em corte do novo módulo atuador com lista de peças 40

Figura 36: À esquerda, força máxima gerada pelos músculos supinadores, adaptado de (KAPANDJI, 2000); à direita, o transporte da força aplicada pelo usuário sobre o exoesqueleto no apoio do pé provoca a mesma força axial sobre o módulo atuador do joelho com um momento - a distância considerada é para o caso mais crítico, pessoa de $1,90 \mathrm{~m}$ de altura (detalhes sobre a estrutura serão explicados posteriormente, no item "Melhorias da estrutura")

Figura 37: À esquerda, vista em corte das peças que fazem o acoplamento entre o eixo do motor e a redução; à direita, vista em perspectiva da peça "Anel de pressão"... 42

Figura 38: Vista em corte do conjunto "Módulo atuador" com "Célula de Carga". Com o conjunto completo, é possível garantir o posicionamento do Wave Generator e do Flex Spline quando o Harmonic Drive está em funcionamento.

Figura 39: Conceito utilizado no Protótipo I para o desacoplamento do módulo do tornozelo 45

Figura 40: (A) Descrição do módulo passivo com os principais componentes e distância transversal do CG. (B) Distância transversal do CG do módulo ativo. 46 
Figura 41: Conceito usado no protótipo I para o ajuste da altura da haste da canela.

Figura 42: Células de carga do protótipo I.

Figura 43: Parametrização dos comprimentos dos membros de acordo com a altura. Adaptado de (WINTER, 2005).

Figura 44: Ajuste do exoesqueleto para a coxa. 49

Figura 45: Ajuste do exoesqueleto para a canela. 49

Figura 46: À esquerda, módulo do tornozelo ajustado para um usuário de 1,90m de altura; à direita, módulo do tornozelo ajustado para um usuário de $1,50 \mathrm{~m}$ de altura. 50

Figura 47: Alinhamento dos módulos atuadores: à esquerda, no protótipo I, o peso do módulo atuador do tornozelo à frente do eixo da estrutura causava desconforto para caminhar; à direita, o protótipo II apresenta ambos módulos atuadores alinhados com a estrutura.

Figura 48: Diagrama de blocos da arquitetura de controle por impedâncias. Adaptado de (ARAUJO, TANNURI e FORNER-CORDERO, 2012).

Figura 49: Sinais provenientes de um encoder incremental (SYSTEMS, 2014) 56

Figura 50: Gráfico fornecido pelo driver do motor - eixo vertical é o ângulo (qc) e o eixo horizontal é o tempo (ms). A medida máxima do gráfico (18000qc) representa $32,4^{\circ}$ no movimento do exoesqueleto.

Figura 51: Configuração de uma célula de carga. Adaptado de (ISHIDA, 2015).

Figura 52: Ponte de Wheatstone completa. Adaptado de (ISHIDA, 2015). 58

Figura 53: Regiões onde ocorre maior deformação da célula de carga e comportamento da deformação (formato de paralelogramo). Adaptado de (ISHIDA, 2015). 
Figura 54: Configuração de instalação dos extensômetro ideal (deformações de módulo igual). Adaptado de (ISHIDA, 2015).

Figura 55: Configuração de instalação dos extensômetros na "haste da canela" protótipo I (SOUIT e MALGUEIRO, 2012).

Figura 56: Célula de carga do módulo do joelho - Protótipo II.

Figura 57: Célula de carga do módulo do tornozelo - Protótipo II.

Figura 58: Instalação dos extensômetros nas células de carga do Protótipo II.... 62

Figura 59: Instalação dos extensômetros e solda da ponte de Wheatstone. 62

Figura 60: Curva esperada durante a calibração da célula de carga. 63

Figura 61: Configuração para a calibração da célula de carga. 64

Figura 62: Curva obtida experimentalmente durante a calibração da célula de carga. 64

Figura 63: Cálculo do torque na articulação pela variação de tensão medida na célula de carga. 65

Figura 64: Exoesqueleto completo: à esquerda, modelo matemático; à direita, Protótipo II construído. 66

Figura 65: Diferentes configurações para o exoesqueleto: (a) exoesqueleto completo - atuação no joelho e no tornozelo; (b) Módulo do joelho - atuação sobre a articulação do joelho apenas; (c) Módulo do tornozelo - atuação sobre o módulo do tornozelo somente (módulo passivo na articulação do joelho) (SOUIT, COELHO, et al., 2016).

Figura 66: Comparação entre os módulos atuador e passivo - protótipos construídos.

Figura 67: Instrumentação para aquisição de dados: à esquerda, usuário sem o exoesqueleto; à direita, usuário com exoesqueleto (SOUIT, COELHO, et al., 2016)... 69 
Figura 68: Resultados de EMG para marcha normal, com o exoesqueleto e com o exoesqueleto com carga adicional (1 kg): (a) músculo Rectus Femoris da perna direita (RRf); músculo Biceps Femoris da perna direita (RBf). Adaptado de (SOUIT, COELHO, et al., 2016).

Figura 69: Disposição dos equipamentos para o teste em bancada do módulo do joelho. 71

Figura 70: Descrição do experimento de bancada com o módulo do joelho. Indicação dos dispositivos de medição e de controle.

Figura 71: Configuração do software EPOS Studio para o controle de posição.. 73

Figura 72: Deformação real da célula de carga durante o teste em bancada. ...... 75

Figura 73: Comparação entre a deformação prevista em elementos finitos e a deformação real. 76

Figura 74: Pinos para limitar o movimento da célula de carga - posicionados nos limites de flexão-extensão do joelho... 76

Figura 75: Calibração da nova célula de carga. 77

Figura 76: Configuração do exoesqueleto para a medição da força de interação para a simulação do "controle seguidor" (exoesqueleto acompanhando o movimento do usuário). 78

Figura 77: Torque medido pela célula de carga durante os experimentos com o exoesqueleto passivo.

Figura 78: Fixação entre o eixo de saída e a haste a ser movida (vista em corte).

Figura 79: Detalhe no contato entre as peças: decomposição de forças.

Figura 80: Condição de contorno da simulação - rigidez transversal da estrutura do módulo do tornozelo. 
Figura 81: Resultado da análise - deslocamento de aprox 40mm para a aplicação

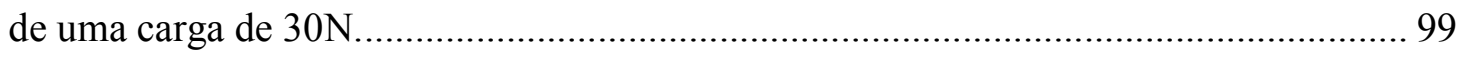

Figura 82: Condições de contorno da análise em elementos finitos da haste da canela do protótipo I. 100

Figura 83: Deformações observadas na análise em elementos finitos da "haste da canela" - protótipo I 100

Figura 84: Condições de contorno da análise de elementos finitos da célula de carga do Protótipo II. 101

Figura 85: Resultado da análise - deformações iguais observadas pelos quatro extensômetros.

Figura 86: Disposição dos equipamentos para o teste em bancada do módulo do joelho com as dimensões para o cálculo do momento de inércia. 102

Figura 87: Ferramenta de regressão disponível em "Análise de Dados" do Excel 2007. 104

Figura 88: Seleção dos dados para o cálculo da regressão. 105

Figura 89: Formato da apresentação dos resultados da regressão. 105 


\section{LISTA DE TABELAS}

Tabela 1: Resumo e referência dos principais exoesqueletos estudados 15

Tabela 2: Amplitudes angulares máximas das articulações durante a marcha. Adaptado de (KAPANDJI, 2000) e (ZOSS, 2006).

Tabela 3: Especificações do motor Maxon e da redução harmônica 26

Tabela 4: Comparação entre as características dos módulos atuadores. 44

Tabela 5: Especificações do módulo atuador do Protótipo II 44

Tabela 6: Valores da calibração da célula de carga. 64

Tabela 7: Parâmetros de impedância do exoesqueleto (módulo do joelho). 74

Tabela 8: Valores de torque obtidos pela célula de carga durante o experimento (média e variância). 79

Tabela 9: Sinais de eletromiografia do músculo Rectus Femoris durante os experimentos com o exoesqueleto passivo 80

Tabela 10: Parâmetros inercial do exoesqueleto para cada experimento. 103 


\section{SUMÁRIO}

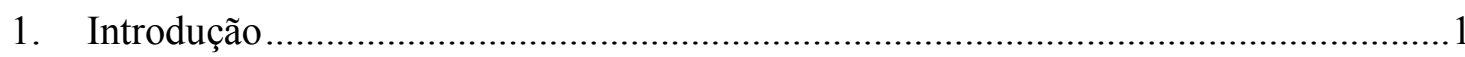

2. Exoesqueletos - Revisão Bibliográfica .................................................................

2.1. Classificação e aplicação dos exoesqueletos ......................................................

2.1.1. Exoesqueletos para amplificação das capacidades humanas ..............3

2.1.2. Exoesqueletos para suporte funcional .............................................4

2.1.3. Exoesqueletos para reabilitação …................................................

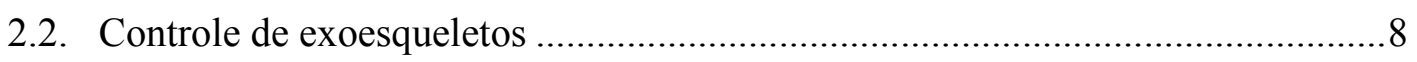

2.2.1. Controle de impedância............................................................... 9

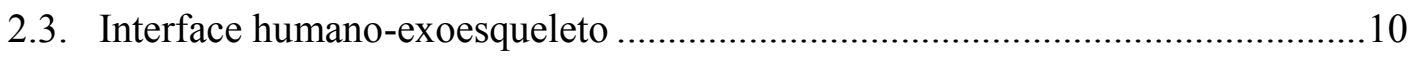

2.4. Mecânica dos exoesqueletos de membro inferior ...........................................11

2.4.1. Estruturas dos exoesqueletos de membro inferior...........................11

2.4.2. Atuadores de exoesqueletos .................................................... 12

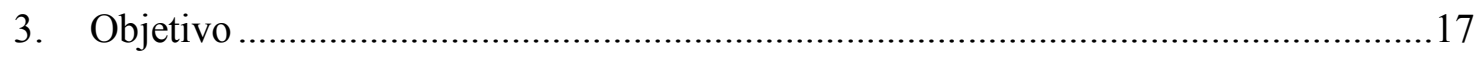

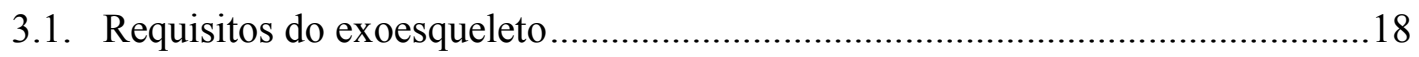

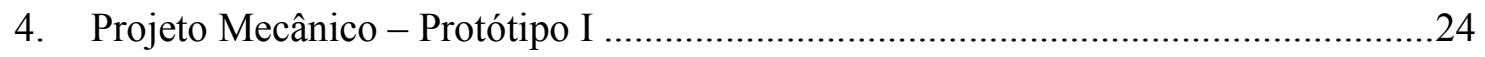

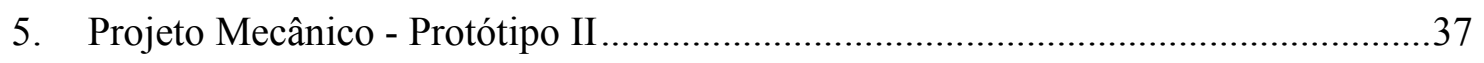

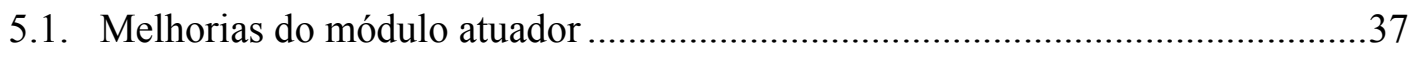

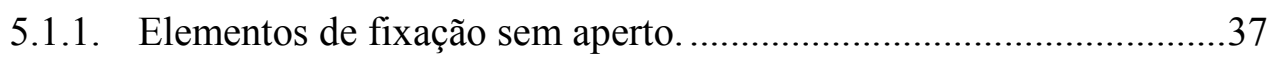

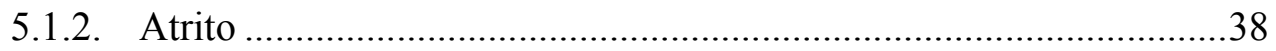

5.1.3. Força axial gerada pelo Harmonic Drive não considerada ................38

5.1.4. Novo projeto para o módulo atuador.............................................40

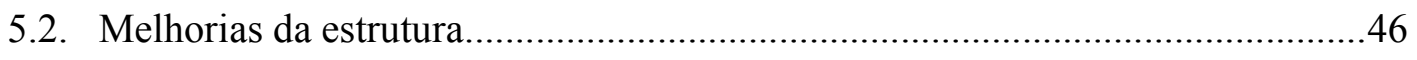

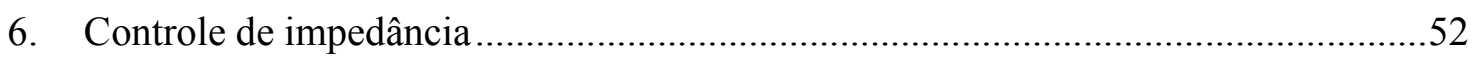




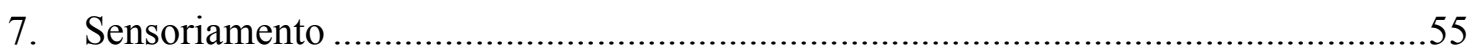

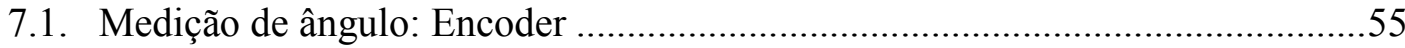

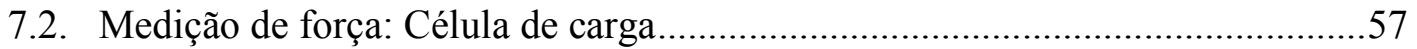

7.2.1. Células de Carga dos protótipos I e II .............................................60

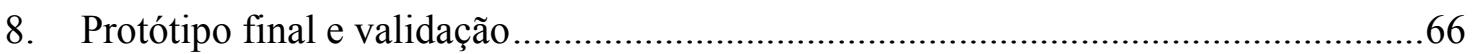

8.1. Análise de EMG - Módulo do joelho passivo .....................................................68

8.2. Medição dos parâmetros do exoesqueleto - teste em bancada .............................71

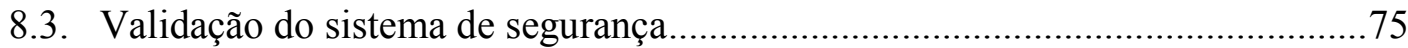

8.4. Análise da força de interação - exoesqueleto passivo ........................................77

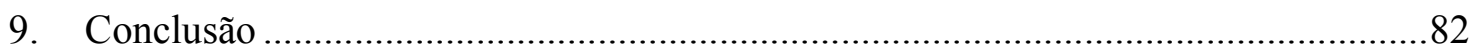

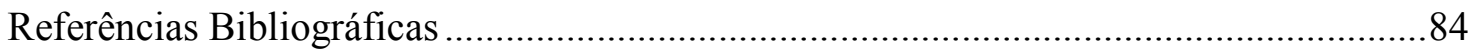

A - Cálculo do atrito - módulo atuador do Protótipo I ..................................................93

B - Cálculo da força axial gerada pelo Harmonic Drive ....................................................94

$\mathrm{C}$ - Dimensionamento do eixo de saída (módulo atuador)...............................................95

D - Cálculo do atrito - acoplamento motor e redução ……............................................97

E - Simulação por elementos finitos - Estrutura Protótipo II .........................................99

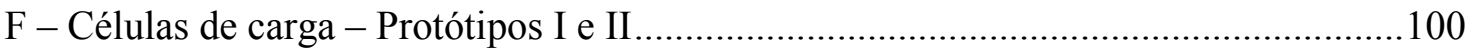

G - Cálculo do parâmetro de impedância inercial do exoesqueleto ................................102

H - Regressão para cálculos dos parâmetros inerciais do exoesqueleto ..........................104

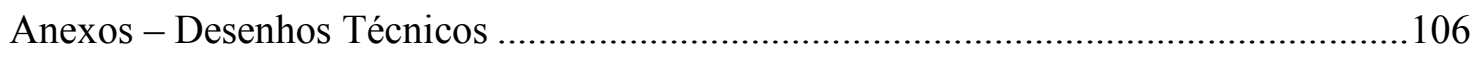




\section{Introdução}

Essa dissertação de mestrado consiste no projeto, fabricação e validação de um exoesqueleto de membro inferior a ser usado por pessoas saudáveis. A motivação deste estudo é a análise da função do joelho e do tornozelo durante a marcha. $\mathrm{O}$ exoesqueleto será uma ferramenta para análise da marcha. Ele poderá ser usado, por exemplo, para aplicar perturbações nas articulações da perna e para medir a impedância dessas articulações (joelho e tornozelo).

O conhecimento da impedância do joelho e tornozelo é importante para o desenvolvimento de exoesqueletos e dispositivos ortopédicos ativos porque pode tornar a interface homem-máquina mais confortável e natural, com um consumo energético mais eficiente (TUCKER, MOSER, et al., 2013). Como exemplo, uma prótese ativa capaz de emular as impedâncias de uma pessoa saudável reduziria a dor sentida pelo usuário além de aumentar sua mobilidade (LAMBRECHT e KAZEROONI, 2009).

A medição direta da impedância das articulações do joelho e tornozelo foi encontrada em estudos relacionados a condições específicas (como o usuário deitado ou sentado) (SUCH, UNSWORTH, et al., 1975), (CROWNINSHIELD, POPE, et al., 1976), (ZHANG, NUBER, et al., 1998), (TAI e ROBINSON, 1999), (LEE, PATTERSON, et al., 2011) e (LEE, KREBS e HOGAN, 2014), bem como durante a marcha (ROUSE, 2015). Este último apresentou resultados para a medição dos parâmetros da articulação do tornozelo.

O presente trabalho propõe um exoesqueleto que seja uma ferramenta de estudo capaz de fornecer as estimativas das impedâncias empíricas do tornozelo e também do joelho nas diferentes fases da marcha (o que não foi apresentado em trabalhos anteriores). A ferramenta deve ser ajustável e flexível para permitir diferentes medições: joelho e tornozelo simultaneamente, apenas joelho e apenas tornozelo.

A dificuldade de realizar essa medição durante a marcha está na contradição: por um lado, é necessário um equipamento leve o suficiente para fazer as medições sem perturbar o padrão natural da caminhada; e de outro, um equipamento capaz de aplicar 
um torque suficiente para perturbar a articulação. A perna executa diferentes funções durante a caminhada. $\mathrm{Na}$ fase de apoio deve suportar o peso do corpo e proporcionar o impulso no tornozelo. Na fase de balanço a perna deve flexionar e movimentar para frente com a separação suficiente do pé em relação ao chão, com o tornozelo em flexão dorsal. No fim da fase de balanço o joelho deve se estender para a seguinte fase de apoio. A Figura 1 ilustra as fases de um ciclo da marcha.
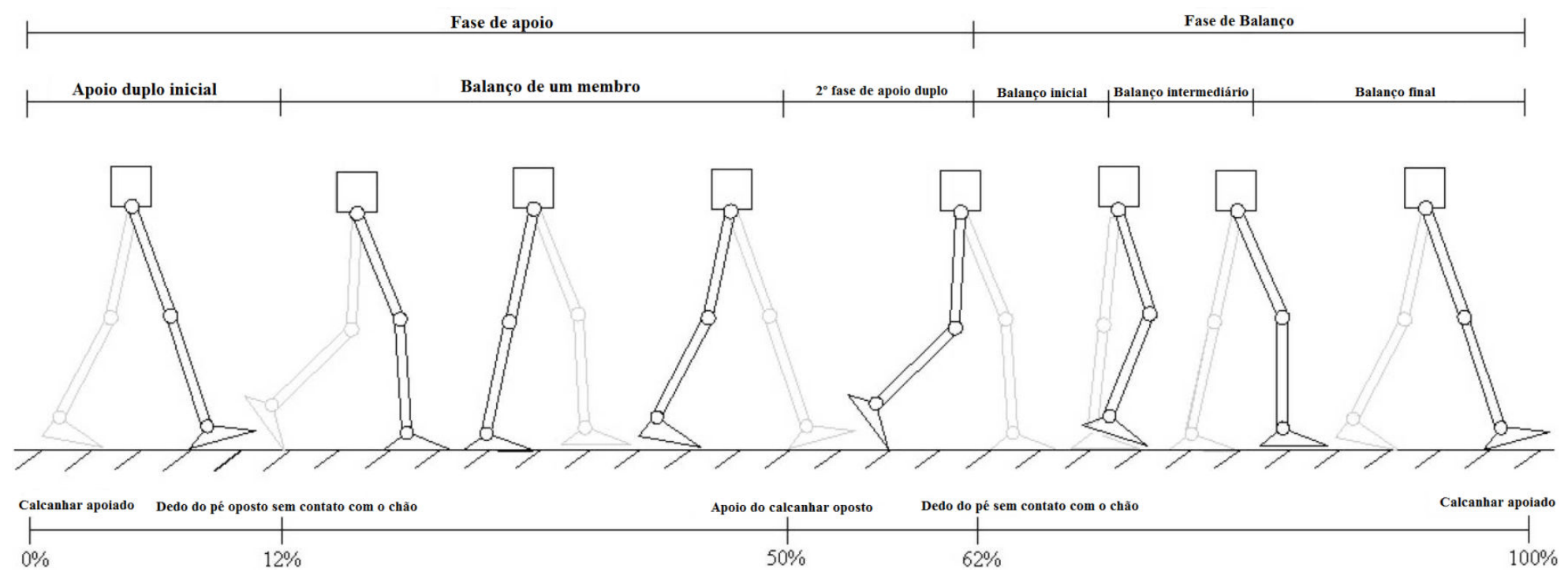

Figura 1: Fases de um ciclo da marcha humana. As porcentagens mostram a localização aproximada dos eventos de contato (SOUIT e MALGUEIRO, 2012) apud (HERR, 2008).

O desenvolvimento de um exoesqueleto para estudo da marcha é o foco deste trabalho. O objetivo é construir um protótipo que seja o hardware para qualquer tipo de experimento do movimento do membro inferior durante a marcha, tais como estudos de interface cérebro máquina (brain machine interface), reabilitação, ativação muscular perante distúrbios, etc. Com o objetivo de compreender os requisitos e o estado da arte de exoesqueletos, a revisão bibliográfica deste trabalho é centralizada nesse assunto. 


\section{Exoesqueletos - Revisão Bibliográfica}

A palavra "exoesqueleto" significa "esqueleto externo". Na biologia, é possível encontrar animais que possuem uma estrutura externa que os protege e os fornece rigidez (por exemplo, crustáceos e insetos). Assim, este termo é utilizado na biomecânica para definir os equipamentos que vestem os indivíduos para lhes fornecer rigidez estrutural, ampliação de força, entre outras características encontradas na natureza. Por isso, nesta área da ciência e tecnologia, pode-se definir exoesqueleto como sendo um equipamento robótico constituído de um conjunto de segmentos estruturais e articulações que atuam em paralelo ao corpo humano (SOUIT e MALGUEIRO, 2012).

\subsection{Classificação e aplicação dos exoesqueletos}

Os exoesqueletos podem ser classificados de acordo com o tipo de atuadores nas articulações (elétrico, hidráulico ou pneumático), ou com os membros que estão vestindo (superiores ou inferiores). Ainda é possível classificá-los pela portabilidade. Existem exoesqueletos não portáteis que são fixos a uma base externa (RUIZ A.F., 2009), nos quais não há a necessidade, durante a fase de projeto, de reduzir massa e espaço ocupado. Os exoesqueletos portáteis são diretamente suportados pelo usuário, exercendo forças de reação sobre a pessoa ou sobre um dispositivo móvel, como uma cadeira de rodas. O requisito mais importante no projeto deste tipo de exoesqueleto é redução de massa. Isso implica em atuadores com alta eficiência, baixo peso e pequenas dimensões, que é o caso deste trabalho. Por fim, os exoesqueletos podem ser classificados por suas aplicações: aumento das capacidades dos usuários, suporte funcional e reabilitação.

\subsubsection{Exoesqueletos para amplificação das capacidades humanas}

Este tipo de exoesqueleto é usado por pessoas saudáveis com o intuito de amplificar seus limites, por exemplo, carregar peso e percorrer longas distâncias. O primeiro exoesqueleto ativo foi desenvolvido na década de 1960 com a finalidade de aumentar a capacidade de carga suportada pelo usuário (ZOSS, 2006), chamado de Hardiman. A Universidade de Berkeley também desenvolveu um exoesqueleto para amplificação da potência humana, chamado de BLEEX. A Figura 2 ilustra o projeto feito. 


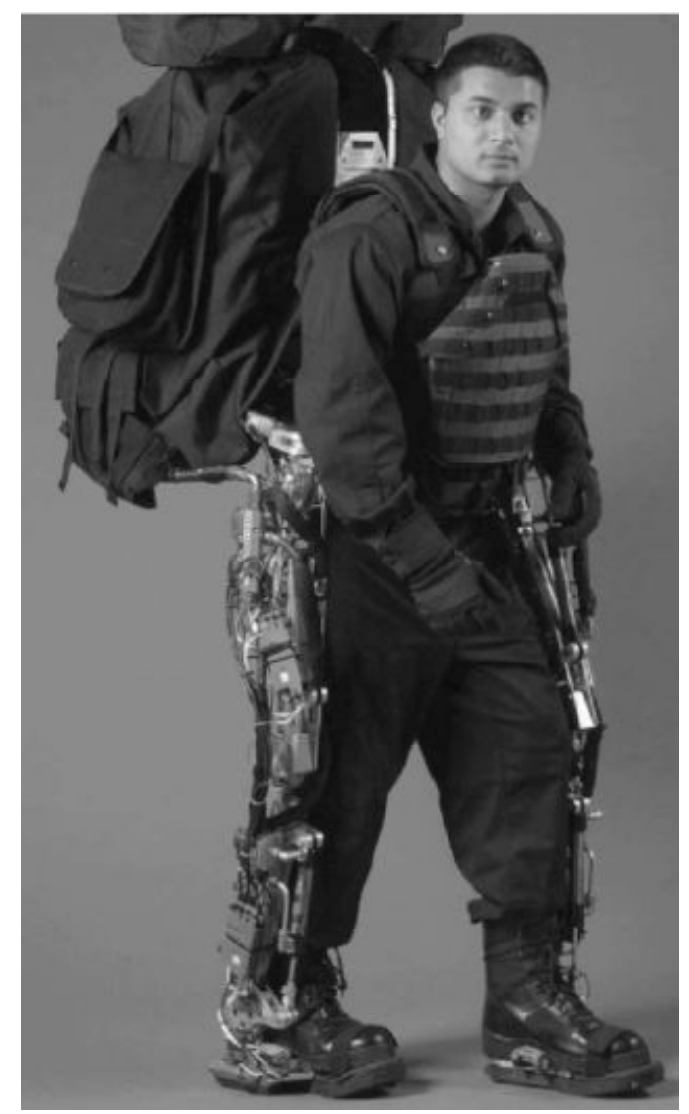

Figura 2: Foto do projeto concluído do exoesqueleto BLEEX (ZOSS, 2006).

\subsubsection{Exoesqueletos para suporte funcional}

Os exoesqueletos para suporte funcional e reabilitação são destinados a pessoas que sofreram patologias, lesões neuromotoras e idosos. Este tipo de equipamento assiste ou amplifica os movimentos residuais do paciente. O principal gargalo desses sistemas é a identificação da intenção do paciente. Para isso, dispõe-se de técnicas para medir o movimento residual, tais como: medição das forças de interação com o dispositivo e medições eletrofisiológicas - eletromiografia (EMG), eletroneurografia (ENG) ou eletroencefalografia (EEG). Além disso, estes pacientes não podem carregar peso, o que limita a massa do exoesqueleto (KONG e JEON, 2006).

O exoesqueleto HAL-5 foi criado pela Cyberdyne Inc., em Tsukuba, no Japão. Ele foi projetado para auxiliar pessoas idosas ou com deficiência física a andar. Liderado pelo professor Yoshiyuki Sankai, da Universidade de Tsukuba, o exoesqueleto foi construído por uma estrutura feita de níquel-molibidênio e extra-super-duralumínio e 
enrijecido por uma capa plástica, a estrutura é presa ao corpo do usuário paralelamente às articulações; motores elétricos são responsáveis por auxiliar o movimento da marcha (GUIZZO e GOLDSTEIN, 2005). O HAL-5 é controlado por meio de EMG: a intenção do usuário é medida por meio da atividade elétrica encontrada nas membranas excitáveis das células musculares e, então, os motores entram em ação para colaborar com o movimento.

O exoesqueleto "E-Legs" foi criado pela Esko Bionics, empresa que surgiu da Universidade da Califórnia. Projeto liderado pelo professor Homayoon Kazerooni, visa auxiliar pessoas paraplégicas a andar (STRICKLAND, 2012). O grande desafio, na aplicação em paraplégicos, é que a comunicação do cérebro com os músculos foi interrompida e, portanto, não é possível usar a eletromiografia para controlar o exoesqueleto. Assim, o "E-legs" possui botões que estabelecem "modos operantes", tais como "levantar da cadeira", "andar" e "subir escada". Assim, os movimentos do exoesqueleto são pré-programados (como um robô), seguindo os padrões do usuário (altura, massa, etc). Outra característica é que os pacientes paraplégicos não conseguem se equilibrar sozinhos, sendo necessário o uso de muletas (marcha quadrúpede) (ZOSS, STRAUSSER, et al., 2013). 

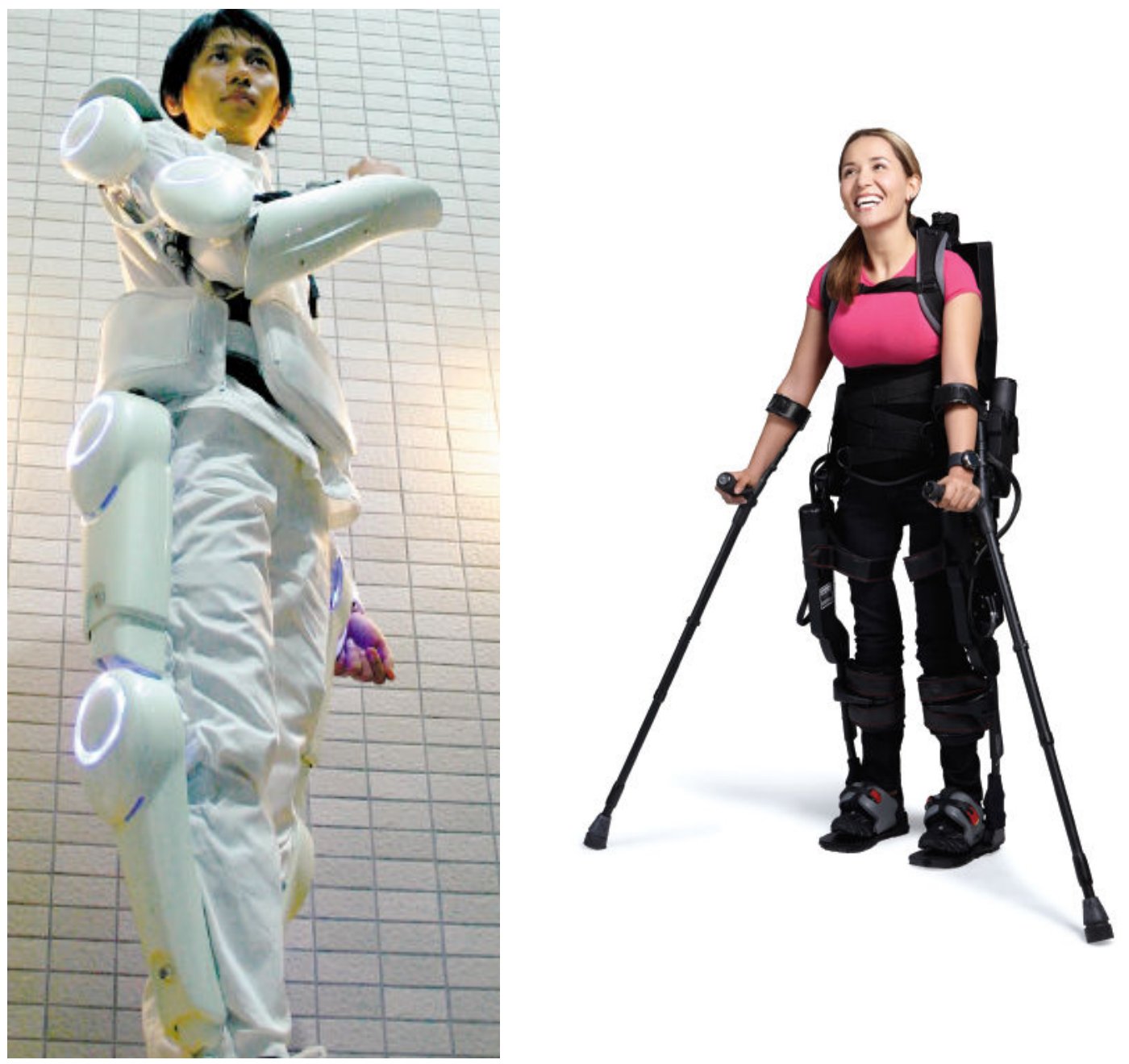

Figura 3: Exoesqueleto "HAL-5" à esquerda e "E-Legs" à direita, (GUIZZO e GOLDSTEIN, 2005) e (STRICKLAND, 2012), respectivamente.

Os exoesqueletos citados custam em torno de US\$130.000,00 (MERTZ, 2012). A aplicação deste tipo de exoesqueleto poderá ter demanda no Brasil (se forem acessíveis financeiramente) porque a população brasileira envelhece em ritmo acelerado: o índice de envelhecimento aponta para mudanças na estrutura etária da população brasileira. Em 2008, para cada grupo de 100 crianças de 0 a 14 anos existem 24,7 idosos de 65 anos ou mais. Em 2050, o quadro muda e para cada 100 crianças de 0 a 14 anos existirão 172, 7 idosos (IBGE, 2014). Além disso, os resultados do Censo 2000 mostram que, aproximadamente, 24,6 milhões de pessoas, ou 14,5\% da população total, apresentaram algum tipo de incapacidade ou deficiência. São pessoas com ao menos alguma 
dificuldade de enxergar, ouvir, locomover-se ou alguma deficiência física ou mental (IBGE, 2013) - esse tipo de exoesqueleto é a possibilidade de melhorar a qualidade de vida dessa população.

Outros estudos indicam que dos $14,5 \%$ da população brasileira que apresenta algum tipo de deficiência, 27\% deste valor corresponde à deficiência motora (IBGE, 2012). A deficiência motora possui diferentes causas. Entre elas, podem ser citadas: paralisia cerebral, acidente vascular encefálico (AVC) e lesão na medula espinhal.

\subsubsection{Exoesqueletos para reabilitação}

O tratamento fisioterápico de pessoas com deficiência motora devido ao acidente vascular encefálico e lesão medular é baseado em exercícios repetitivos passivos (BÜTEFISCH, HUMMELSHEIM, et al., 1994) ou ativos (KRAKAUER, CARMICHAEL, et al., 2012). Estes exercícios podem ser auxiliados e/ou realizados por exoesqueletos ativos (exercem força sobre o usuário por meio de atuadores) (KREBS, HOGAN, et al., 1998) e (LENZI, VITIELLO, et al., 2011).

$\mathrm{Na}$ área de reabilitação, destacam-se os exoesqueletos focados para o treino dos movimentos da marcha, tais como o LOKOMAT (COLOMBO, JOERG, et al., 2000) (COLOMBO, WIRZ e DIETZ, 2001), LOPES (VENEMAN, KRUIDHOF, et al., 2007) (KOOPMAN, ASSELDONK, et al., 2011) e ALEX (BANALA, AGRAWAL e SCHOLZ, 2007) (BANALA, KIM, et al., 2009). Esses equipamentos são utilizados, por exemplo, por pacientes que sofreram lesão na medula espinhal. Como não é possível reverter a lesão, a reabilitação é focada na prevenção de lesões futuras e no treinamento dos movimentos residuais. Esses exoesqueletos são ativos e de membro inferior e realizam o movimento da marcha de acordo com o trajeto especificado.

O Lokomat, além do exoesqueleto, também conta com um suporte que segura o tronco e todo o peso do usuário, facilitando o movimento da marcha para pacientes que não conseguem manter o equilíbrio. Com a trajetória pré-definida, não é possível verificar a contribuição do paciente para o movimento (LÜNENBURGER, COLOMBO, et al., 2004). Para aumentar a participação do paciente aos exercícios gradativamente, é necessário aplicar um controle que considera a força de interação com o usuário 
(controle de impedância), como é o caso do "MIT-MANUS" (KREBS, HOGAN, et al., 1998), “Anklebot” (ROY, KREBS, et al., 2013) e "Exo-Kanguera” (NOGUEIRA, SIQUEIRA, et al., 2014). Vale ressaltar que o "Anklebot" também foi utilizado para a medição dos parâmetros de impedância do tornozelo (ROY, KREBS, et al., 2007), assim como o exoesqueleto desta dissertação também propõe fazer.
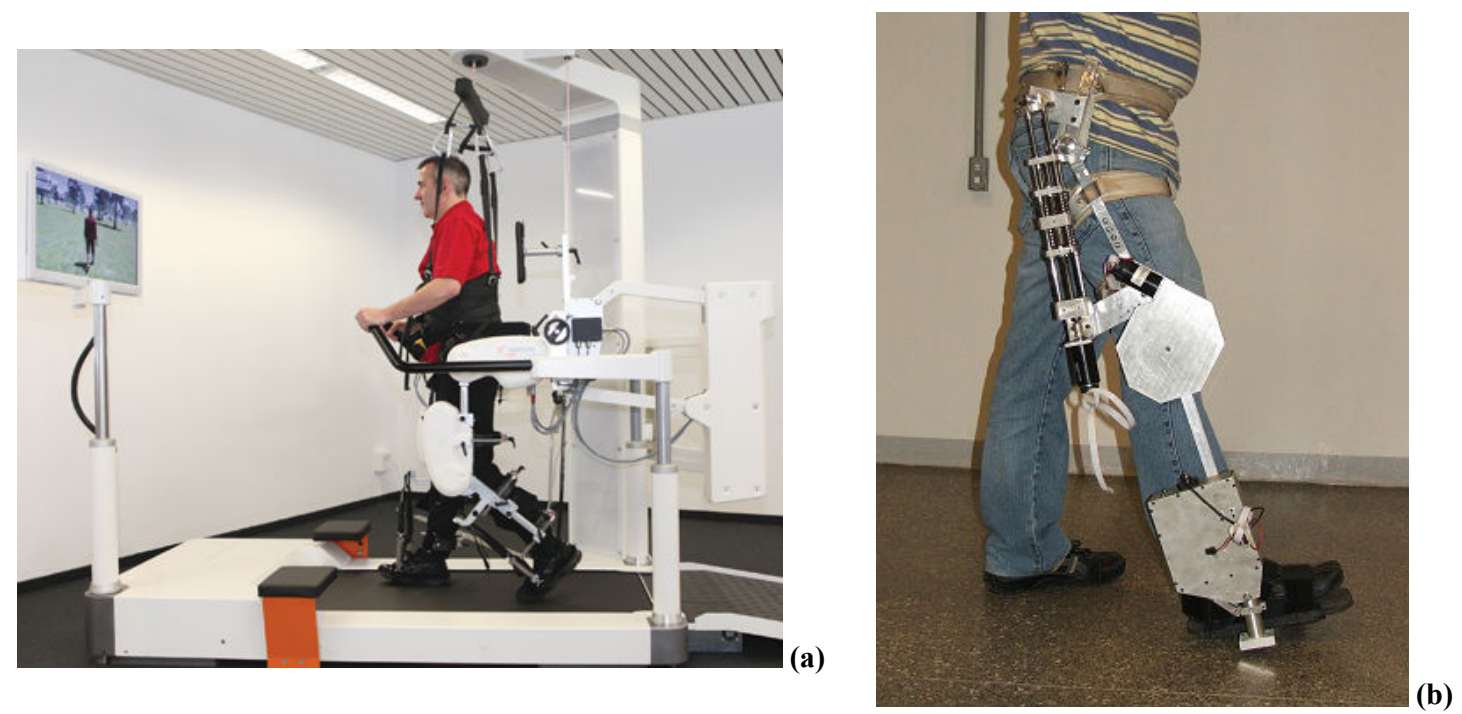

Figura 4: (a) LOKOMAT, adaptado de (AIM2WALK, 2014); (b) EXO-Kanguera, adaptado de (NOGUEIRA, SIQUEIRA, et al., 2014).

\subsection{Controle de exoesqueletos}

Os exoesqueletos são sistemas robóticos que trabalham em conjunto com o corpo humano. A interação entre o robô (nesse caso, o exoesqueleto) e o objeto a ser movimentado (nesse caso, o corpo humano) é chamada de manipulação. Por definição, a manipulação requer interação mecânica com o objeto a ser manipulado, a qual pode ser representada pelo trabalho mecânico trocado entre o manipulador e seu ambiente. Em alguns casos, as forças de interação são insignificantes, o trabalho mecânico instantâneo feito pelo manipulador é negligenciável e para fins de controle do robô, este pode ser tratado como um sistema isolado, com a sua posição de saída ou velocidade sendo a única variável controlada (como exemplo, tem-se os robôs industriais que aplicam pintura e soldagem: o controle é feito apenas pela posição ou velocidade do end-effector) (HOGAN, 1985). 
Em outros casos, o manipulador encontra restrições no ambiente e as forças de interação não são negligenciáveis (exemplo: exoesqueletos - é desejável controlar o movimento do robô ponderando a força de interação com o usuário). Nesses casos, a estratégia de controle deve ser complacente com a intenção de movimento do usuário (HOGAN, 1985). O controle o qual considera as duas variáveis (posição e força) simultaneamente é chamado de controle de impedância.

\subsubsection{Controle de impedância}

A variável de controle mais adequada para interação humana é a impedância porque o controle de impedância traz vantagens frente às outras possibilidades, pois o controle simplesmente de trajetória ou de força pode gerar forças ou velocidades incompatíveis com os membros humanos (HOGAN, 1985).

A impedância não é medida diretamente durante o funcionamento do exoesqueleto, mas é calculada a partir de medições de força e posição. Assim, força e posição são as variáveis a serem medidas através de sensores para um controle eficiente. Considerando o exoesqueleto como uma simples junta mecânica em 2D, sem contar as atuações dos motores, o movimento seria regido pela equação diferencial descrita a seguir (modelagem dinâmica do exoesqueleto).

$$
\tau=\ddot{\theta} I+\dot{\theta} B+\theta K
$$

onde

$\tau$ é o torque aplicado na articulação,

$I$ é a momento de inércia das peças,

$B$ é o coeficiente de amortecimento,

$K$ é o coeficiente de elasticidade e

$\theta, \dot{\theta}$ e $\ddot{\theta}$ são a posição da articulação e suas derivadas.

Com estas hipóteses, os parâmetros I, B e K (chamados de parâmetros de impedância) são fixos e determinados pelas propriedades geométricas e do material da articulação em questão. No entanto, quando a atuação dos motores é considerada, esses parâmetros passam a ser variáveis que dependem da intensidade da tensão no motor. 


\subsection{Interface humano-exoesqueleto}

Os desafios encontrados para a construção de um exoesqueleto são principalmente relacionados com a interface com o ser humano. Podem ser citados, principalmente: segurança, conforto, estabilidade e complacência (para o caso em que o usuário quiser sobrepor seus comandos sobre os do exoesqueleto) (KREBS, HOGAN, et al., 1998). Para suprir essas necessidades, o projeto mecânico deve ser compatível com o controlador para atender aos requisitos de força e movimento e prover a complacência necessária (HOGAN, 1985). Algumas formas de medir a intenção de movimento do usuário são:

a) Interface física: medição da força de interação entre o equipamento e o usuário (controle de impedância), exemplo: MIT-MANUS (KREBS, HOGAN, et al., 1998).

b) Interface neuro-motora: interpretação das intenções de movimento a baixo nível, utilizando sensores de movimento e medindo a ativação dos músculos por eletromiografia (EMG), exemplo: "HAL-5" (GUIZZO e GOLDSTEIN, 2005).

c) Interface cognitiva: interpretação das intenções e estado mental do usuário usando eletrocorticografia (método invasivo), ou espectrometria de infravermelho próximo funcional e/ou imagens funcionais de ressonância magnética (em inglês, functional near infrared spectroscopy fNIRS - e functional magnetic resonance imaging - fMRI, repectivamente), exemplo: MR-compatible stepper MARCOS (JAEGER, HOLLNAGEL, et al., 2012).

Avanços tecnológicos em hardware e software robóticos permitiram a evolução dos exoesqueletos citados anteriormente, mas há muito que melhorar em relação ao consumo energético e complacência. Foi demonstrado que a arquitetura de controle do exoesqueleto está diretamente relacionada com o consumo energético e conforto/estabilidade do usuário. Um estudo comparou dois tipos de arquitetura: um baseado no controle proporcional aos sinais de EMG (exemplo: HAL-5) e o outro baseado no controle cinemático pré-programado (exemplo: E-legs). O resultado foi 
padrões de marcha totalmente diferentes, mesmo utilizando hardware e atuadores idênticos. No controle por EMG, o usuário era capaz de alterar a magnitude do torque aplicado pela órtese conforme a ativação do músculo (sinal de EMG), o que reduzia a exigência do músculo. Isso não aconteceu no exoesqueleto pré-programado: foi observado que a ativação muscular dos usuários desse tipo de órtese era muito maior do que da primeira. Isso mostra que os exoesqueletos sob o comando proporcional de sinais de EMG são capazes de atingir um consumo energético menor do que aqueles com controle cinemático pré-programado (CAIN, GORDON e FERRIS, 2007) apud (FERRIS, SAWICKI e DALEY, 2007).

\subsection{Mecânica dos exoesqueletos de membro inferior}

Segundo o estado da arte publicado em 2008, (HERR, 2008), o exoesqueleto é definido como um dispositivo mecânico que é essencialmente antropomórfico e é "vestido" pelo operador sendo adaptado ao seu corpo e trabalhando em conjunto com os seus movimentos. Portanto, o exoesqueleto está em contato físico com a pessoa permitindo uma transmissão de energia e de diversos sinais de controle (KAZEROONI, 1990). A seguir, serão apresentados os tipos de estruturas de exoesqueletos bem como os principais atuadores usados por eles.

\subsubsection{Estruturas dos exoesqueletos de membro inferior}

A maior parte dos exoesqueletos é baseada em estruturas rígidas paralelas ao esqueleto humano, como é visto nos exoesqueletos citados anteriormente (HAL-5, ELegs, Lokomat, BLEEX, etc.). Existem também exoesqueletos flexíveis, bioinspirados no comportamento dos músculos e tendões humanos. É o caso do Soft Exosuit, desenvolvido pelo Wyss Institute for Biologically Inspired Engineering da Universidade de Harvard. O exoesqueleto é feito por tecidos que se moldam ao formato do corpo e são presos paralelamente aos músculos e tendões. Os atuadores do exoesqueleto ficam presos às costas do usuário e a potência é transmitida por cabos. A principal vantagem desse tipo de exoesqueleto sobre aqueles feitos com uma estrutura rígida é que a interferência ao padrão natural da marcha é menor. Porém, nesse tipo de acoplamento, a transmissão de potência bem como o controle são muito mais desafiadores, já que sua 
estrutura é complacente aos tecidos superficiais do corpo humano (ASBECK, DE ROSSI, et al., 2015) e (WEHNER, QUINLIVAN, et al., 2013).
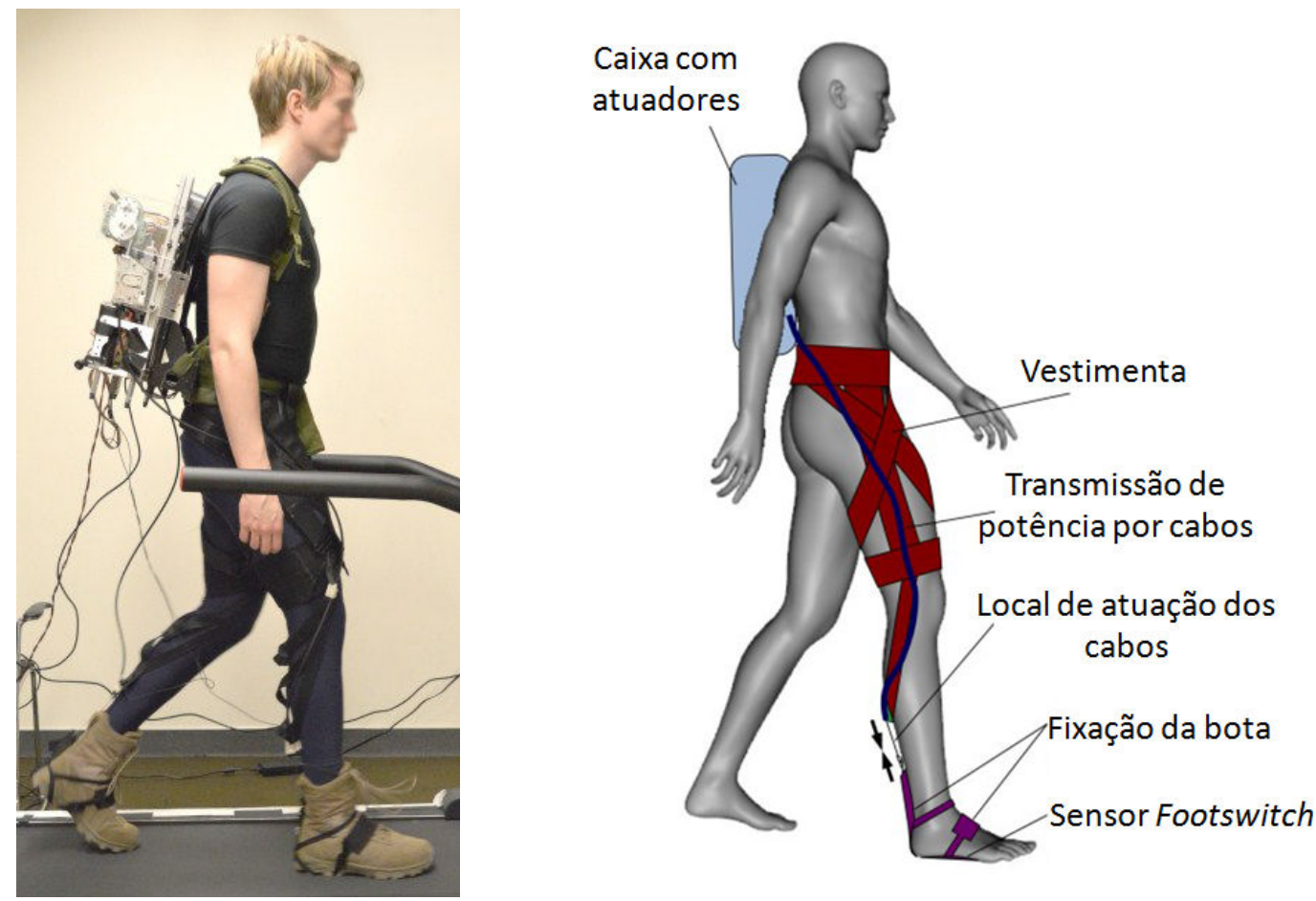

Figura 5: À esquerda, protótipo do Exosuit; à direita, ilustração mostrando os principais componentes do Exosuit. Adaptado de (ASBECK, DYER, et al., 2013).

\subsubsection{Atuadores de exoesqueletos}

Os exoesqueletos podem ser ativos (fonte de potência externa ao corpo humano), como os citados anteriormente (BLEEX, E-legs, HAL-5, etc.) ou semi-ativo (potência provém apenas do corpo humano do usuário; são baseados em armazenadores de energia). Na teoria, o ciclo da marcha em regime permanente não requer nenhum abastecimento de energia adicional (os músculos trabalham de maneira a repor apenas a energia dissipada) (COLLINS, WIGGIN e SAWICKI, 2015). Assim, o potencial dos exoesqueletos semi-ativos está em como armazenar a energia dissipada e retorná-la à marcha no momento certo, de maneira a aumentar o rendimento metabólico.

A coordenação da propulsão do tornozelo é um fator crítico para a eficiência da marcha humana. A flexão plantar contribui com a maior parte do trabalho mecânico da marcha, no final da fase de apoio (o final da fase de apoio ocorre entre $50 \%$ a $60 \%$ do 
ciclo da marcha). A eficiência da marcha humana está diretamente relacionada com a coordenação do impulso gerado no final da fase de apoio e com as forças de reação geradas no impacto com o solo (KUO, DONELAN e RUINA, 2005) apud (WIGGIN, SAWICKI e COLLINS, 2011).

$\mathrm{O}$ exoesqueleto semi-ativo desenvolvido pela equipe do professor Steven $\mathrm{H}$. Collins, da Universidade de Carnegie Mellon, fornece algumas das funções dos músculos e tendões da panturrilha durante a marcha. Ele possui uma mola em paralelo com o tendão de Aquiles conectada à perna por uma estrutura de compósito leve. Uma embreagem mecânica, paralelamente aos músculos da panturrilha, acopla a mola quando o pé está no chão, e a desacopla quando o pé está no ar (fase de balanço). O uso desse exoesqueleto pode reduzir o consumo metabólico da marcha em até 7\% (COLLINS, WIGGIN e SAWICKI, 2015).
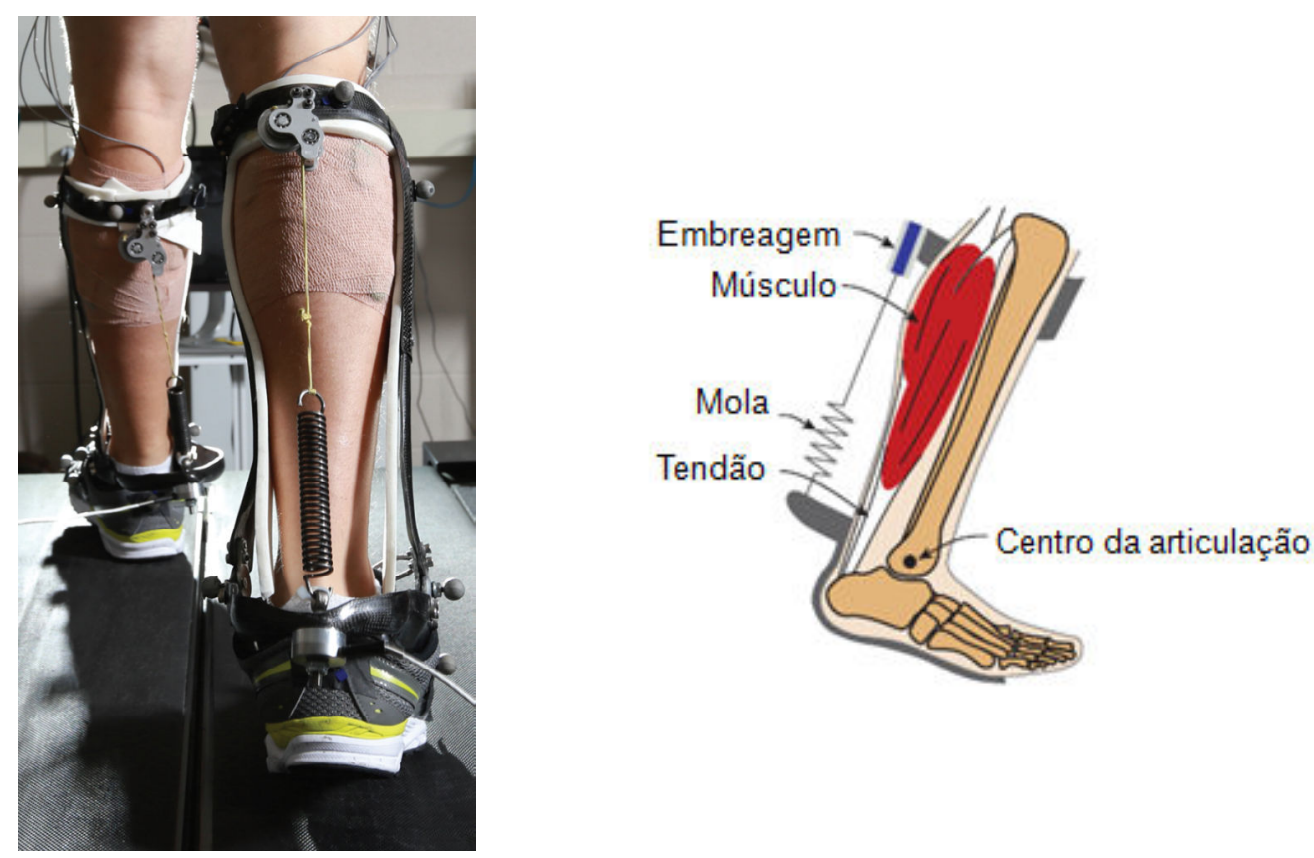

Figura 6: À esquerda, protótipo do exoesqueleto semi-ativo; à direita, figura ilustrando o trabalho em paralelo com a perna humana. Adaptado de (COLLINS, WIGGIN e SAWICKI, 2015).

Exoesqueletos ativos (que recebem energia externa ao corpo humano) também foram desenvolvidos para a redução do consumo metabólico usando o princípio de atuação no final da fase de apoio da marcha. $\mathrm{O}$ primeiro exoesqueleto a fazer isso foi o desenvolvido pela Universidade de Ghent, baseado em bombas pneumáticas e válvulas 
para substituir a articulação do tornozelo (MALCOLM, DERAVE, et al., 2013). Outro exemplo é o exoesqueleto desenvolvido pela equipe do MIT Media Lab, liderada pelo professor Hugh Herr. O princípio de atuação é baseado em um motor elétrico o qual faz uma alavanca para auxiliar o movimento de rotação do tornozelo, também na fase final do apoio da marcha. $\mathrm{O}$ exoesqueleto permite uma redução do custo metabólico de até $8 \%$, quando o usuário está suportando um carregamento de 23kg (MOONEY, ROUSE e HERR, 2014).

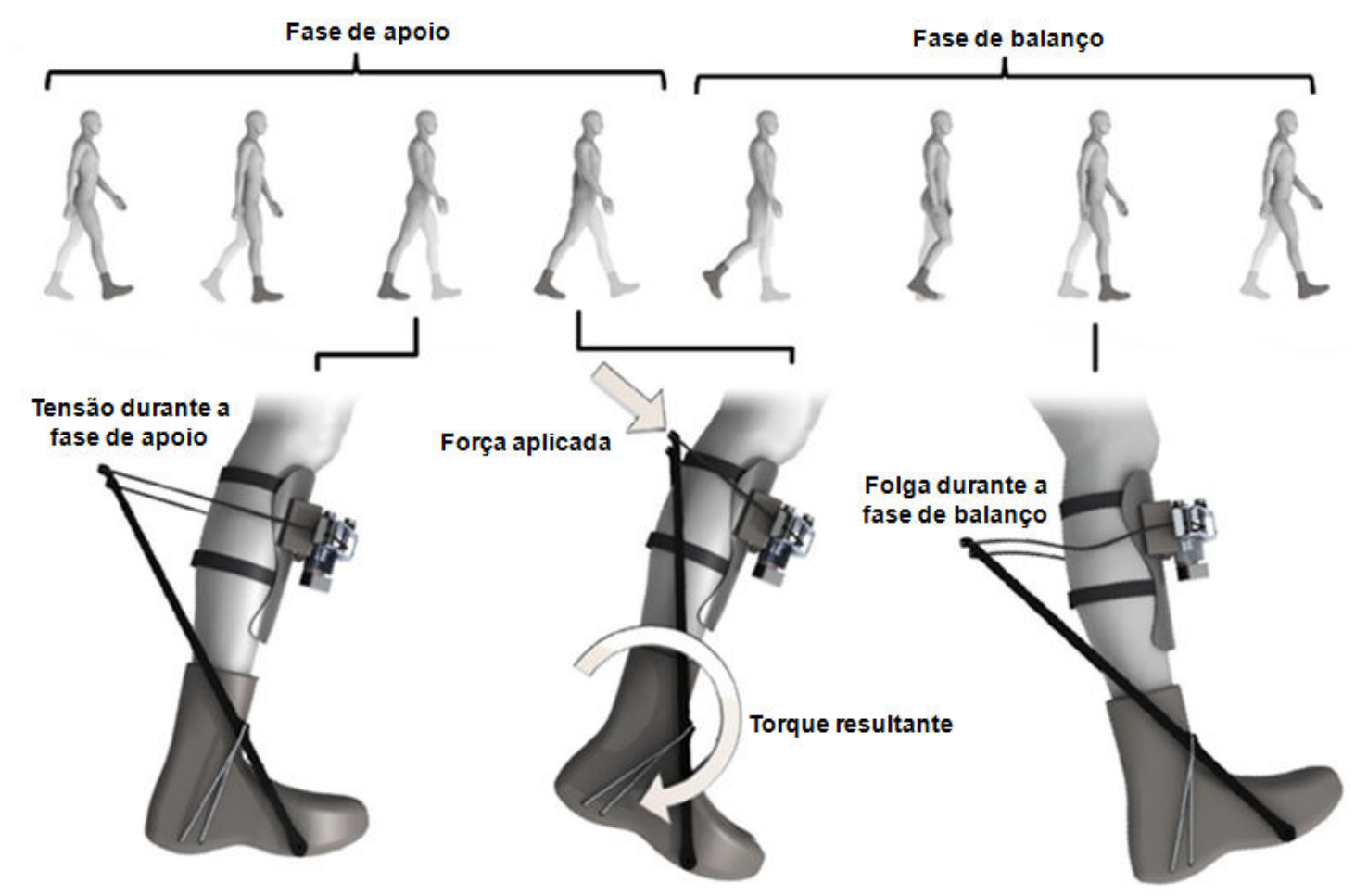

Figura 7: Exoesqueleto autônomo para redução de consumo energético. Adaptado de (MOONEY, ROUSE e HERR, 2014).

Um resumo das principais características dos exoesqueletos ativos estudados está listado na tabela a seguir. Pode-se perceber que nos casos nos quais se deseja uma capacidade de carga maior (aplicação militar - BLEEX) o atuador utilizado é o hidráulico. Já a maior parte dos exoesqueletos usados para o auxílio da marcha, usam os atuadores elétricos (menor massa e atinge o torque necessário para realizar a caminhada). Para o caso do exoesqueleto deste trabalho, o qual será usado como ferramenta de 
análise da marcha, conclui-se que os motores elétricos são suficientes para cumprir a função.

Tabela 1: Resumo e referência dos principais exoesqueletos estudados

\begin{tabular}{|c|c|c|c|c|}
\hline & BLEEX $^{1}$ & HAL-5 $^{2}$ & E-Legs ${ }^{3}$ & Rewalk $^{4}$ \\
\hline Tipo & $\begin{array}{l}\text { Membros } \\
\text { inferiores }\end{array}$ & Corpo inteiro & $\begin{array}{l}\text { Membros } \\
\text { inferiores }\end{array}$ & $\begin{array}{l}\text { Membros } \\
\text { inferiores }\end{array}$ \\
\hline Aplicação & $\begin{array}{c}\text { Militar } \\
\text { (ampliação de } \\
\text { força) }\end{array}$ & $\begin{array}{l}\text { Auxílio da } \\
\text { marcha (pessoas } \\
\text { com deficiência) }\end{array}$ & $\begin{array}{c}\text { Auxílio da } \\
\text { marcha (pessoas } \\
\text { com deficiência) }\end{array}$ & $\begin{array}{c}\text { Auxílio da } \\
\text { marcha (pessoas } \\
\text { com deficiência) }\end{array}$ \\
\hline $\begin{array}{l}\text { Líder do projeto } \\
\text { (referência) }\end{array}$ & $\begin{array}{l}\text { Adam Zoos, } \\
\text { Homayoon } \\
\text { Kazerooni. }\end{array}$ & $\begin{array}{l}\text { Yoshiyuki } \\
\text { Sankai. }\end{array}$ & $\begin{array}{l}\text { Homayoon } \\
\text { Kazerooni }\end{array}$ & Larry Jasinski \\
\hline País & EUA & Japão & EUA & EUA/Israel \\
\hline $\begin{array}{l}\text { Universidade/Empre } \\
\text { sa }\end{array}$ & $\begin{array}{l}\text { Universidade da } \\
\text { Califórnia }\end{array}$ & $\begin{array}{l}\text { Universidade de } \\
\text { Tssukuba/ } \\
\text { Cyberdyne }\end{array}$ & $\begin{array}{l}\text { Universidade da } \\
\text { Califórnia/ } \\
\text { Berkeley } \\
\text { Bionics }\end{array}$ & $\begin{array}{l}\text { Argo Medical } \\
\text { Technologies }\end{array}$ \\
\hline $\begin{array}{l}\text { Massa total aprox. } \\
{[\mathrm{kg}]}\end{array}$ & 15 & 20 & 20 & $*$ \\
\hline Tipo de atuador & $\begin{array}{c}\text { Linear } \\
\text { hidráulico }\end{array}$ & Motor elétrico & Motor elétrico & Motor elétrico \\
\hline Tipo de Controle & $\begin{array}{c}\text { Baseado na } \\
\text { medição da } \\
\text { força e posição }\end{array}$ & $\begin{array}{c}\text { Proporcional ao } \\
\text { sinal medido de } \\
\text { EMG }\end{array}$ & $\begin{array}{l}\text { Baseado na } \\
\text { medição da } \\
\text { força e posição }\end{array}$ & $\begin{array}{c}\text { Baseado na } \\
\text { medição da } \\
\text { força e posição }\end{array}$ \\
\hline
\end{tabular}

${ }^{1}$ Adaptado de (ZOSS, 2006), (GUIZZO e GOLDSTEIN, 2005), (AMUNDSON,

RAADE, et al., 2005) e (HERR, 2009)

${ }^{2}$ Adaptado de (GUIZZO e GOLDSTEIN, 2005) e (HERR, 2009)

${ }^{3}$ Adaptado de (STRICKLAND, 2012) e (BIONICS, 2014)

${ }^{4}$ Adaptado de (TALATY, ESQUENAZI e BRICENO, 2013)

* Informação não encontrada 
A revisão apresentada anteriormente mostrou quais são as principais características a serem consideradas no desenvolvimento de um exoesqueleto. Além da escolha do atuador, a revisão bibliográfica auxiliou no desenvolvimento da estrutura, sensores e controle. Um exoesqueleto pode ser utilizado para analisar a marcha se ele for projetado e controlado para tal (SOUIT, MALGUEIRO, et al., 2013). O "anklebot" é um exemplo disso: é um exoesqueleto de reabilitação que também foi utilizado para medição dos parâmetros de impedância do tornozelo (ROY, KREBS, et al., 2007). A seguir, serão apresentados o objetivo e os requisitos do exoesqueleto proposto. 


\section{Objetivo}

O objetivo deste trabalho é desenvolver um exoesqueleto de membro inferior com dois graus de liberdade ativos (joelho e tornozelo) que seja uma ferramenta para análise da marcha e também um dispositivo mecânico para estudo de diversos tipos de controle. Ou seja, o exoesqueleto deve ser um hardware que permita a avaliação da interface homem-máquina em diferentes aplicações (medição dos parâmetros do humano, reabilitação, etc.).

Conforme descrito na introdução, esse exoesqueleto deverá ser capaz realizar medições durante a marcha de maneira a permitir o cálculo dos parâmetros de impedância do joelho e do tornozelo durante a fase de balanço (aproximadamente, entre $62 \%$ e $100 \%$ do ciclo da marcha) e em diferentes configurações (análise do joelho, do tornozelo, e de ambas as articulações simultaneamente).

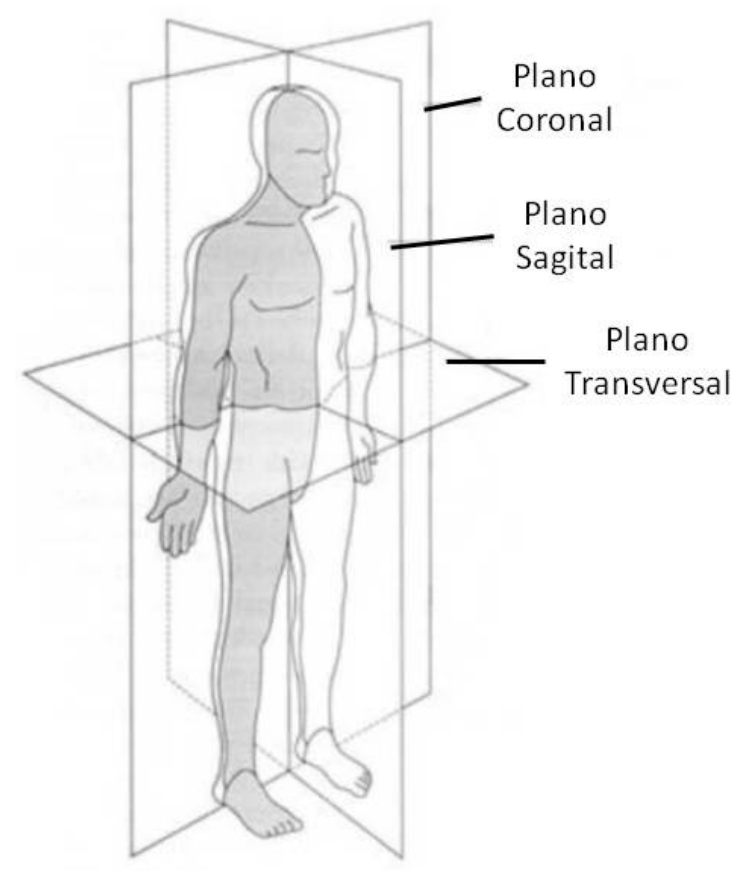

Figura 8: Descrição dos planos anatômicos do corpo humano. Adaptado de (HERR, 2008).

O exoesqueleto será uma ferramenta para analisar o movimento de flexãoextensão do joelho e tornozelo no plano sagital (indicado na Figura 8). O movimento angular de uma articulação no plano sagital (movimento 2D), com eixo fixo, que é o 
modelo simplificado de uma articulação humana, é descrito pela equação diferencial (1), mostrada novamente a seguir:

$$
\tau=\ddot{\theta} I+\dot{\theta} B+\theta K
$$

Sendo $I, B$ e $K$ os parâmetros de impedância inercial, viscoso e elástico, respectivamente. Vale ressaltar que este é um modelo simplificado para uma única articulação. No caso da modelagem do membro inferior, seria necessária a modelagem de um sistema multicorpo considerando os graus de liberdades das outras articulações.

O parâmetro inercial pode ser calculado a partir da massa do membro (por exemplo, a canela e o pé para a articulação do joelho e apenas o pé para o tornozelo) e do raio de giração, que é a distância do centro de massa do membro em relação ao centro da articulação. Os raios de giração e as massas dos membros foram obtidos empiricamente e dependem da massa e altura total do humano; essas informações já estão tabuladas e disponíveis (ENDERLE, BLANCHARD e BRONZINO, 2005) apud (WINTER, 1990).

Os parâmetros $B$ e $K$ (viscosidade e elasticidade) são obtidos empiricamente, por exemplo, por regressão. Obtendo diversas medidas de torque, posição, velocidade e aceleração angulares, e calculando o parâmetro $I$, é possível calcular os parâmetros desconhecidos ( $B$ e $K$ ) por regressão. O exoesqueleto proposto nesta dissertação deve ser capaz de fazer essas medições e, por isso, ele será uma ferramenta para análise da marcha (permitirá o cálculo empírico dos parâmetros viscoso e elástico da articulação).

Este trabalho faz parte do laboratório de Biomecatrônica da Escola Politécnica da Universidade de São Paulo. Assim, o projeto será realizado em equipe com o auxílio de alunos de iniciação científica para o desenvolvimento do projeto eletrônico (placas de aquisição de sinal).

\subsection{Requisitos do exoesqueleto}

Conhecendo as restrições físicas, as metas estabelecidas para o exoesqueleto foram definidas de acordo com a sua finalidade (ferramenta de estudo e protótipo de prova de conceito a ser usada por pessoas diferentes e saudáveis, ou seja, com plena capacidade de andar). Sendo assim, as suas especificações são listadas a seguir. 
- Público alvo: o exoesqueleto será vestido por pessoas saudáveis para a medição dos parâmetros de impedância.

- Ser ajustável a diferentes usuários, podendo variar o comprimento das barras e o diâmetro dos acoplamentos no indivíduo. O exoesqueleto deverá atender pessoas de $1,50 \mathrm{~m}$ de altura até $1,90 \mathrm{~m}$ e pessoas com massa corporal de até $100 \mathrm{~kg}$. Esses limites de altura e massa representam as medianas da população (masculina e feminina) do estado de São Paulo acima de 16 anos (IBGE, 2009). Por ser uma ferramenta de estudo, o exoesqueleto será usado por diferentes voluntários.

- Ser modular, para que as diferentes partes do exoesqueleto possam ser feitas e analisadas separadamente e depois acopladas, caso deseja-se estudar apenas o joelho ou apenas o tornozelo. Neste trabalho, a modularidade está relacionada com os graus de liberdade, ou seja, o exoesqueleto, sendo modular, permite diferentes configurações: apenas módulo do joelho, apenas módulo do tornozelo e ambos (joelho e tornozelo simultaneamente).

- Ter espaço suficiente para fixar os sensores e atuadores necessários, sem que haja um comprometimento estrutural do exoesqueleto.

- Graus de liberdade: uma rotação passiva no quadril, uma rotação atuada no joelho (flexão-extensão) e outra, também atuada, no tornozelo (flexão-extensão).

A próxima figura ilustra a flexão-extensão do tornozelo.

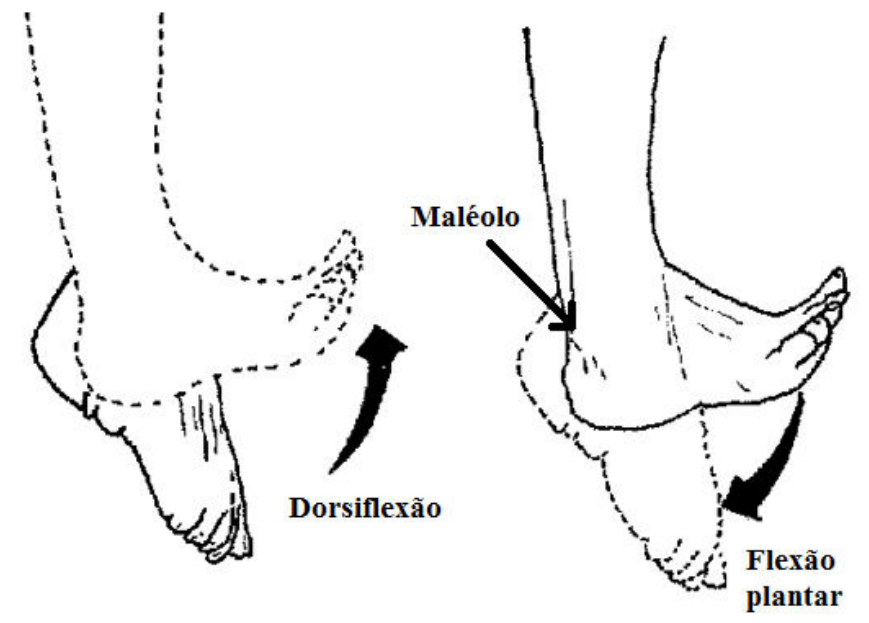

Figura 9: Movimentos do tornozelo. Adaptado de (OUTSIDE, 2011). 
- Amplitudes angulares das articulações: para determinar as amplitudes que o exoesqueleto deveria possuir, analisaram-se as faixas angulares das articulações durante a marcha. A tabela dada a seguir fornece as amplitudes máximas das articulações humanas durante a caminhada em uma superfície plana (que devem ser respeitadas pelo exoesqueleto) (KAPANDJI, 2000) e (ZOSS, 2006).

Tabela 2: Amplitudes angulares máximas das articulações durante a marcha. Adaptado de (KAPANDJI, 2000) e (ZOSS, 2006).

\begin{tabular}{|c|c|c|}
\hline & Amplitude máxima & $\begin{array}{c}\text { Amplitude máxima durante a } \\
\text { marcha }\end{array}$ \\
\hline Dorsiflexão do tornozelo & $30^{\circ}$ & $14,1^{\circ}$ \\
\hline Flexão plantar do tornozelo & $50^{\circ}$ & $20,6^{\circ}$ \\
\hline Extensão do joelho & $10^{\circ}$ & $0^{\circ}$ \\
\hline Flexão do joelho & $160^{\circ}$ & $73,5^{\circ}$ \\
\hline
\end{tabular}

- Para as articulações do joelho e do tornozelo serão utilizadas rotações simples alinhadas ao eixo de rotação da articulação, o máximo possível.

- A interface do exoesqueleto com a perna deverá prover o movimento e torques desejados sem ferir o paciente e evitar desconfortos como transpiração e calor excessivo.

- Os atuadores serão elétricos para evitar o transporte de reservatório de fluidos (o que ocorreria se o atuador fosse hidráulico ou pneumático).

Para a análise dos requisitos de torque, foi considerado que o exoesqueleto deve ser capaz de realizar perturbações durante a fase de balanço, a qual se inicia a $62 \%$ do ciclo da marcha. Isto porque, para a identificação de um sistema, é necessário verificar as suas respostas mediante diferentes distúrbios.

Segundo (HERR, 2008), os torques e potências das articulações durante a marcha de um indivíduo masculino, de 28 anos, $82 \mathrm{~kg}$ e $0,99 \mathrm{~m}$ de comprimento de perna são dadas pelos gráficos das Figuras 10 e 11. As informações dadas pelos gráficos são das três articulações do membro inferior (quadril, joelho e tornozelo) nos movimentos de flexão-extensão durante a marcha. 


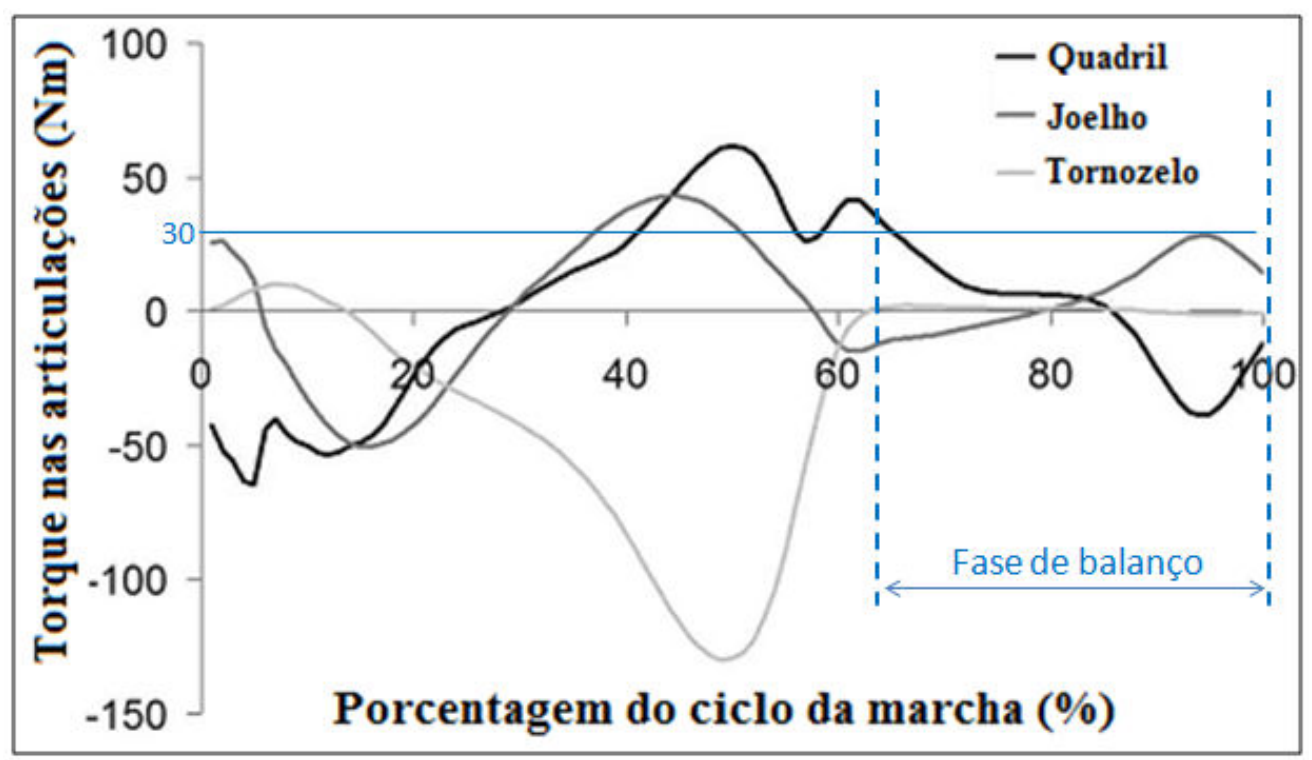

Figura 10: Torque nas articulações durante a marcha. Adaptado de (HERR, 2008).

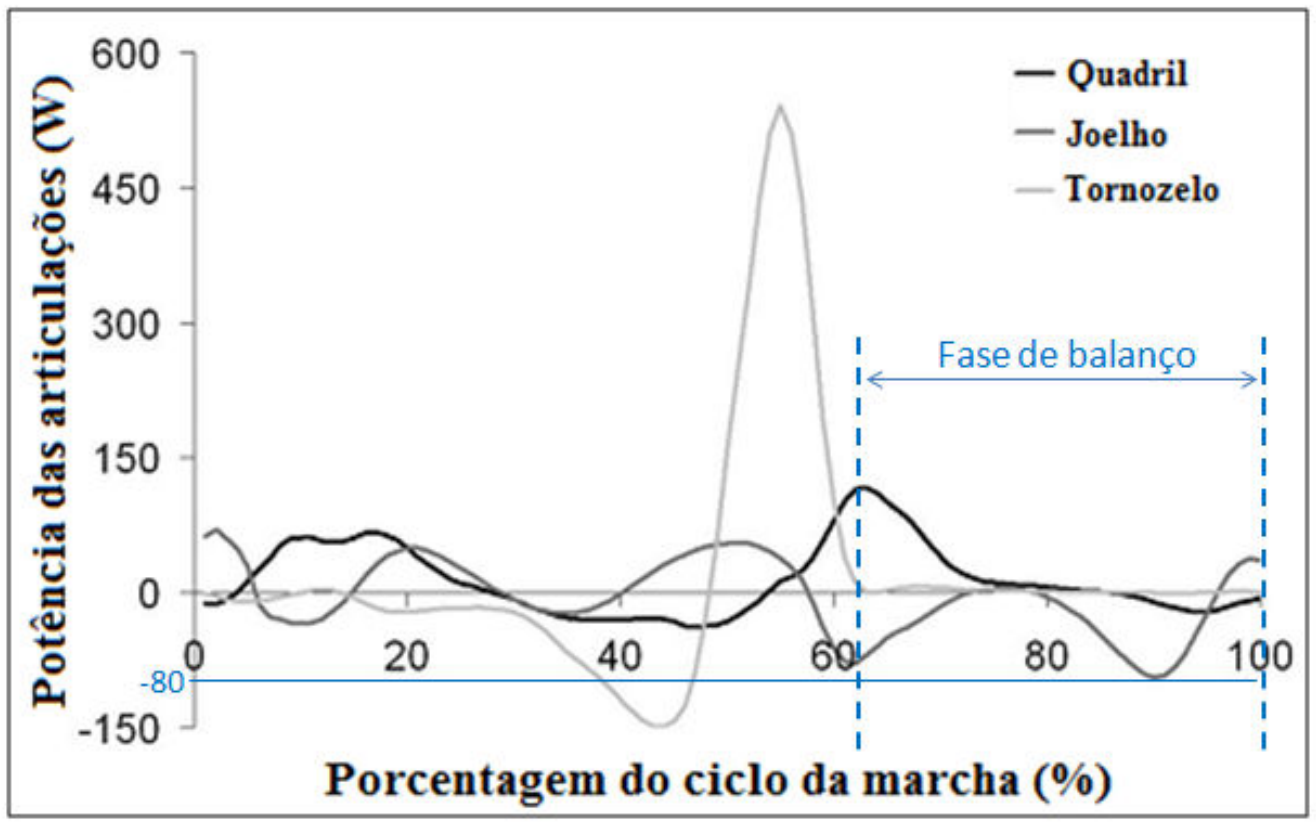

Figura 11: Potência nas articulações durante a marcha. Adaptado de (HERR, 2008).

Primeiramente, analisaram-se os requisitos necessários para a atuação do joelho e do tornozelo durante a fase de balanço, que é a fase na qual se deseja aplicar perturbações para a identificação do sistema. 
Para a estimativa de torque do atuador, pode-se avaliar o movimento da perna por um sistema multicorpo quase estático porque as acelerações durante a caminhada são relativamente baixas. Neste caso, se um torque de mesmo módulo (valor identificado no gráfico) e sentido oposto for aplicado sobre a articulação, ela atingirá velocidade angular zero (que é considerada a perturbação máxima).

Analisando os dois gráficos nos pontos que correspondem à fase de balanço da perna, e considerando a definição de perturbação máxima (levar a velocidade angular da articulação à zero), têm-se as seguintes condições máximas para a perturbação do joelho e do tornozelo:

$$
\begin{gathered}
\text { Potência: } P_{\text {operação }} \cong 80 \mathrm{~W} \\
\text { Torque: } T_{\text {operação }} \cong 30 \mathrm{Nm} \\
\text { Velocidade de rotação: } w_{\text {operação }} \cong \frac{P}{T} \cong 4 \mathrm{rad} / \mathrm{s} \cong 38,2 \mathrm{rpm}
\end{gathered}
$$

Inicialmente, no Protótipo I, optou-se por atuar até $60 \%$ acima do torque máximo da articulação, conforme os dados abaixo:

$$
\begin{gathered}
T_{\text {max }}=50 \mathrm{Nm} \\
P_{\text {max }}=80 \mathrm{~W} \\
w_{\text {max }}=40 \mathrm{rpm}
\end{gathered}
$$

Já no Protótipo II, o foco foi interferir na função do joelho e do tornozelo durante a fase de balanço e, portanto, considerou-se o critério de $T_{\text {operação }} \cong 30 \mathrm{Nm}$. Assim, o atuador deve ser capaz de aplicar 30Nm sobre a articulação.

O exoesqueleto deve ser uma ferramenta de estudo da marcha, mais especificamente, ferramenta para medição de torque e posição angular (dados necessários para obter os parâmetros viscosos e elásticos da articulação). Para a medição da posição angular serão utilizados os encoders já presentes no motor selecionado (veja a seção "Projeto Mecânico - Protótipo I" para a justificativa dessa seleção). Os ângulos medidos por esses encoders são relativos, por isso, será necessária a calibração para definir o referencial "zero". Além disso, é importante salientar que o encoder medirá a posição angular do motor, assim, para obter a posição da articulação, será necessário considerar a redução (a qual será detalhada posteriormente). 
O torque será obtido pelas forças de interação, geradas entre o acoplamento que envolve o membro do usuário e sua pele. Essa força, dependendo do posicionamento do acoplamento, pode ser transformada em um torque no centro de rotação das articulações (DEL-AMA, MORENO, et al., 2012).

Para obter informações sobre a interação física, podem-se utilizar sensores de força na estrutura do exoesqueleto. Há uma série de sensores de força disponíveis no mercado, tais como: piezoelétricos, capacitivos e polímeros piezoresistivos (PONS, 2008). Porém, é difícil encontrar um sensor de força adequado para a aplicação no exoesqueleto, com a geometria adequada e faixa de medida necessária. Além disso, a instalação desses sensores resultaria na descontinuidade da estrutura, o que pode fragilizar sua resistência (DEL-AMA, MORENO, et al., 2012). Por isso, optou-se por instrumentar a estrutura de maneira que ela mesma seja um sensor de força, utilizando-se extensômetros (strain gauges), como será detalhado posteriormente.

O desenvolvimento do exoesqueleto envolve o projeto mecânico (definição dos atuadores e da estrutura), o controle, o sensoriamento e a validação do protótipo (resultados). Portanto, o trabalho será apresentado nesta sequencia e, por fim, serão apresentadas as possíveis aplicações do exoesqueleto como trabalhos futuros. 


\section{Projeto Mecânico - Protótipo I}

Este exoesqueleto é uma ferramenta para análise da função do joelho e tornozelo. O equipamento deve ser capaz de perturbar o movimento do joelho e do tornozelo durante a marcha. Isso significa que o exoesqueleto pode aplicar torques controlados durante a locomoção, para simular perturbações elásticas, viscosas e inerciais.

O exoesqueleto foi tema do trabalho de conclusão de curso da autora e foi construído previamente. A seguir, serão detalhados o projeto e a construção mecânica realizados como trabalho de graduação, e posteriormente, propostas de melhoria para atender o objetivo (refino do projeto mecânico) e o controle do exoesqueleto serão explicitados.

O exoesqueleto desenvolvido previamente era composto por uma estrutura paralela à coxa e à canela (perna direita) com dois módulos atuadores. Como o módulo atuador do joelho foi o primeiro a ser usinado, o do tornozelo já possui algumas melhorias (redução de massa e facilidade de montagem). Os critérios utilizados para o desenvolvimento do módulo atuador foram:

1. Menor peso

2. Menor momento de inércia e produto de inércia (quanto maior a distância do centro de massa em relação ao centro de rotação, maior o desconforto). Este critério leva em consideração a geometria que modifica a distribuição de carregamento sobre o usuário. Vale notar que os músculos possuem capacidade de cargas diferentes. Por exemplo, segurar um peso de $1 \mathrm{kgf}$ na coxa durante a marcha é diferente de segurá-lo no tornozelo (que é muito mais incômodo).

3. Backdrivability (capacidade de o usuário interferir no movimento do atuador, o que está diretamente relacionado com a segurança).

4. Maior segurança ao usuário

5. Maior facilidade de ajuste (set up)

Entre as opções estudadas no trabalho de graduação (motor preso no quadril e transmissão por parafuso sem fim e coroa, por cabos de aço ou fuso de esferas ou 
atuação direta na articulação), foi escolhido um módulo atuador composto pelo motor Maxon acoplado a uma redução Harmonic Drive, de maneira a melhor atender os critérios descritos. Esta alternativa não oferece elementos intermediários entre o atuador e a haste do exoesqueleto a ser movida, o que reduz a massa móvel e as perdas em transmissões, além do erro entre a resposta do mecanismo e o comando controlador (SOUIT e MALGUEIRO, 2012).

Frequentemente, o torque que um motor oferece é diretamente proporcional ao seu tamanho. Assim, os motores comumente comercializados que oferecem esse torque de saída $(50 \mathrm{Nm})$ são pesados (aproximadamente $3 \mathrm{~kg}$ ), não sendo possível acoplá-lo diretamente ao joelho, pois isso interferiria indesejavelmente na marcha do usuário.

Porém, foi encontrado um motor "plano" leve (motor MAXON EC90 flat brushless de $90 \mathrm{~W}$ ) (MAXON, 2011). O problema deste motor é que fornece baixo torque $\left(T_{\max }=0,387 \mathrm{Nm}\right)$. Para usar este atuador, é necessário encontrar uma transmissão pequena, leve e com uma redução adequada.

Encontrou-se assim, uma redução harmônica, a qual atende a esses requisitos. $\mathrm{O}$ seu princípio de funcionamento é explicado na Figura 12.
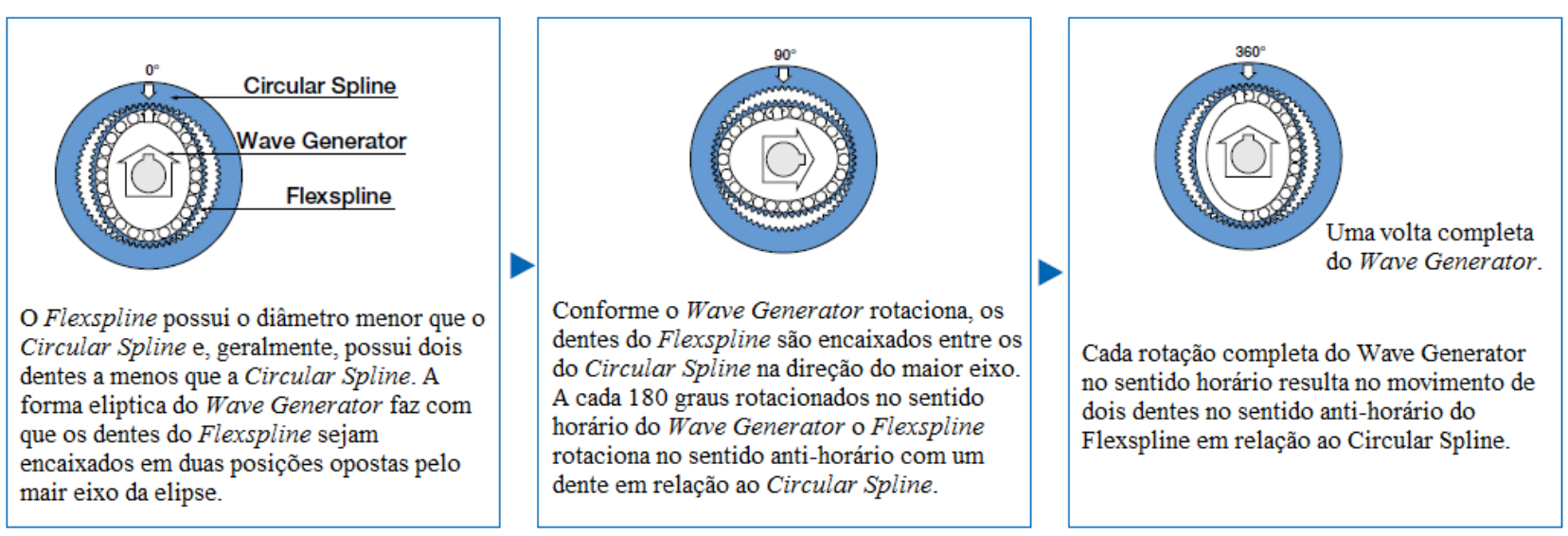

Figura 12: Explicação do princípio de funcionamento da redução harmônica. Adaptado de

(HARMONICDRIVE, 2011).

O tipo de redução harmônica correta para esta aplicação é o tipo flat, por ser menor que as outras. A seleção foi feita considerando a redução mínima desejada $\left(i_{\text {min }}\right)$ e o torque que deveria suportar durante utilização $\left(T_{\max }\right)$. 


$$
\begin{gathered}
i_{\min }=\frac{50}{0,387} \cong 130 \\
T_{\max }=50 \mathrm{Nm}
\end{gathered}
$$

Sendo assim, segundo (HARMONICDRIVE, 2011), a redução correta para esta aplicação é a CSD-25-160.

O motor e a redução especificados, quando usados conjuntamente, fornecem as especificações desejadas. Essas especificações são dadas na Tabela 3.

Tabela 3: Especificações do motor Maxon e da redução harmônica.

\begin{tabular}{|l|c|}
\hline \multicolumn{2}{|c|}{ Motor MAXON EC90 flat brushless } \\
\hline Máximo torque contínuo [mNm] & 387 \\
\hline Rotação nominal [rpm] & 2650 \\
\hline Largura [mm] & 27,3 \\
\hline Massa [g] & 600 \\
\hline Redução harmônica CSD-25-160 da Harmonic Drive \\
\hline Redução & 160 \\
\hline Máximo torque médio [Nm] & 75 \\
\hline Máxima rotação de entrada [rpm] & 7500 \\
\hline Largura [mm] & 17 \\
\hline Massa [g] & 240 \\
\hline
\end{tabular}

Com este conjunto, é possível obter o torque de saída e a rotação desejados, como pode ser visto a seguir.

$$
\begin{gathered}
T_{\text {saída máximo }}=T_{\text {motor }} * \text { redução }=0,387 * 160=61,92 \mathrm{Nm} \\
N_{\text {saída nominal }}=\frac{N_{\text {motor }}}{\text { redução }}=\frac{2650}{160} \cong 17 \mathrm{rpm}
\end{gathered}
$$

Vale ressaltar que, como a redução é alta (160 vezes), a capacidade do usuário impor o seu movimento sobre o atuador é pequena, pois essa capacidade é diretamente relacionada com a redução, como é ilustrado na Figura 13. 


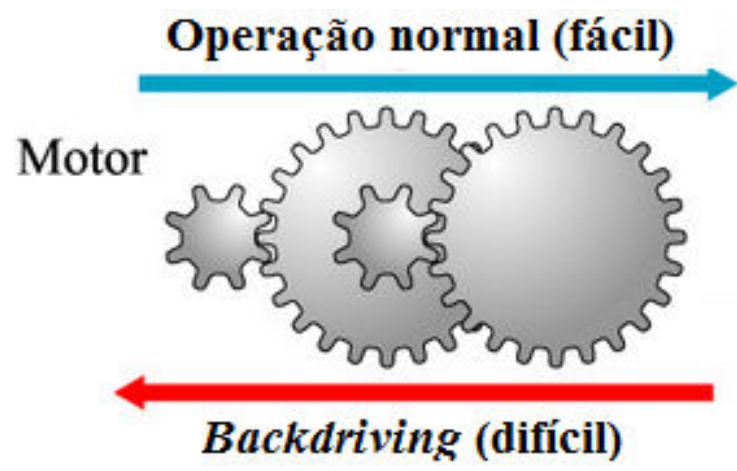

Figura 13: Dentes de engrenagem dificultam o caminho inverso da transmissão. Adaptado de (BACKDRIVABILITY, 2011).

Como a backdrivability é deficiente, o controle para a segurança deverá ser severo (controle de impedâncias deve limitar a força máxima de interação entre o exoesqueleto e o usuário).

Como o objetivo era evitar a transmissão de esforços para os componentes da redução (Harmonic Drive) e reduzir a sua largura, pensou-se na eliminação dos rolamentos e a utilização de um elemento flexível (feito de poliuretano), que funcionaria como fusível mecânico (posteriormente, verificou-se que isso não acontecia e uma correção foi necessária, como será detalhado posteriormente). A Figura 14 é o corte do módulo atuador.

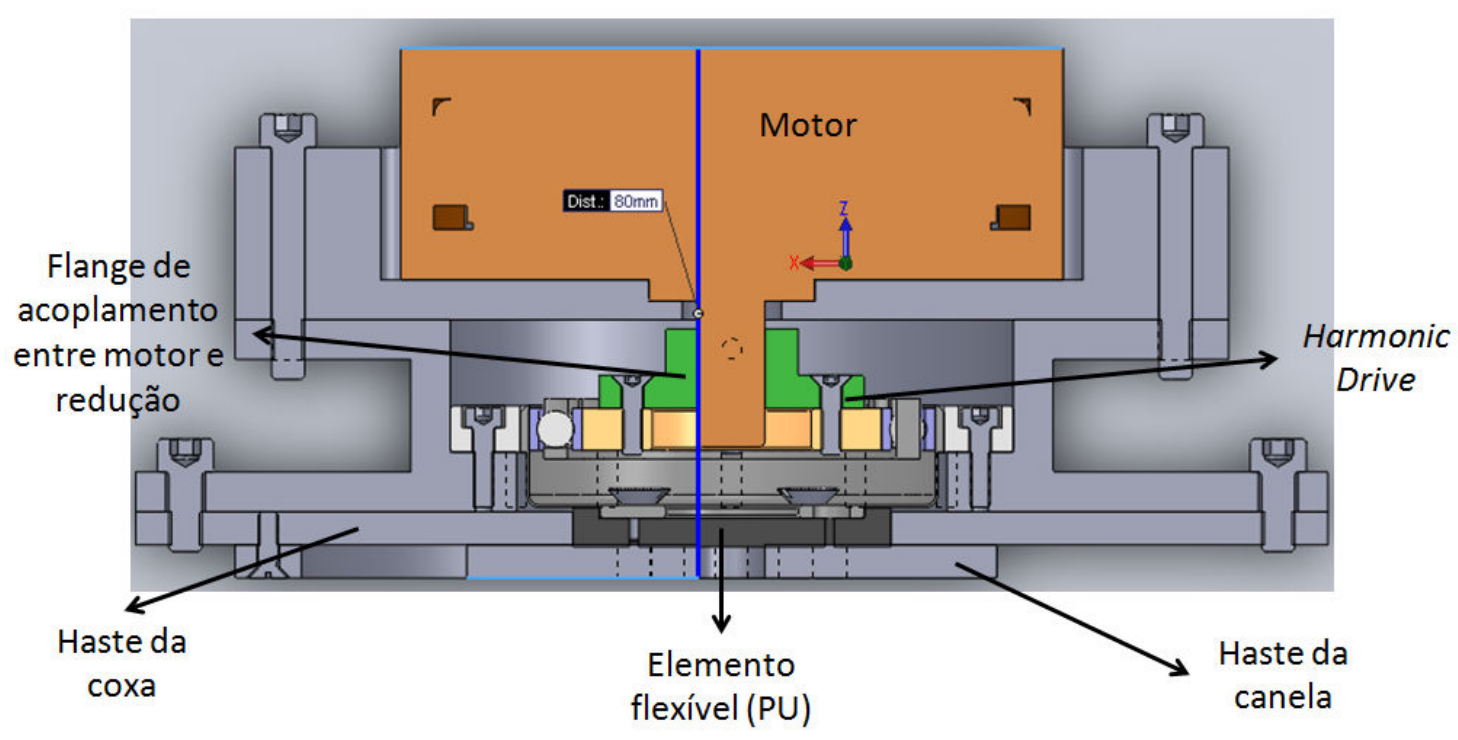

Figura 14: Vista em corte do quarto módulo atuador (SOUIT, MALGUEIRO, et al., 2013). 
O primeiro protótipo construído envolvia a articulação do joelho. O módulo atuador foi montado e acoplado aos apoios das pernas, conforme ilustrado nas Figuras 15 e 16.

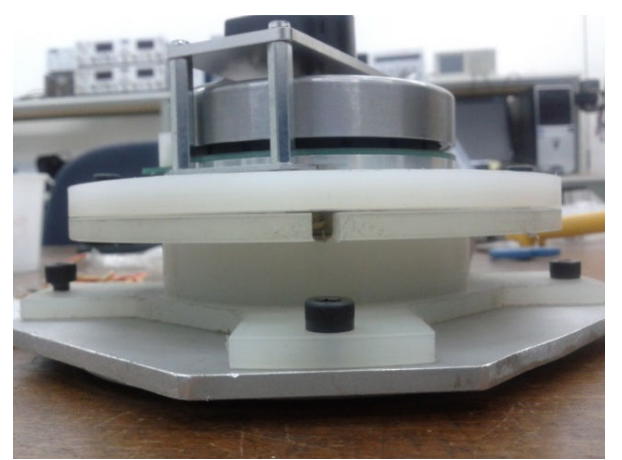

Figura 15: Módulo atuador completo (SOUIT e MALGUEIRO, 2012).
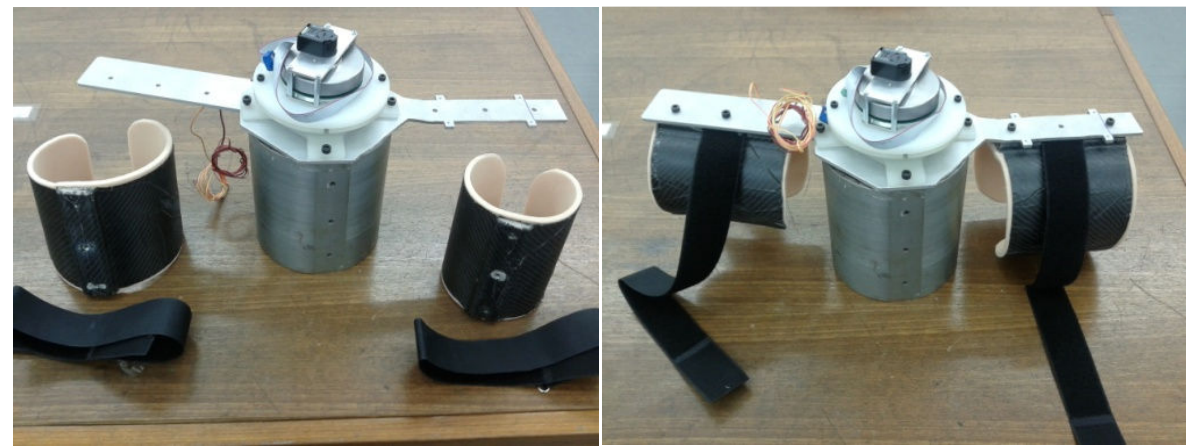

Figura 16: Montagem dos apoios de fibra de carbono (SOUIT e MALGUEIRO, 2012) e (SOUIT, MALGUEIRO, et al., 2013), respectivamente.

Assim, a primeira versão do protótipo foi finalizada. A Figura 17 mostra o primeiro protótipo montado ao corpo.

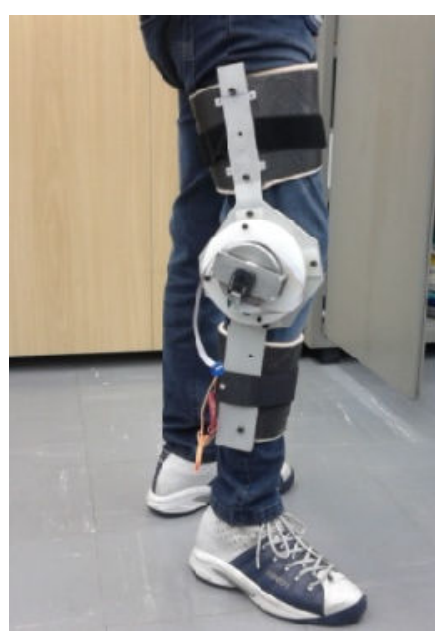

Figura 17: Primeira versão do protótipo acoplado na perna (SOUIT, MALGUEIRO, et al., 2013). 
Ao prender o protótipo construído na perna de uma pessoa, observou-se que com poucos movimentos havia um deslocamento para baixo, devido ao formato cônico da coxa e da canela.

A solução encontrada foi usar um tutor de quadril comercial, da marca Dilepé, e adaptá-lo para integrá-lo ao protótipo construído.

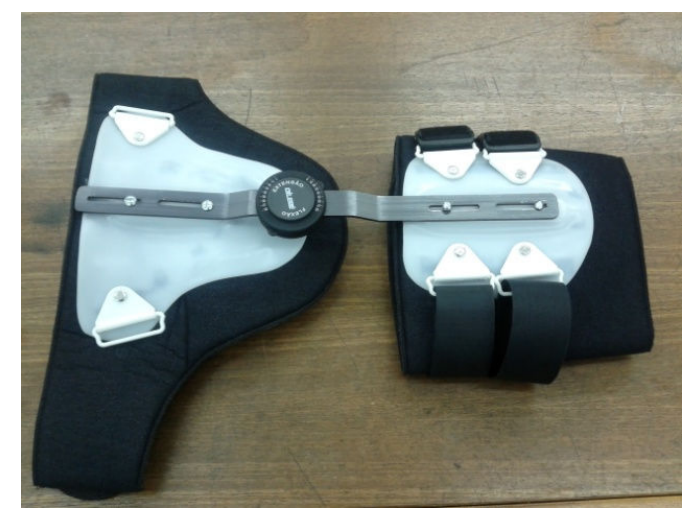

Figura 18: Tutor de quadril (SOUIT e MALGUEIRO, 2012).

O tutor possui um ajuste de posição vertical para o acoplamento da coxa e o acoplamento do quadril. Esses ajustes serão usados para alinhar a junta de rotação do tutor ao ponto médio de rotação do quadril e a rotação entre as hastes e o joelho.

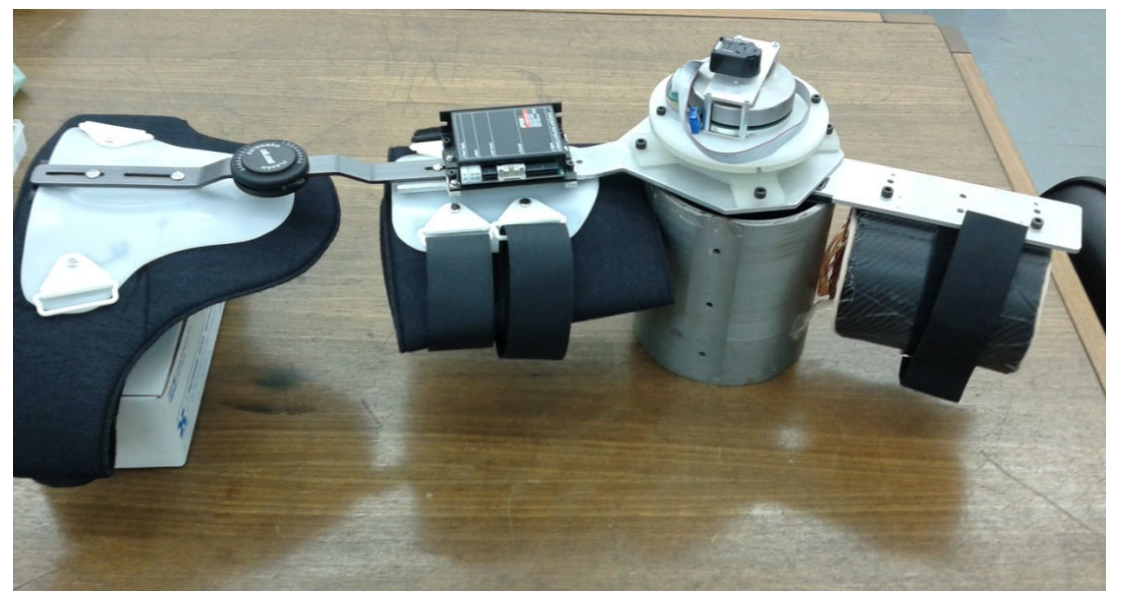

Figura 19: Exoesqueleto com acoplamentos no quadril, coxa e canela (SOUIT, MALGUEIRO, et al., 2013).

Ao iniciar o projeto do módulo do tornozelo, pensou-se em colocar o módulo atuador alinhado com a articulação do maléolo, mas essa alternativa logo foi excluída por dois motivos: 
a) Primeiro porque o módulo encostar-se-ia ao chão devido ao diâmetro da caixa de redução que abriga o harmonic drive e para que isso não ocorresse o usuário teria que vestir uma plataforma que o deixasse mais alto, o que complicaria o projeto e deixaria o exoesqueleto mais desconfortável;

b) Segundo porque quanto maior o momento de inércia em relação ao eixo de rotação do joelho, maior será a dificuldade para o usuário flexionar o joelho, ou seja, quanto maior o peso na extremidade da perna, mais difícil fica executar a marcha.

Sendo assim, outra solução era necessária. Pensou-se então em prender o módulo atuador entre as articulações do joelho e do tornozelo e transmitir o movimento por meio de um mecanismo de quatro barras (também chamado de "quadrilátero articulado").

Com a experiência adquirida no desenvolvimento do primeiro módulo atuador, foi possível reduzir a massa do segundo módulo e melhorar a sua montagem. Primeiramente, pensou-se na caixa da redução. Quanto menor for o seu diâmetro, menor será o seu volume e, portanto, menor será o seu produto de inércia, o que melhora o conforto para o usuário. Assim, os furos de fixação foram reposicionados para que o diâmetro ficasse menor, conforme ilustrado na Figura 20.

Caixa de redução do joelho (original)

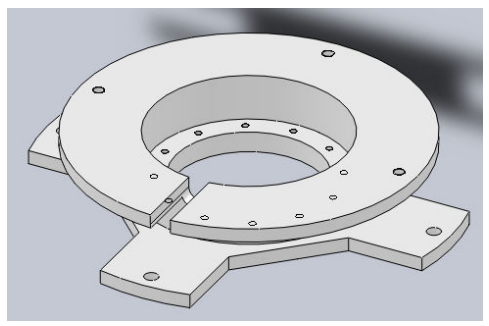

Diâmetro externo máximo: $180 \mathrm{~mm}$
Caixa de redução do tornozelo (massa reduzida)

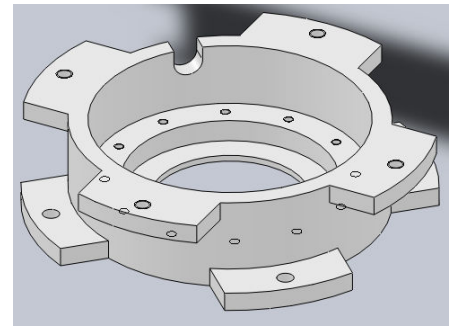

Diâmetro externo máximo: 130mm

Figura 20: Comparação entre a "Caixa de redução" do joelho e do tornozelo (SOUIT e MALGUEIRO, 2012).

Para que não houvesse atrito entre o flex spline e a peça acoplada à redução (chamada de "barra 1 do quadrilátero") e não fosse necessário usinar um anel separadamente (como foi feito no módulo do joelho), fez-se um rebaixo na caixa de maneira a apoiar o flex spline. Veja a vista em corte da caixa de redução modificada na Figura 21. 


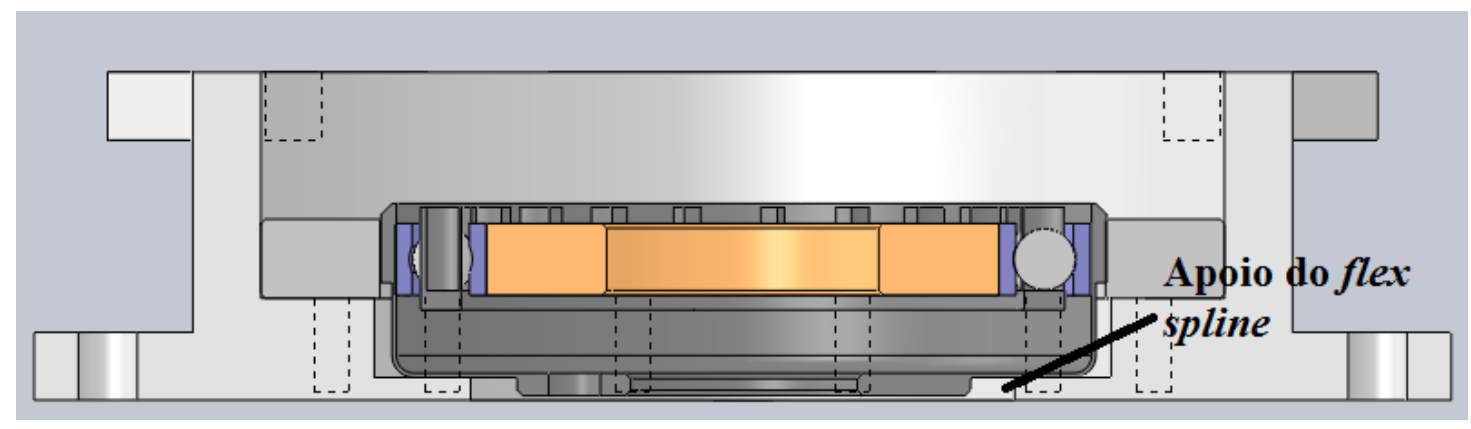

Figura 21: Montagem entre a "caixa de redução" otimizada e o harmonic drive (SOUIT e MALGUEIRO, 2012).

Além da alteração do formato, pensou-se também no material. Anteriormente, para construir a caixa foi utilizado o nylon, que possui densidade igual a $1,13 \mathrm{~g} / \mathrm{cm}^{3}$, enquanto que o PEAD (PoliEtileno de Alta Densidade) possui densidade igual a $0,95 \mathrm{~g} / \mathrm{cm}^{3}$ (VICK, 2012). Como esta peça não sofre carregamentos dinâmicos durante a marcha, pois serve para fixar a redução e o motor, este material suporta os esforços aos quais será submetido. Sendo assim, a nova caixa de redução foi feita com o PEAD o que a deixou ainda mais leve.

Para a construção da caixa de redução, seria necessário construir um dispositivo para fazer os cortes indicados na figura a seguir. Assim, para facilitar a fabricação, ao invés de rasgos, são feitos furos que servem para reduzir a massa e viabilizar a montagem dos parafusos (são passagens para a chave de fenda), conforme ilustrado na Figura 22.

Caixa de redução projetada

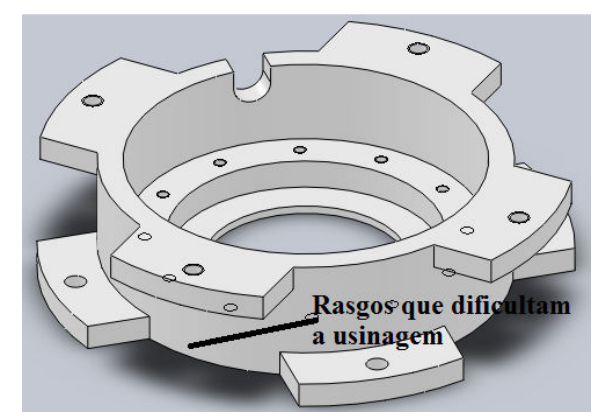

Caixa de redução revisada para a fabricação

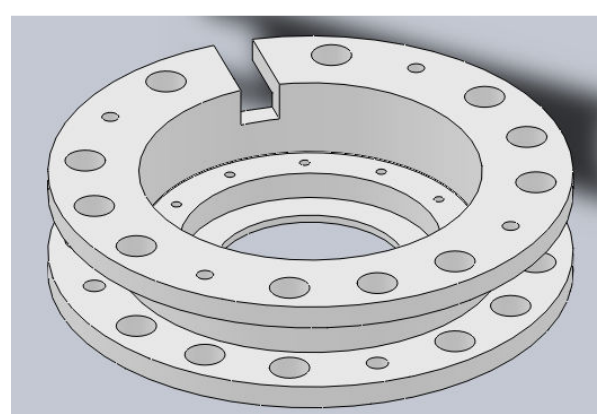

Figura 22: Modificação feita na "Caixa da redução" para facilitar a usinagem (SOUIT e MALGUEIRO, 2012).

Assim, o projeto do módulo atuador foi aprimorado e finalizado. Uma ilustração do módulo atuador é apresentada na Figura 23. Vale ressaltar novamente que este 
conjunto pode ser utilizado para atuar em qualquer articulação do corpo para executar o movimento de flexão-extensão.
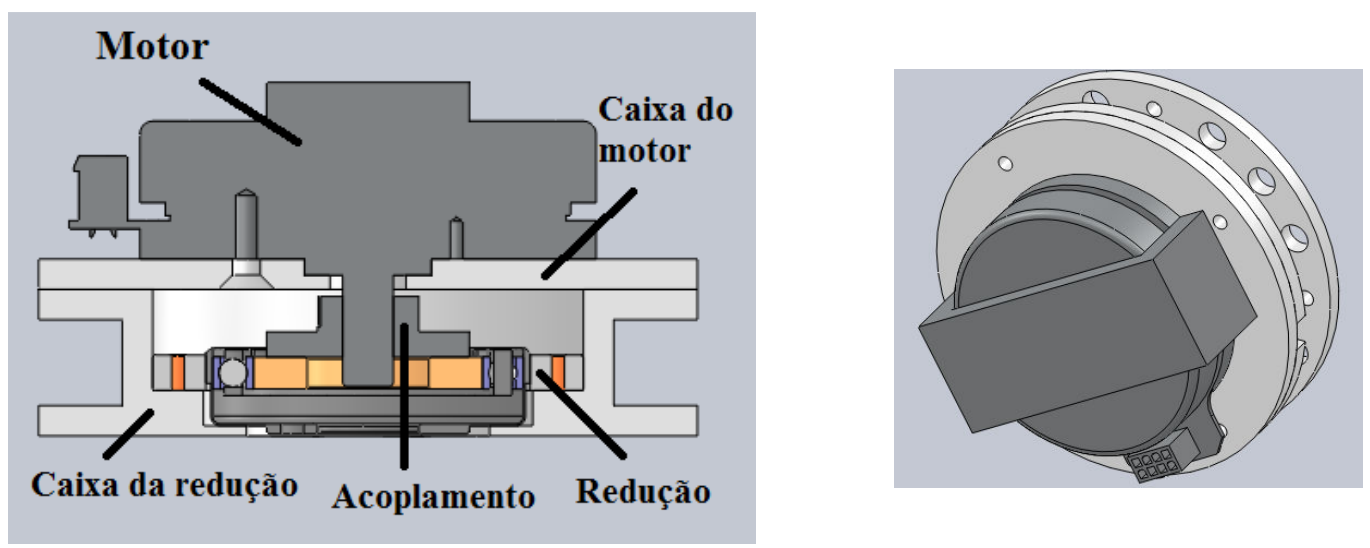

Figura 23: Módulo atuador otimizado e finalizado (SOUIT e MALGUEIRO, 2012) e (SOUIT, MALGUEIRO, et al., 2013), respectivamente.

Segundo as restrições dadas no escopo do projeto, o exoesqueleto deveria ser modular e ajustável. Sendo assim, pensou-se em uma estrutura que fosse ajustável em relação ao módulo do joelho.

Primeiramente, projetou-se uma peça que fixaria o módulo atuador na haste da canela. Essa peça foi chamada de "Apoio motor" e possui dois rasgos de maneira a possibilitar o ajuste em diferentes usuários. Ela foi feita com uma chapa de alumínio de $5 \mathrm{~mm}$ de espessura. A Figura 24 explica todos os detalhes da peça.

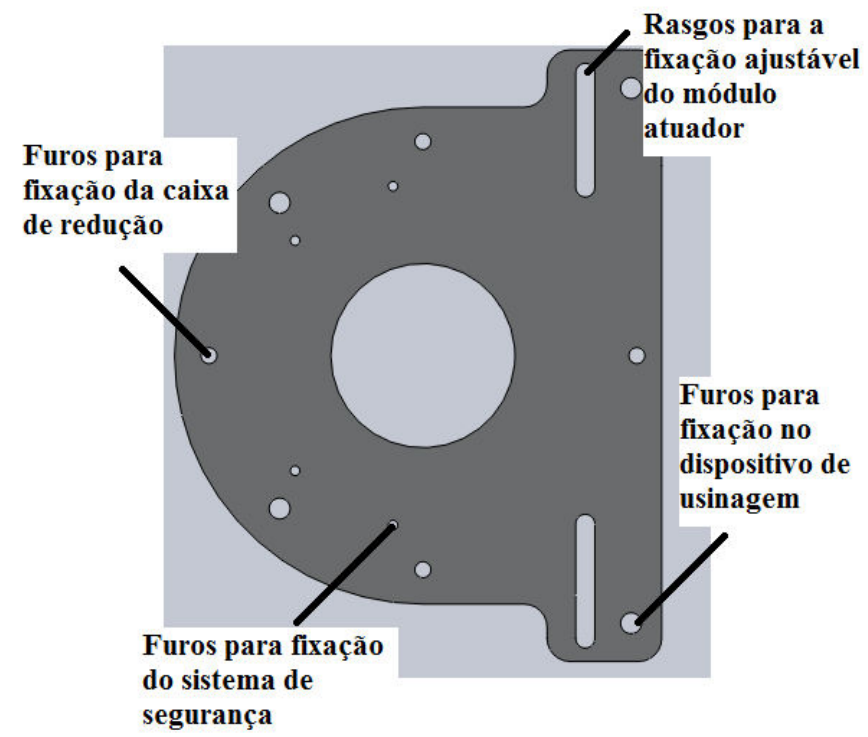

Figura 24: Detalhes da peça "Apoio Motor" (SOUIT e MALGUEIRO, 2012). 
Assim como no módulo do joelho, este módulo também possui um sistema de segurança para evitar que o movimento do motor ultrapasse os limites humanos de flexão-extensão do tornozelo (mais ou menos $20^{\circ}$ ). O sistema de segurança é composto por duas chapas de alumínio de $5 \mathrm{~mm}$ de espessura cada uma. O intuito deste sistema é limitar o movimento da "Barra 1 do quadrilátero" que será explicada posteriormente. A Figura 25 ilustra a montagem entre o apoio motor e o sistema de segurança.

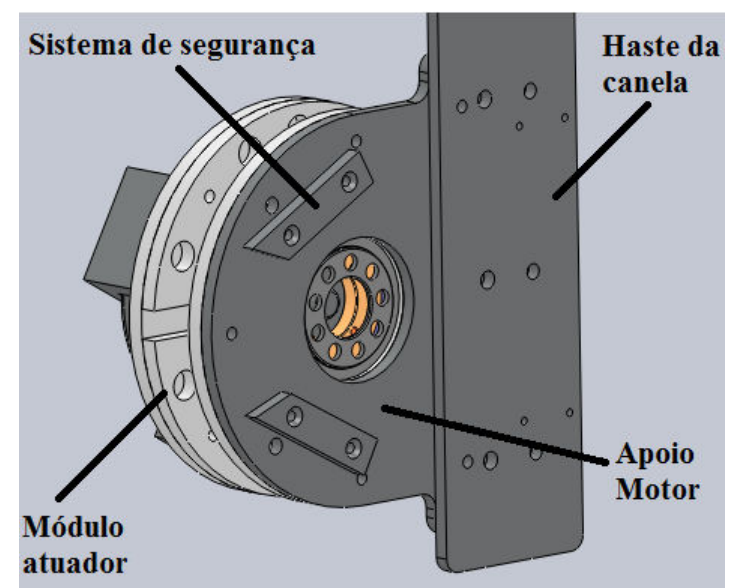

Figura 25: Montagem entre o "Apoio Motor" e o "sistema de segurança" (SOUIT e MALGUEIRO, 2012).

Para apoiar o pé do usuário, comprou-se uma órtese da Dilepé que possui um eixo de rotação na articulação do tornozelo. Essa órtese é chamada de "Tutor plástico para fratura da tíbia”. Neste exoesqueleto, será utilizada somente a parte inferior da órtese, indicada na Figura 26.

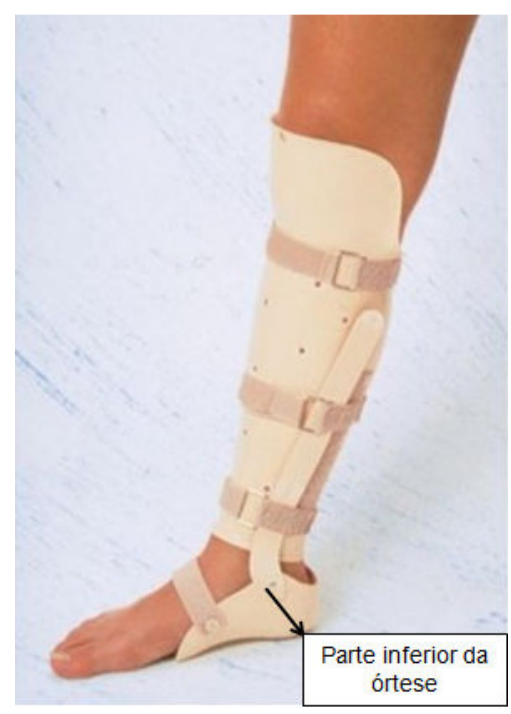

Figura 26: Tutor plástico para fratura da tíbia, fabricado pela Dilepé. Adaptado de (MÉDICO, 2012) 
Esta peça será fixada à canela por meio de velcro entre as abas laterais da órtese e o coxal de neopreme vestido na canela do usuário, conforme ilustrado na Figura 27. Isto permite que o módulo do tornozelo seja ajustável ao módulo do joelho.

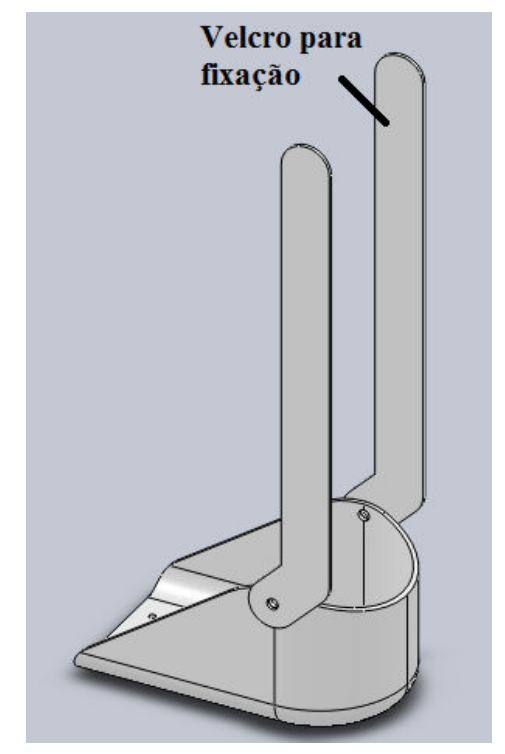

Figura 27: Órtese do tornozelo (SOUIT e MALGUEIRO, 2012).

Para transmitir o movimento do módulo atuador até a órtese do tornozelo, foi projetado um quadrilátero articulado no formato de um paralelogramo, ou seja, a barra 1 é igual e paralela à barra 3 assim como a barra 2 é igual e paralela à barra 4 em todos os instantes. Isto facilita o controle e a modelagem do sistema, pois a barra 3 se comporta da mesma maneira que a barra 1, a qual é acoplada ao motor. A Figura 28 ilustra este quadrilátero articulado.

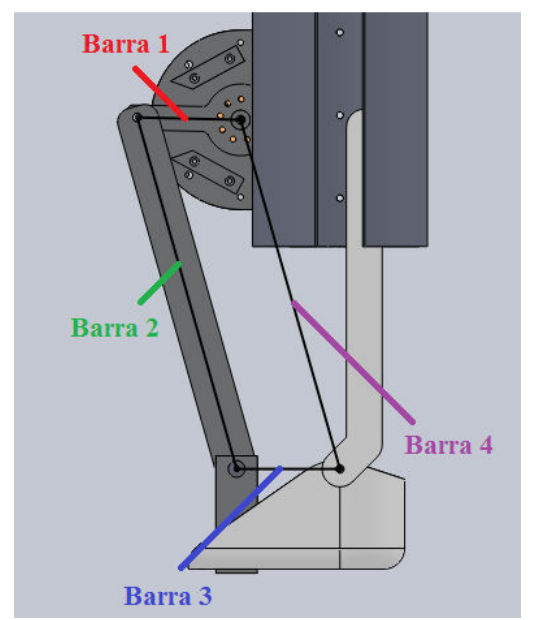

Figura 28: Representação do quadrilátero articulado (SOUIT, MALGUEIRO, et al., 2013). 
A "Barra 2" do quadrilátero, indicada na Figura 28, é apenas uma viga para ligar os dois eixos de rotação. Para facilitar a usinagem, foi comprado um perfil de alumínio padronizado de $13 / 16$ " (30,16 mm) de largura e 3/8" de espessura $(9,52 \mathrm{~mm})$.

Com isso, o projeto do módulo do tornozelo foi concluído, conforme ilustrado na Figura 29.

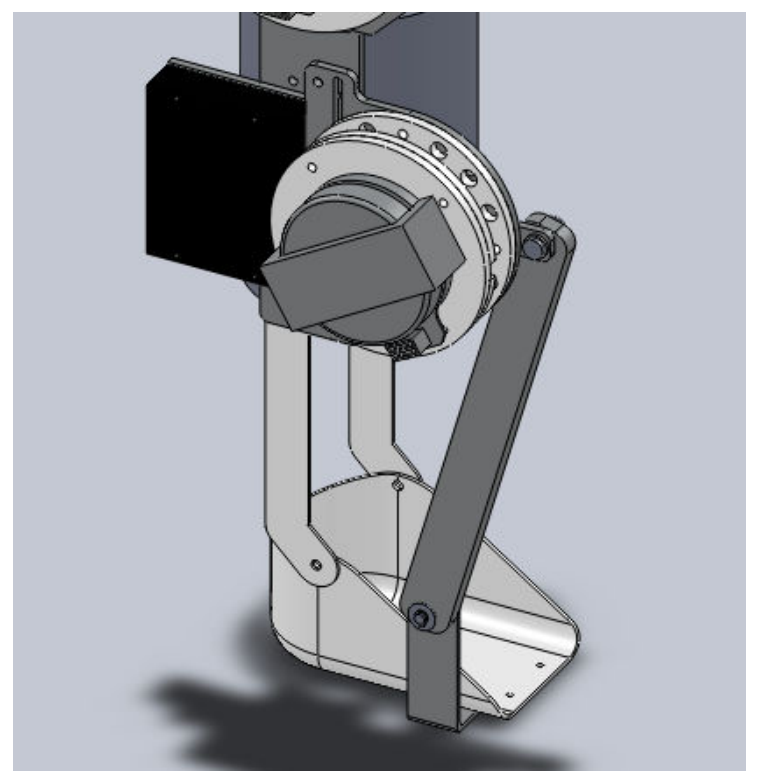

Figura 29: Montagem completa do módulo do tornozelo (SOUIT e MALGUEIRO, 2012).

O exoesqueleto completo concluído na época da graduação está na Figura 30. Em seguida, serão listados os problemas encontrados na primeira versão do exoesqueleto e as propostas de melhorias. 

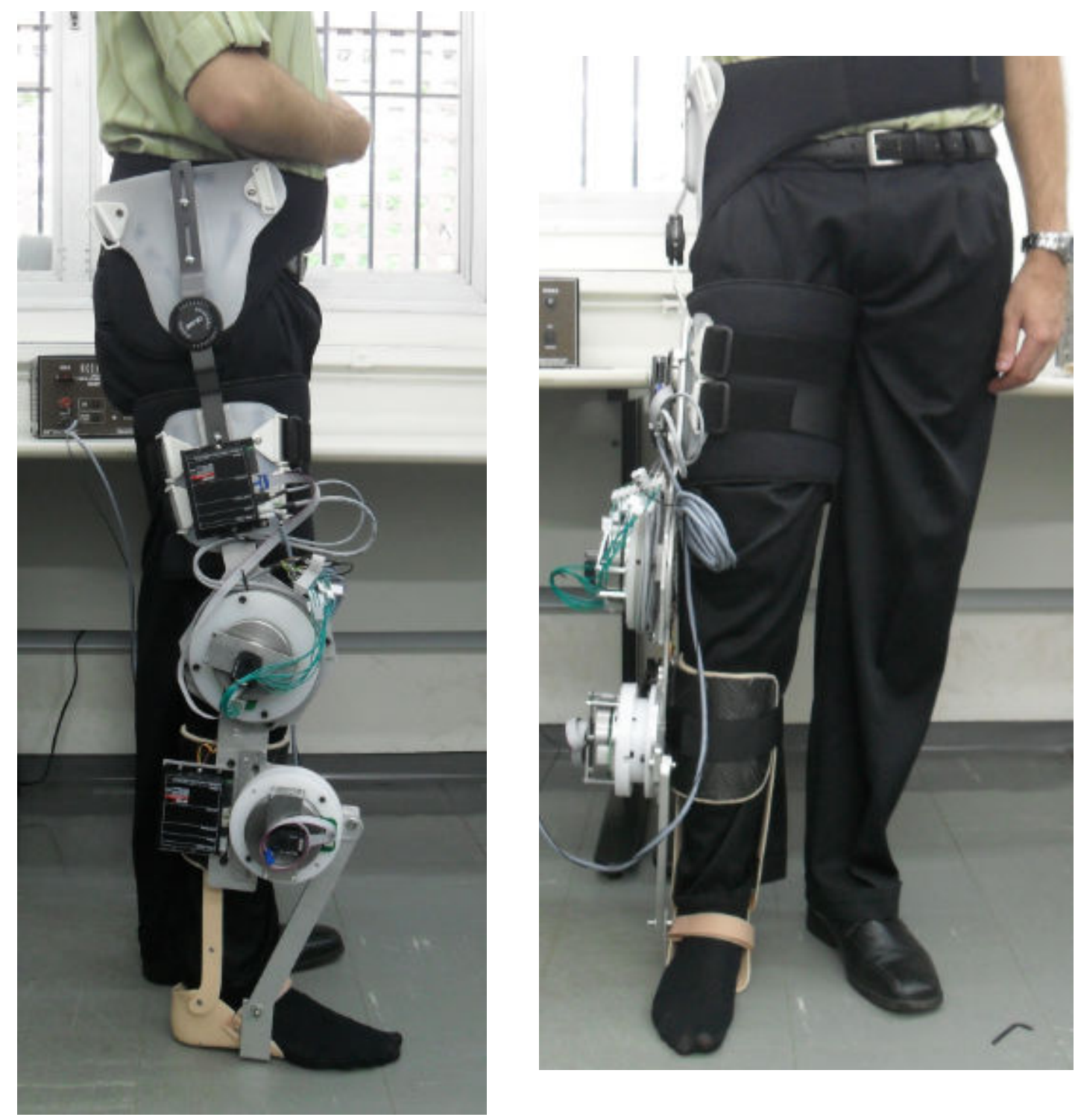

Figura 30: Protótipo I do exoesqueleto completo. 


\section{Projeto Mecânico - Protótipo II}

O exoesqueleto será uma ferramenta de estudo da marcha. O exoesqueleto deverá ser capaz de medir a força de interação e a posição das articulações na configuração desejada. Além disso, deverá permitir montagens e desmontagens constantes e ser ajustável para a faixa de massa e altura da população do estado de São Paulo (IBGE, 2009). Para o projeto e construção do Protótipo II (também chamado de Exololi Exoskeleton Lower Limb) foram feitas melhorias baseadas nos seguintes critérios:

1) Redução de massa: quanto menor a massa do exoesqueleto, menor será o desvio ao padrão natural da marcha. Como explicitado anteriormente, há potenciais para redução de massa na estrutura do exoesqueleto, pois o coeficiente de segurança utilizado foi superestimado.

2) Modularidade: no Protótipo I, não era possível usar apenas o módulo do tornozelo sem que o módulo do joelho estivesse montado. Portanto, foi necessário reprojetar a estrutura do exoesqueleto de maneira a permitir que o módulo do tornozelo fosse independente do joelho. Só assim, o exoesqueleto pode ser chamado de modular.

A seguir, as propostas de melhorias serão apresentadas: do módulo atuador e da estrutura.

\subsection{Melhorias do módulo atuador}

O módulo atuador do tornozelo projetado e construído para o protótipo I foi baseado no do joelho e já possui melhorias sobre este. Assim, para fins de melhorias, serão consideradas as informações desse módulo atuador. Para a construção do protótipo II, deseja-se projetar um módulo atuador o qual não apresenta os problemas constatados no protótipo atual. A seguir, estão listados os problemas e as modificações para o novo módulo atuador.

\subsubsection{Elementos de fixação sem aperto.}

O invólucro do módulo atuador do protótipo I foi feito em plástico (PEAD PoliEtileno de Alta Densidade), apesar de ser menos denso que o alumínio, não possui a 
mesma resistência. Por isso, quando os parafusos foram fixados e desmontados algumas vezes, alguns furos perderam a rosca. Assim, o novo módulo terá o invólucro feito de alumínio.

\subsubsection{Atrito}

No módulo atuador do protótipo I, a haste conectada ao Harmonic Drive, estava sendo movimentada sobre a base fixa de alumínio. Assim, havia um desgaste desnecessário entre as partes (atrito de alumínio com alumínio). O torque resistivo do atrito é calculado no Apêndice A. Para o novo módulo atuador, é necessário eliminar esse desperdício de energia.

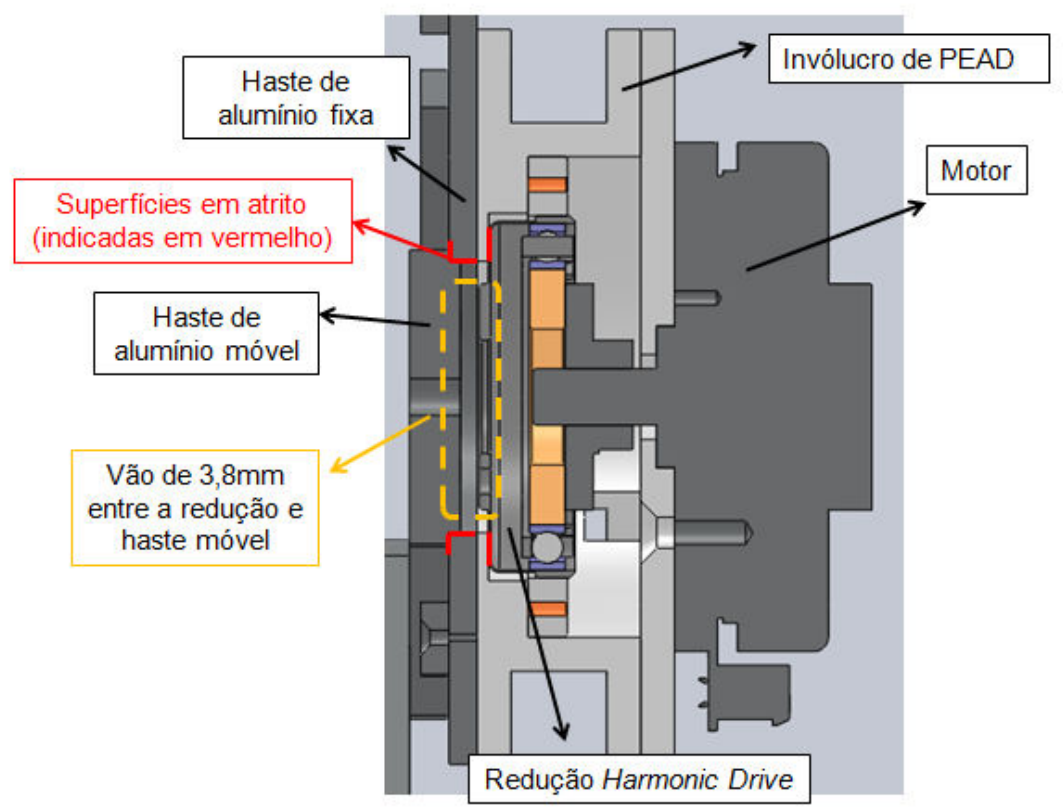

Figura 31: Vista em corte do modulo atuador do protótipo I.

Outro problema deste módulo atuador é a distância entre o Harmonic Drive e a haste móvel (distância normal de 3,8mm). Se, durante a montagem, os parafusos forem montados de maneira a apertar o vão existente, é possível deformar o flexspline do Harmonic Drive e prejudicar o seu funcionamento.

\subsubsection{Força axial gerada pelo Harmonic Drive não considerada}

O Harmonic Drive em desaceleração provoca uma força axial no sentido de empurrar o Wave Generator para fora do Flexspline (HARMONICDRIVE, 2015). Por 
ação e reação, a força axial também empurra o Flexspline no sentido oposto. É necessário fixar o Wave Generator e o Flexspline na direção axial em ambos os sentidos.

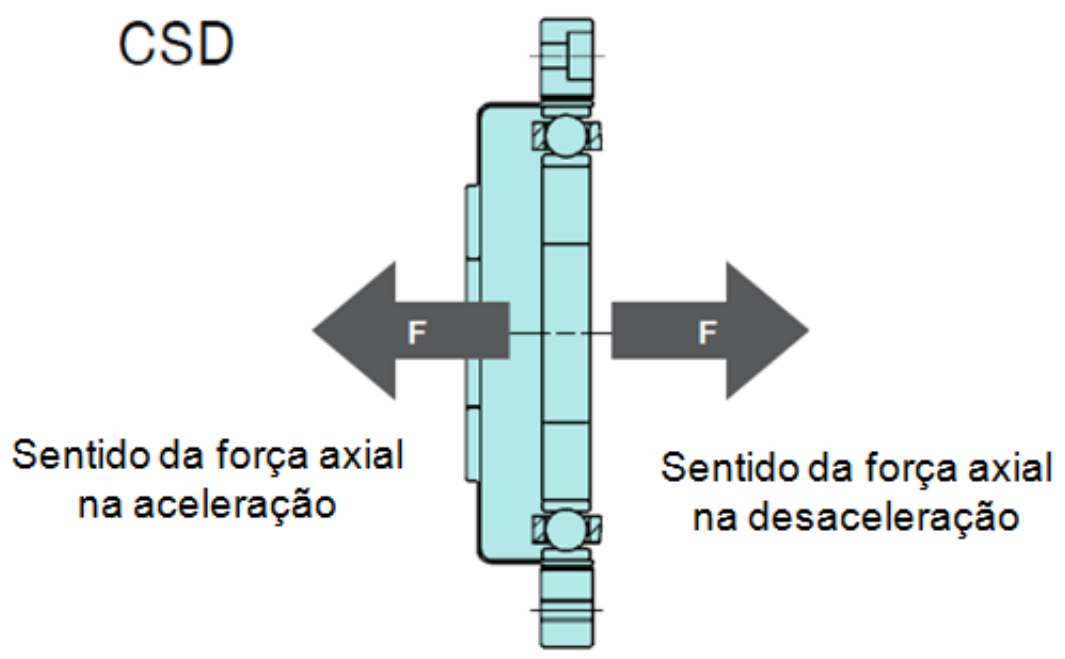

Figura 32: Sentido da força axial gerada pelo Harmonic Drive em funcionamento. Adaptado de (HARMONICDRIVE, 2015).

A força axial gerada pelo Harmonic Drive é de $60 \mathrm{~N}$. Os cálculos estão disponíveis no Apêndice B. O módulo atuador do protótipo I fixa o Flexspline apenas por uma superfície de $2 \mathrm{~mm}$ de espessura de PEAD.

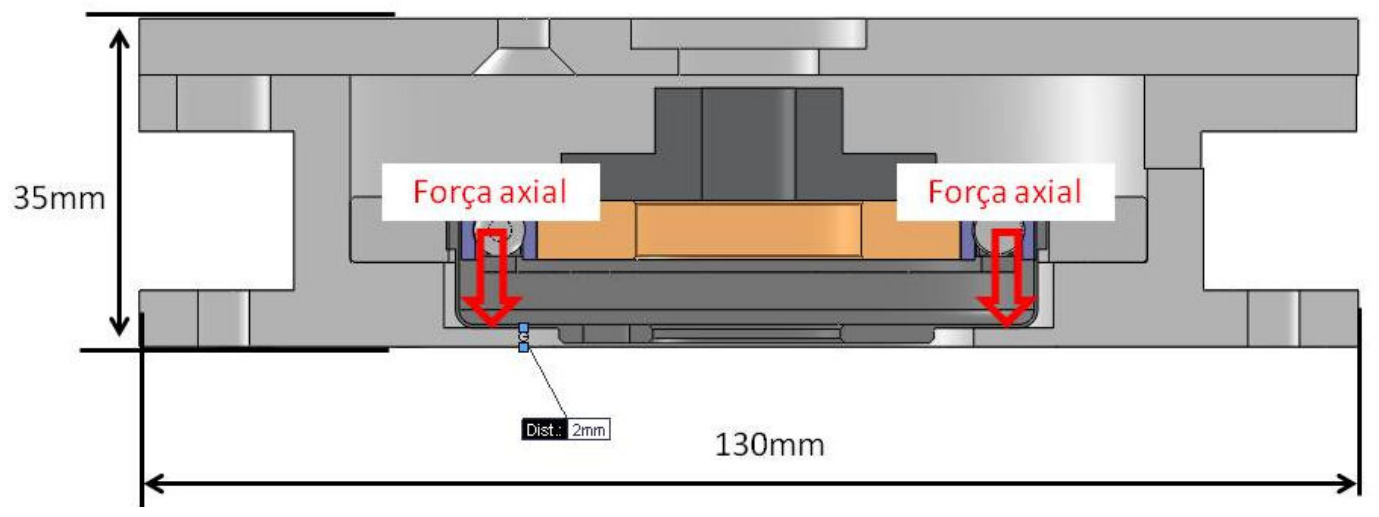

Figura 33: Apoio do Flexspline.

$\mathrm{O}$ atrito gerado por esse contato provoca um torque resistivo de $0,32 \mathrm{Nm}$ (desperdício de energia). Além do atrito, a força gerada pelo Harmonic Drive durante funcionamento movimenta o Wave Generator axialmente, impedindo o funcionamento correto do módulo atuador. 


\subsubsection{Novo projeto para o módulo atuador}

Neste tópico serão explicadas as soluções sugeridas para a correção dos problemas constatados no módulo atuador do protótipo I. As Figuras 34 e 35 ilustram o conteúdo do novo módulo atuador (protótipo II).

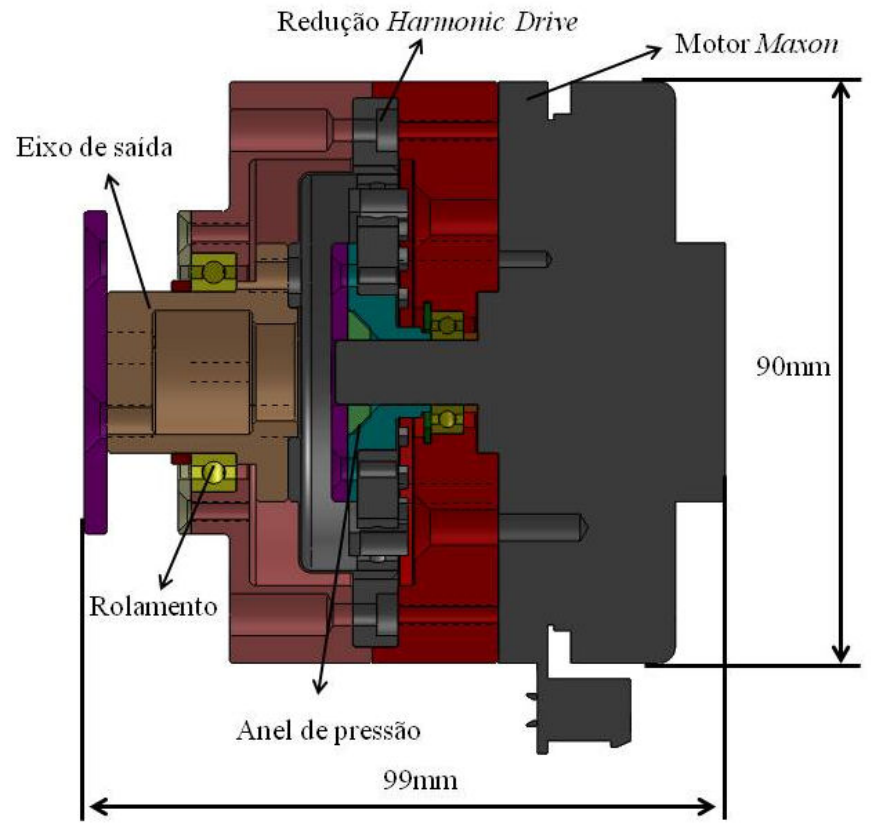

Figura 34: Vista em corte do modelo 3D novo módulo atuador.

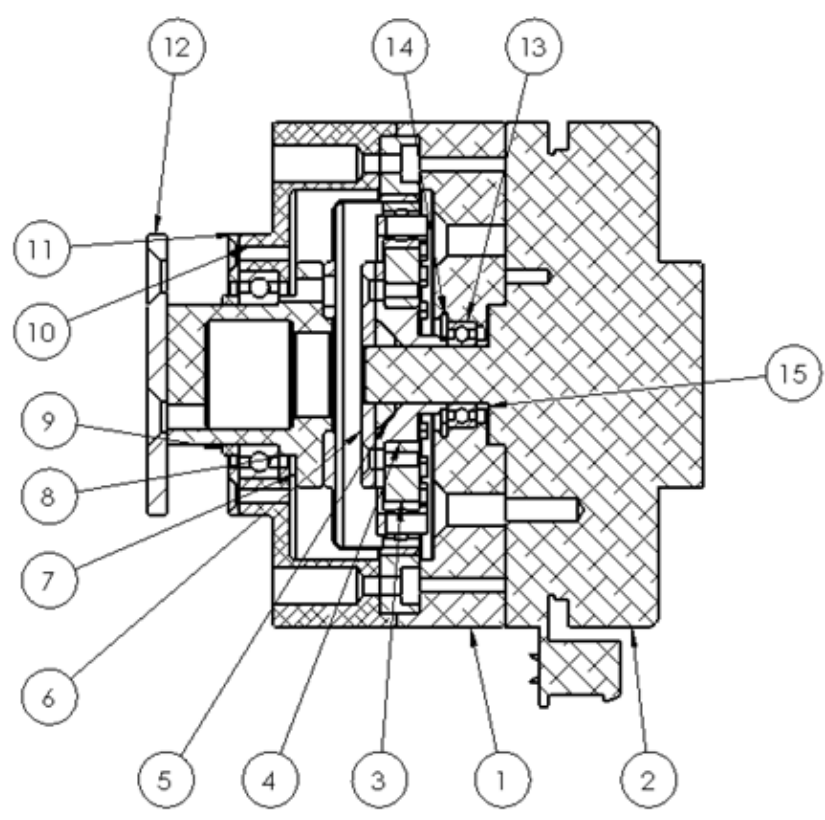

\begin{tabular}{|c|c|c|}
\hline $\begin{array}{l}N_{\text {NIDO }} \\
\text { IIEM }\end{array}$ & $N^{\circ}$ DA PEÇA & QDT. \\
\hline$\frac{11}{1}$ & Caixa de reducao 1 & 1 \\
\hline 2 & Motor Maxon EC-90 & 1 \\
\hline 3 & HD_CSD_25_160_STD & 1 \\
\hline 4 & Acoplamento motor & 1 \\
\hline 5 & AnelDePressao & 1 \\
\hline 6 & TampaAnelPressao & 1 \\
\hline 7 & EixoDesaida & 1 \\
\hline 8 & $\begin{array}{l}25 \times 37 \times] \text { RadialDeepGroove } \\
\text { DIN } 625-61805-2 R Z\end{array}$ & 1 \\
\hline 9 & Batente rolamento int & 1 \\
\hline 10 & Calxa de reducao 2 & 1 \\
\hline 11 & Batente rolamento ext & 1 \\
\hline 12 & TampaEixoSaida & 1 \\
\hline 13 & $\begin{array}{l}\text { I0xiox_RadialDeepGroove } \\
\text { DIN 625-61800-27 }\end{array}$ & 1 \\
\hline 14 & Circlip DIN 472-1 - 21X1 & 1 \\
\hline 15 & BatRollntMotor & 1 \\
\hline
\end{tabular}

Figura 35: Vista em corte do novo módulo atuador com lista de peças 
Para evitar o problema de perda de aperto dos parafusos, a caixa da redução (invólucro) é feita de alumínio, não mais de PEAD. Também, para corrigir o problema do atrito, um rolamento foi incluído entre o eixo de saída e a caixa da redução. O rolamento também servirá para suportar as forças axiais sobre o módulo atuador, a saber:

a) Força axial gerada pelo Harmonic Drive em funcionamento $F=60 \mathrm{~N}$.

b) Força axial gerada pelo usuário, pelos músculos supinadores, a qual pode chegar até $3 \mathrm{kgf}$ (KAPANDJI, 2000), como descrito na próxima figura. É necessário que um rolamento suporte essa carga de maneira a proteger o Harmonic Drive, $F=30 N$.
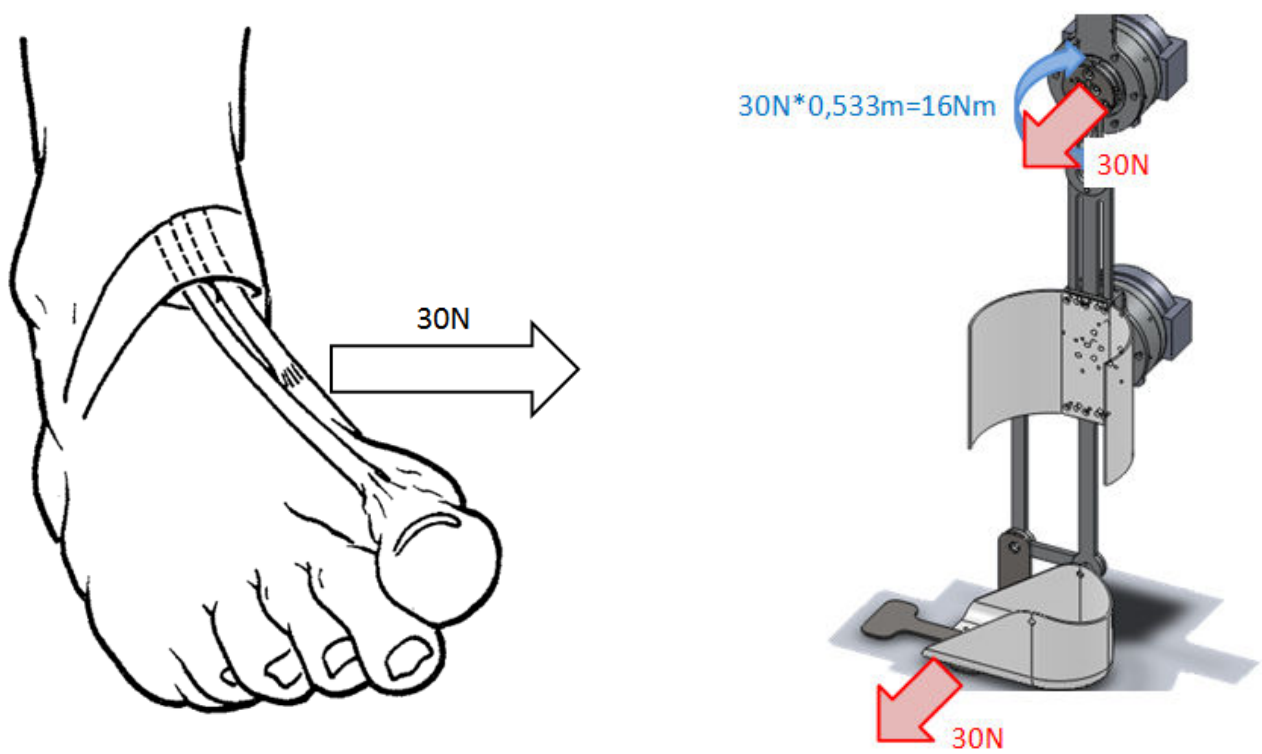

Figura 36: À esquerda, força máxima gerada pelos músculos supinadores, adaptado de (KAPANDJI, 2000); à direita, o transporte da força aplicada pelo usuário sobre o exoesqueleto no apoio do pé provoca a mesma força axial sobre o módulo atuador do joelho com um momento - a distância considerada é para o caso mais crítico, pessoa de $1,90 \mathrm{~m}$ de altura (detalhes sobre a estrutura serão explicados posteriormente, no item "Melhorias da estrutura").

Para selecionar o rolamento, era necessário definir o diâmetro do eixo de saída. Com o objetivo de reduzir ou manter o mesmo comprimento transversal do módulo atuador (quanto maior o comprimento transversal, maior o desconforto para a marcha), optou-se por conectar a haste a ser movida diretamente no eixo de saída por meio de uma chapa de inox. Para tanto, o diâmetro do eixo deve ser tal que os parafusos suportem a 
força cortante. Os cálculos para o dimensionamento do eixo são apresentados no Apêndice C. O diâmetro do eixo de saída do módulo atuador dimensionado é $25 \mathrm{~mm}$.

Considerando o eixo de $25 \mathrm{~mm}$ de diâmetro, selecionou-se o rolamento radial de uma fileira de esferas (DIN625) por suportar cargas radiais e axiais e atender ao requisito de $90 \mathrm{~N}$ de carga axial (NSK, 2015).

Para evitar o escorregamento entre o motor e a redução, optou-se pelo conceito de anel de pressão para o acoplamento do eixo do motor e a redução Harmonic Drive. Esse conceito é baseado em uma abraçadeira, que pressiona o eixo por todo o perímetro. A Figura 37 ilustra esse conceito: a peça "Anel de pressão" é fixa por interferência no “Acoplamento Motor" e na "Tampa anel de pressão", assim, ela é pressionada no sentido radial contra o eixo do motor.

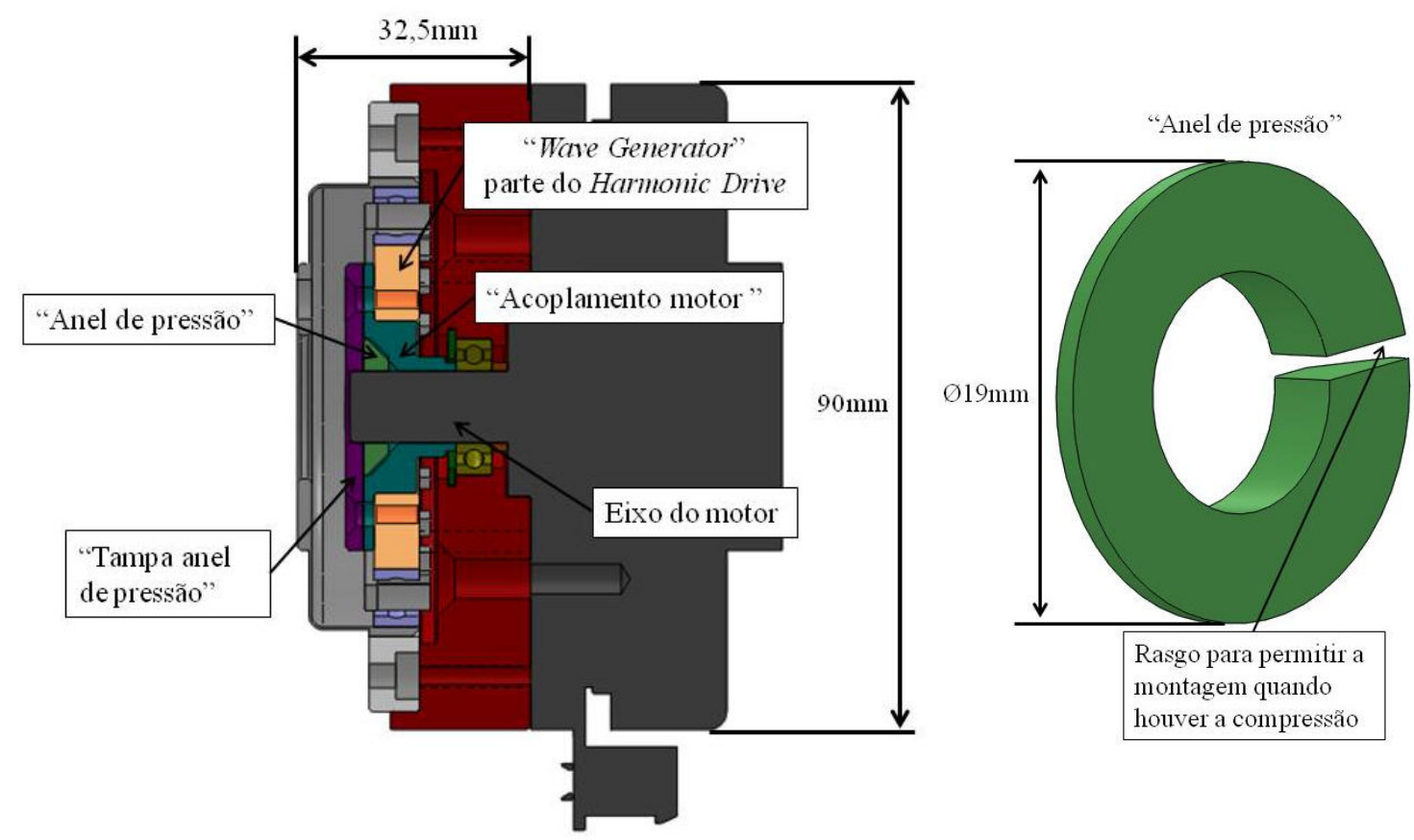

Figura 37: À esquerda, vista em corte das peças que fazem o acoplamento entre o eixo do motor e a redução; à direita, vista em perspectiva da peça "Anel de pressão".

Para garantir que não haja escorregamento, o torque gerado pelo atrito entre as peças "Anel de Pressão" e o eixo do motor deve ser, no mínimo, duas vezes o torque de saída do motor (coeficiente de segurança igual a $2: T_{\text {atrito }} \geq 2 * T_{\text {motor }}=2 * 0,387 \cong$ $0,8 \mathrm{Nm}$ ). O torque de atrito é calculado no Apêndice D. Por fim, para garantir o correto 
posicionamento do Wave Generator durante a montagem, a peça "acoplamento motor" encosta no rolamento fixo ao eixo do motor.

Para que o Flex Spline não se movimente durante o funcionamento do Harmonic Drive (por causa da força axial de $60 \mathrm{~N}$ ), é necessário que o módulo atuador funcione apenas quando a "Célula de Carga" está montada ao conjunto, pois ela garantirá o espaçamento correto entre o Wave Generator e as "Caixas da Redução", conforme ilustrado na Figura 38.

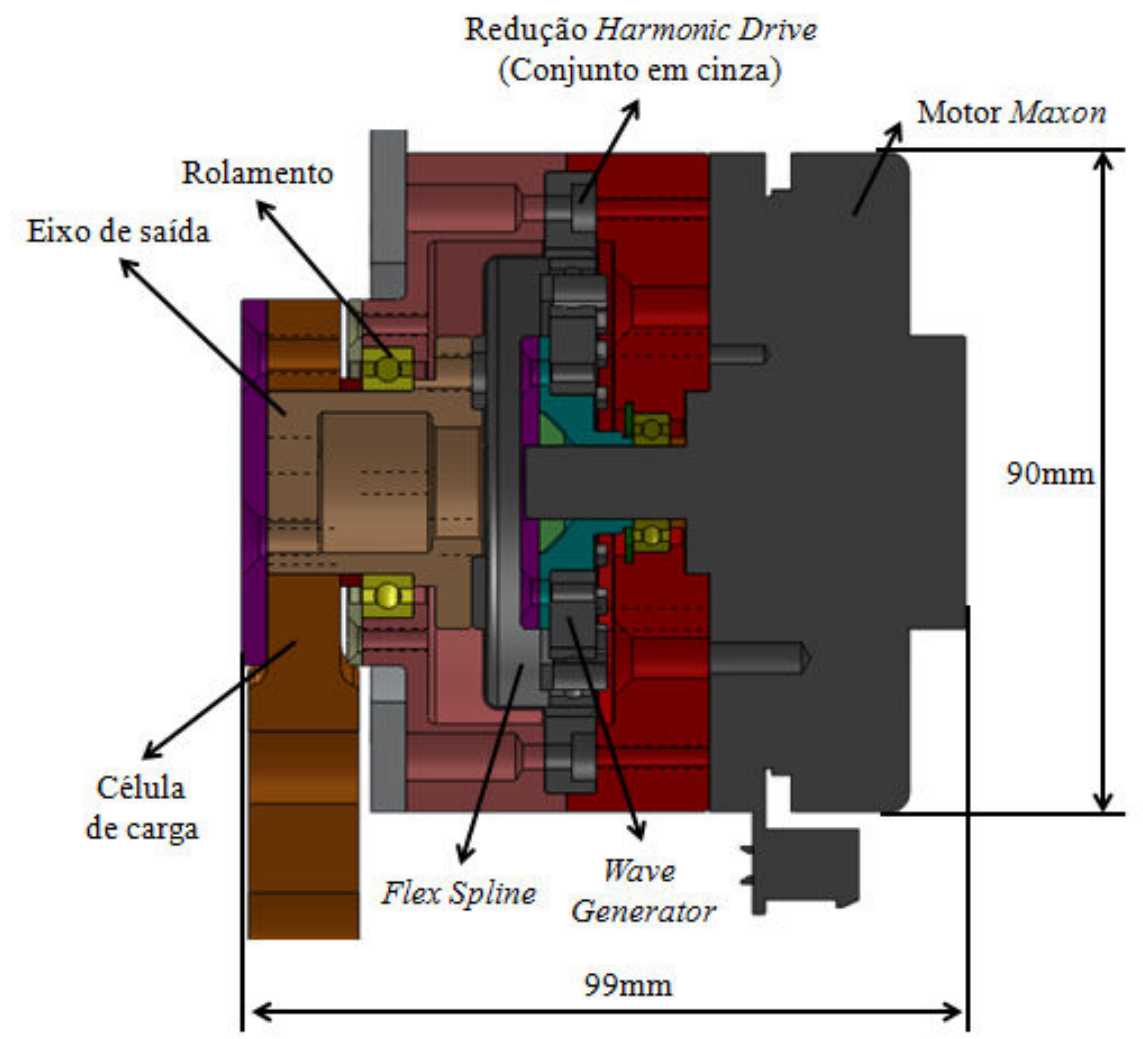

Figura 38: Vista em corte do conjunto "Módulo atuador" com "Célula de Carga". Com o conjunto completo, é possível garantir o posicionamento do Wave Generator e do Flex Spline quando o Harmonic Drive está em funcionamento.

Com isso, os problemas detectados no módulo atuador do protótipo I foram solucionados. A Tabela 4 compara as características dos dois projetos. O novo módulo atuador é mais robusto (não perde energia por atrito e não permite escorregamento entre o motor e a redução) e a massa é equiparada ao modelo anterior. 
Tabela 4: Comparação entre as características dos módulos atuadores.

\begin{tabular}{|c|c|c|}
\hline Característica & $\begin{array}{c}\text { Módulo atuador } \\
\text { Protótipo I }\end{array}$ & $\begin{array}{c}\text { Módulo atuador } \\
\text { Protótipo II }\end{array}$ \\
\hline Massa & $1,30 \mathrm{~kg}$ & $1,19 \mathrm{~kg}$ \\
\hline Diâmetro externo & $130 \mathrm{~mm}$ & $90 \mathrm{~mm}$ \\
\hline
\end{tabular}

O módulo atuador do Protótipo II pode ser montado tanto no tornozelo quanto no joelho, aumentando a flexibilidade para a configuração do exoesqueleto. Neste Protótipo, optou-se por atender ao torque de operação do tornozelo e joelho durante a fase de balanço $\left(T_{\text {operação }} \cong 30 \mathrm{Nm}\right)$. Assim, a redução usada no Protótipo II é de 100 vezes. A Tabela 5 mostra todas as especificações do módulo atuador deste último protótipo.

Tabela 5: Especificações do módulo atuador do Protótipo II.

\begin{tabular}{|l|c|}
\hline \multicolumn{2}{|c|}{ Motor Maxon EC90 flat } \\
\hline Máximo torque contínuo & $0,387 \mathrm{Nm}$ \\
\hline Rotação nominal & $2650 \mathrm{rpm}$ \\
\hline Massa & $0,600 \mathrm{~kg}$ \\
\hline \multicolumn{2}{|c|}{ Redução harmônica Harmonic Drive CSD-25-100 } \\
\hline Taxa de redução & 100 \\
\hline Velocidade máxima de entrada & $5600 \mathrm{rpm}$ (graxa) \\
\hline Massa & $0,240 \mathrm{~kg}$ \\
\hline \multicolumn{2}{|c|}{ Módulo Atuador - Protótipo II } \\
\hline Máximo torque de saída & $38,7 \mathrm{Nm}$ \\
\hline Rotação nominal & $26,5 \mathrm{rpm}$ \\
\hline Massa total & $1,190 \mathrm{~kg}$ \\
\hline
\end{tabular}

Outro problema identificado no Protótipo I, como já dito anteriormente é que a estrutura era parcialmente modular: só era possível utilizar o módulo do tornozelo se o módulo do joelho estivesse montado. Além disso, para desmontar o módulo do tornozelo, era necessário desmontar a redução do módulo do joelho, conforme ilustrado na Figura 39, o que dificultava a utilização do Protótipo I. 


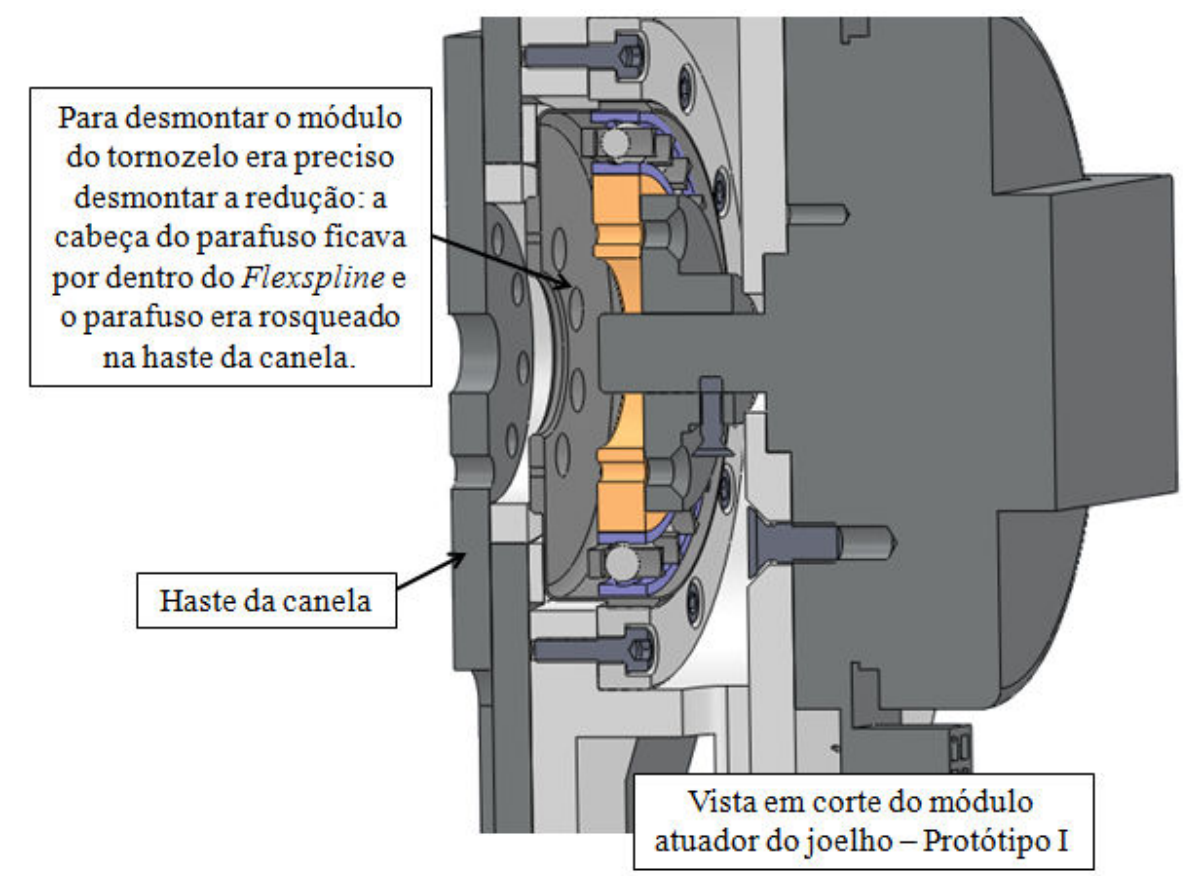

Figura 39: Conceito utilizado no Protótipo I para o desacoplamento do módulo do tornozelo

Para viabilizar o uso do módulo do tornozelo independentemente do joelho, foi desenvolvido o "Módulo Passivo": um conjunto com as mesmas dimensões externas, massa e centro de gravidade do módulo atuador, porém, com o funcionamento de rolamento (não possui motor; apenas acompanha o movimento da articulação). Desta forma, quando se deseja testar apenas o tornozelo, a estrutura deve ser montada com o módulo passivo paralelo ao joelho.

O módulo passivo contém um rolamento e um eixo de saída com as mesmas dimensões do módulo atuador. Assim, é possível montar o módulo passivo no lugar do módulo ativo com a mesma interface. O módulo passivo foi projetado com as mesmas dimensões, massa e centro de gravidade $(\mathrm{CG})$ do módulo atuador para que fosse possível medir a interferência do exoesqueleto sobre o padrão de marcha sem a atuação dos motores. Conhecendo a interferência do exoesqueleto sobre o padrão da marcha, é possível identificar os parâmetros do exoesqueleto e desconsiderá-los para obter os parâmetros do humano (por meio da linearização ao redor de uma posição da marcha). 
A próxima figura descreve o conteúdo do módulo passivo bem como compara a posição do centro de gravidade (no sentido transversal) e a massa dos dois módulos (passivo e ativo).

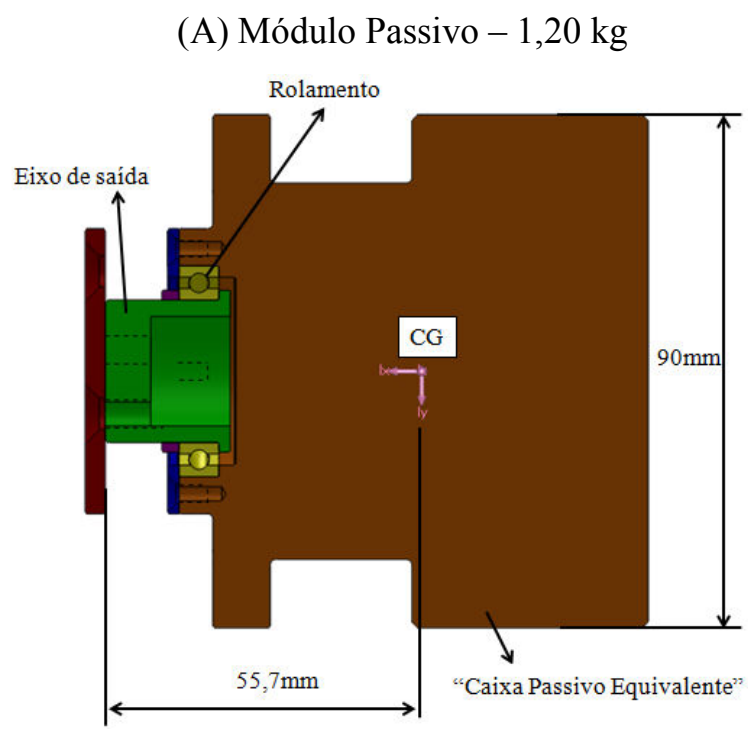

(B) Módulo Ativo - 1,19 kg

Figura 40: (A) Descrição do módulo passivo com os principais componentes e distância transversal do CG. (B) Distância transversal do CG do módulo ativo.

\subsection{Melhorias da estrutura}

Conforme já descrito nos "Requisitos do Projeto", a estrutura do exoesqueleto deve suportar usuários de $60 \mathrm{~kg}$ à $100 \mathrm{~kg}$; com altura de 1,50 m à 1,90 m; ser modular, ou seja, o desacoplamento entre os módulos do joelho deve ser acessível; e deve ser capaz de medir a força de interação com o usuário. O protótipo I não era ajustável para a faixa de altura citada: era ajustável apenas para pessoas entre $1,75 \mathrm{~m}$ e 1,90m, o que limitava o número de usuários. Outro ponto identificado era que o protótipo I continha células de carga para medir a força de interação com o usuário, mas o comportamento da deformação não era ideal para montar a ponte de wheatstone, como será detalhado no item "Medição de Força - Célula de carga". Além disso, como a célula de carga possui regiões projetadas para facilitar a deformação, é desejável que ela seja facilmente trocada, funcionando como um item de segurança (caso seja rompida, deve ser possível trocá-la assegurando a integridade do resto da estrutura). No protótipo I, as células de 
carga eram as próprias hastes estruturais; no novo protótipo, as células de cargas são peças separadas, as quais funcionam exatamente conforme descrito.

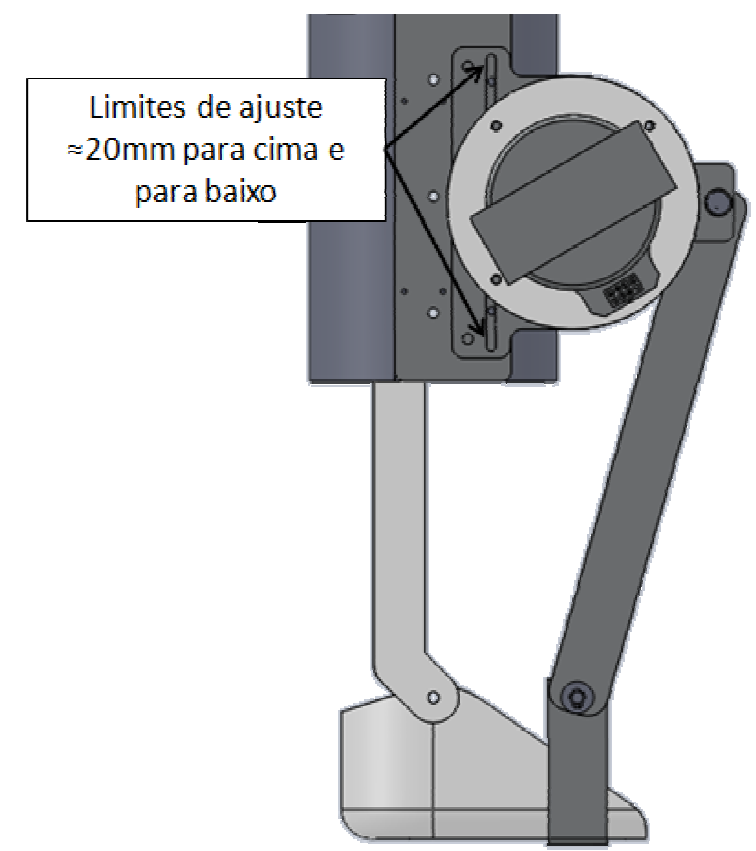

Figura 41: Conceito usado no protótipo I para o ajuste da altura da haste da canela.

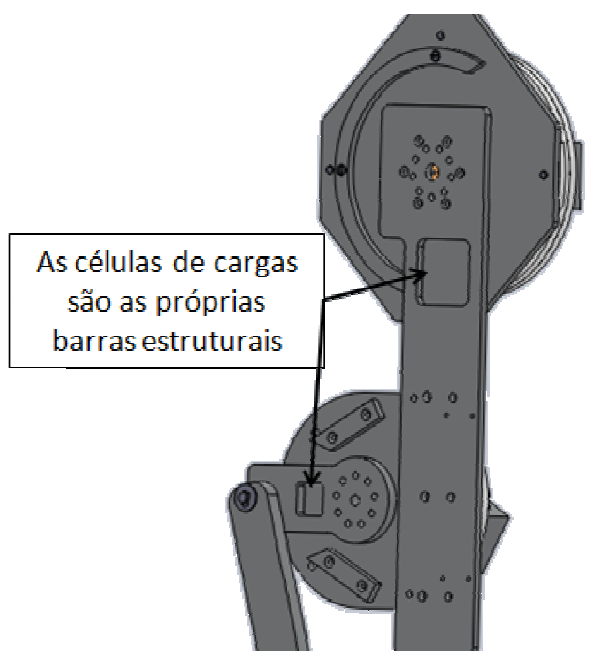

Figura 42: Células de carga do protótipo I.

O primeiro passo para projetar a estrutura foi definir os tamanhos dos membros (máximos e mínimos) para as diferentes alturas. Segundo (WINTER, 2005), os 
comprimentos dos membros são parametrizados em relação à altura, conforme descrito na Figura 43.

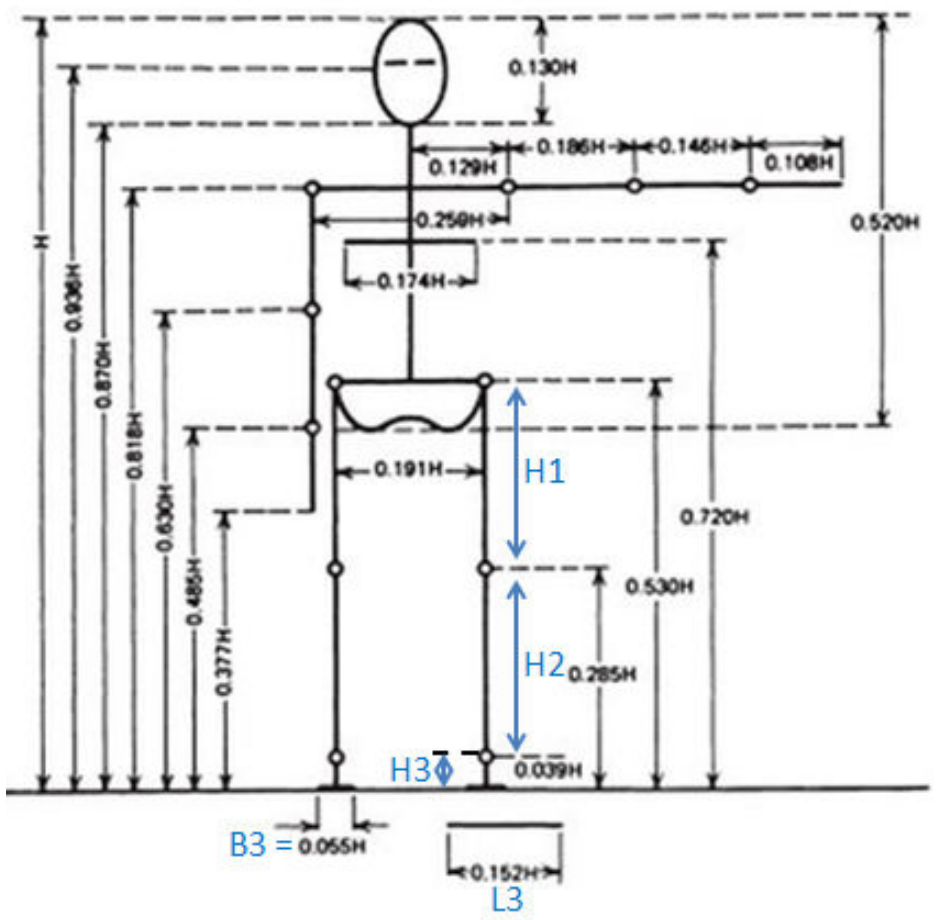

Figura 43: Parametrização dos comprimentos dos membros de acordo com a altura. Adaptado de (WINTER, 2005).

Assim, a estrutura do exoesqueleto deverá ser ajustável e vestir as seguintes variações:

1) Coxa (membro $\left.H_{1}\right): H_{1}=(0,530-0,285) * H=0,245 * H$

$$
\begin{gathered}
H_{1 \text { min }}=0,245 * 1,5=0,3675 \mathrm{~m} \\
H_{1 \text { max }}=0,245 * 1,9=0,4655 \mathrm{~m} \\
\Delta \cong 10 \mathrm{~cm}
\end{gathered}
$$

2) Canela (membro $\left.H_{2}\right): H_{2}=(0,285-0,039) * H=0,246 * H$

$$
\begin{gathered}
H_{2 \text { min }}=0,246 * 1,5=0,369 \mathrm{~m} \\
H_{2 \text { max }}=0,246 * 1,9=0,4674 \mathrm{~m} \\
\Delta \cong 10 \mathrm{~cm}
\end{gathered}
$$

3) Pé (membro $\mathrm{H}_{3}$ ): $\mathrm{H}_{3}=0,039 * \mathrm{H}$ - Os tamanhos para o apoio do pé foram considerados para a altura de 1,90m (os ajustes para tamanhos menores devem ser feitos adicionando espumas). 
Altura: $H_{3}=0,039 * 1,9=0,0741 \mathrm{~m} \cong 7,5 \mathrm{~cm}$

Largura: $B_{3}=0,055 * 1,9=0,1045 \mathrm{~m} \cong 11 \mathrm{~cm}$

Comprimento: $L_{3}=0,152 * 1,5=0,228 \mathrm{~m} \cong 23 \mathrm{~cm}$ - para o comprimento do pé considerou-se o menor possível para evitar o tropeço.

Conhecendo-se as restrições de tamanho e as dimensões da órtese da Dilepé para o quadril (a mesma usada no protótipo I: Dilepé DL-541), a estrutura do protótipo II foi projetada considerando as variações de $10 \mathrm{~cm}$ de ajuste para a coxa e canela. $\mathrm{O}$ ajuste na coxa é feito posicionando a órtese do quadril nos furos desejados da haste da coxa, conforme a Figura 44 ilustra.

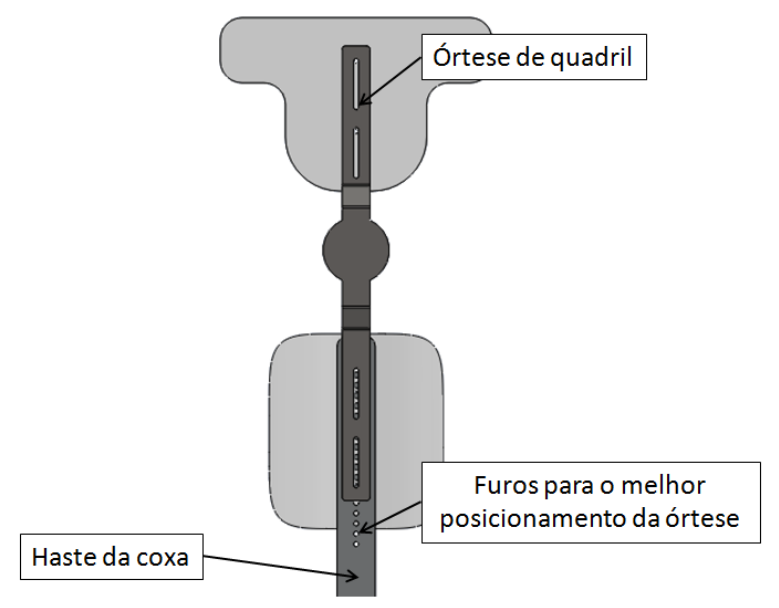

Figura 44: Ajuste do exoesqueleto para a coxa.

Para o ajuste da canela, foi projetada uma haste com rasgos que possibilitam o posicionamento do módulo do tornozelo, conforme ilustrado na Figura 45.

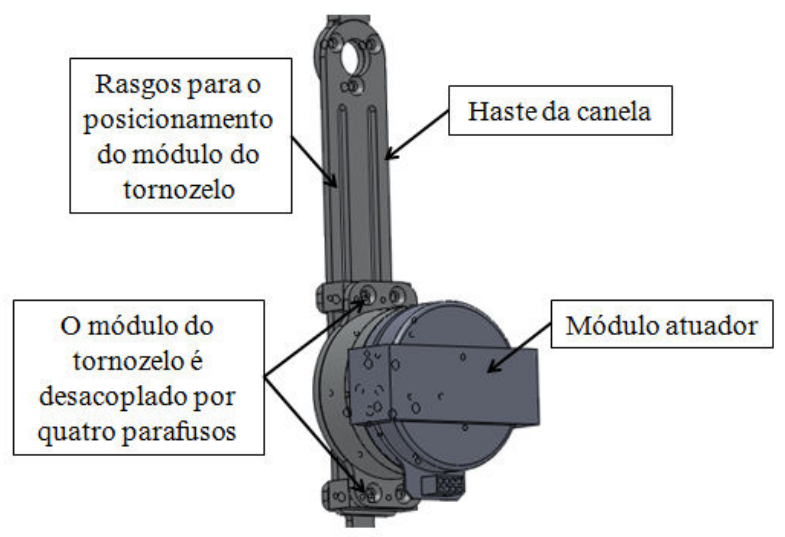

Figura 45: Ajuste do exoesqueleto para a canela. 
Os pré-ajustes de altura devem ser feitos antes de o usuário vestir o equipamento. O ajuste fino deve ser feito com o exoesqueleto montado no corpo. Se for desejado utilizar somente o módulo do tornozelo, é possível acoplar o módulo passivo paralelo ao joelho, assim, apenas o tornozelo teria o grau de liberdade atuado (conceito de modularidade: é possível atuar o tornozelo sem atuar o joelho).

Diferentemente do protótipo I, o novo módulo do tornozelo é uma estrutura única, conforme ilustrado na Figura 46. Anteriormente, a órtese do pé era separada do módulo atuador e era presa ao usuário por velcro. Isso deixava a estrutura pouco rígida e com folga (sem a confiabilidade de controle) e também o processo para vestir o exoesqueleto exigia o auxílio de outra pessoa (o usuário não era capaz de vestir sozinho por ter que segurar a estrutura do tornozelo separadamente e vesti-lo por último).
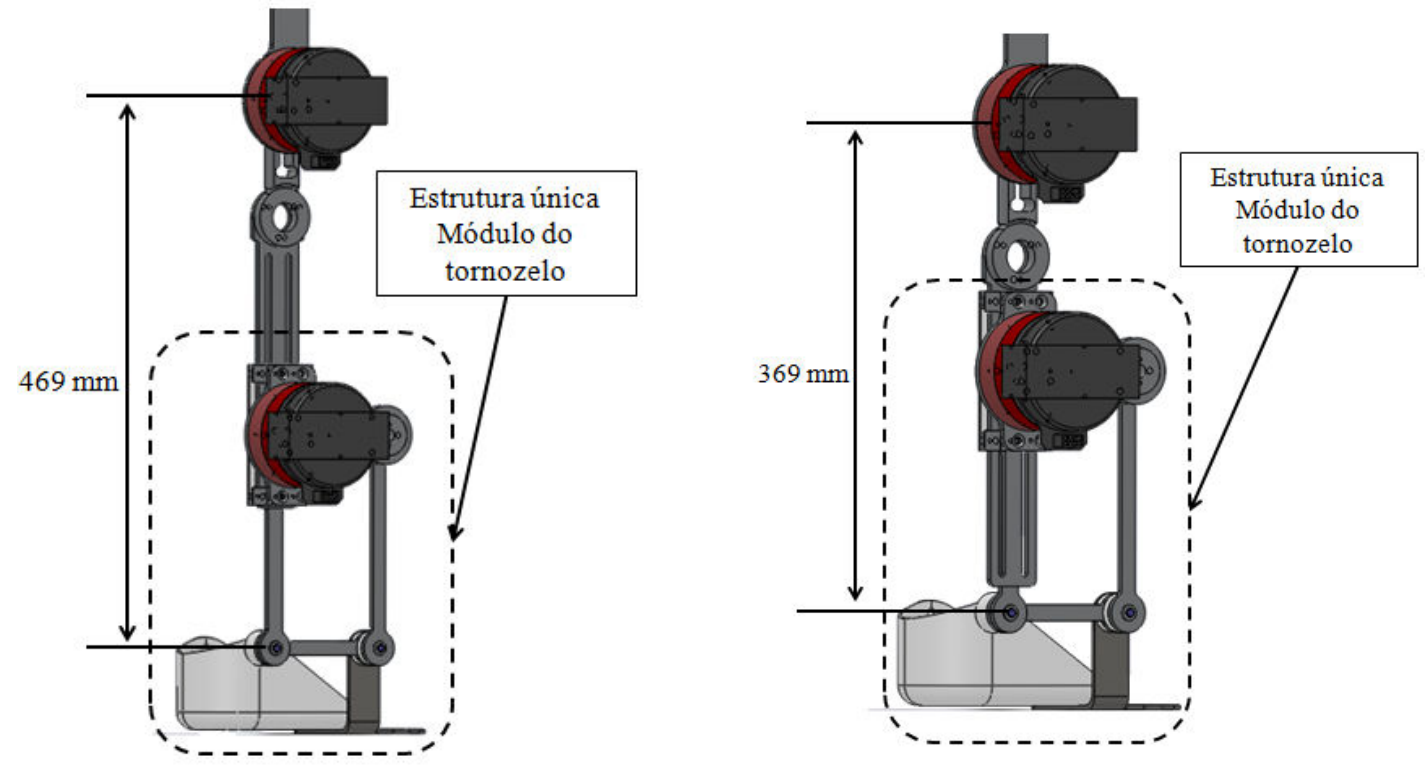

Figura 46: À esquerda, módulo do tornozelo ajustado para um usuário de 1,90m de altura; à direita, módulo do tornozelo ajustado para um usuário de $1,50 \mathrm{~m}$ de altura.

Por simulação em elementos finitos foi possível determinar a rigidez da estrutura do protótipo II no caso mais crítico: módulo do tornozelo posicionado na distância máxima em relação ao joelho. As condições de contorno da simulação foram: a fixação da estrutura no joelho e uma carga de $30 \mathrm{~N}$ transversal ao pé a qual representa a força do usuário no movimento de inversão (KAPANDJI, 2000). A rigidez transversal encontrada 
na estrutura do Protótipo II foi de $0,75 \mathrm{~N} / \mathrm{mm}$. As condições de contorno da simulação e o resultado estão disponíveis no Apêndice E.

Por fim, a fixação do módulo do tornozelo foi feita de maneira a alinhar o eixo vertical do módulo atuador com o eixo vertical da haste da canela. Isso porque no protótipo I o módulo estava posicionado à frente (acima do pé) o que provocava um desconforto na sua utilização (momentos e produtos de inércia maiores).
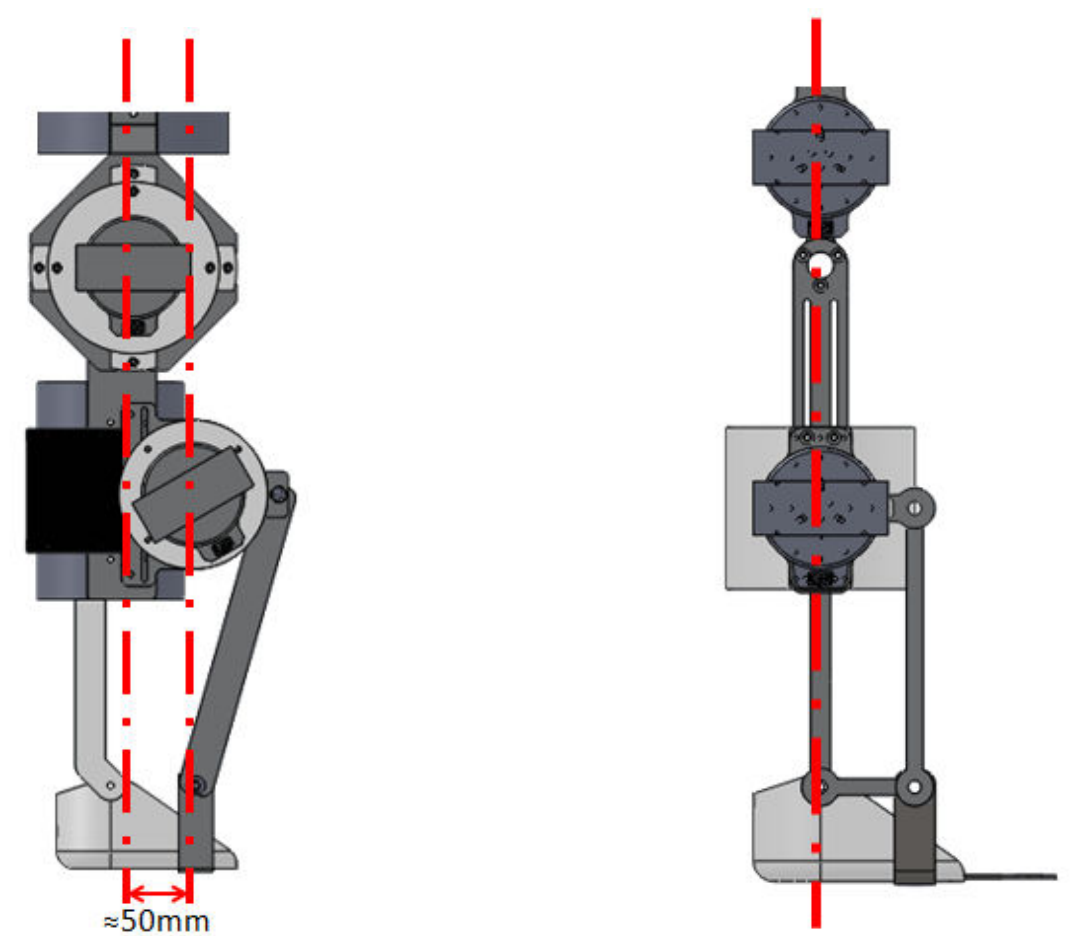

Figura 47: Alinhamento dos módulos atuadores: à esquerda, no protótipo I, o peso do módulo atuador do tornozelo à frente do eixo da estrutura causava desconforto para caminhar; à direita, o protótipo II apresenta ambos módulos atuadores alinhados com a estrutura. 


\section{Controle de impedância}

O controle de um robô que interage com o ser humano não deveria ser descrito somente pela força ou pelo movimento, mas é recomendável definir uma função entre eles, o qual é chamado de controle de impedância (HOGAN, 1985). No sistema em estudo (corpo humano - exoesqueleto), o controle ideal é o de impedâncias. A impedância pode ser definida em termos de torque e velocidade angular, ou seja:

$$
Z(t)=\frac{\tau(t)}{\frac{d \theta(t)}{d t}}
$$

O comportamento dinâmico das articulações da perna humana, neste trabalho, é definido da mesma forma que no estudo de (PACHLER e YABUKI, 2014): por um modelo linear de segunda ordem, como apresentado a seguir.

$$
\frac{\theta_{h}(s)}{\tau_{h}(s)}=\frac{1}{J_{h} s^{2}+B_{h} s+K_{h}}
$$

Este modelo relaciona a posição angular da articulação com o torque aplicado pelo humano através dos parâmetros do usuário: a inércia $J_{h}$, a viscosidade $B_{h}$ e a rigidez $K_{h}$. Este modelo é amplamente utilizado na literatura, uma vez que aproxima razoavelmente as propriedades mecânicas dominantes da articulação isolada com eixo fixo (OLAYA, 2008). Os fatores $J_{h}, B_{h}$ e $K_{h}$ são os parâmetros de impedância do humano. Neste estudo, será considerado que o exoesqueleto apresenta uma dinâmica semelhante a do humano, com parâmetros diferentes:

$$
\frac{\theta_{\text {exo }}(s)}{\tau_{\text {exo }}(s)}=\frac{1}{J_{\text {exo }} s^{2}+B_{\text {exo }} s+K_{\text {exo }}}
$$

A estratégia do controle de impedância considerada neste trabalho é a mesma apresentada em (ARAUJO, TANNURI e FORNER-CORDERO, 2012) a qual é baseada nos estudos de (HOGAN, 1985) e (AGUIRRE-OLLINGER, 2009). A arquitetura de controle de impedância está representada no diagrama de blocos da Figura 48. 


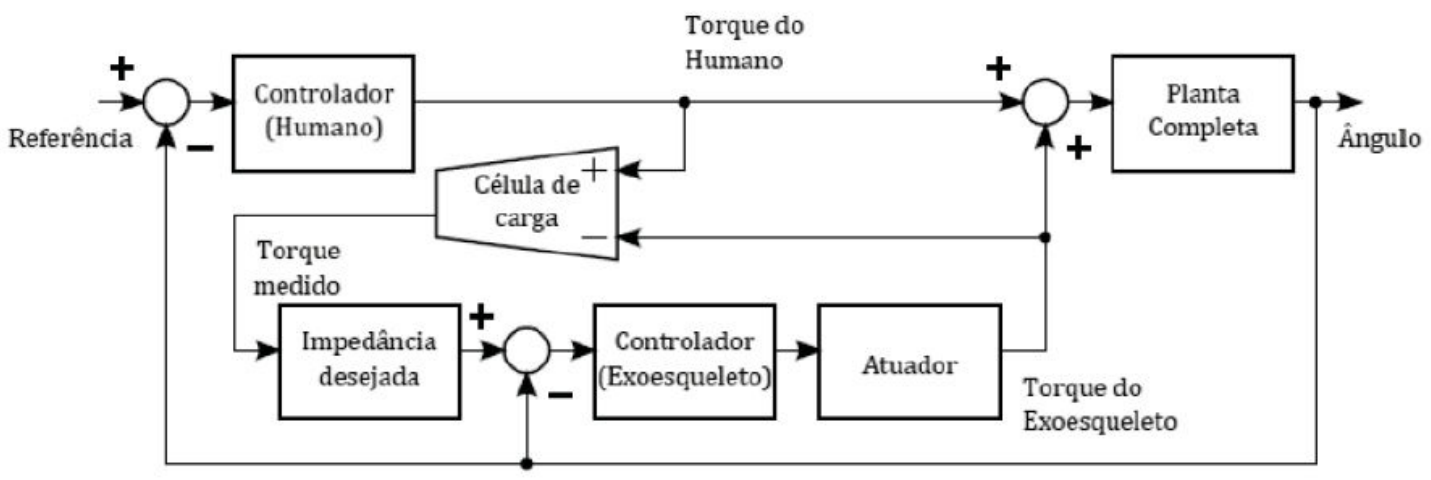

Figura 48: Diagrama de blocos da arquitetura de controle por impedâncias. Adaptado de (ARAUJO,

TANNURI E FORNER-CORDERO, 2012).

Do diagrama pode-se observar que a entrada do controlador de impedâncias é o torque de interação entre humano e exoesqueleto, dado por

$$
\tau_{m}=\tau_{h}-\tau_{\text {exo }}
$$

A posição desejada do exoesqueleto é, então, determinada por meio da multiplicação desse sinal pela função de transferência da impedância desejada, ou seja,

$$
\frac{\theta_{d}(s)}{\tau_{m}(s)}=\frac{1}{J_{d} s^{2}+B_{d} s+K_{d}}
$$

onde, os parâmetros de impedância do controlador $\left(J_{d}, B_{d} e K_{d}\right)$ são definidos de maneira a obter o comportamento desejado (parâmetros de impedância menores que do humano fornecem a amplificação do desempenho dinâmico; parâmetros maiores fornecem a oposição ao movimento e parâmetros iguais fornecem o controle seguidor).

Este sinal de referência de posição é, por sua vez, enviado ao controlador do driver do motor. No caso do driver MAXON EPOS2 70/10, tem-se uma malha de controle com realimentação negativa da posição medida do motor e um PID que fornece a referência de torque do motor.

O exoesqueleto desta dissertação (chamado de Protótipo II ou ExoLoLi) deve ser capaz de fazer as medições necessárias para a obtenção dos parâmetros de impedância do humano $\left(B_{h}\right.$ e $\left.K_{h}\right)$. O parâmetro inercial, $J_{h}$, pode ser obtido por valores parametrizados da massa e altura do humano (ENDERLE, BLANCHARD e BRONZINO, 2005) ou obtidos empiricamente por meio de experimentos pendulares. O controlador deste exoesqueleto pode ser seguidor de posição (o qual já está disponível pelo driver EPOS 
70/10), porque para a obtenção dos parâmetros $B_{h}$ e $K_{h}$ basta que o exoesqueleto seja capaz de adquirir informações sobre o torque e posição angular para a calcular a regressão. 


\section{Sensoriamento}

A necessidade de sensores está relacionada com a função do exoesqueleto. Neste caso, o exoesqueleto deve ser capaz de medir o torque de interação e a posição, velocidade e aceleração angulares. Com essas medições, é possível obter os parâmetros $B_{h}$ e $K_{h}$ por regressão (utilizando o modelo dado pela equação diferencial $\tau=\ddot{\theta} I+$ $\dot{\theta} B+\theta K$; vale ressaltar que esse modelo é uma simplificação do comportamento da articulação humana).

O sensoriamento do exoesqueleto é feito por encoder (medição de ângulo de deslocamento entre as hastes) e célula de carga, que mede a força aplicada pelo usuário ao exoesqueleto, conforme será detalhado adiante. A velocidade e a aceleração angulares são obtidas pela derivação da posição pelo tempo.

\subsection{Medição de ângulo: Encoder}

Para o sensor de posição, foram analisados os possíveis modos de se medir a posição relativa entre dois segmentos do exoesqueleto. $\mathrm{O}$ método escolhido foi utilizar os dados provenientes do encoder acoplado ao motor, já que este manda um sinal digital a cada pequeno deslocamento do motor. Um encoder é um sensor ótico composto de um emissor de luz e um receptor, que emite sinais digitais conforme a luz chega ou não ao receptor. Este encoder está ligado ao motor antes da redução, logo é necessário levar em consideração que o deslocamento angular do exoesqueleto é apenas uma fração do deslocamento do motor.

O encoder em questão é do tipo incremental (Maxon Motors - HEDL 5540), o que significa que este equipamento emite sinais de quadratura, tal como mostrado na figura a seguir. O sentido de rotação do motor é determinado pelo sinal que está em avanço em relação ao outro. 

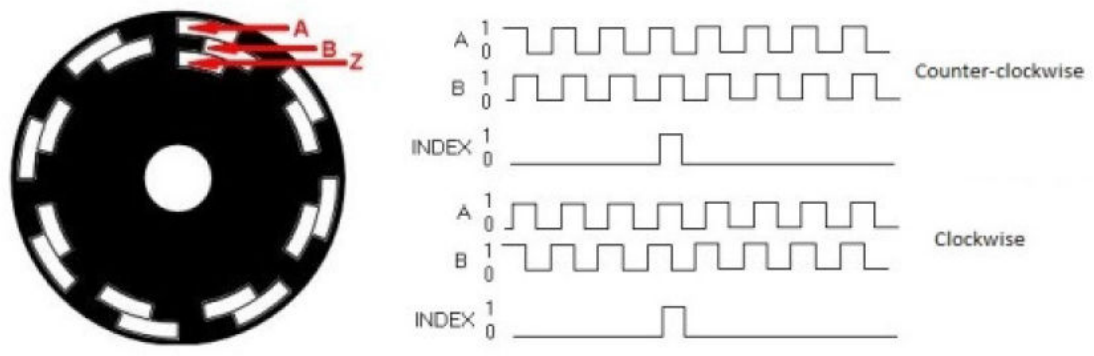

Figura 49: Sinais provenientes de um encoder incremental (SYSTEMS, 2014)

O circuito usado para a captação desse sinal é chamado de decodificador de quadratura. Sua função é interpretar os sinais recebidos e fazer uma contagem que representa a posição do motor. O sinal de index não é utilizado, uma vez que este sinal indica uma rotação completa do motor, e essa informação não tem significado prático uma vez que o encoder está instalado antes da redução.

O driver EPOS2 70/10 fornece as informações de posição do eixo do motor pelo tempo de forma gráfica e em arquivo texto. A próxima figura ilustra o gráfico fornecido pelo driver. A unidade de ângulo dado pelo EPOS é qc, que significa Quadrature Counts. A conversão de qc para graus depende da quantidade de pulsos que o encoder fornece por volta. Em cada pulso, são contados quatro sinais de quadratura. Neste caso, tem-se 500 pulsos por volta, o que significa 2000 sinais de quadratura por volta. Portanto, 1 qc é equivalente à $0,18^{\circ}$ para o eixo do motor. Para obter o ângulo da perna, é necessário dividir pelo raio da redução (100 vezes).

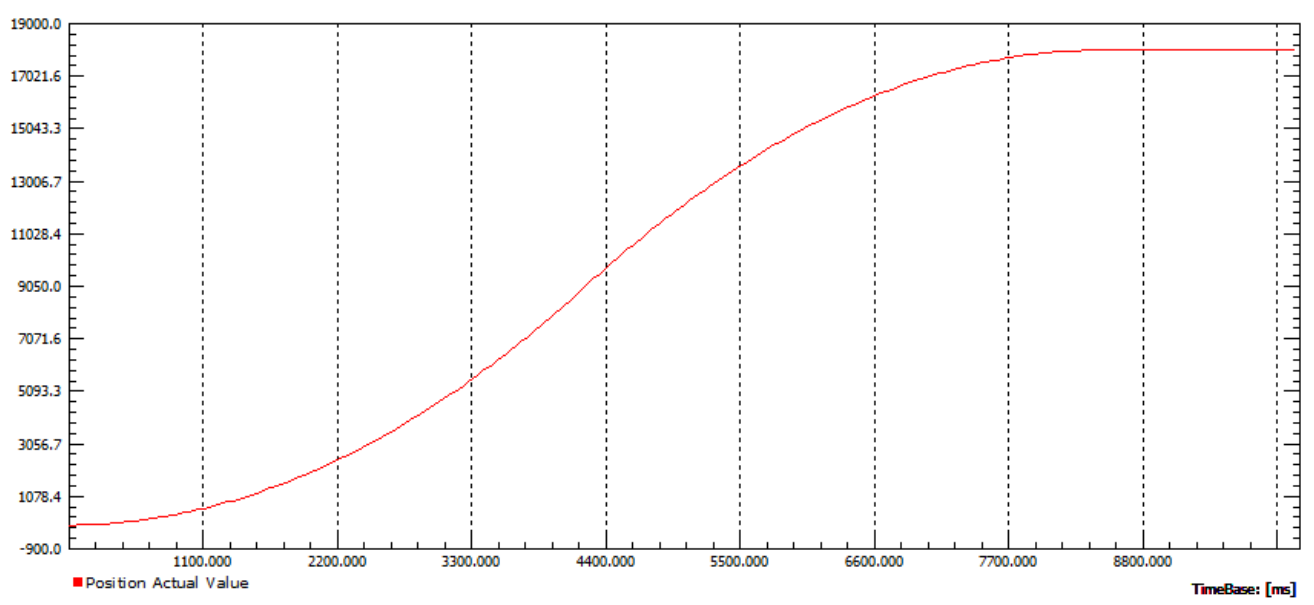

Figura 50: Gráfico fornecido pelo driver do motor - eixo vertical é o ângulo (qc) e o eixo horizontal é o tempo (ms). A medida máxima do gráfico (18000qc) representa $32,4^{\circ}$ no movimento do exoesqueleto. 


\subsection{Medição de força: Célula de carga}

Para realizar a medição da força atuante pelo usuário no exoesqueleto, serão utilizadas duas células de carga. Células de carga são transdutores de força, os quais transformam uma grandeza física (força) em um sinal elétrico. $O$ princípio de funcionamento das células de carga baseia-se na variação da resistência ôhmica de um sensor denominado extensômetro (strain gauge), quando submetido a uma deformação (CARGA, 2015).

A célula de carga é composta por uma estrutura elástica, que neste trabalho será feita com a liga de alumínio 6061 T6, e quatro strain gauges formando uma ponte de Wheatstone.

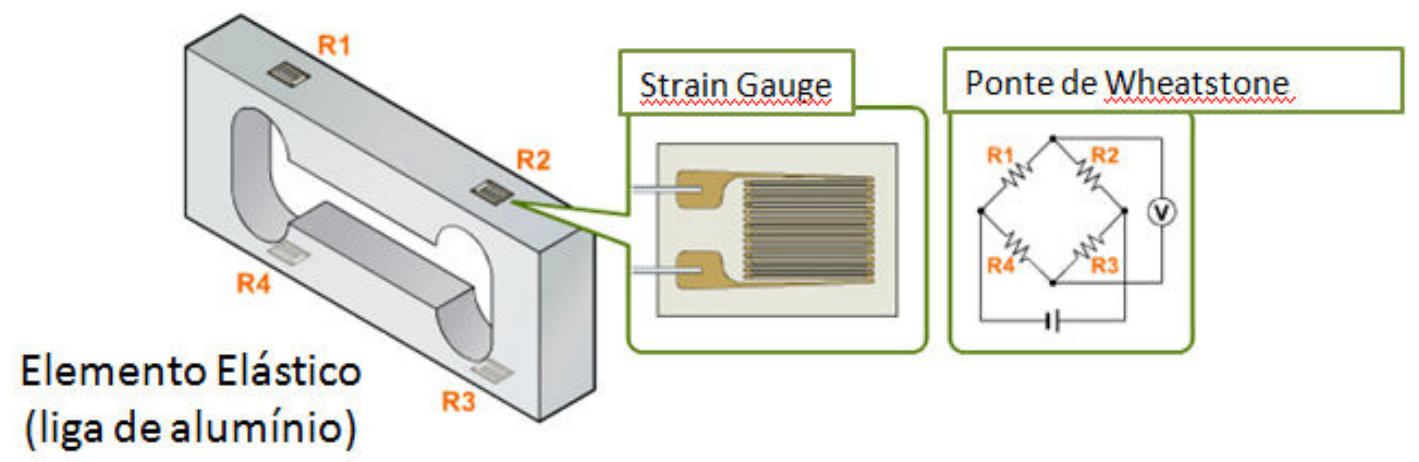

Figura 51: Configuração de uma célula de carga. Adaptado de (ISHIDA, 2015).

Os extensômetros são posicionados nas quatro regiões que são mais deformadas no elemento elástico. A variação da resistência dos extensômetros provoca uma variação de tensão na ponte de Wheatstone proporcional à carga aplicada sobre o elemento elástico (barra feita de alumínio).

A ponte de Wheatstone composta por quatro extensômetros (ponte completa) é o circuito mais utilizado para medir deformações mecânicas, principalmente porque a sensibilidade da deformação é a maior (em relação a um quarto de ponte e meia ponte) e porque ocorre a compensação da variação da temperatura. 


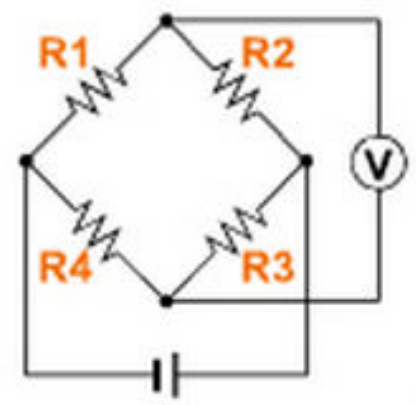

Figura 52: Ponte de Wheatstone completa. Adaptado de (ISHIDA, 2015).
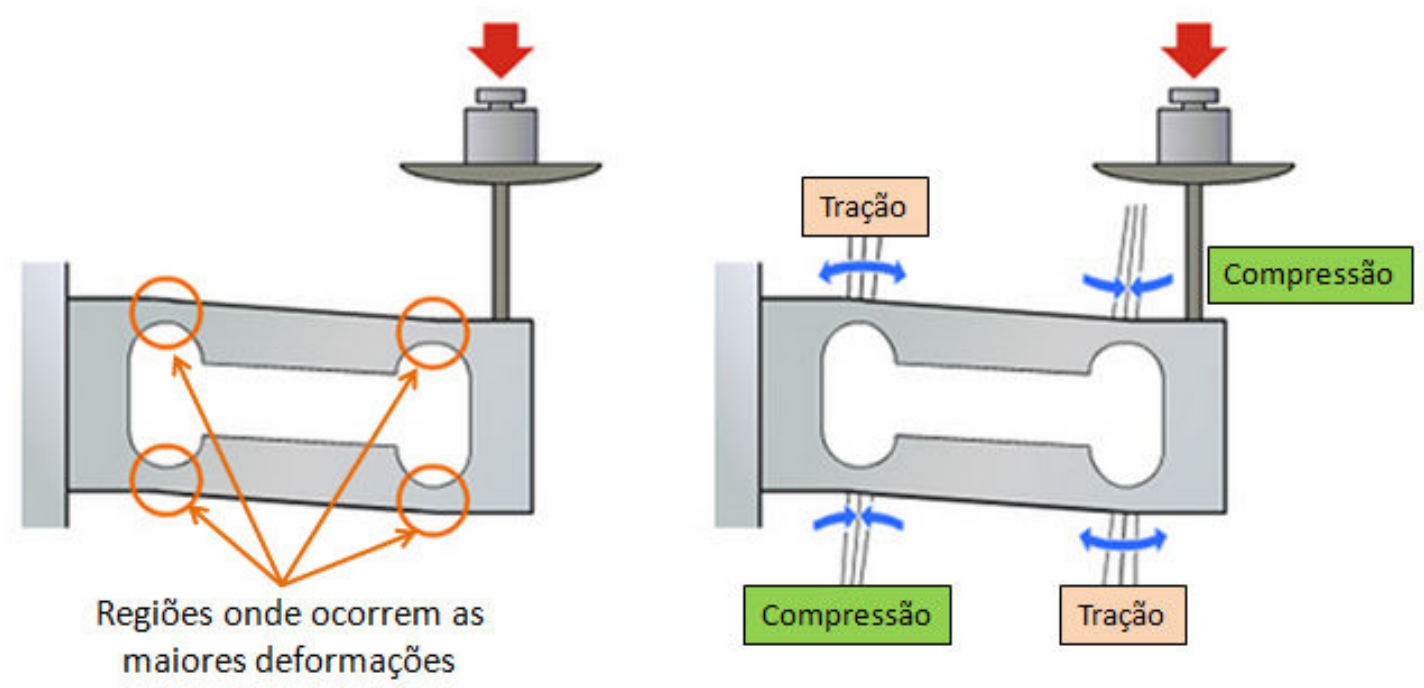

Figura 53: Regiões onde ocorre maior deformação da célula de carga e comportamento da deformação (formato de paralelogramo). Adaptado de (ISHIDA, 2015).

A relação entre a tensão de entrada e de saída depende do valor dos resistores. Considerando a ponte completa composta por quatro extensômetros iguais, a relação entre a tensão de entrada e de saída é dada pela deformação observada por cada extensômetro, conforme a equação a seguir.

$$
\varepsilon_{1}-\varepsilon_{2}+\varepsilon_{3}-\varepsilon_{4}=\frac{4 V}{K E}
$$

Onde:

- $\varepsilon=$ deformação observada por cada extensômetro

$-V=$ tensão de saída

- $K$ = fator de sensibilidade do material do extensômetro, neste caso: $K \cong 2$

- $E=$ tensão de entrada 
Essa é a expressão que será usada para mensurar a deformação sofrida pela estrutura, considerando a utilização de quatro extensômetros. É importante ressaltar que é preciso instalar os sensores de tal forma que valores iguais de tensão e compressão não se anulem.

O ideal é que as deformações observadas pelos quatro extensômetros sejam iguais, caso contrário, seria necessário calcular a deformação dos extensômetros em cada instante da deformação para conseguir obter a razão entre a tensão de entrada e de saída. Considerando deformações iguais, é possível simplificar a equação: a tensão de saída é proporcional à deformação que por sua vez é proporcional à carga aplicada. Após a fabricação da célula de carga, é possível fazer a calibração do equipamento aplicando cargas conhecidas e medindo a tensão de saída. Nessa condição simplificada, a curva entre a carga aplicada e a tensão de saída obtida durante a calibração será uma reta.

$$
\varepsilon-(-\varepsilon)+\varepsilon-(-\varepsilon)=\frac{4 V}{K E} \leftrightarrow \varepsilon=\frac{V}{K E} \leftrightarrow V=K E \varepsilon
$$

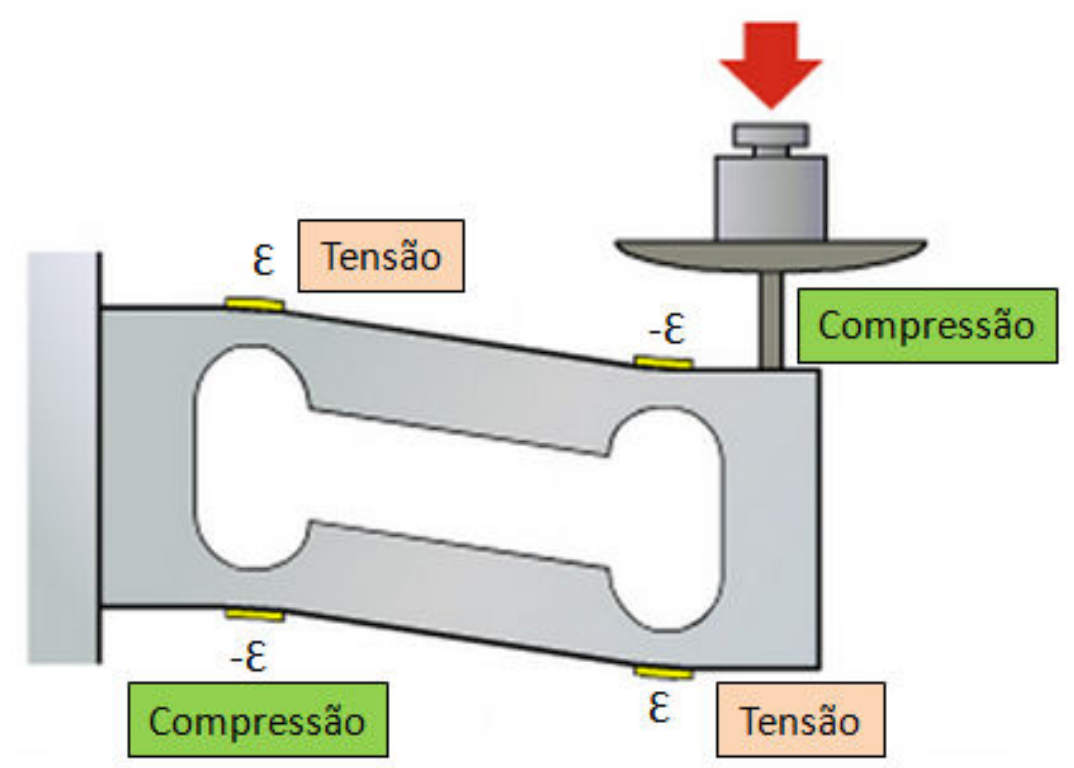

Figura 54: Configuração de instalação dos extensômetro ideal (deformações de módulo igual). Adaptado de (ISHIDA, 2015). 


\subsubsection{Células de Carga dos protótipos I e II}

No protótipo I, a célula da carga era a própria haste da canela. O seu formato e a sua configuração de instalação não permitia uma relação linear entre a carga aplicada e a tensão de saída porque as deformações observadas pelos quatro extensômetros não são iguais. Como é possível visualizar na figura a seguir, a peça não é simétrica. Além disso, os extensômetros foram instalados do mesmo lado da haste para protegê-los durante o movimento.

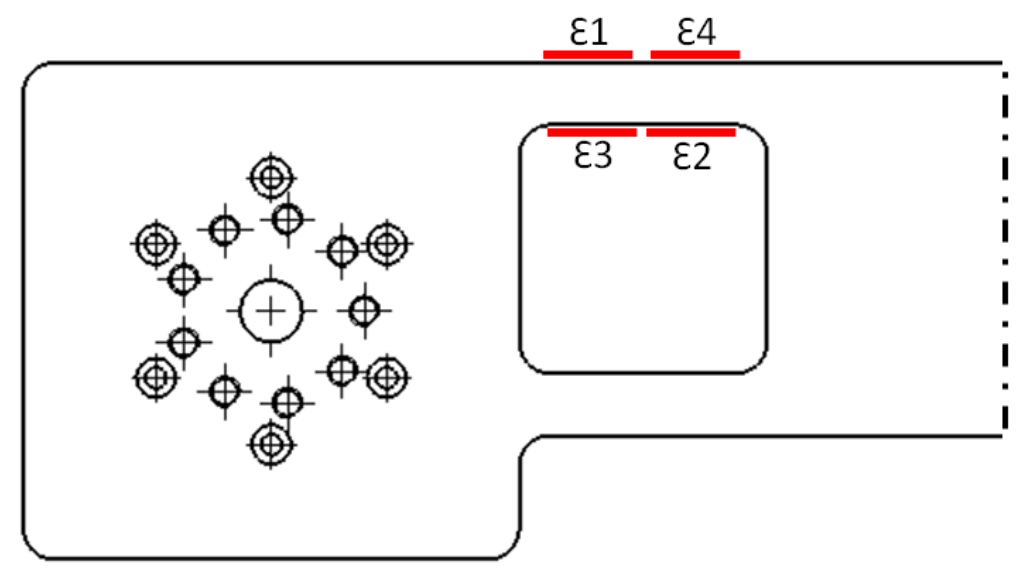

Figura 55: Configuração de instalação dos extensômetros na "haste da canela" - protótipo I (SOUIT e MALGUEIRO, 2012).

Analisando essa haste por elementos finitos, é possível visualizar as deformações desiguais observadas nos quatro extensômetros. As condições de contorno da análise bem como os resultados estão no Apêndice F.

Com o objetivo de tornar a medição da força de interação com o usuário proporcional à tensão de saída medida na ponte de Wheatstone, as células de carga dos módulos do joelho e tornozelo foram refeitas para o Protótipo II. Como explicado anteriormente, as células de carga serão fixadas à estrutura, de maneira que, se elas forem danificadas, o resto da estrutura permanecerá intacto. Neste aspecto, as células de carga funcionam como se fossem "fusíveis mecânicos" que deformam plasticamente quando há uma força de interação entre o humano e o exoesqueleto (força cortante) superior à $300 \mathrm{~N}$. As Figuras 56 e 57 ilustram o posicionamento das células de carga no exoesqueleto. A Figura 58 mostra o posicionamento da instalação dos extensômetros. 


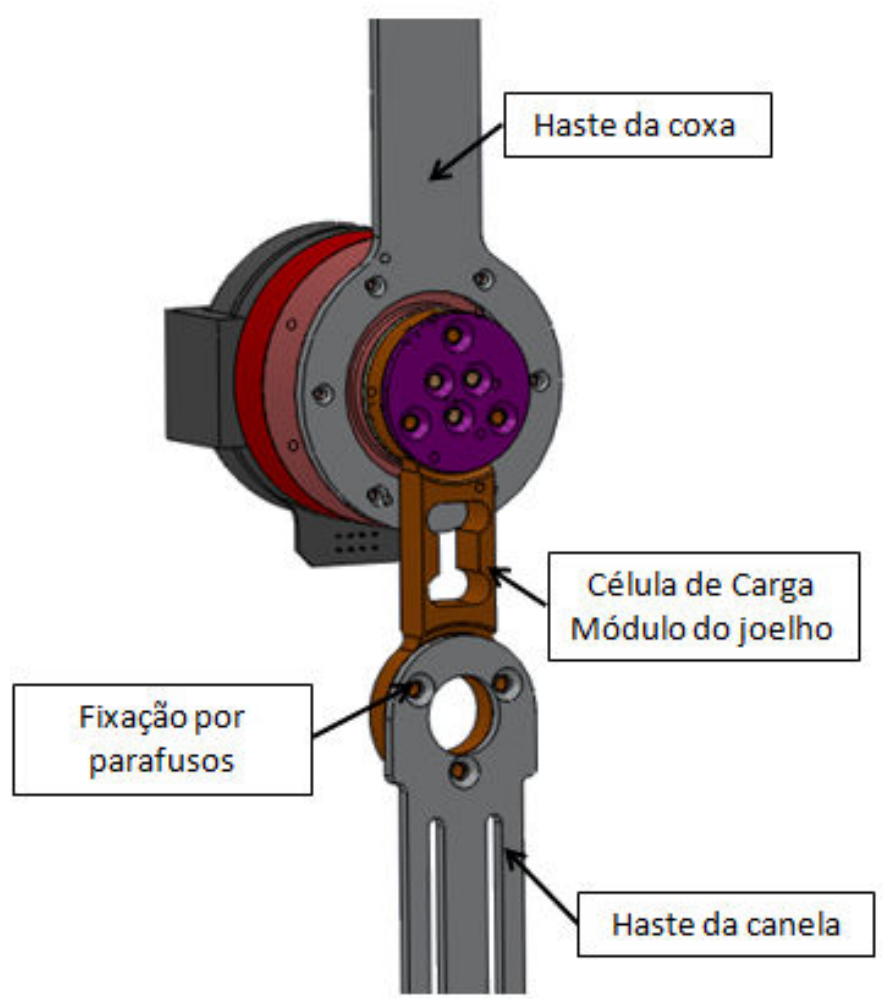

Figura 56: Célula de carga do módulo do joelho - Protótipo II.

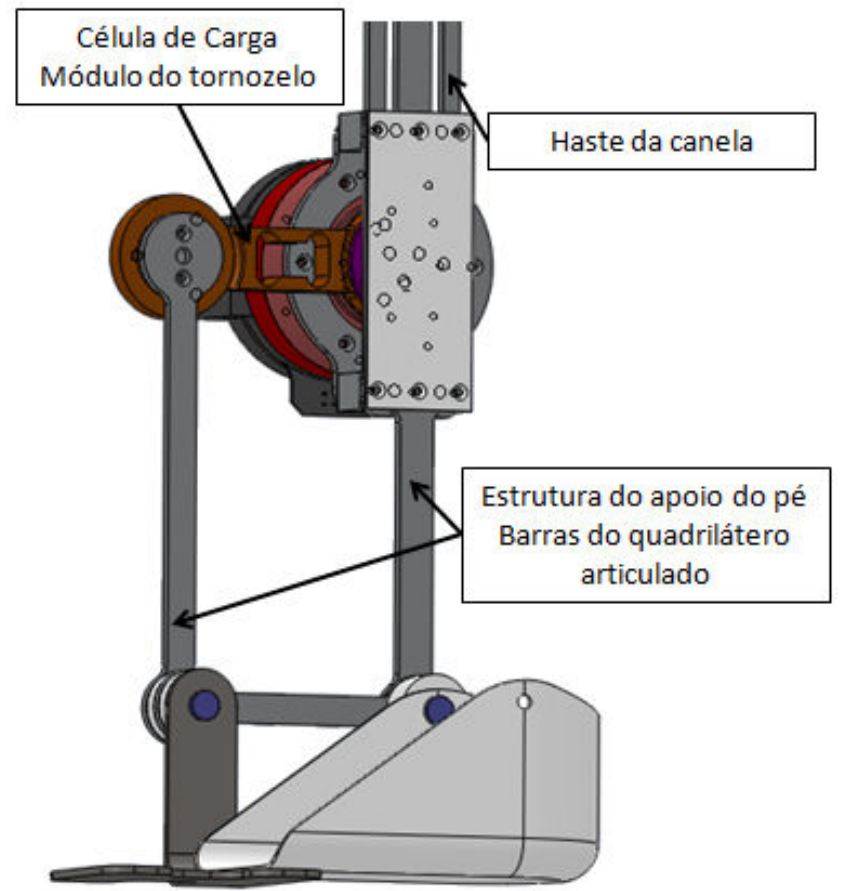

Figura 57: Célula de carga do módulo do tornozelo - Protótipo II. 


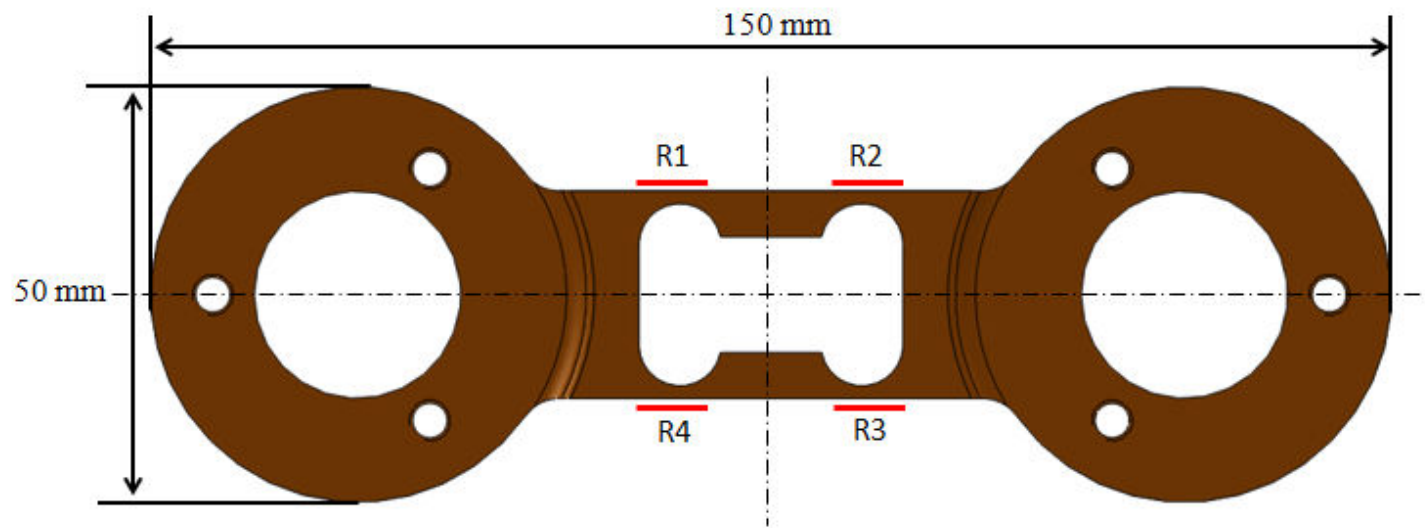

Figura 58: Instalação dos extensômetros nas células de carga do Protótipo II.

Assim, no novo protótipo, as células de carga são peças substituíveis, idênticas e simétricas. A região de instalação dos strain gauges bem como a fixação na estrutura é exatamente a mesma entre as células de carga do joelho e tornozelo (o que facilita a montagem, substituição e calibração). A análise em elementos finitos mostra que as deformações observadas pelos quatro extensômetros são iguais (detalhes da análise estão no Apêndice F).

Com a peça "célula de carga" usinada, foi possível instalar os extensômetros e soldar a ponte de Wheatstone. A próxima figura ilustra a instalação dos extensômetros (HBM).

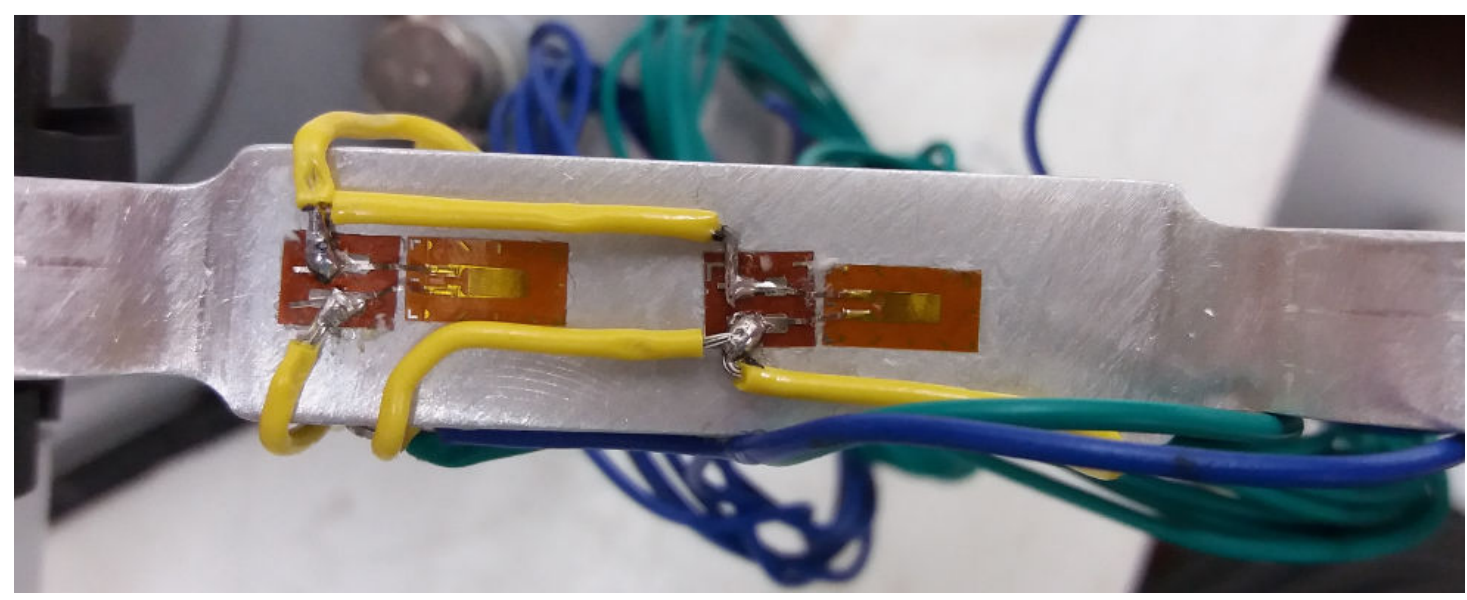

Figura 59: Instalação dos extensômetros e solda da ponte de Wheatstone.

Com a ponte de Wheatstone devidamente instalada nas células de carga, é preciso fazer a leitura do sinal. Para tanto, foi necessária a construção de uma placa para amplificação e filtro do sinal da ponte de Wheatstone. Alunos de iniciação científica 
fizeram a placa para aquisição de sinal. A placa amplifica o sinal em 200 vezes e filtra os sinais de frequências altas (filtro do tipo "passa-baixa").

Considerando que a tensão de entrada na ponte de Wheatstone seja $5 \mathrm{~V}$ e que o fator de sensibilidade do material do extensômetro seja 2, para uma carga aplicada de $300 \mathrm{~N}$ (análise em elementos finitos mostra que para 300N a célula de carga deforma 0,005 nas regiões dos extensômetros), a tensão de saída medida na ponte é dada por:

$$
V=K E \varepsilon \leftrightarrow V \cong 2 * 5 * 0,005 \cong 0,05 V
$$

e após passar pela placa de aquisição de sinal (amplificação de 200 vezes), a tensão de saída esperada é:

$$
V_{\text {saída }} \cong 0,05 \mathrm{~V} * 200=10 \mathrm{~V}
$$

Assim, após a construção das células de cargas, espera-se que a curva obtida durante a sua calibração seja como a mostrada a seguir.

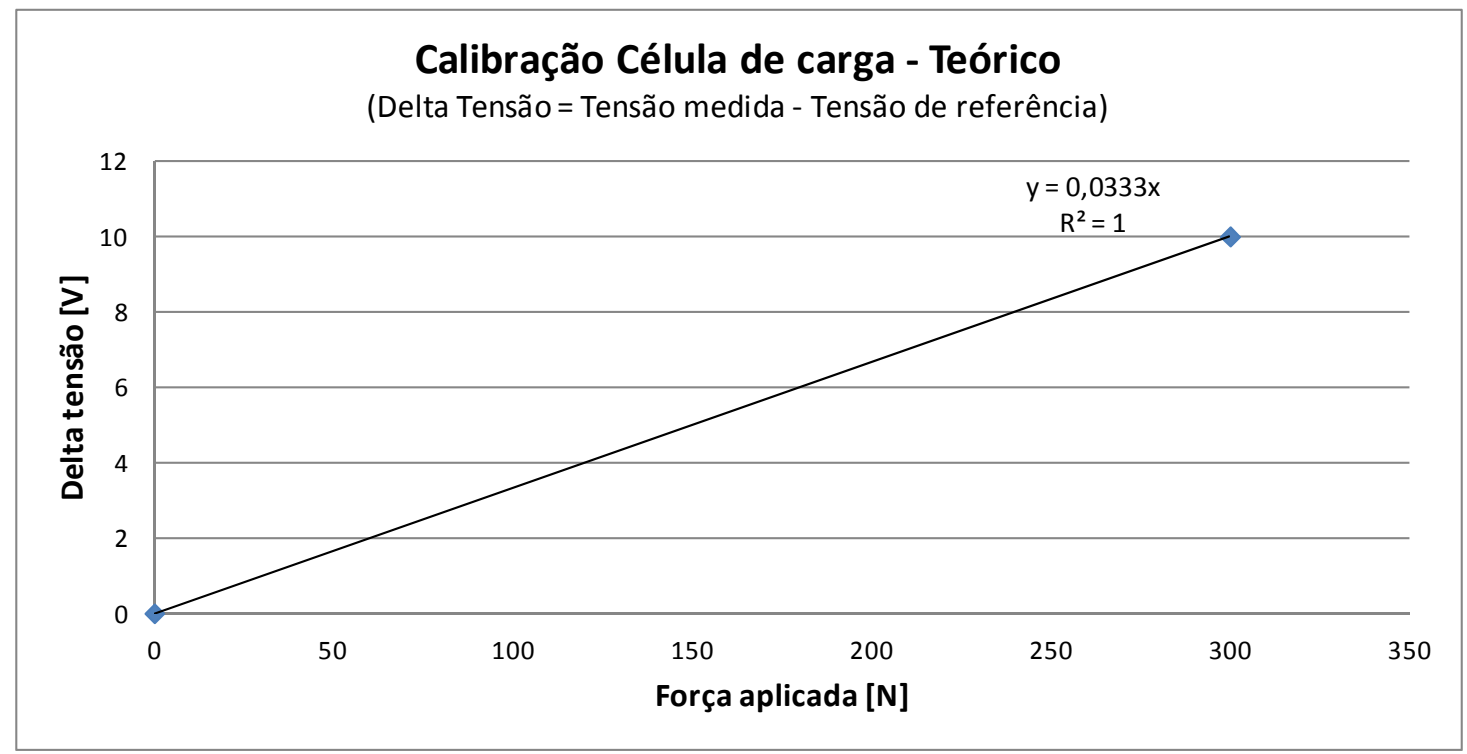

Figura 60: Curva esperada durante a calibração da célula de carga.

Após a usinagem da peça e instalação dos extensômetros, foi possível fazer a calibração física, conforme ilustrado Figura 61. Uma das extremidades da célula de carga foi engastada (fixação no motor sem movimento) e na outra a haste da canela foi fixada. Os pesos foram instalados na extremidade da haste da canela (distância entre o centro de apoio e a aplicação da força é $b=339 \mathrm{~mm}$ ). 


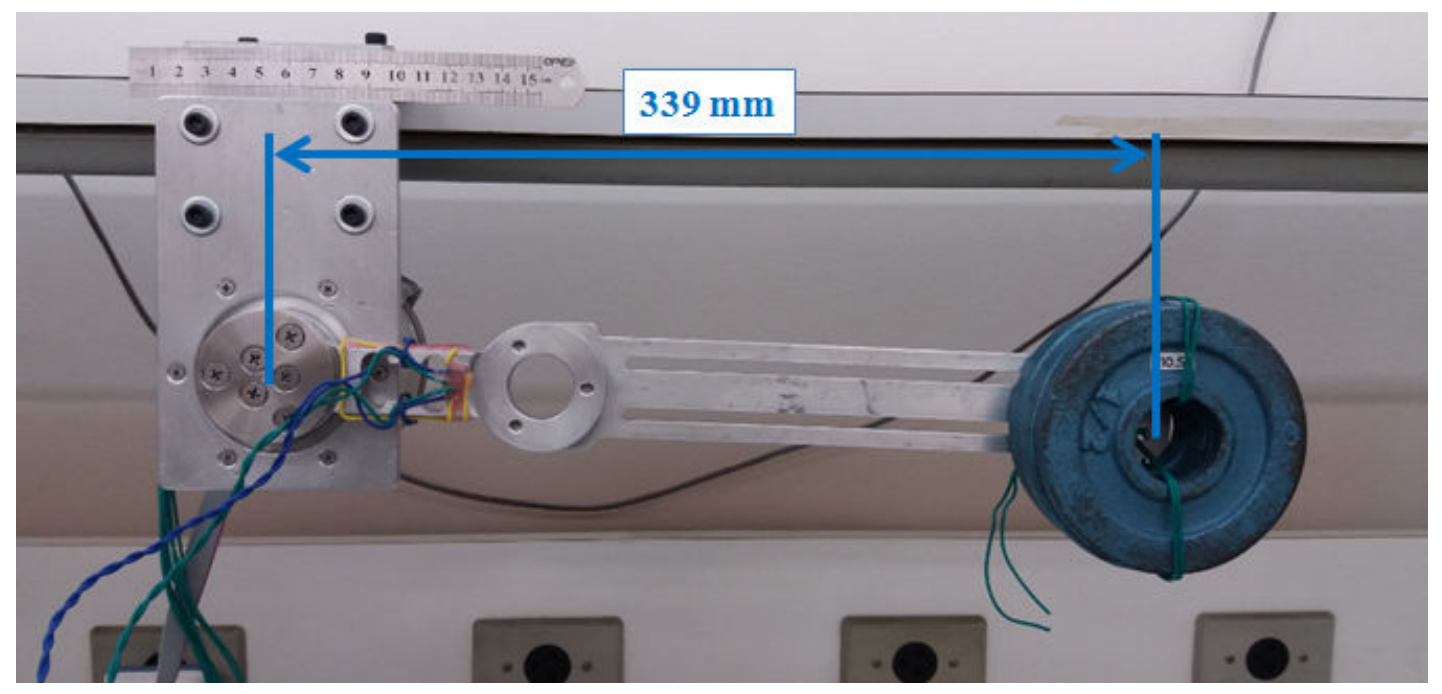

Figura 61: Configuração para a calibração da célula de carga.

Tabela 6: Valores da calibração da célula de carga.

\begin{tabular}{|c|c|c|c|c|}
\hline Peso [kg] & Força [N] & $\begin{array}{c}\text { Torque } \\
{[\mathbf{N m}]}\end{array}$ & Tensão medida [V] & $\begin{array}{c}\text { Delta Tensão [V] } \\
\text { (Tensão medida - } \\
\text { Tensão de } \\
\text { referência) }\end{array}$ \\
\hline 0,00 & 0,00 & 0,00 & 2,27 & 0,00 \\
\hline 0,51 & 5,00 & 1,70 & 2,43 & 0,15 \\
\hline 1,04 & 10,16 & 3,44 & 2,49 & 0,21 \\
\hline 1,57 & 15,34 & 5,20 & 2,62 & 0,34 \\
\hline 2,09 & 20,52 & 6,96 & 2,74 & 0,47 \\
\hline
\end{tabular}

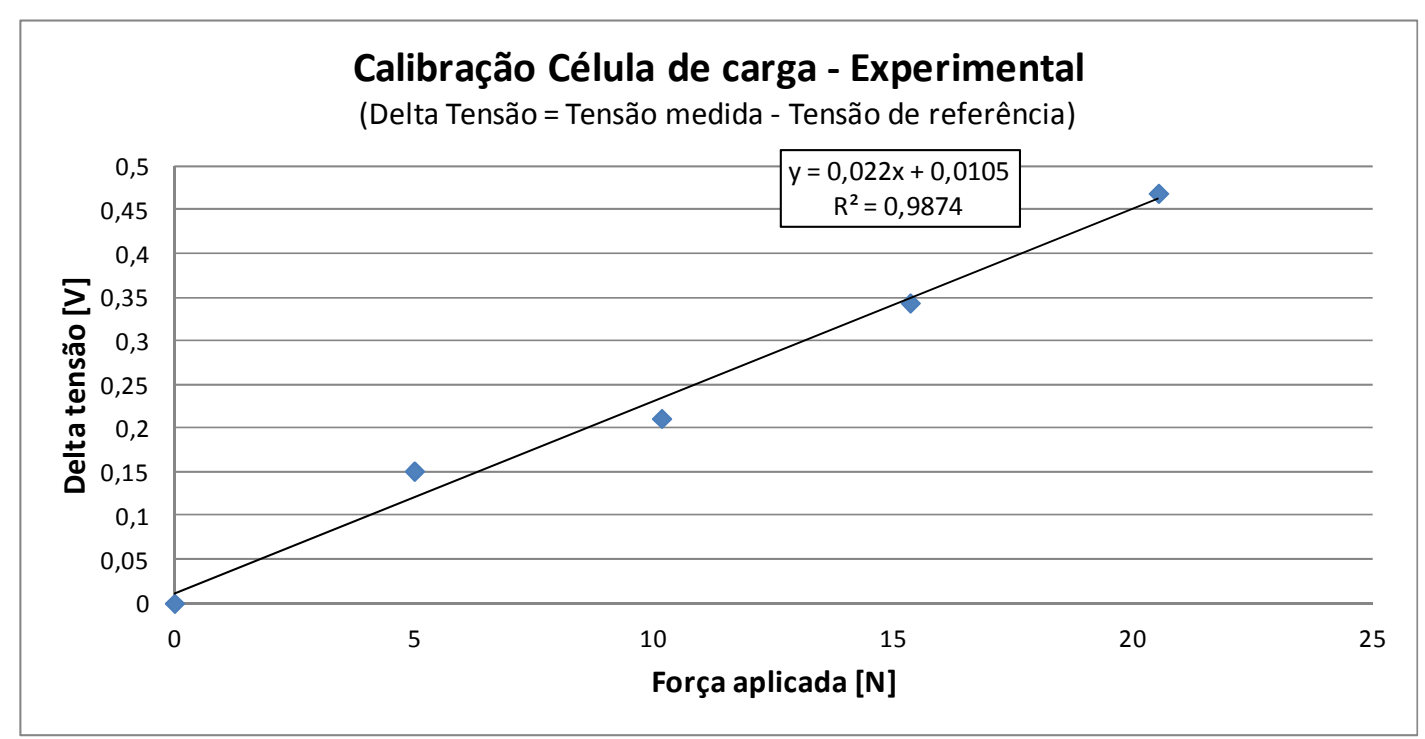

Figura 62: Curva obtida experimentalmente durante a calibração da célula de carga. 
Considerando a distância da aplicação da força cortante em relação ao centro da articulação $(b=339 \mathrm{~mm})$, é possível calcular o torque. Assim, por meio da multiplicação da força cortante pelo braço, obtém-se a curva dada na Figura 63 (com coeficiente de determinação, $R^{2}$, de $98 \%$ ).

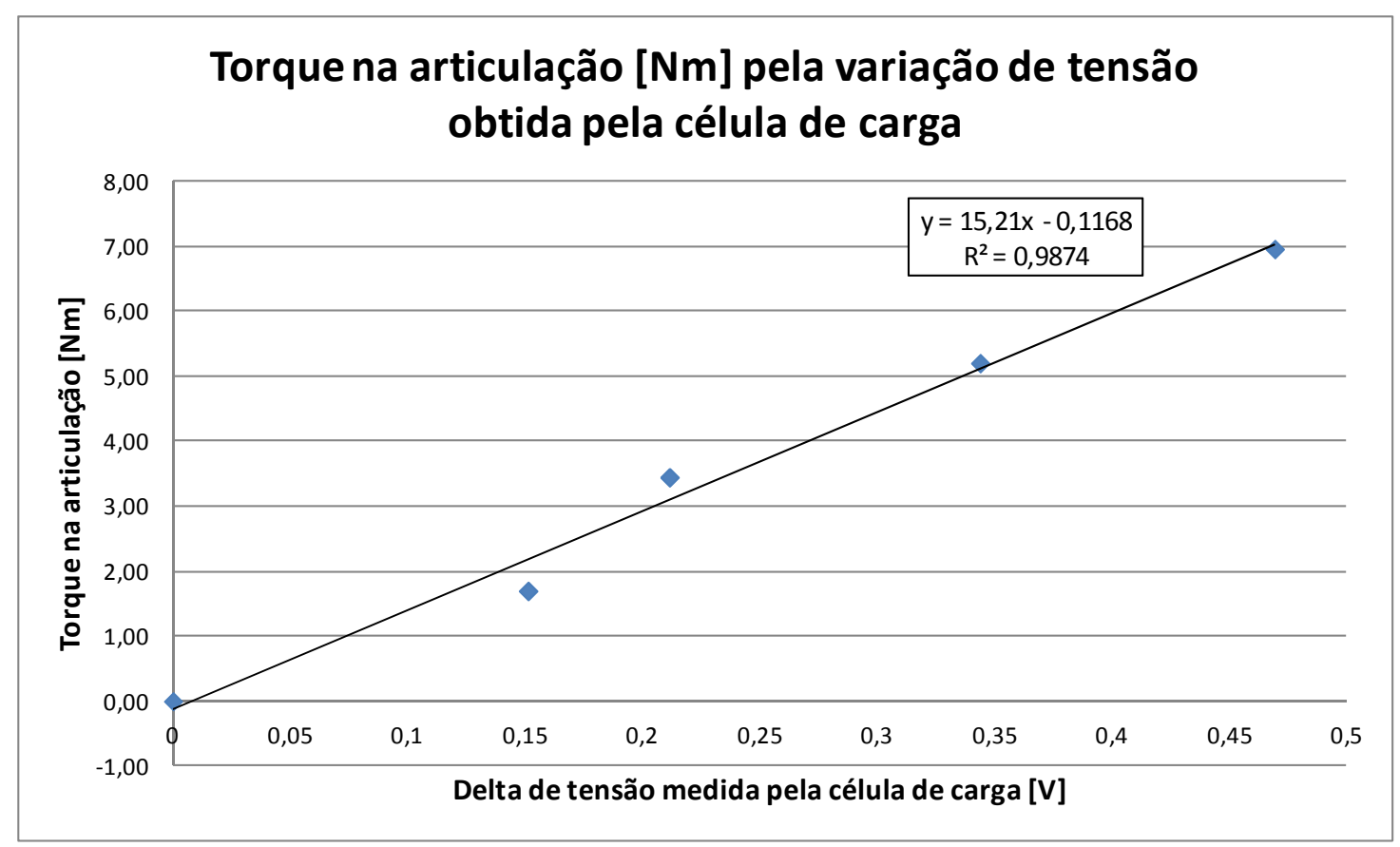

Figura 63: Cálculo do torque na articulação pela variação de tensão medida na célula de carga. 


\section{Protótipo final e validação}

O exoesqueleto foi projetado para ser uma ferramenta de medição e por isso ele atende aos requisitos de projetos definidos anteriormente. Em outras palavras, o ExoLoLi foi desenhado para ser vestido por pessoas saudáveis, é modular e permite diferentes configurações bem como ajustes para diferentes alturas (usuários de 1,50m até $1,90 \mathrm{~m}$ ). Os módulos atuadores são intercambiáveis entre as articulações (joelho e tornozelo) e também com os módulos passivos. A estrutura permite a separação do módulo do tornozelo (no caso em que se deseja analisar apenas o joelho) e o inverso também é possível, se o módulo passivo for montado paralelo ao joelho. A Figura 64 mostra o exoesqueleto completo (modelo 3D e protótipo construído), identificando os módulos atuadores, as células de carga e a estrutura (acoplamento com o corpo humano). Nas Figuras 65 e 66, também são ilustradas as possíveis configurações do exoesqueleto, mostrando a sua modularidade (SOUIT, COELHO, et al., 2016), bem como a comparação entre os módulos atuador e passivo. A massa do exoesqueleto completo é de $4,40 \mathrm{~kg}$.
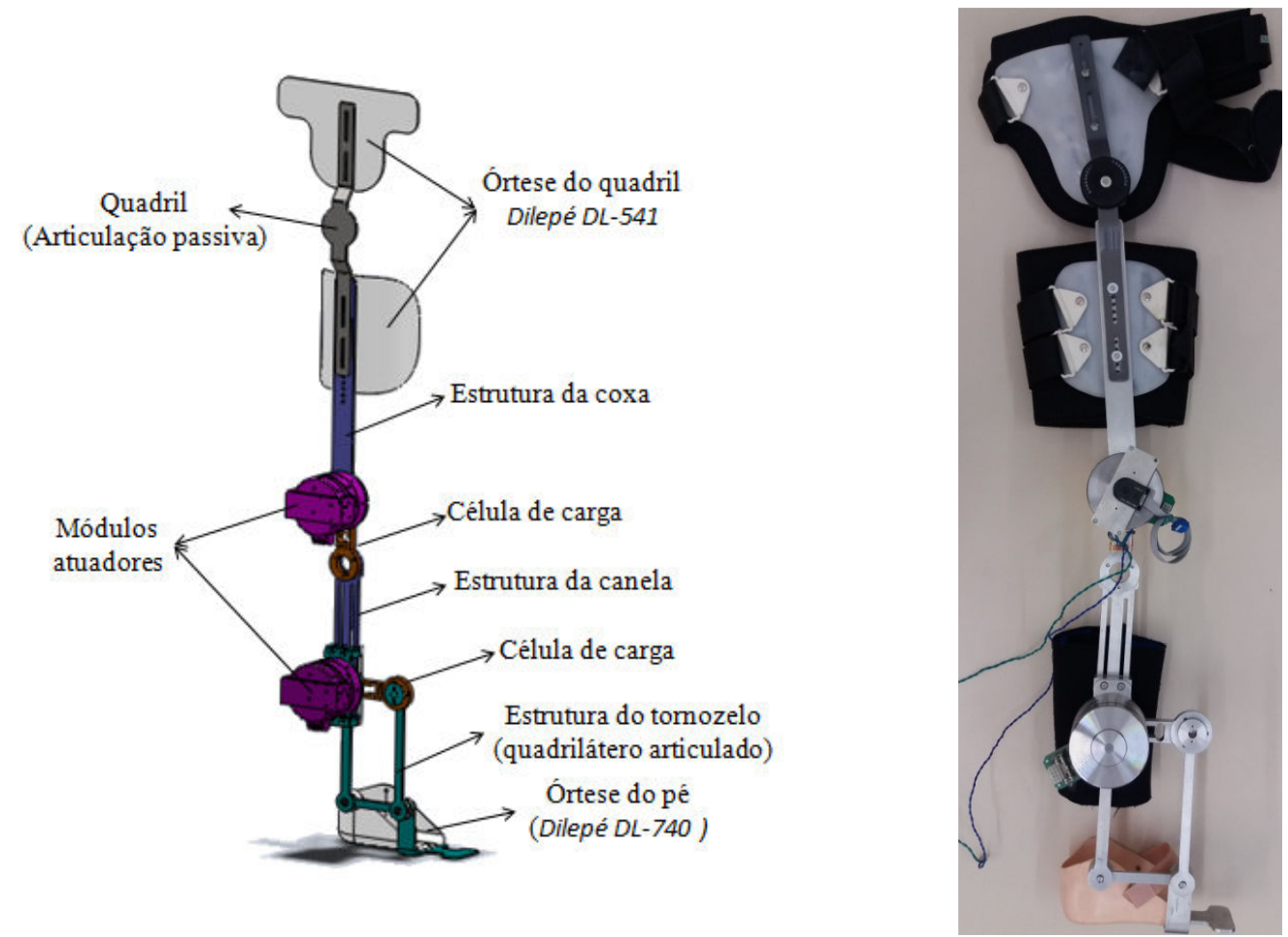

Figura 64: Exoesqueleto completo: à esquerda, modelo matemático; à direita, Protótipo II construído. 
(a)

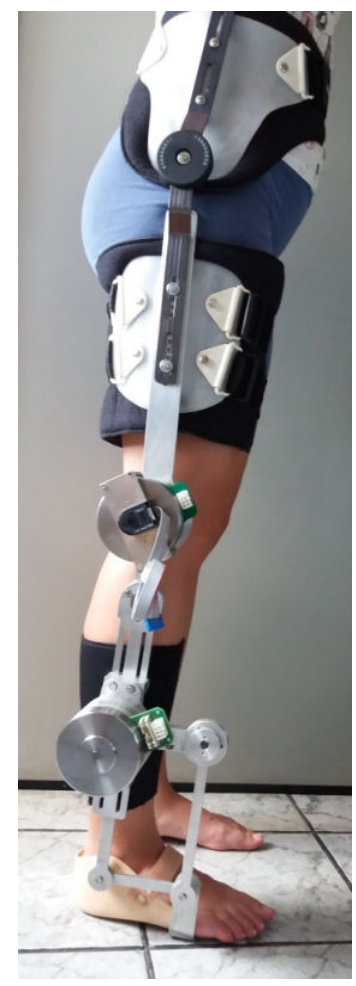

(b)

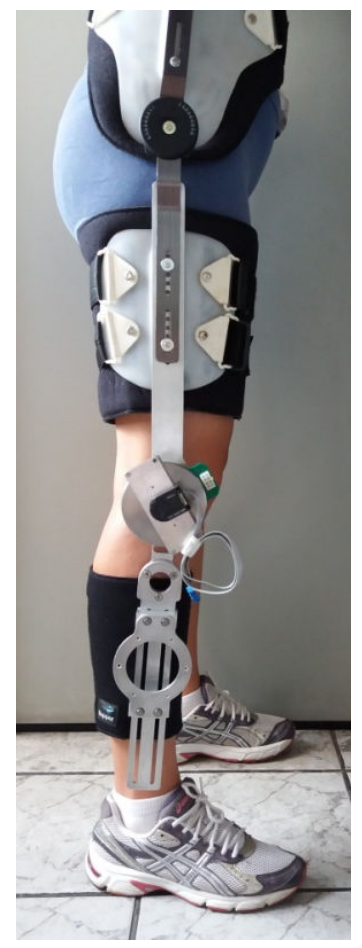

(c)

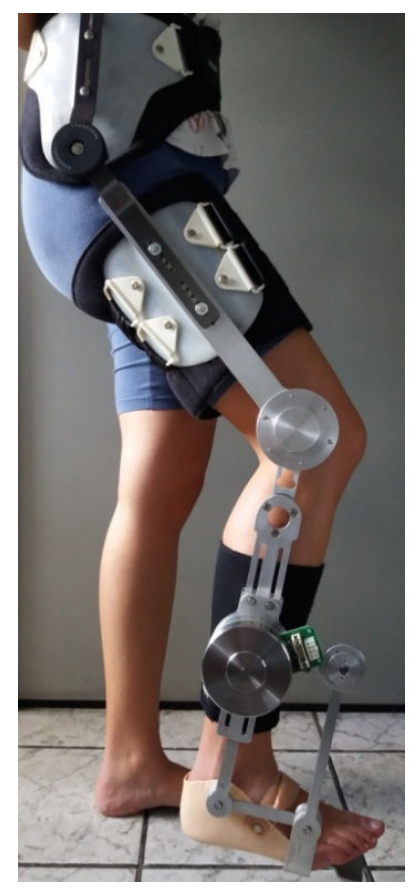

Figura 65: Diferentes configurações para o exoesqueleto: (a) exoesqueleto completo - atuação no joelho e no tornozelo; (b) Módulo do joelho - atuação sobre a articulação do joelho apenas; (c) Módulo do tornozelo atuação sobre o módulo do tornozelo somente (módulo passivo na articulação do joelho) (SOUIT, COELHO, et al., 2016).

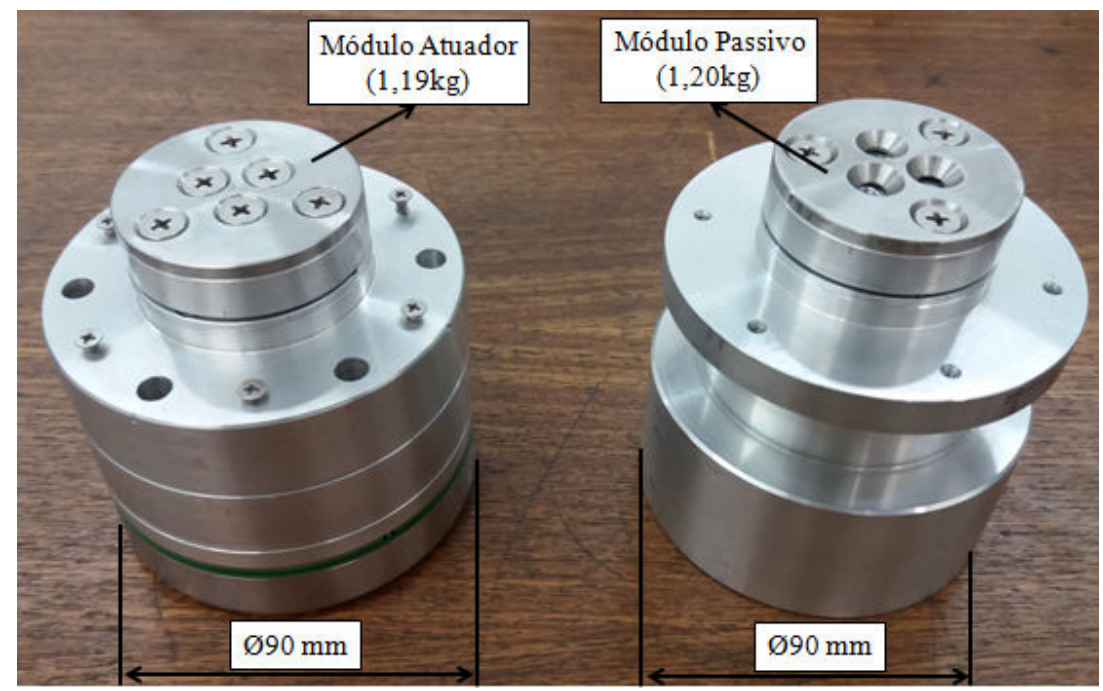

Figura 66: Comparação entre os módulos atuador e passivo - protótipos construídos. 
O ExoLoli foi projetado para ser uma ferramenta de estudo da marcha humana. Para que seja possível extrair as informações do corpo humano, é necessário saber exatamente quais são os parâmetros do exoesqueleto e também saber como o uso do exoesqueleto interfere na marcha natural. A seguir, são apresentados alguns resultados para a validação do ExoLoLi como ferramenta de estudo da marcha. Os experimentos preliminares mostram a interferência do exoesqueleto sobre a ativação muscular durante a marcha bem como a medição experimental dos parâmetros inerciais do exoesqueleto $\left(J_{\text {exo }}, B_{\text {exo }}\right.$ e $K_{\text {exo }}$ ) em bancada. O sistema de segurança (para a proteção do usuário) foi avaliado durante a execução do teste em bancada. Por fim, uma simulação foi realizada com o exoesqueleto completo sob o comportamento de controle seguidor, ou seja, com o exoesqueleto seguindo o movimento do usuário. Essa simulação permite a validação do sistema de medição da força de interação: se o exoesqueleto está seguindo o movimento do usuário, a célula de carga deve medir uma força de interação próxima de zero.

\subsection{Análise de EMG - Módulo do joelho passivo}

Experimentos iniciais foram realizados com o exoesqueleto configurado com o módulo passivo no joelho apenas. $\mathrm{O}$ intuito era verificar como o exoesqueleto altera $\mathrm{o}$ padrão da marcha natural do usuário apenas pela fixação no corpo. O módulo passivo utilizado nesse experimento não possuía a massa equivalente do módulo atuador (era mais leve, aprox. 0,2 kg). Por isso, durante o experimento, foi adicionado um peso concentrado de $1 \mathrm{~kg}$ para representar a massa do módulo atuador. Posteriormente a esse experimento, um módulo passivo foi projetado e usinado para apresentar a mesma massa e centro de gravidade do módulo atuador (conforme descrito no capítulo anterior, “Projeto Mecânico - Protótipo II”). A Figura 67 mostra a instrumentação para aquisição de dados. Quatro músculos (Rectus Femoris, Biceps Femoris, Tibialis Anterior e Gastrocnemius medialis) de cada perna foram monitorados com um sistema de eletrodos de EMG sem fio $(1000 \mathrm{~Hz}$, FreeEMG , BTS spA). O posicionamento dos eletrodos seguiu o protocolo SENIAM (HERMENS, FRERIKS, et al., 2000). Portanto, os padrões dos sinais musculares durante a marcha do usuário com e sem exoesqueleto serão observados. 

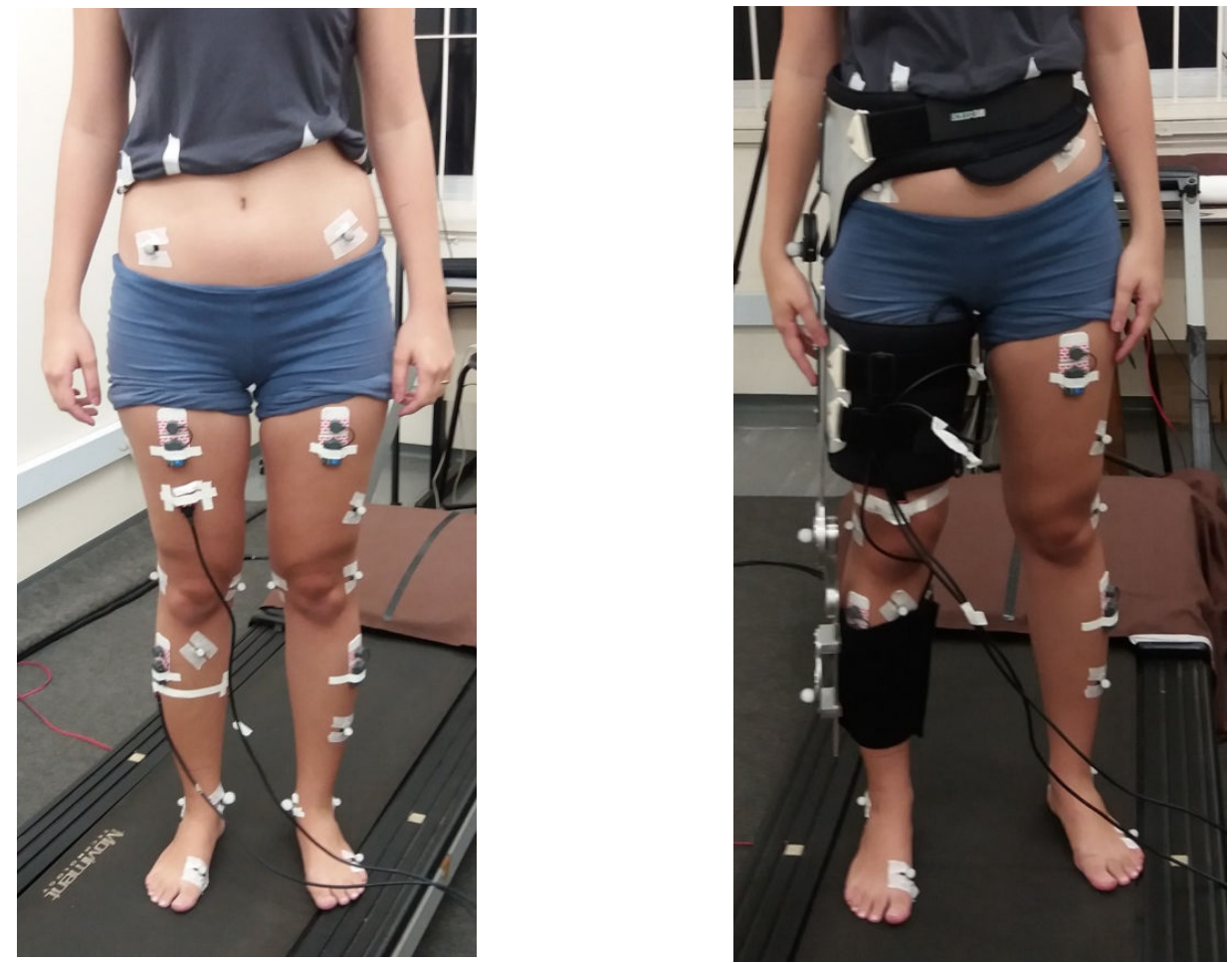

Figura 67: Instrumentação para aquisição de dados: à esquerda, usuário sem o exoesqueleto; à direita, usuário com exoesqueleto (SOUIT, COELHO, et al., 2016).

Os testes foram realizados com uma mulher saudável (26 anos de idade, 1,71 m de altura e $62 \mathrm{~kg}$ ) que caminhou em uma esteira em velocidade constante de $4 \mathrm{~km} / \mathrm{h}$ sob as seguintes condições: 1) marcha normal; 2) vestindo o exoesqueleto com o módulo passivo $(0,2 \mathrm{~kg})$ e 3$)$ vestindo o exoesqueleto com o módulo passivo mais $1 \mathrm{~kg}$ fixo ao módulo passivo.

O uso do exoesqueleto provocou alterações nos padrões de ativação em todos os músculos. A perna direita, a qual veste o exoesqueleto, exibe um nível de ativação superior à perna esquerda devido à adição de carga (peso próprio do exoesqueleto). A Figura 68 mostra os resultados de EMG para este experimento. 
(a)
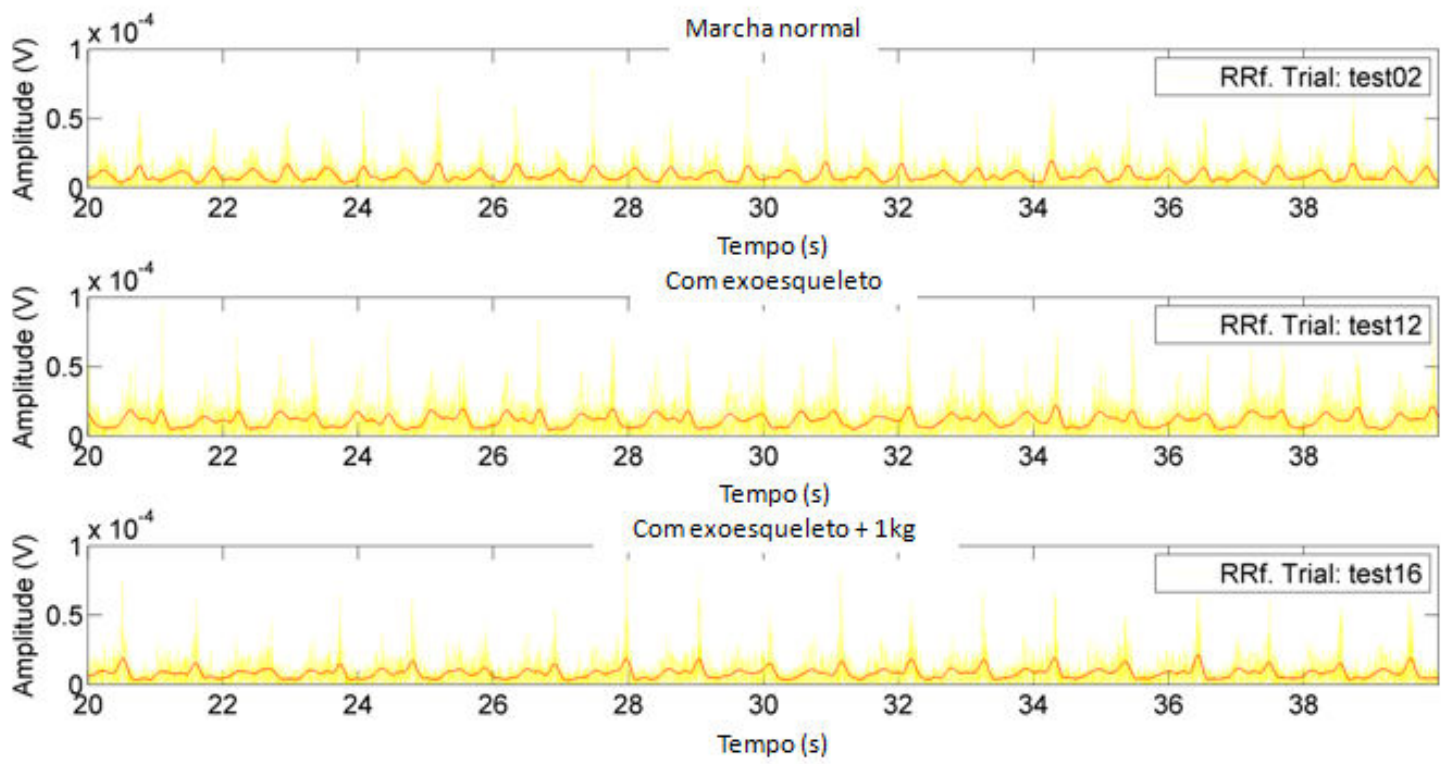

(b)
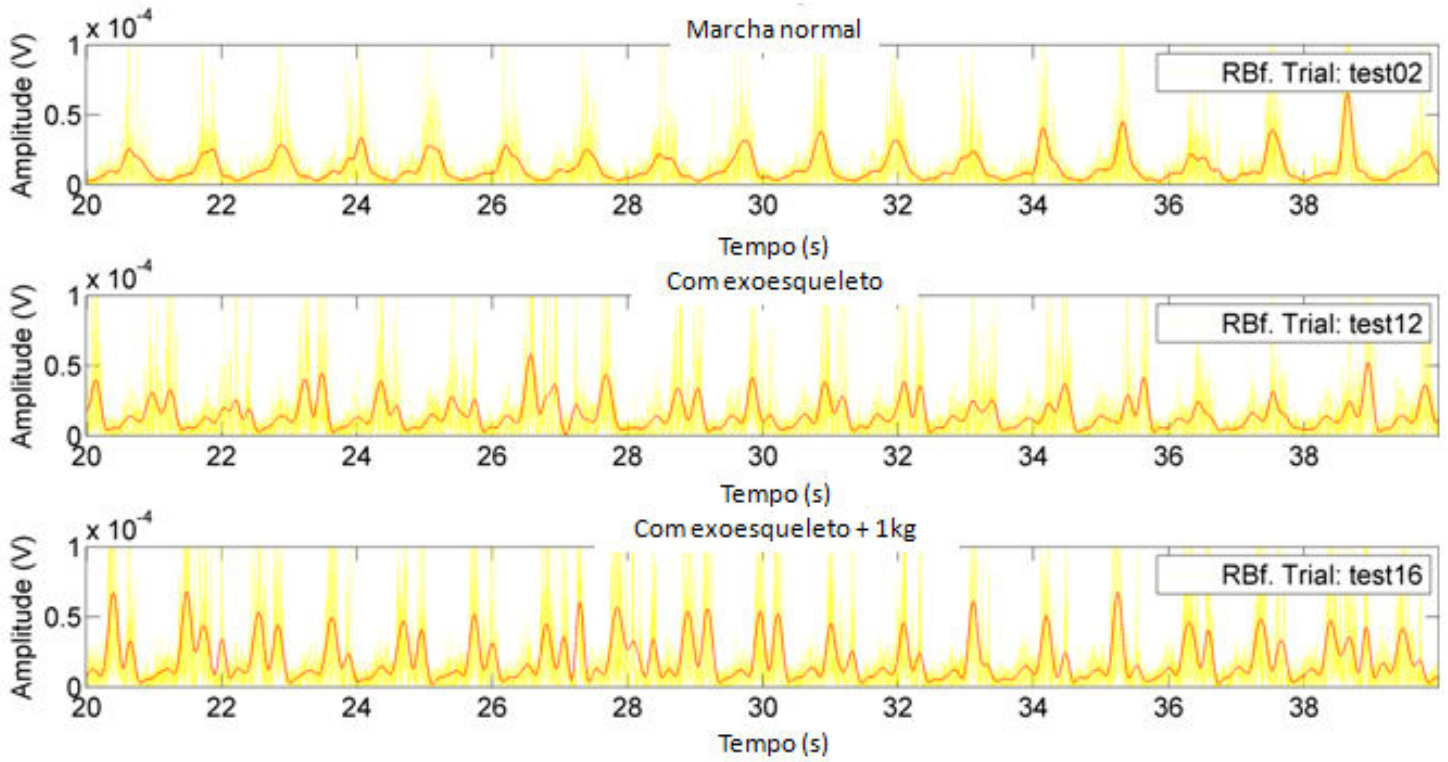

Figura 68: Resultados de EMG para marcha normal, com o exoesqueleto e com o exoesqueleto com carga adicional (1 kg): (a) músculo Rectus Femoris da perna direita (RRf); músculo Biceps Femoris da perna direita (RBf). Adaptado de (SOUIT, COELHO, et al., 2016).

No caso do Rectus Femoris, o maior momento de inércia causado pelo peso próprio do exoesqueleto diminuiu o nível de ativação desse músculo durante a fase de pré-balanço. Já no caso do Biceps Femoris, o qual em marcha normal apresenta um pico 
de atividade no final da fase de balanço (SUTHERLAND, 2001), um segundo pico se torna evidente com o uso do exoesqueleto com carga adicional de $1 \mathrm{~kg}$. A razão para isso é a necessidade da contração para elevar o pé em relação ao chão (SOUIT, COELHO, et al., 2016).

\subsection{Medição dos parâmetros do exoesqueleto - teste em bancada}

Para a medição dos parâmetros de impedância do exoesqueleto, foram realizados testes em bancada com o módulo atuador e a haste da canela, conforme descrito na Figura 69. O teste foi realizado considerando o módulo do joelho somente.

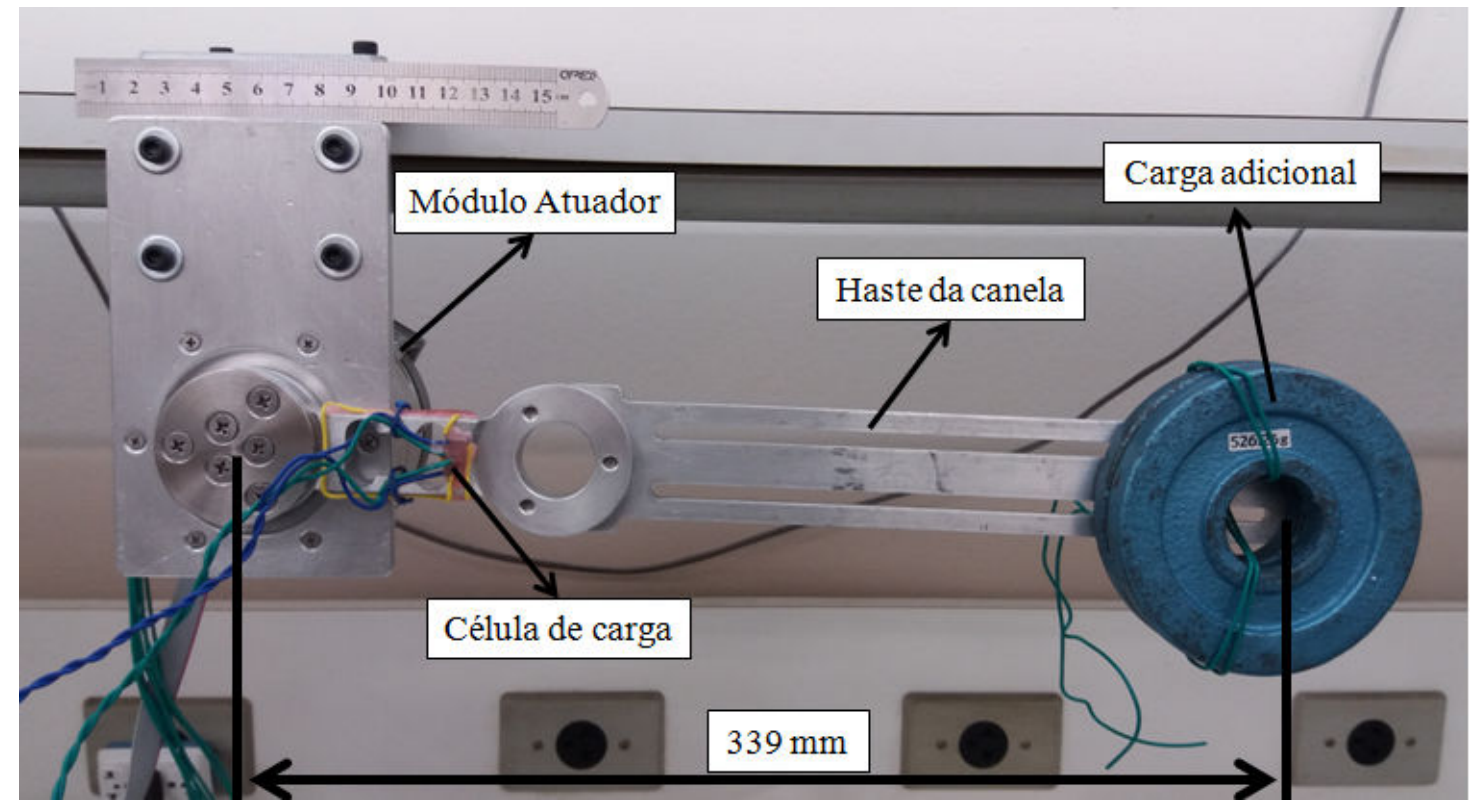

Figura 69: Disposição dos equipamentos para o teste em bancada do módulo do joelho.

Para o cálculo do parâmetro de impedância inercial do exoesqueleto $\left(J_{\text {exo }}\right)$, foram consideradas as informações de massa e geometria da haste da canela e da carga adicional, conforme descrito no Apêndice G.

Já para a medição dos parâmetros viscosos $\left(B_{\text {exo }}\right)$ e elásticos $\left(K_{\text {exo }}\right)$ do módulo do joelho, foram necessários ensaios experimentais obtendo as informações de posição e de força (para o cálculo do torque na articulação do joelho).

A Figura 70 ilustra o sistema de medição e de controle para o experimento em bancada do módulo do joelho. A medição de posição é feita pelo encoder (1) acoplado 
ao eixo do motor. A informação de posição é dada em qc (quadrature counts) por tempo pelo software EPOS Studio (2) (o qual fornece um arquivo texto com esses dados). O movimento é dado por controle de posição pelo Driver EPOS 2 70/10 (3). O driver movimenta o eixo do motor entre as posições especificadas. Nestes experimentos, foi especificado que o motor deveria ir de $0 \mathrm{qc}$ à $18000 \mathrm{qc}$, o que representa o movimento de $0^{\circ}$, posição horizontal da haste, à $32,4^{\circ}$ (movimento no sentido horário).

A informação de torque na articulação do joelho é obtida pela variação de tensão oferecida pela célula de carga (4), a qual mede a força cortante (o torque é dado pela multiplicação da força cortante pelo braço da aplicação da força). O sinal da célula de carga é adquirido pela placa de amplificação e filtro (5) e enviado ao PC-104 (6), que armazena as informações em um arquivo texto. As informações armazenadas pelo PC104 são exibidas no monitor (7). A sincronização dos dados medidos pelo encoder (1) e pela célula de carga (4) é feita por meio de um sinal digital enviado pelo Driver (3) para o PC-104 (6) enquanto o motor está em movimento.

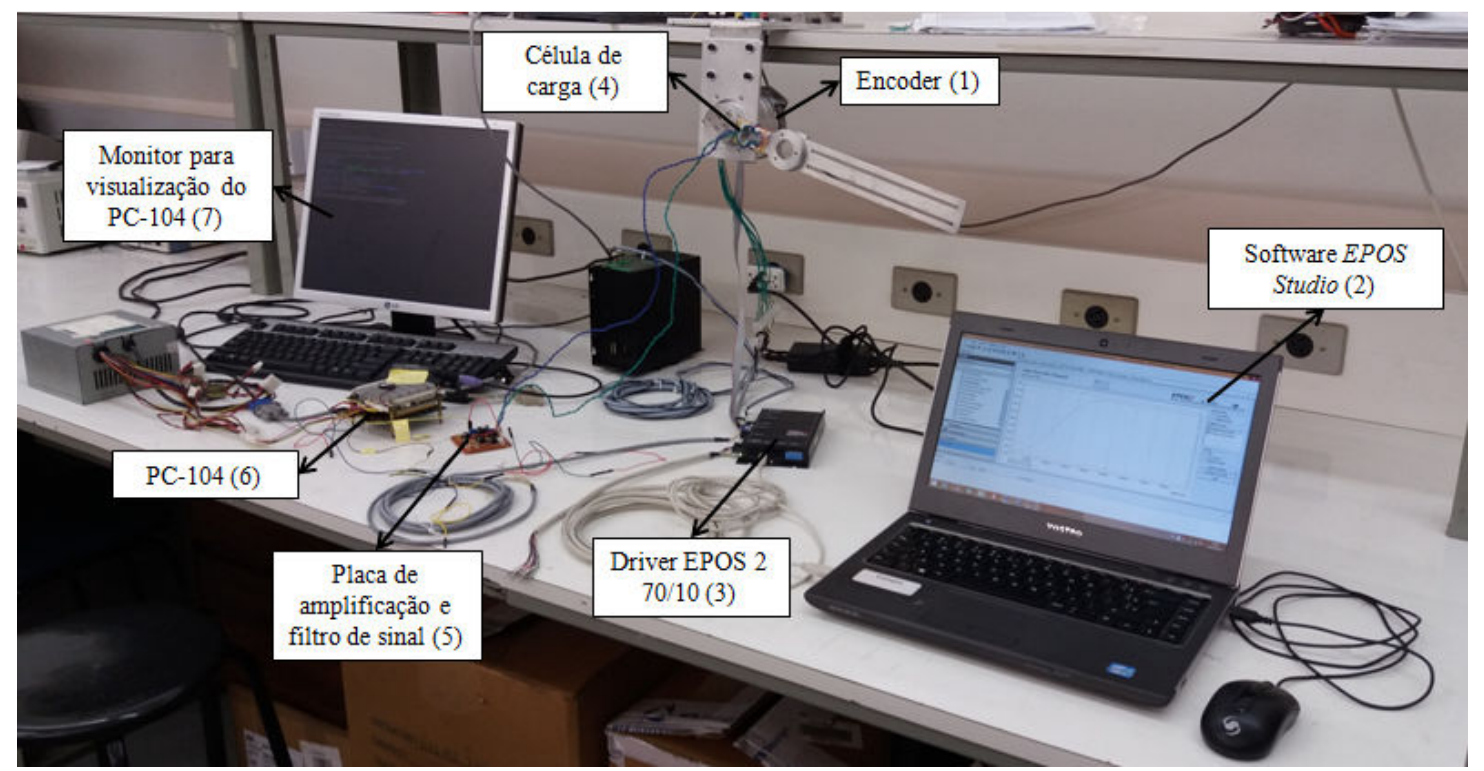

Figura 70: Descrição do experimento de bancada com o módulo do joelho. Indicação dos dispositivos de medição e de controle.

A Figura 71 mostra os parâmetros do controle seguidor de posição definidas para o software EPOS Studio. 


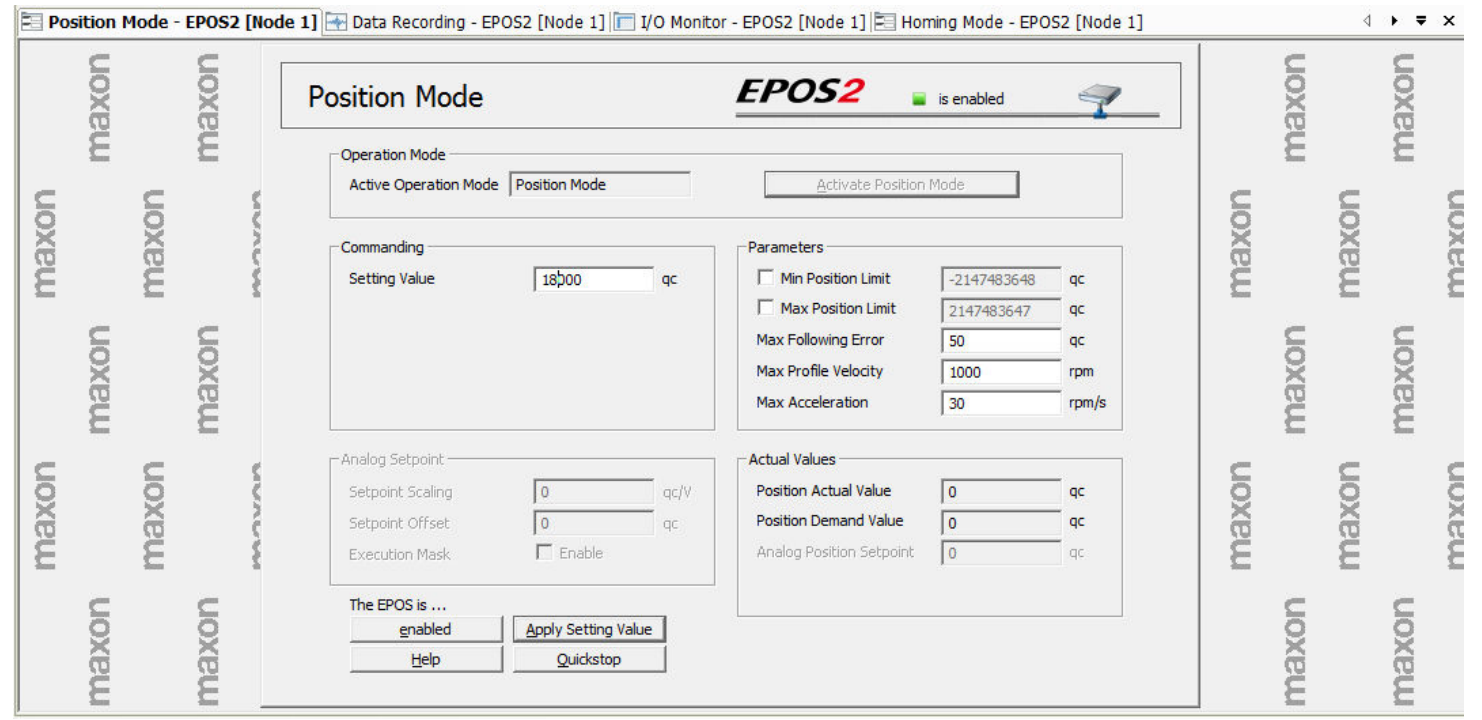

Figura 71: Configuração do software EPOS Studio para o controle de posição.

Foram realizados cinco experimentos. Em cada experimento foram aplicadas as seguintes cargas, respectivamente: $0 \mathrm{~kg} ; 0,528 \mathrm{~kg} ; 1,039 \mathrm{~kg} ; 1,568 \mathrm{~kg}$ e $2,094 \mathrm{~kg}$. Para o cálculo da regressão, foram consideradas três hipóteses simplificadoras:

1) O módulo do joelho do exoesqueleto pode ser modelado pela equação diferencial $\tau_{\text {exo }}=J_{\text {exo }} \ddot{\theta}+B_{\text {exo }} \dot{\theta}+K_{\text {exo }} \theta$;

2) Os parâmetros $J_{\text {exo }}, B_{\text {exo }}$ e $K_{\text {exo }}$ são constantes por todo o movimento da haste da canela;

3) O parâmetro $J_{\text {exo }}$ difere para cada carga aplicada, por isso, será realizada uma regressão para cada carga.

Com a medição da variação de tensão da célula de carga é possível obter o torque na articulação considerando o braço da aplicação da força cortante $(b=339 \mathrm{~mm})$, conforme descrito no item "Medição de força: Célula de carga". Além disso, também é possível obter as informações de aceleração, velocidade e posição angulares porque o encoder faz essa medição e o driver mede o tempo.

Com os dados experimentais disponíveis, os parâmetros $B_{\text {exo }}$ e $K_{\text {exo }}$ podem ser obtidos por regressão. Neste trabalho, a regressão foi feita por meio da ferramenta “Análise de Dados", disponível no Excel 2007. Os detalhes da regressão estão 
disponíveis no Apêndice H. Os resultados dos cálculos da regressão para os cinco experimentos estão apresentados na tabela a seguir.

Tabela 7: Parâmetros de impedância do exoesqueleto (módulo do joelho).

\begin{tabular}{|c|c|c|c|c|c|}
\hline $\begin{array}{l}N^{\circ} \text { do } \\
\text { experi- } \\
\text { mento }\end{array}$ & $\begin{array}{c}\text { Carga } \\
\text { Adicional } \\
{[k g]}\end{array}$ & $\begin{array}{c}\text { Momento } \\
\text { de Inércia } \\
\left(J_{\text {exo }}\right) \\
{\left[\mathrm{kgm}^{2}\right]}\end{array}$ & $\begin{array}{c}\text { Parâmetro } \\
\text { Viscoso } \\
\left(B_{\text {exo }}\right) \\
{\left[k g \frac{m^{2}}{s}\right]}\end{array}$ & $\begin{array}{c}\text { Parâmetro } \\
\text { Elástico } \\
\left(K_{\text {exo }}\right) \\
{\left[k g \frac{m^{2}}{s^{2}}\right]}\end{array}$ & $\begin{array}{c}\mathbf{R}^{2} \\
\text { (Coeficiente de } \\
\text { determina- } \\
\text { ção) }\end{array}$ \\
\hline 1 & 0,000 & 0,004 & 0,256 & $-0,152$ & $49 \%$ \\
\hline 2 & 0,528 & 0,065 & 0,796 & $-0,397$ & $79 \%$ \\
\hline 3 & 1,039 & 0,123 & 1,593 & $-0,710$ & $95 \%$ \\
\hline 4 & 1,568 & 0,184 & 2,256 & $-1,057$ & $97 \%$ \\
\hline 5 & 2,094 & 0,245 & 2,202 & $-1,516$ & $97 \%$ \\
\hline
\end{tabular}

Este experimento provou que é possível calcular os parâmetros de impedância utilizando o ExoLoLi (Protótipo II). Porém, ainda é necessário aprimorar a aquisição de dados de maneira a obter valores experimentais dos parâmetros viscosos e elásticos mais coerentes, pois eles não deveriam variar de acordo com a aplicação de carga. Algumas formas para isso são:

- Fazer medições empíricas do momento de inércia por meio de experimentos pendulares;

- Obter o valor de torque sem ter que estimar o braço da aplicação da força. Isto porque a célula de carga apresentada neste trabalho mede a força cortante. O torque na articulação é obtido pela multiplicação da força cortante pelo braço, o qual é estimado. É possível notar que quanto maior a carga aplicada na extremidade da haste da canela, maior é o coeficiente de determinação. Isto é devido ao fato de que, quanto maior a carga aplicada, a posição da aplicação da força cortante fica mais próxima do valor considerado, $b=339 \mathrm{~mm}$ (neste caso, a posição de aplicação da força cortante é o centro de massa da carga adicional mais a massa da barra). 
Como próximo passo, seria necessário refazer a coleta de dados para os experimentos 1 e 2 (variando o valor considerado para o braço da aplicação da força) para que a regressão atinja um coeficiente de determinação de aproximadamente $95 \%$, ou seja, para que os coeficientes de impedância sejam representativos com a realidade. Com os valores adquiridos para os dois primeiros experimentos, não foi possível obter a representatividade mínima (95\%).

\subsection{Validação do sistema de segurança}

Durante os experimentos com o módulo atuador, ocorreu um acidente no qual o motor movimentou a célula de carga até a colisão com o parafuso de fixação na bancada, conforme ilustrado na Figura 72. O acidente ocorreu durante uma tentativa de definição da referência "0qc" no software Epos Studio.

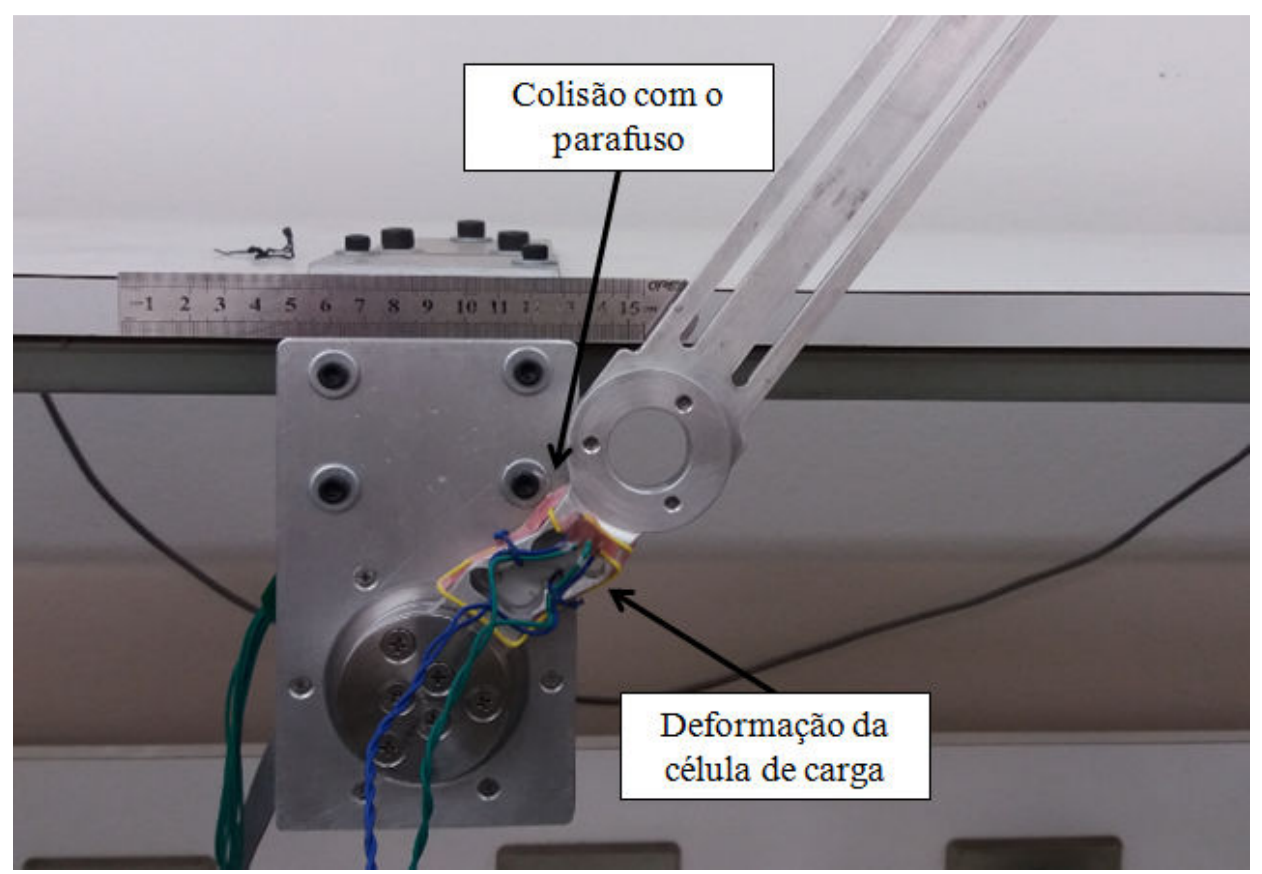

Figura 72: Deformação real da célula de carga durante o teste em bancada.

Este "acidente" serviu para a validação física da simulação feita em elementos finitos, pois a deformação real foi exatamente igual à deformação prevista pela simulação, conforme ilustrado na Figura 73. 


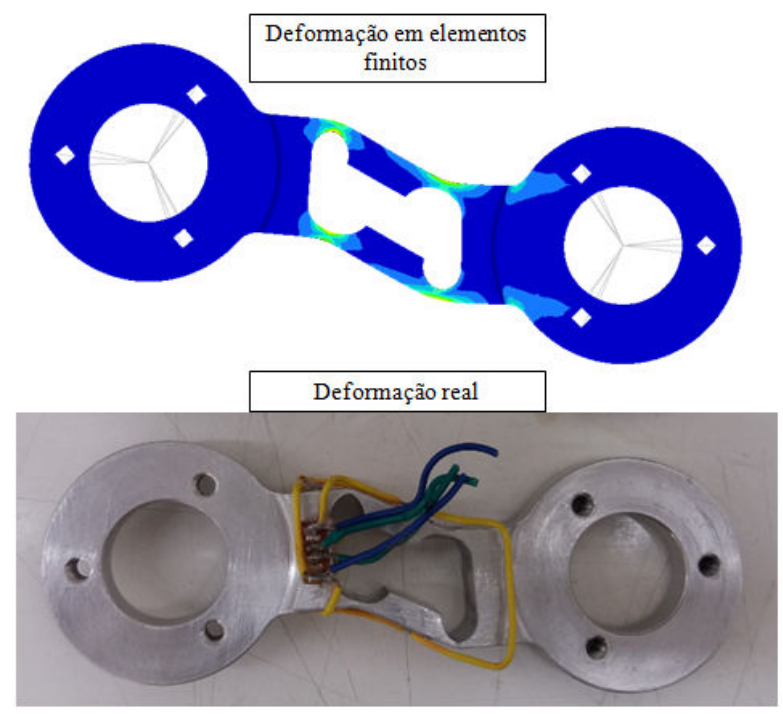

Figura 73: Comparação entre a deformação prevista em elementos finitos e a deformação real.

Como explicado anteriormente, as células de carga são fixadas à estrutura, de maneira que, se elas fossem danificadas, o resto da estrutura permaneceria intacto ("fusível mecânico"). Foi exatamente o que aconteceu neste evento. Além disso, a deformação da célula de carga protege o usuário de um eventual problema no controlador porque ela deforma antes de machucá-lo. Para que isso aconteça, pinos foram fixados à estrutura de maneira a limitar o movimento da célula de carga, conforme ilustrado na Figura 74.

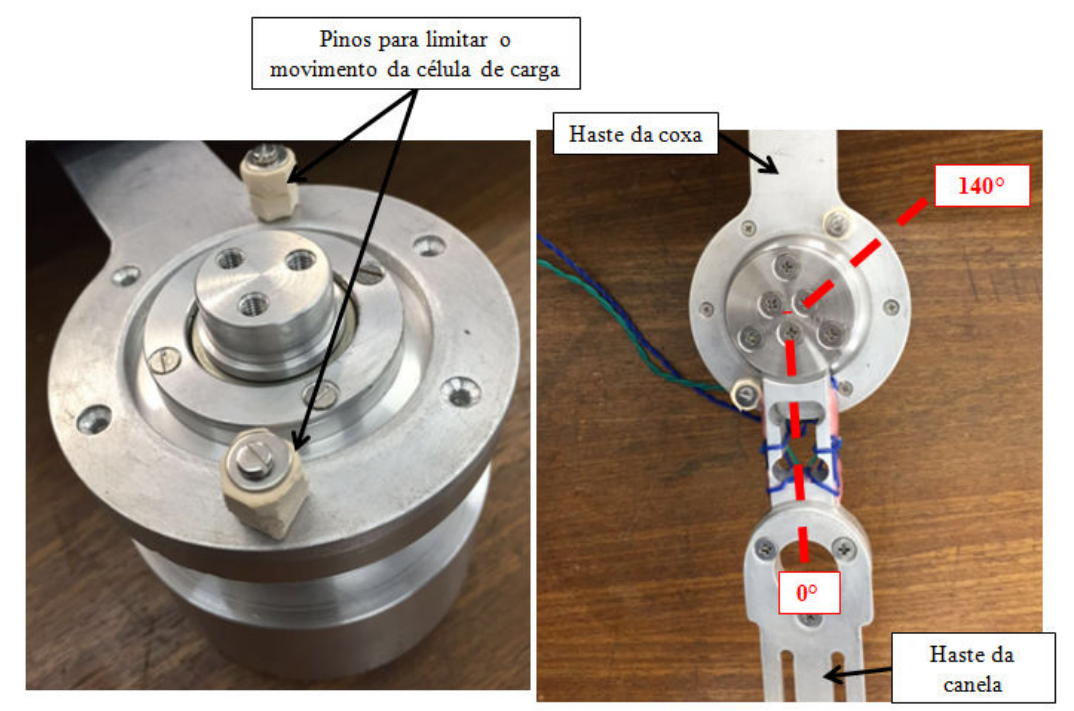

Figura 74: Pinos para limitar o movimento da célula de carga - posicionados nos limites de flexão-extensão do joelho. 
Após a deformação permanente da célula de carga, foi necessário instrumentar outra peça. Como a instalação dos extensômetros é manual, o posicionamento dos sensores pode variar e é necessário realizar a calibração novamente. O gráfico da Figura 75 mostra a calibração da nova célula de carga bem como a fórmula para o cálculo da força cortante pela variação de tensão medida pela ponte de Wheatstone. Neste sistema, para obter o momento na articulação, é necessário multiplicar a força cortante pelo braço da aplicação da força.

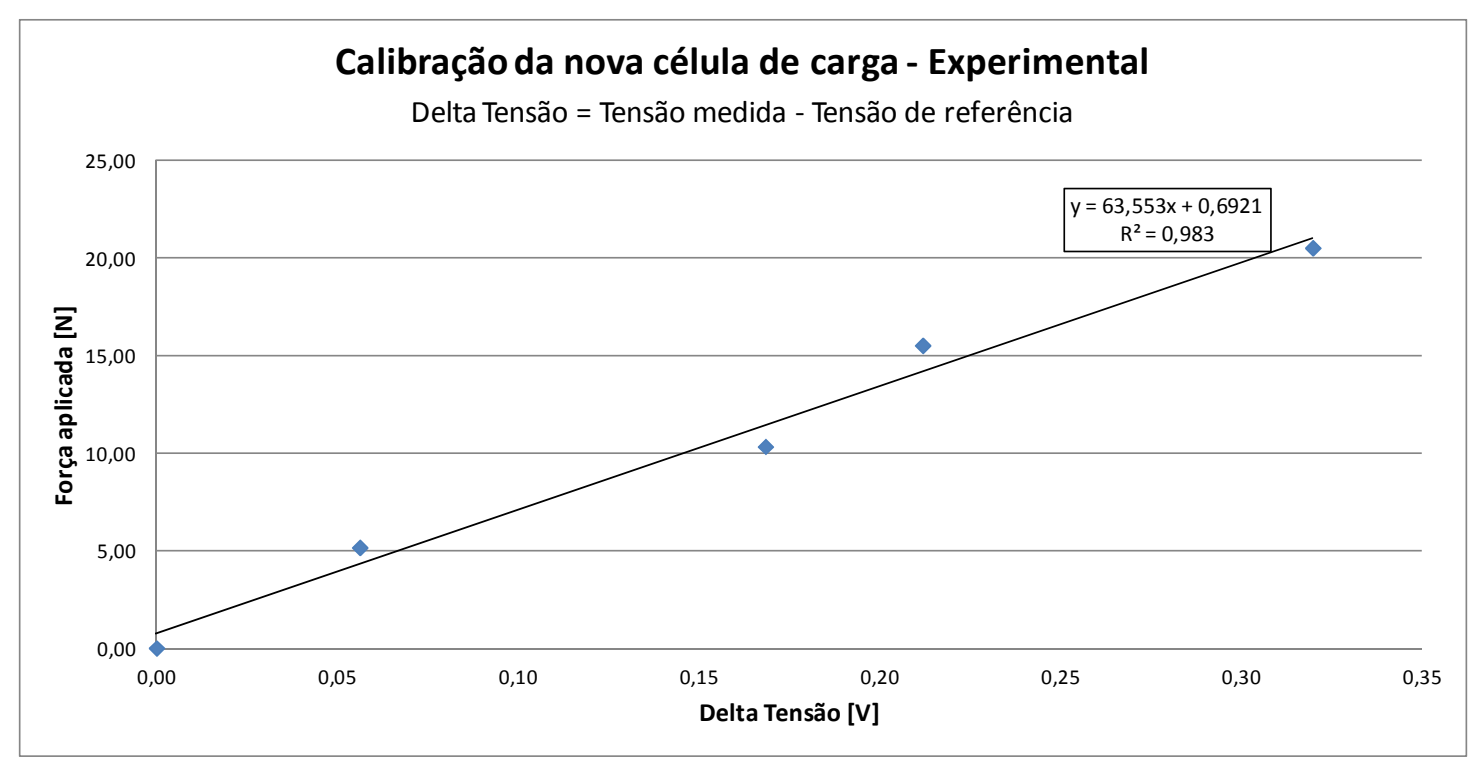

Figura 75: Calibração da nova célula de carga.

\subsection{Análise da força de interação - exoesqueleto passivo}

A simulação com o exoesqueleto completo sob o comportamento de controle seguidor, ou seja, com o exoesqueleto seguindo o movimento do usuário, permite a validação do sistema de medição da força de interação. Para essa simulação, foram utilizados dois módulos passivos (um para o joelho e outro para o tornozelo). O módulo passivo foi projetado e usinado para apresentar a mesma massa e centro de gravidade do módulo atuador. A Figura 76 mostra o exoesqueleto utilizado para este experimento. A célula de carga do joelho estava instrumentada com strain gauges formando uma ponte de Wheatstone. Assim, foi possível obter a força de interação entre o exoesqueleto e o usuário durante a marcha. 
Os experimentos foram realizados com três velocidades diferentes: $2 \mathrm{~km} / \mathrm{h}, 3 \mathrm{~km} / \mathrm{h}$ e $4 \mathrm{~km} / \mathrm{h}$. Para cada experimento, o procedimento de teste envolvia os seguintes passos (duração de cada experimento: $55 \mathrm{~s}$ ):

- Permanecer $5 \mathrm{~s}$ com velocidade igual a 0 ;

- Atingir a velocidade desejada em 10s;

- Permanecer na velocidade desejada por 30s;

- Retornar à velocidade 0 em $10 \mathrm{~s}$;

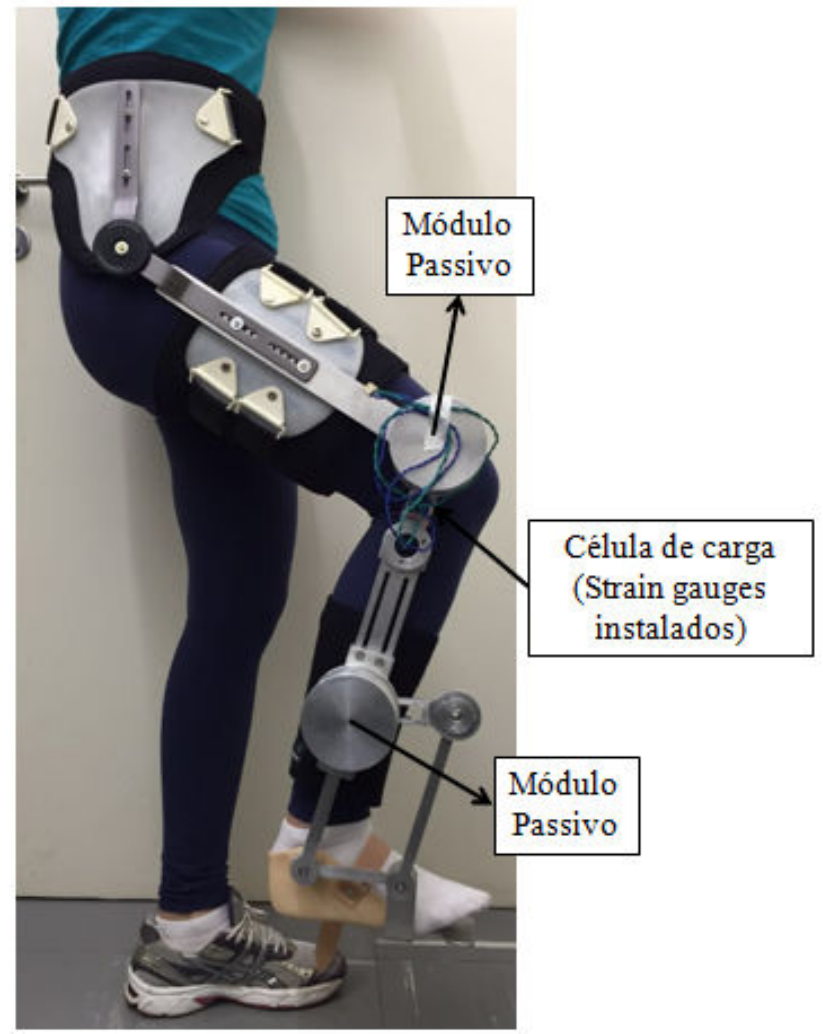

Figura 76: Configuração do exoesqueleto para a medição da força de interação para a simulação do "controle seguidor" (exoesqueleto acompanhando o movimento do usuário).

O gráfico da Figura 77 mostra os valores de força cortante medidas pela célula de carga durante os experimentos. É possível verificar picos que sinalizam ruídos durante a medição, mas o importante é que os valores obtidos não ultrapassam $2 \mathrm{~N}$, o que era esperado, já que o exoesqueleto estava acompanhando o movimento. A Tabela 8 fornece as médias dos valores medidos e a variância. 
Tabela 8: Valores de torque obtidos pela célula de carga durante o experimento (média e variância).

\begin{tabular}{|c|c|c|c|}
\hline & $\begin{array}{c}\text { Força cortante } \\
(\text { Veloc. } \mathbf{2 k m} / \mathbf{h})[\mathbf{N}]\end{array}$ & $\begin{array}{c}\text { Força Cortante } \\
(\text { Veloc. } \mathbf{3 k m} / \mathbf{h})[\mathbf{N}]\end{array}$ & $\begin{array}{c}\text { Força Cortante } \\
(\text { Veloc. } \mathbf{4 k m} / \mathbf{h})[\mathbf{N}]\end{array}$ \\
\hline Média & 0,867 & 0,546 & 0,168 \\
\hline Variância & 0,061 & 0,033 & 0,028 \\
\hline
\end{tabular}

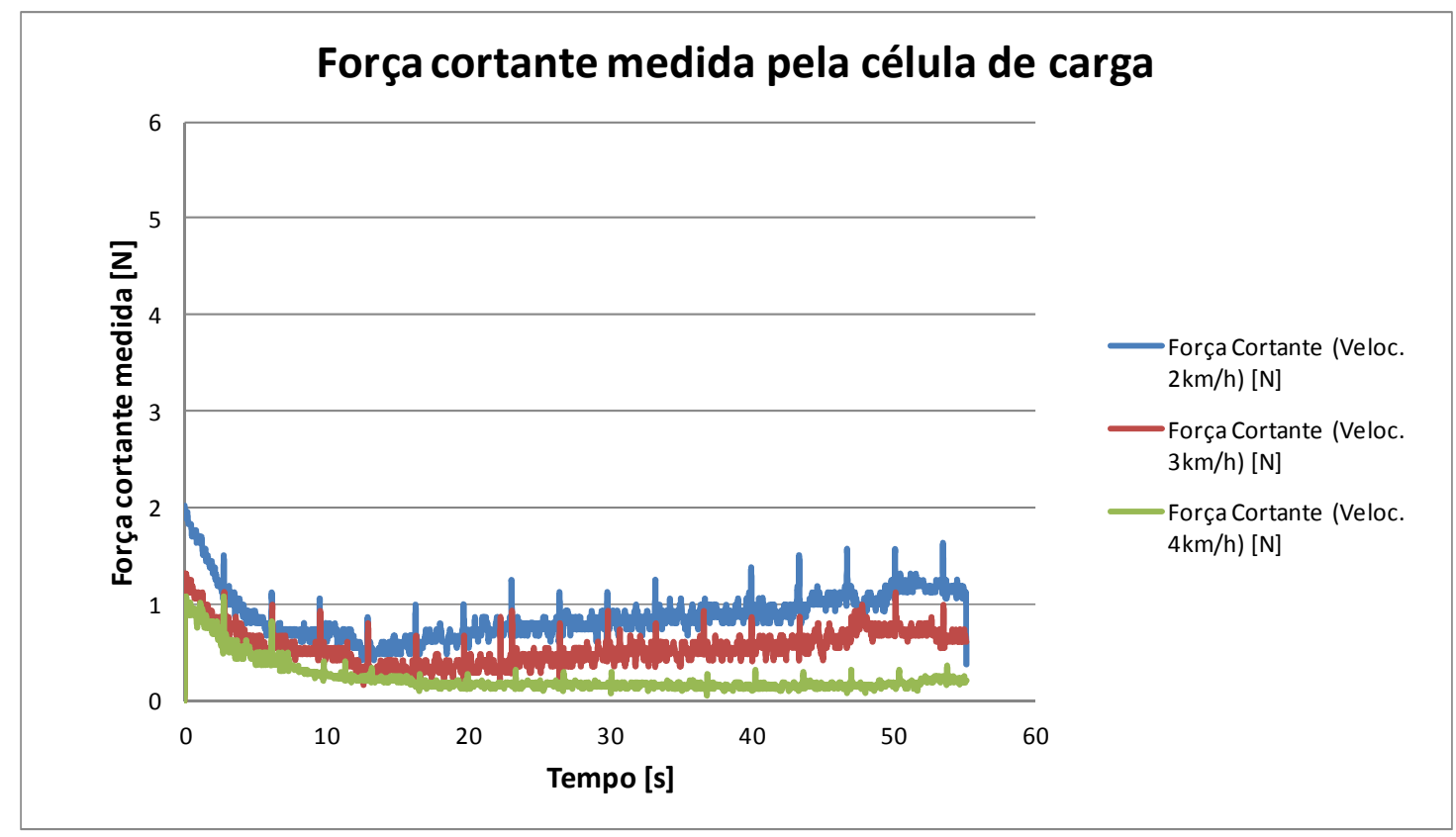

Figura 77: Torque medido pela célula de carga durante os experimentos com o exoesqueleto passivo.

Para a realização desse experimento, também foram instalados eletrodos de eletromiografia (EMG) para a medição da ativação muscular durante a marcha com e sem exoesqueleto, permitindo o comparativo de como o exoesqueleto interfere no padrão da marcha. Seis músculos (Rectus Femoris, Biceps Femoris, Tibialis Anterior, Gastrocnemius medialis, Vastus Laterallis e Vastus Medialis) da perna direita foram monitorados com um sistema de eletrodos de EMG sem fio $(1000 \mathrm{~Hz}$, FreeEMG , BTS spA). O posicionamento dos eletrodos seguiu o protocolo SENIAM (HERMENS, FRERIKS, et al., 2000). A Tabela 9 mostra o sinal de eletromiografia para o músculo Rectus Femoris, nas três velocidades, com e sem exoesqueleto. 
Tabela 9: Sinais de eletromiografia do músculo Rectus Femoris durante os experimentos com o exoesqueleto passivo.

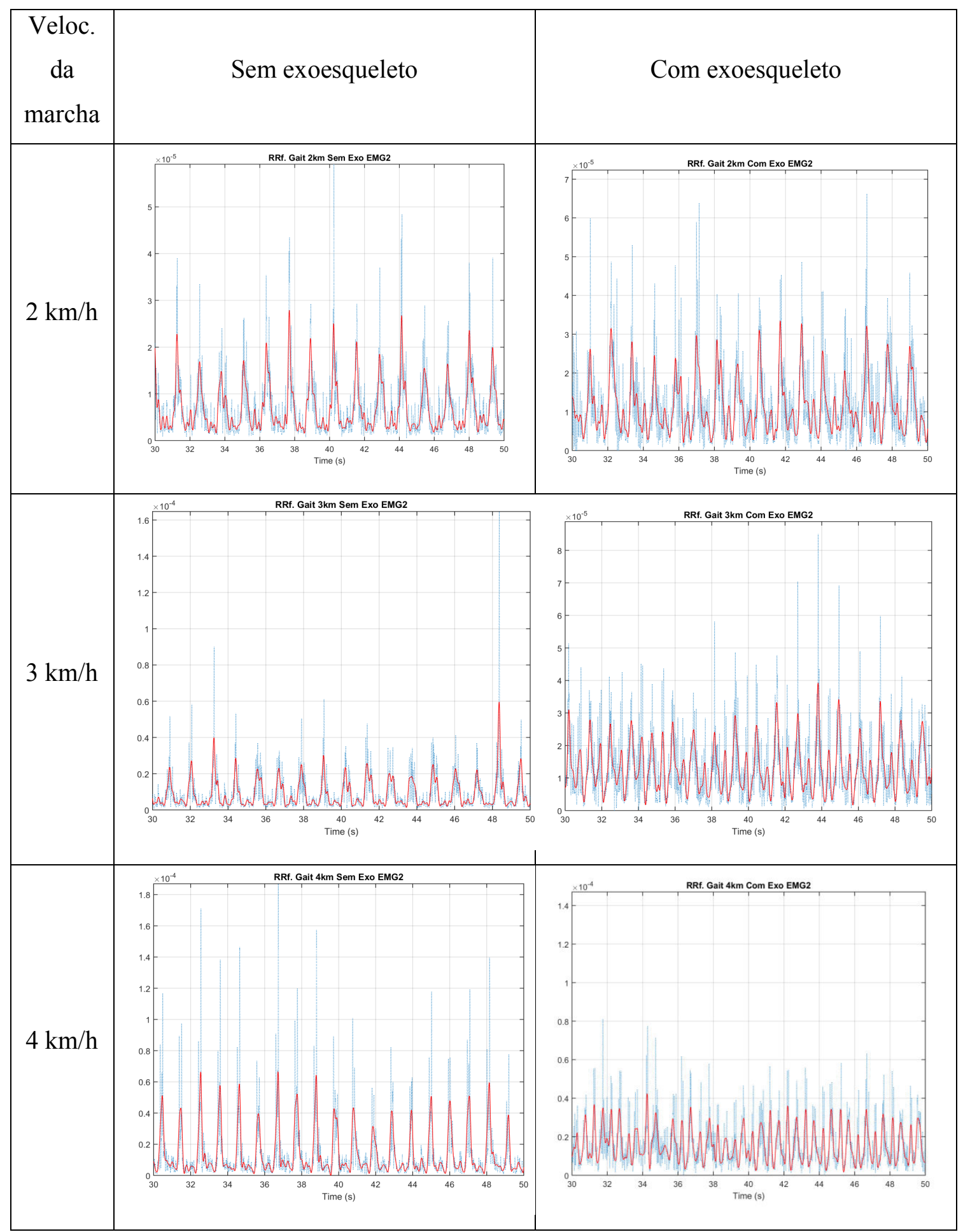


Quanto maior a velocidade e peso suportado pela perna, maior a frequência de ativação, assim, a marcha com o exoesqueleto é diferente da marcha sem o exoesqueleto para todas as velocidades. Na linha da velocidade de $3 \mathrm{~km} / \mathrm{h}$, os gráficos estão em escalas diferentes, mas é possível fazer a comparação. Verifica-se que a ativação muscular é mais intensa com o uso do exoesqueleto para todas as velocidades. De maneira geral, o padrão da marcha em $3 \mathrm{~km} / \mathrm{h}$ e $4 \mathrm{~km} / \mathrm{h}$ é totalmente alterado com o uso do exoesqueleto; a marcha fica mais assimétrica. Dois trabalhos futuros são: 1) definir e mensurar exatamente como o exoesqueleto afeta o padrão de ativação muscular por meio de mais medições e análises estatísticas e 2) comparar as ativações musculares utilizando o exoesqueleto passivo com o exoesqueleto com um controlador seguidor. 


\section{Conclusão}

Este trabalho apresentou o desenvolvimento de uma ferramenta para análise da marcha humana. O equipamento é capaz de adquirir sinais de força de interação e de posição angular que podem ser usados para o cálculo dos parâmetros de impedância das articulações da perna (joelho e tornozelo). O exoesqueleto construído, chamado de ExoLoLi, atendeu todos os requisitos de projeto, pois ele é modular, ou seja, é possível separar o módulo do joelho do tornozelo e vice-versa, é ajustável para usuários de diferentes alturas (de $1,50 \mathrm{~m}$ à $1,90 \mathrm{~m}$ ) e diferentes massas (de $60 \mathrm{~kg}$ à $100 \mathrm{~kg}$ ), possui um dispositivo de segurança para evitar danos aos usuários e células de carga que funcionam como "fusível mecânico" (deformam plasticamente sob forças cortantes superiores a $300 \mathrm{~N}$ ), apresenta momentos e produtos de inércia menores que o Protótipo I e, por fim, possui dois modos operacionais, o ativo e o passivo, o qual permite a avaliação da interferência do exoesqueleto sobre o padrão da marcha sem a presença de qualquer tipo de controlador.

Foram apresentados resultados de experimentos preliminares do exoesqueleto em bancada bem como em marcha. Com esses resultados é possível confirmar que o dispositivo é uma ferramenta de análise, pois ele adquire os sinais de força de interação e de posição corretamente. Além disso, é possível confirmar que o exoesqueleto interfere na marcha, principalmente, em velocidades superiores à $3 \mathrm{~km} / \mathrm{h}$. Este trabalho também apresentou os parâmetros de impedância do exoesqueleto (módulo do joelho), os quais podem ser usados durante os cálculos de impedância da articulação humana.

Como trabalhos futuros, pode-se mencionar: o estudo quantitativo da interferência do exoesqueleto sobre a ativação muscular; a aplicação de um elemento elástico em série no módulo atuador para aprimorar a medição do torque na articulação (sem a necessidade de estimar o braço de aplicação da força) e viabilizar o backdrivability, ou seja, a complacência do exoesqueleto sob os movimentos do usuário, bem como a sua segurança; e, por fim, o estudo do consumo energético para diferentes tipos de controle (controle de força e de impedância, por exemplo), isto porque o 
exoesqueleto está conectado ao PC-104 e é possível fazer a programação de diferentes tipos de controle para a análise de consumo energético.

Pode-se dizer que este trabalho construiu um exoesqueleto que é um hardware que pode ser configurado para analisar os parâmetros da articulação do joelho e tornozelo (ferramenta de análise da marcha), bem como para ser utilizado para fins fisioterápicos ou aumento da força humana; tudo depende do controlador (software) que comandará os seus movimentos. Também será possível avaliar a utilização de um sistema de comutação de acionamentos (CORTEZ JUNIOR, 2015) para a redução do consumo energético com o uso do exoesqueleto. 


\section{Referências Bibliográficas}

AGUIRRE-OLLINGER, G. Active impedance control of a lower limb assistive - Doutorado. Northwestern University. Evaston. 2009.

AIM2WALK. Aim2walk. Aim2walk, 2014. Disponivel em: $<$ http://aim2walk.ca/?page_id=598>. Acesso em: Novembro 2014.

AMUNDSON, K. et al. Hybrid Hydraulic-Electric Power Unit for Field and Service Robots. IEEE, California, 2005.

ARAUJO, A. A. M.; TANNURI, E. A.; FORNER-CORDERO, A. Simulation of model-based impedance control applied to a biomechatronic exoskeleton with shape memory alloy actuators. IEEE International Conference on Biomedical Robotics and Biomechatronics, Roma, p. 1567-1572, Junho 2012.

ASBECK, A. T. et al. Biologically-inspired Soft Exosuit. IEEE International Conference on Rehabilitation Robotics, Seattle, 2013.

ASBECK, A. T. et al. A biologically inspired soft exosuit for walking assistance. The International Journal of Robotics Research, p. 1-19, 2015.

BACKDRIVABILITY. Backdrivability. Backdrivability, 2011. Disponivel em: $<$ http://www.ynl.t.u-tokyo.ac.jp/research/backdrive/index.php>. Acesso em: 19 Julho 2011.

BANALA, S. K. et al. Robot Assisted Gait Training With Active Leg Exoskeleton (ALEX). Neural Systems and Rehabilitation Engineering, v. 17, n. 1, p. 2-8, 2009.

BANALA, S. K.; AGRAWAL, S. K.; SCHOLZ, J. P. Active Leg Exoskeleton (ALEX) for Gait Rehabilitation of Motor-Impaired Patients. IEEE International Conference on Rehabilitation Robotics, p. 401-407, 2007.

BARRAS, F. D. Flambagem de Barras. Flambagem de Barras, 2012. Disponivel em: <http://www.fec.unicamp.br/ nilson/apostilas/flambagemdebarras.pdf $>$. Acesso em: 02 Outubro 2012. 
BIONICS, E. Esko Bionics. Battery-powered motors drive the legs, replacing deficient neuromuscular function, 2014. Disponivel em: $<$ http://www.eksobionics.com/ekso>. Acesso em: Dezembro 2014.

BOLTDEPOT. boltdepot. boltdepot, 2015. Disponivel em: $<$ https://www.boltdepot.com/fastener-information/materials-and-grades/bolt-gradechart.aspx>. Acesso em: Fevereiro 2015.

BÜTEFISCH, C. et al. Repetitive training of isolated movements improves the outcome of motor rehabilitation of the centrally paretic hand. Journal of the Neurological Sciences, 18 Dezembro 1994. 59-68.

BUZINELLI, D. V.; MALITE, M. Dimensionamento de elementos estruturais em alumínio. Escola de Engenharia de São Carlos - USP. São Carlos. 2008.

CAIN, S. M.; GORDON, K. E.; FERRIS, D. P. Locomotor adaptation to a powered ankle-foot orthosis depends on control method. Journal of Neuroengineering Rehabilitation, 2007.

CAMERON, A. C. EXCEL 2007: Multiple Regression. Dept. of Economics, Univ. of Calif. - Davis, 2009. Disponivel em: $<\mathrm{http}$ ://cameron.econ.ucdavis.edu/excel/ex61multipleregression.html $>$. Acesso em: 14 Julho 2016.

CARGA, C. D. Celula de Carga. Celula de Carga, 2015. Disponivel em: $<$ http://www.celuladecarga.com.br/portal/?page_id=8>. Acesso em: 2015.

COLLINS, S. H.; WIGGIN, M. B.; SAWICKI, G. S. Reducing the energy cost of human walking using an unpowered exoskeleton. Nature - Macmillan Publishers Limited, 2015.

COLOMBO, G. et al. Treadmill training of paraplegic patients using a robotic orthosis. Journal of Rehabilitation Research and, v. 37, n. 6, p. 693-700, 2000.

COLOMBO, G.; WIRZ, M.; DIETZ, V. Driven gait orthosis for improvement of locomotor training in paraplegic patients. Spinal Cord, v. 39, p. 252-255, 2001.

CORTEZ JUNIOR, M. P. Dispositivo de acoplamento bioinspirado para comutação de acionamentos em juntas robóticas e de exoesqueletos. Escola Politécnica da Universidade de São Paulo. São Paulo, p. 152. 2015. 
CROWNINSHIELD, R. et al. The impedance of the human knee. Journal of Biomechanics, 1976. 529-535.

DEL-AMA, A. J. et al. Online Assessment of Human-Robot Interaction for Hybrid Control of Walking. Sensors, 2012.

DOTMAR. Dotmar. Dotmar, 2015. Disponivel em: $<$ http://www.dotmar.com.au/co-efficient-of-friction.html>. Acesso em: Março 2015.

ENDERLE, J. D.; BLANCHARD, S. M.; BRONZINO, J. D. Introduction to biomedical engineering. 2. ed. San Diego: Elsevier Academic Press, 2005.

ENGINEERING, T. Toolbox Engineering. Toolbox Engineering, 2012. Disponivel em: <http://www.engineeringtoolbox.com/young-modulus-d_417.html $>$. Acesso em: 02 Outubro 2012.

FERRIS, D. P.; SAWICKI, G. S.; DALEY, M. A. A physiologist's perspective on robotic exoskeletons for human locomotion. National Institute of Health, Setembro 2007. 507-528.

GETSCHKO, N. Dimensionamento de elementos rosqueados - Notas de aula. Escola Politécnica da USP. São Paulo. 2010.

GUIZZO, E.; GOLDSTEIN, H. The rise of the boots. IEEE Spectrum, Outubro 2005. 52-56.

HANDBOOK, E. Engineers Handbook. Engineers Handbook, 2015. Disponivel em: <http://www.engineershandbook.com/Tables/frictioncoefficients.htm>. Acesso em: 15 Abril 2015.

HARMONICDRIVE. Harmonic drive. Harmonic drive, 2011. Disponivel em: <www.harmonicdrive.de>. Acesso em: 16 Junho 2011.

HARMONICDRIVE. Catálogo Harmonic Drive. Catálogo Harmonic Drive, 2015. Disponivel em: <http://harmonicdrive.net/media/support/catalogs/pdf/csd-shdcatalog.pdf $>$. Acesso em: 15 Março 2015.

HERMENS, H. J. et al. Development of recommendations for SEMG sensors and sensor placement procedures. Journal of Electromyography and Kinesiology, v. 10, p. 361-374, 2000. 
HERR, A. M. D. E. H. Lower extremity exoskeletons and active orthoses: challenges and state-of-the-art. IEEE Transactions on Robotics, Fevereiro 2008. 144158.

HERR, H. Exoskeletons and orthoses: classification, design challenges and future directions. Journal of Neuroengineering and Rehabilitation, 2009.

HOGAN, N. Impedance Control: An approach to manipulation: Part I, Part II, Part III. Journal of Dynamic Systems, Measurement and Control, 1985. 1-24.

IBGE. IBGE - Indicadores demográficos. IBGE - Indicadores demográficos, 2009.

Disponivel

em:

$<$ http://www.ibge.gov.br/home/estatistica/populacao/indic_sociosaude/2009/indicsaude. pdf $>$. Acesso em: 27 Maio 2012.

IBGE. IBGE - Censo demográfico. IBGE - Censo demográfico, 2012. Disponivel

em:

$<$ http://www.ibge.gov.br/home/presidencia/noticias/08052002tabulacao.shtm>. Acesso em: 27 Maio 2012.

IBGE. Vida de cadeirante. Vida de cadeirante, 2013. Disponivel em: $<$ http://mayconemerson.blogspot.com.br/2013/01/alguns-dados-do-ibge-sobredeficiencia.html>. Acesso em: Novembro 2014.

IBGE. IBGE - Envelhecimento da população. IBGE - Envelhecimento da população, 2014. Disponivel em: $<\mathrm{http}$ //saladeimprensa.ibge.gov.br/noticias?view=noticia\&id=1\&idnoticia=1272\&busca $=1 \& \mathrm{t}=$ ibge-populacao-brasileira-envelhece-ritmo-acelerado $>$. Acesso em: Novembro 2014.

ISHIDA. Ishida. Ishida, 2015. Disponivel em: $<$ http://www.ishida.com/technologies/loadcell/html.html>. Acesso em: Fevereiro 2015.

JAEGER, L. et al. Balancing objects on the feet - an fMRI experiment using the MR-compatible stepper MARCOS. IEEE on Biomedical Robotics and Biomechatronics, Roma, Julho 2012.

KAPANDJI, A. I. Fisiologia Articular. [S.1.]: Medicina Panamericana Editora do Brasil LTDA, v. Volume 2, 2000. 
KAZEROONI, H. Human-robot interaction via the transfer of power and information signals. IEEE Transaction On Systems, Man and Cybernetics., v. 2, p. 450-463, 1990.

KONG, K.; JEON, D. Design and control of an exoskeleton for the elderly and patients. IEEE/ASME Transactions on Mechatronics, v. 11, p. 428-432, Agosto 2006. ISSN 4.

KOOPMAN, B. et al. Rendering potential wearable robot designs with the LOPES gait trainer. Rehabilitation Robotics, p. 978-983, 2011.

KRAKAUER, J. W. et al. Getting neurorehabilitation right: What can be learned from animal models? Neurorehabilitation and Neural Repair, 30 Março 2012. 1-9.

KREBS, H. I. et al. Robot-Aided Neurorehabilitation. IEEE Transactions on Rehabilitation Engineering, 1 Março 1998. 75-87.

KUO, A. D.; DONELAN, J. M.; RUINA, A. Energetic consequences of walking like an inverted pendulum: step-to-step transitions. Exerc Sport Sci Rev, v. 33, p. 88-97, 2005.

LAMBRECHT, B. G. A.; KAZEROONI, H. Design of a semi-active knee prosthesis. IEEE International Conference on Robotics and Automation, Kobe, Japão, Maio 2009.

LEE, H. et al. Static Ankle Impedance in Stroke and Multiple Sclerosis: A Feasibility Study. IEEE on Engineering in Medicine and Biology Society, Boston, Massachusetts EUA, September 2011.

LEE, H.; KREBS, H. I.; HOGAN, N. Multivariable Dynamic Ankle Mechanical Impedance With Active Muscles. IEEE TRANSACTIONS ON NEURAL SYSTEMS AND REHABILITATION ENGINEERING, v. 22, p. 971-981, Setembro 2014. ISSN 5 .

LENZI, T. et al. NEUROExos: a variable impedance powered elbow exoskeleton. International Conference on Robotics and Automation, Shanghai, 13 Maio 2011. 1419-1426. 
LÜNENBURGER, L. et al. Biofeedback in gait training with the robotic orthosis Lokomat. IEEE on Engineering in Medicine and Biology Society, São Francisco, CA, EUA, 2004.

MALCOLM, P. et al. A Simple Exoskeleton That Assists Plantarflexion Can Reduce the Metabolic Cost of Human Walking. PLoS ONE, 2013.

MAXON. Motores Maxon. Motores Maxon, 2011. Disponivel em: $<$ http://www.maxonmotor.com/maxon/view/content/>. Acesso em: 16 Junho 2011.

MÉDICO, E. Empório Médico. Empório Médico, 2012. Disponivel em: $<$ http://www.emporiomedico.com.br/loja/products.php?product=DL-740-TUTORPLASTICO-PARA-FRATURA-DA-T\%EDBIA-DILEPE $>$. Acesso em: 02 Setembro 2012.

MERTZ, L. The next generation of exoskeletons. IEEE Pulse, Agosto 2012. 5661.

MOONEY, L. M.; ROUSE, E. J.; HERR, H. M. Autonomous exoskeleton reduces metabolic cost of human walking during load carriage. Journal of NeuroEngineering and Rehabilitation, 2014.

NOGUEIRA, S. L. et al. Markov Jump Linear Systems-Based Position Estimation for Lower Limb Exoskeletons. Sensors, 2014.

NPFASTENERS. NPfasteners. NPfasteners, 2015. Disponivel em: $<$ http://www.npfasteners.com/pdfs/max-rec-tightening-torque.pdf $>$. Acesso em: 09 Abril 2015.

NSK. NSK. NSK, 2015. Disponivel em: <http://nskjp.partcommunity.com/portal/portal/nsk-jp>. Acesso em: Fevereiro 2015.

OLAYA, A. F. R. Sistema robótico multimodal para análisis y estudios en biomecánica, movimiento humano y control neuromotor - Doutorado. Universidad Carlos III. [S.1.]. 2008.

OUTSIDE, T. F. S. Two feet stuck outside. Two feet stuck outside, 2011. Disponivel em: <http://twofeetstuckoutside.blogspot.com.br/2010/07/to-plantarflex-todorsiflex.html>. Acesso em: 15 Junho 2011. 
PACHLER, C.; YABUKI, D. K. Implementação de um controle de impedâncias modular para um exoesqueleto robótico de membro superior Trabalho de conclusão de Curso. Escola Politécnica da USP. São Paulo. 2014.

PONS, J. L. Wearable Robots: Biomechatronic Exoskeletons. [S.1.]: John Wiley \& Sons, 2008.

ROUSE, E. J. Rouse, Elliott J. Rouse, Elliott J., 2015. Disponivel em: $<$ http://www.elliottjrouse.com/doctoral-research/>. Acesso em: Abril 2015.

ROY, A. et al. Measurement of Human Ankle Stiffness Using the Anklebot. International Conference on Rehabilitation Robotics, Noordwijk, June 2007. 356363.

ROY, A. et al. Anklebot-Assisted Locomotor Training After Stroke: A Novel deficit-adjusted control approach. International Conference on Robotics and Automation (ICRA), Karlsruhe, Maio 2013. 2175-2182.

RUIZ A.F., R. E. . F.-C. A. Exoskeleton-Based Robotic Platform Applied in Biomechanical Modelling. Applied Bionics and Biomechanics, p. 205-216, 2009.

SHIGLEY, J. E.; MISCHKE, C. R.; BUDYNAS, R. G. Projeto de Engenharia Mecânica. $7^{\text {a }}$ ed. [S.1.]: Bookman, 2005.

SOUIT, C. et al. Design of a knee ankle robotic exoskeleton to induce pertubations during gait. Congress of Mechanical Engineering (COBEM), Ribeirão Preto, Novembro 2013. 9426-9436.

SOUIT, C. et al. Design of a lower limb exoskeleton for experimental research on gait control. International Conference on Biomedical Robotics and Biomechatronics, Sigapore, Junho 2016. 1098 - 1103.

SOUIT, C.; MALGUEIRO, L. L. Exoesqueleto ativo de membro inferior para o estudo do controle motor humano. Escola Politécnica da Universidade de São Paulo. São Paulo. 2012.

STRICKLAND, E. Good-bye wheelchair. IEEE Spectrum, 2012. 30-33.

SUCH, C. et al. Quantitative study of stiffness in the knee joint. Annals of the Rheumatic Diseases, 1975. 286-291. 
SUTHERLAND, D. H. The evolution of clinical gait analysis part I: kinesiological EMG. Gait Posture., v. 14, n. 1, p. 61-70, 2001.

SYSTEMS, A. M. Automated Motion Systems. Automated Motion Systems, 2014. Disponivel em: <http://www.automotsys.com.au/encodersmc.html $>$. Acesso em: Novembro 2014.

TAI, C.; ROBINSON, C. Knee elasticity influenced by joint angle and perturbation intensity. IEEE Transactions on Rehabilitation Engineering, 1999. 111115.

TALATY, M.; ESQUENAZI, A.; BRICENO, J. E. Differentiating Ability in Users of the ReWalk Powered Exoskeleton. IEEE International Conference on Rehabilitation Robotics, Seattle, 24-26 June 2013.

TUCKER, M. R. et al. Design of a Wearable Perturbator for Human Knee Impedance Estimation during Gait. IEEE International Conference on Rehabilitation Robotics, Seattle, Washington EUA, Junho 2013.

VENEMAN, J. F. et al. Design and Evaluation of the LOPES Exoskeleton Robot for Interactive Gait Rehabilitation. Neural Systems and Rehabilitation Engineering, v. 15, n. 3, p. 379-386, 2007.

VICK. Vick Plásticos e Metais. Vick Plásticos e Metais, 2012. Disponivel em: $<$ http://www.vick.com.br/vick/novo/datasheets/datasheet-pead.pdf $>$. Acesso em: 18 Agosto 2012.

WEHNER, M. et al. A Lightweight Soft Exosuit for Gait Assistance. IEEE International Conference on Robotics and Automation (ICRA), Karlsruhe, Alemanhã, 2013.

WIGGIN, M. B.; SAWICKI, G. S.; COLLINS, S. H. An Exoskeleton Using Controlled Energy Storage and Release to Aid Ankle Propulsion. IEEE International Conference on Rehabilitation Robotics, 2011.

WINTER, D. A. Biomechanics and motor control of human movement. Primeira edição. ed. New Jersey: John Wiley \& Sons Inc., 1990.

WINTER, D. A. Biomechanics and motor control of human movement. Quarta edição. ed. New Jersey: John Wiley \& Sons Inc., 2005. 
ZHANG, L. et al. In vivo human knee joint dynamic properties as functions of muscle contraction and joint position. Journal of Biomechanics, 1998.

ZOSS, A. B. . H. E. C. A. Biomechanical Design of the Berkeley Lower Extremity Exoskeleton (BLEEX). IEEE/ASME Transactions on mechatronics, v. 11, p. 128-138, Abril 2006. ISSN 2.

ZOSS, A. et al. Human machine interface for human exoskeleton. US Patent 2013/0231595 A1, 5 Setembro 2013. 


\section{A - Cálculo do atrito - módulo atuador do Protótipo I}

Para o cálculo do atrito entre as hastes de alumínio, considera-se a força normal (N) proveniente dos 3 parafusos M5 zincados, usados na fixação entre a redução e a haste móvel. Segundo (SHIGLEY, MISCHKE e BUDYNAS, 2005), a força normal de um parafuso é função do torque de aperto:

$$
N=\frac{T}{K * d}
$$

Onde:

$T=$ Torque de aperto $=2,7 \mathrm{Nm}($ NPFASTENERS, 2015)

$K=$ Coeficiente de torque $=0,20$ para parafusos zincados (SHIGLEY, MISCHKE e BUDYNAS, 2005)

$d=$ Diâmetro nominal do parafuso $=5 \mathrm{~mm}(\mathrm{M} 5)$

Assim, a força normal de aperto é:

$$
N=\frac{T}{K * d}=\frac{2,7}{0,2 * 5 * 10^{-3}}=2,7 * 10^{3} N
$$

O torque resistivo devido à força de atrito é calculado pela força de atrito vezes a distância média do centro de rotação à força de atrito $(25 \mathrm{~mm})$ :

$$
T_{a t r}=F_{a t r} * D_{F a t}=N * \mu_{a l / a l} * 25 * 10^{-3}
$$

Onde:

$N=$ Força normal de aperto

$\mu_{a l / a l}=$ Coeficiente de atrito dinâmico entre alumínio e alumínio $=1,4$ (HANDBOOK, 2015)

Assim:

$$
T_{\text {atr }}=2,7 * 10^{3} * 1,4 * 25 * 10^{-3}=94,5 \mathrm{Nm}
$$

$\mathrm{Na}$ prática, os parafusos foram montados com aproximadamente $0,5 \mathrm{Nm}$ e, por isso, o torque resistivo causado pelo atrito $(17,5 \mathrm{Nm})$ não ultrapassa o torque fornecido pelo módulo atuador $(62 \mathrm{Nm})$ pois a haste móvel se mexe no protótipo I. De qualquer forma, o cálculo mostra que a força de atrito é considerável e é necessário eliminar esse desperdício de energia. 


\section{B - Cálculo da força axial gerada pelo Harmonic Drive}

A força axial gerada pelo Harmonic Drive é calculada por (HARMONICDRIVE, 2015):

$$
F=2 * \frac{T}{D} * 0,07 * \tan 20^{\circ}+2 \mu P F
$$

Onde:

$F=$ Força axial gerada pelo Harmonic Drive em funcionamento

$T=$ Torque de saída $=0,387 * 160 \cong 62 \mathrm{Nm}$

$D=$ Tamanho do Harmonic Drive *0,00254= $25 * 0,00254=0,0635 \mathrm{~m}$

$2 \mu P F=$ Fator tabelado que depende do tamanho da redução $=9,8 \mathrm{Nm}$

Assim, tem-se:

$$
F=2 * \frac{62}{0,0635} * 0,07 * \tan 20^{\circ}+9,8 \leftrightarrow F=59,55 N \leftrightarrow F=60 N
$$

O módulo atuador do protótipo I fixa o Flexspline apenas por uma superfície de $2 \mathrm{~mm}$ de espessura de PEAD. O atrito gerado pelo contato do Flex Spline e a caixa da redução é dado por:

$$
F_{\text {atr }}=60 * \mu
$$

Onde:

$\mu=$ Coeficiente de atrito dinâmico entre o aço e o PEAD = 0,2 (DOTMAR, 2015)

$$
F_{\text {atr }}=60 * 0,2=12 \mathrm{~N}
$$

O torque resistivo gerado pelo atrito é uma dissipação de energia desnecessária e é calculado por:

$$
T_{a t r}=F_{a t r} * b
$$

Onde:

$b=$ Braço entre a força de atrito e o centro de rotação $=26,5 \mathrm{~mm}$

$$
T_{\text {atr }}=12 * 26,5 * 10^{-3}=0,32 \mathrm{Nm}
$$




\section{C - Dimensionamento do eixo de saída (módulo atuador)}

Com o objetivo de manter o mesmo comprimento transversal do módulo atuador do Protótipo I, optou-se por conectar a haste a ser movida diretamente no eixo de saída por meio de uma chapa de inox. Para tanto, o diâmetro do eixo deve ser tal que os parafusos suportem a força cortante. Os cálculos para o dimensionamento do eixo são apresentados a seguir .

Dados:

- Limite de escoamento do parafuso: 57000psi $\cong 390 \mathrm{MPa}$ (BOLTDEPOT, 2015)

- Coeficiente de segurança (CS) adotado: 2

- Tensão de cisalhamento máxima admissível sobre o parafuso: $\tau_{a d m}=\frac{\tau_{e s c}}{C S}=$ $\frac{390 M p a}{2}=195 \mathrm{Mpa}$

- Tensão de cisalhamento sobre o parafuso: $\tau_{a d m}=\frac{F}{A}$

- F - Força cortante sobre o parafuso: $F=\frac{T}{R}$, onde $T$ é o torque de saída da redução (62Nm) e $R$ é o raio de posicionamento

- $A$ - área dos parafusos suportando a carga: $A=n * \pi * \frac{d^{2}}{4}$, onde $n$ é o número de parafusos e $d$ é o diâmetro dos parafusos. Pela montagem do conjunto, optou-se por utilizar 3 parafusos M5 (o mesmo utilizado para fixar o Flexspline).

Assim, o raio de posicionamento dos parafusos é dado por:

$$
R_{\text {mínimo }}=\frac{T}{F}=\frac{T}{\tau_{a d m} * A}=\frac{T}{\tau_{a d m} * n * \pi * \frac{d^{2}}{4}}=\frac{62}{195 * 10^{6} * 3 * \pi * \frac{\left(5 * 10^{-3}\right)^{2}}{4}} \cong 5,4 \mathrm{~mm}
$$

Assim, optou-se por posicionar os parafusos com $R=7,5 \mathrm{~mm}$ e o diâmetro do eixo de saída ficou em $D=25 \mathrm{~mm}$. Em relação ao comprimento de rosca, há a seguinte recomendação:

$$
t=\text { comprimento da rosca } \geq 0,8 * d=0,8 * 5=4 \mathrm{~mm}
$$
(GETSCHKO, 2010). Seguindo essa recomendação, os comprimentos de rosca para os parafusos M5 são $5 \mathrm{~mm}$. 


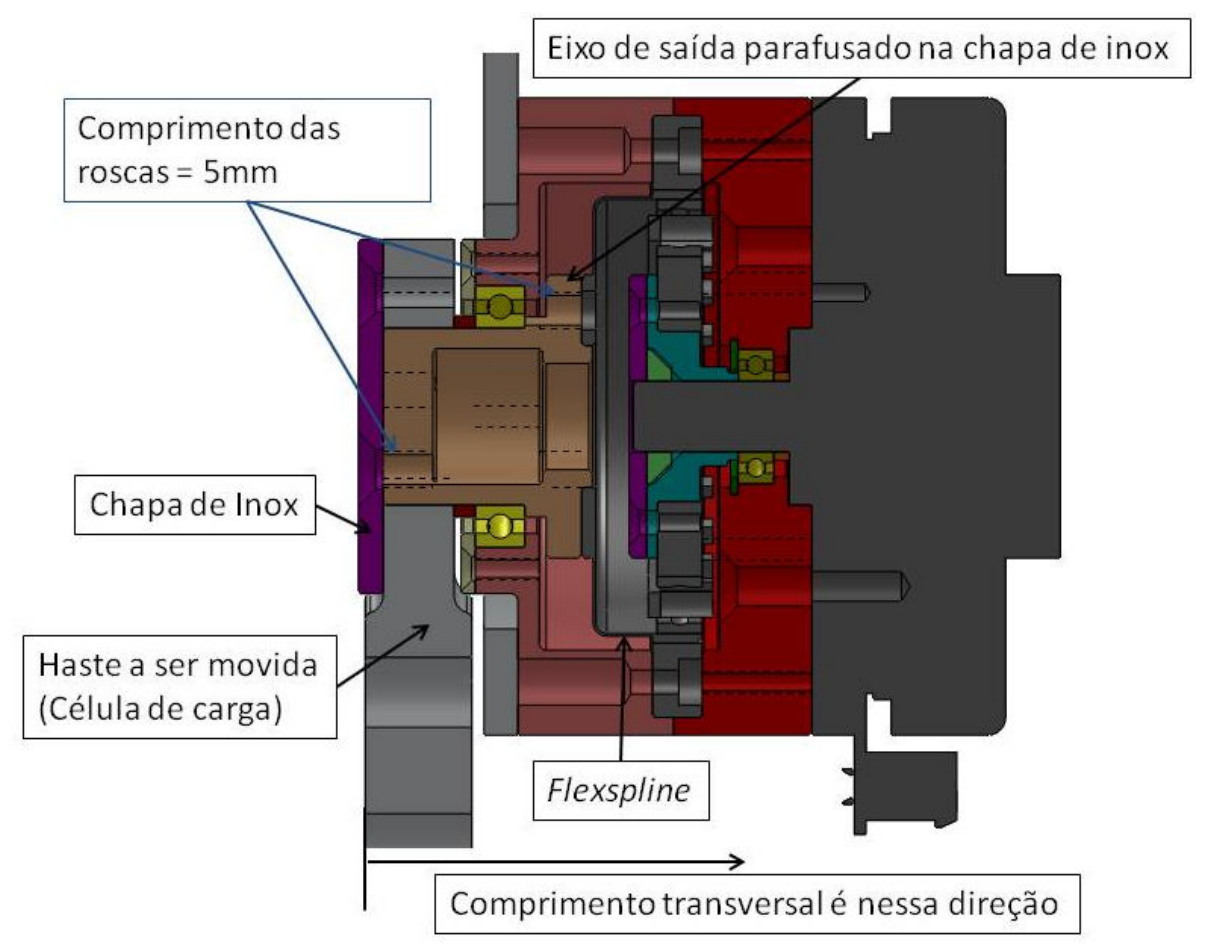

Figura 78: Fixação entre o eixo de saída e a haste a ser movida (vista em corte). 


\section{D - Cálculo do atrito - acoplamento motor e redução}

Para garantir que não haja escorregamento, o torque gerado pelo atrito entre as peças "Anel de pressão" e o eixo do motor deve ser, no mínimo, duas vezes o torque de saída do motor (coeficiente de segurança igual a $2: T_{\text {atrito }} \geq 2 * T_{\text {motor }}=2 * 0,387 \cong$ $0,8 \mathrm{Nm})$. O torque de atrito é calculado a seguir:

$$
T_{\text {atrito }}=F_{\text {atrito }} * R_{\text {motor }}=\mu_{\text {al } / \text { aço }} * F_{\text {radial }} * R_{\text {motor }}
$$

Onde:

- $\mu_{a l / a c ̧ o}=$ coeficiente de atrito estático entre o alumínio e o aço $=0,61$ (HANDBOOK, 2015)

- $R_{\text {motor }}=$ raio do eixo do motor $=5 \mathrm{~mm}$

- $F_{\text {radial }}=$ força radial gerada pela compressão da peça “Acoplamento motor 2".

A figura a seguir ilustra a decomposição das forças e como a $F_{\text {radial }}$ é obtida.

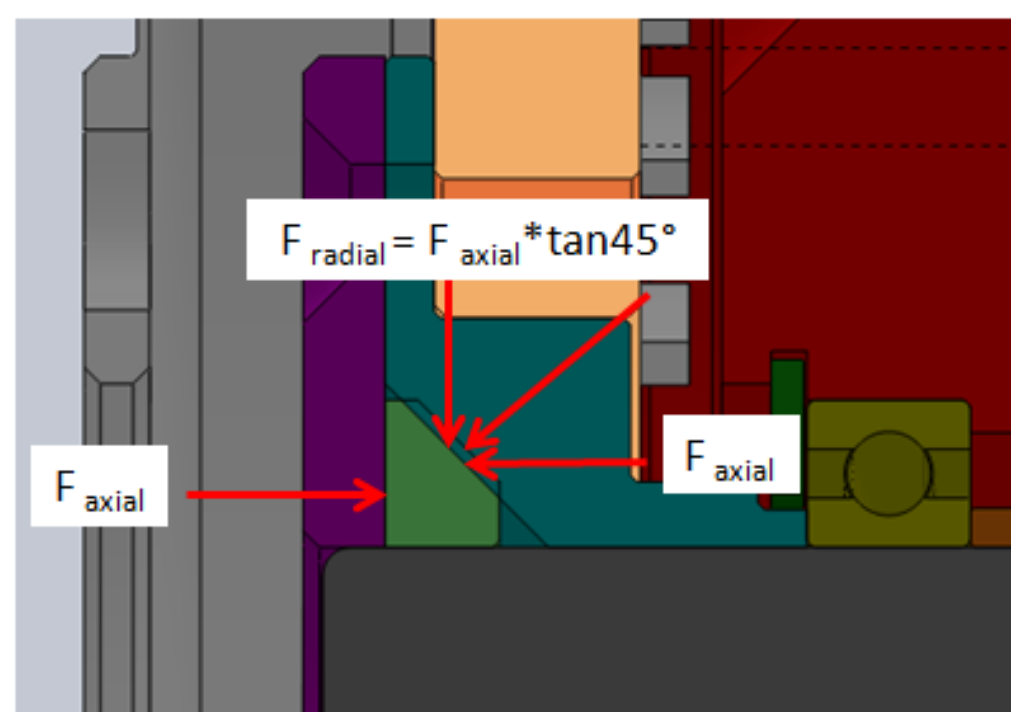

Figura 79: Detalhe no contato entre as peças: decomposição de forças.

- $F_{\text {axial }}=$ força axial gerada pela deformação da peça "Acoplamento motor 2".

Sabe-se que: $\sigma=E * \varepsilon$ e que $\sigma=\frac{F_{\text {axial }}}{A}$ (SHIGLEY, MISCHKE e BUDYNAS, 2005), portanto:

$$
F_{\text {axial }}=E * \varepsilon * A
$$

Onde: 
- $E=$ Módulo de elasticidade do alumínio $=70 G P a(B U Z I N E L L I$ e MALITE, 2008)

- $\varepsilon=$ Deformação axial $=\frac{l_{0}-l}{l_{0}}=\frac{4-3,5}{4}=0,125$

- $A$ = área de contato axial $=\frac{\pi *\left(D^{2}-d^{2}\right)}{4}=\frac{\pi *\left(20^{2}-10^{2}\right)}{4} \cong 236 \mathrm{~mm}^{2}$

Assim, a força axial é dada por:

$$
F_{\text {axial }}=70 * 10^{9} * 0,125 * 236 * 10^{-6} \cong 2 * 10^{6} \mathrm{~N}
$$

O torque de atrito é dado por:

$$
\begin{gathered}
T_{\text {atrito }}=\mu_{\frac{\text { al }}{\text { aço }}} * F_{\text {radial }} * R_{\text {motor }}=\mu_{\text {al } / \text { aço }} * F_{\text {axial }} * \text { tan } 45^{\circ} * R_{\text {motor }} \\
T_{\text {atrito }}=0,61 * 2 * 10^{6} * 1 * 5 * 10^{-3}=6,1 * 10^{3} \mathrm{Nm}
\end{gathered}
$$

O valor calculado supera muito o valor mínimo admissível para o torque de atrito. Assim, tem-se a garantia de que não haverá escorregamento. 


\section{E - Simulação por elementos finitos - Estrutura Protótipo II}

Por simulação em elementos finitos foi possível determinar a rigidez da estrutura do protótipo II no caso mais crítico: módulo do tornozelo posicionado na distância máxima em relação ao joelho. As condições de contorno da simulação foram: a fixação da estrutura no joelho e uma carga de $30 \mathrm{~N}$ transversal ao pé a qual representa a força do usuário no movimento de inversão (KAPANDJI, 2000). A rigidez transversal encontrada na estrutura do Protótipo II foi de $0,75 \mathrm{~N} / \mathrm{mm}$. As próximas figuras mostram a aplicação das condições de contorno da simulação e o resultado da deformação.

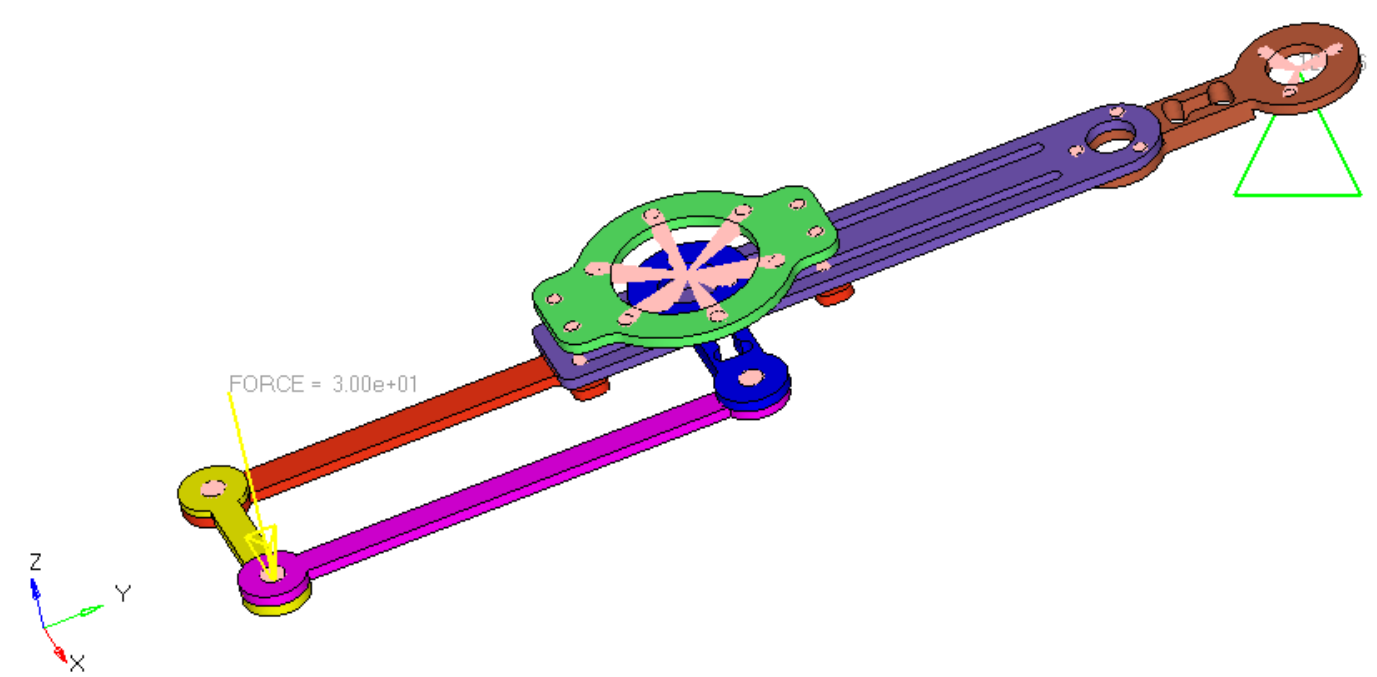

Figura 80: Condição de contorno da simulação - rigidez transversal da estrutura do módulo do tornozelo.

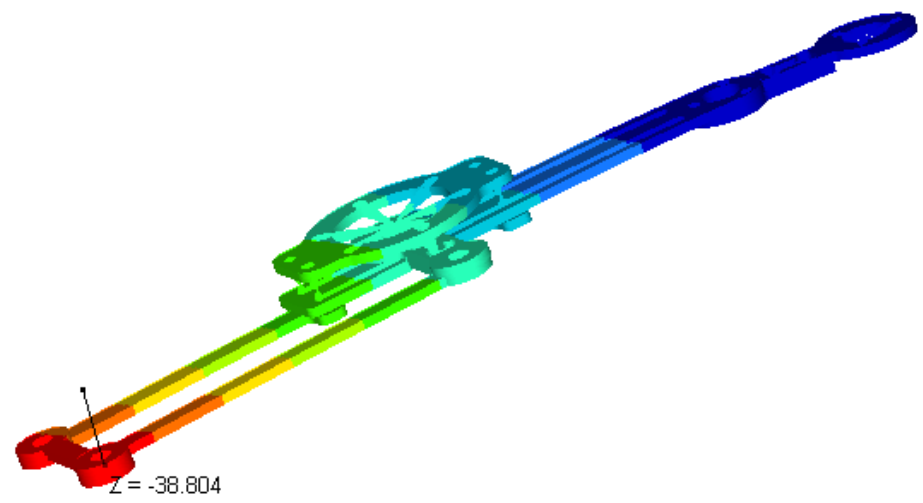

Figura 81: Resultado da análise - deslocamento de aprox 40mm para a aplicação de uma carga de $30 \mathrm{~N}$. 


\section{F - Células de carga - Protótipos I e II}

Analisando a haste do joelho do Protótipo I por elementos finitos, é possível visualizar as deformações desiguais observadas nos quatro extensômetros. As condições de contorno da análise foram a restrição de movimento na região de fixação do motor e uma carga de $300 \mathrm{~N}$ aplicada no ponto médio do acoplamento com a canela (o que representaria uma força contrária ao movimento aplicada pelo usuário sobre o exoesqueleto - força de interação).

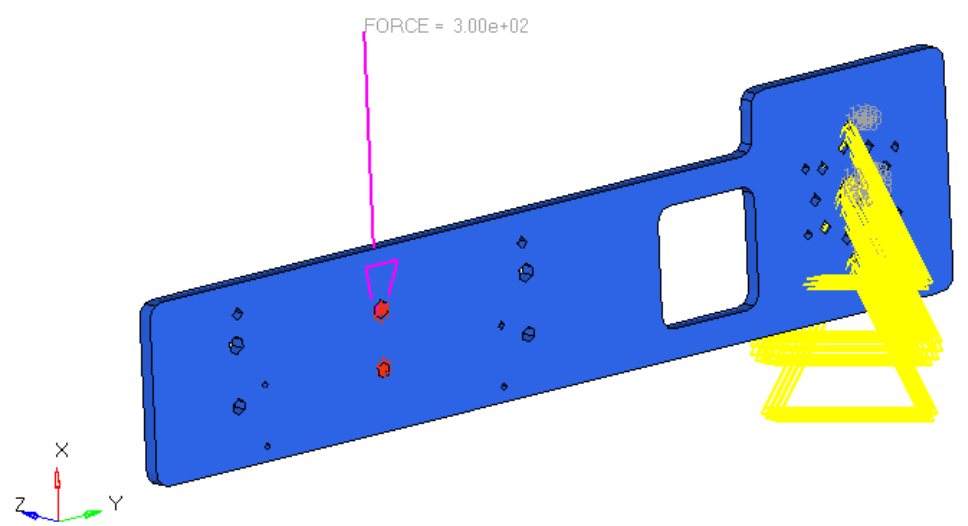

Figura 82: Condições de contorno da análise em elementos finitos da haste da canela do protótipo I.

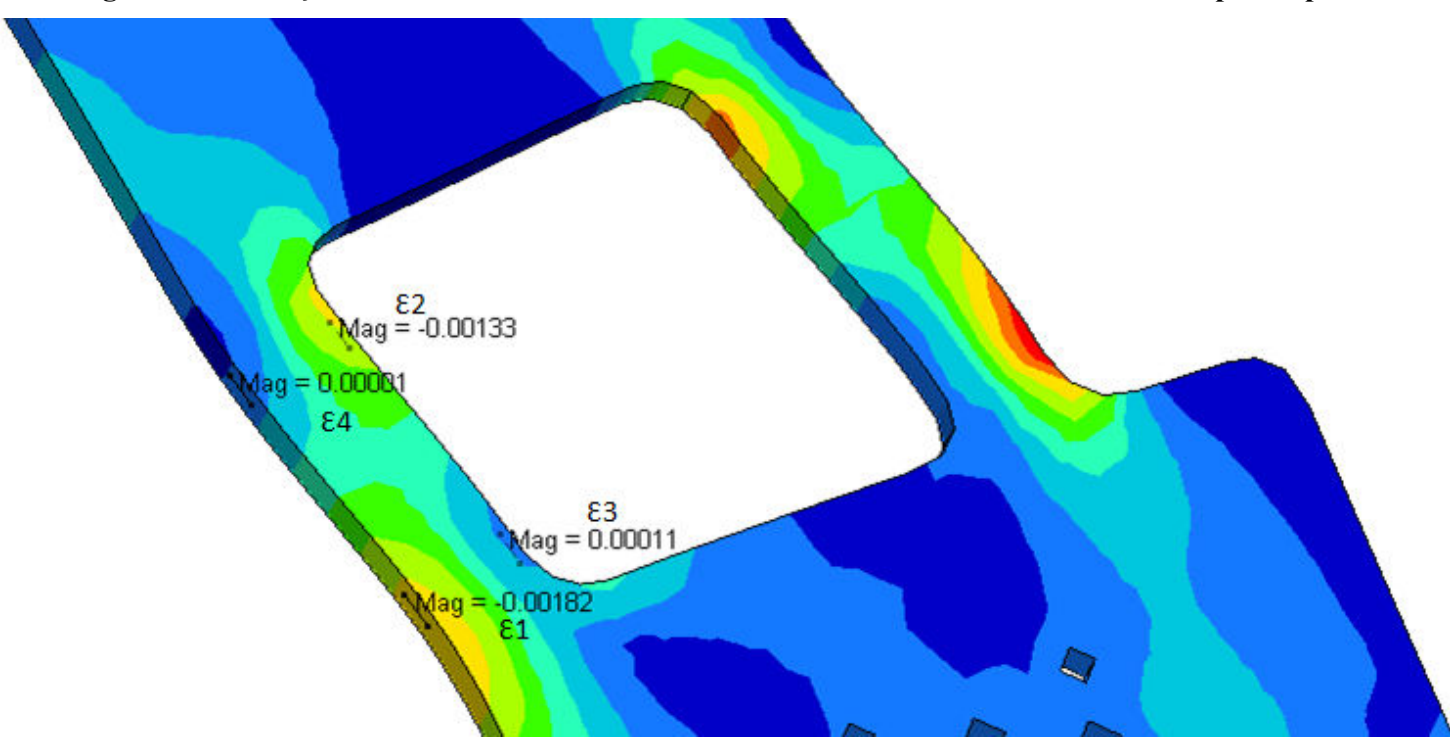

Figura 83: Deformações observadas na análise em elementos finitos da "haste da canela" - protótipo I

As células de carga são do Protótipo II são peças substituíveis, idênticas e simétricas. A análise em elementos finitos mostra que as deformações observadas pelos quatro extensômetros são iguais. As condições de contorno da análise são a fixação nas 
seis direções de um lado e a aplicação de uma carga de 300N de outro, conforme ilustra a próxima figura.

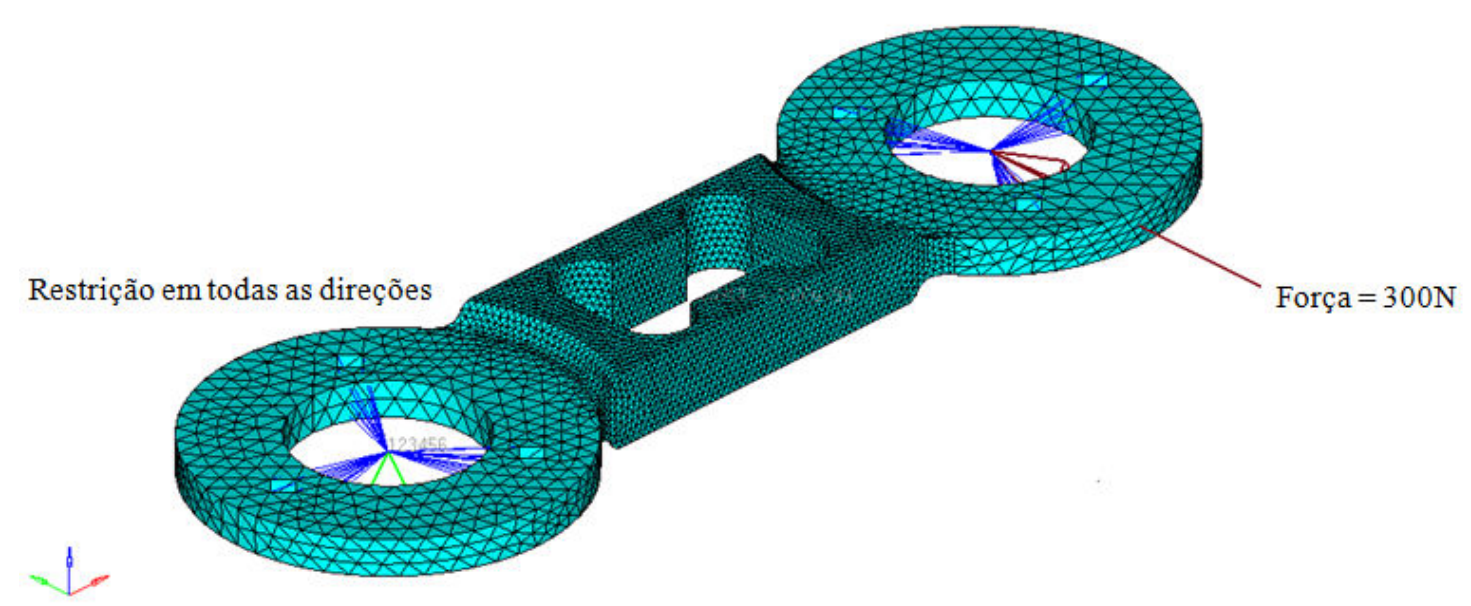

Figura 84: Condições de contorno da análise de elementos finitos da célula de carga do Protótipo II.

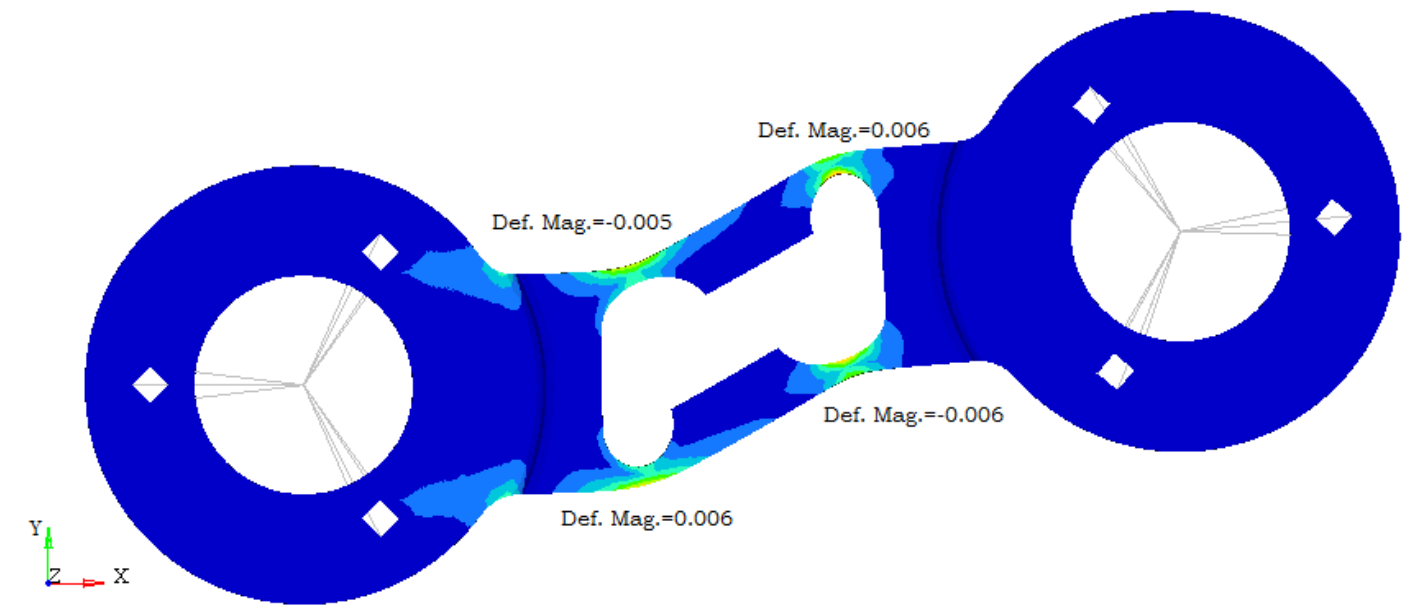

Figura 85: Resultado da análise - deformações iguais observadas pelos quatro extensômetros. 


\section{G - Cálculo do parâmetro de impedância inercial do exoesqueleto}

O parâmetro inercial do exoesqueleto $\left(J_{\text {exo }}\right)$ pode ser calculado por meio das informações de massa e geometria, conforme a equação a seguir (SHIGLEY, MISCHKE e BUDYNAS, 2005):

$$
J_{\text {exo }}=\frac{m_{h}\left(a^{2}+b^{2}\right)}{12}+m_{h}\left(\frac{b}{2}\right)^{2}+m_{a} b^{2}
$$

Onde:

$m_{h}=$ massa da peça "haste da canela" $=0,106 \mathrm{~kg}$

$a=$ largura da peça "haste da canela" $=0,040 \mathrm{~m}$

$b=$ comprimento total do sistema em rotação $=0,339 \mathrm{~m}$

$m_{a}=$ massa adicional aplicada na extremidade da haste da canela.

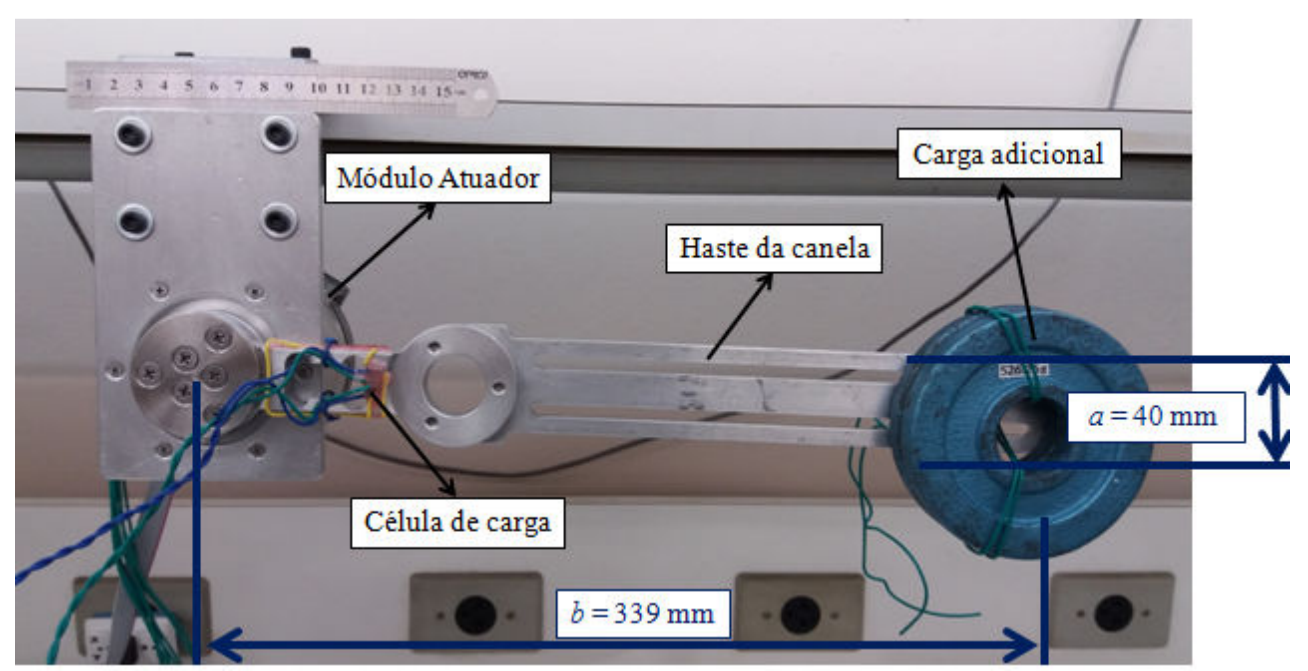

Figura 86: Disposição dos equipamentos para o teste em bancada do módulo do joelho com as dimensões para o cálculo do momento de inércia.

Foram realizados cinco experimentos variando a carga adicional, portanto, para cada experimento, há um valor diferente para o parâmetro inercial. A tabela a seguir mostra o valor de cada $J_{\text {exo }}$ para cada experimento. 
Tabela 10: Parâmetros inercial do exoesqueleto para cada experimento.

\begin{tabular}{|c|c|c|}
\hline Experimento & $\begin{array}{c}\text { Carga Adicional }\left(\boldsymbol{m}_{\boldsymbol{a}}\right) \\
{[\mathbf{k g}]}\end{array}$ & $\begin{array}{c}\text { Parâmetro inercial } \\
\left(\boldsymbol{J e x o}_{\boldsymbol{o}}\right)\left[\mathbf{k g m}^{\mathbf{2}}\right]\end{array}$ \\
\hline 1 & 0,000 & 0,004 \\
\hline 2 & 0,528 & 0,065 \\
\hline 3 & 1,039 & 0,123 \\
\hline 4 & 1,568 & 0,184 \\
\hline 5 & 2,094 & 0,245 \\
\hline
\end{tabular}




\section{H - Regressão para cálculos dos parâmetros inerciais do exoesqueleto}

Com os dados experimentais disponíveis $\left(J_{\text {exo }}, \tau, \theta, \dot{\theta}\right.$ e $\left.\ddot{\theta}\right)$ os parâmetros $B_{\text {exo }} \mathrm{e}$ $K_{\text {exo }}$ podem ser obtidos por regressão. Neste trabalho, a regressão foi feita por meio da ferramenta "Análise de Dados", disponível no Excel 2007. Utilizando o modelo da equação diferencial:

$$
\tau_{\text {exo }}=J_{\text {exo }} \ddot{\theta}+B_{\text {exo }} \dot{\theta}+K_{\text {exo }} \theta
$$

a equação foi simplificada para o cálculo da regressão:

$$
\tau_{\text {exo }}-J_{\text {exo }} \ddot{\theta}=B_{\text {exo }} \dot{\theta}+K_{\text {exo }} \theta
$$

onde as incógnitas são $B_{\text {exo }}$ e $K_{\text {exo }}$.

A regressão utilizada é linear (CAMERON, 2009). Sessenta conjuntos de dados foram usados para cada cálculo. A escolha desses sessenta pontos é feita pela sincronização das medições da célula de carga e do encoder. As próximas figuras ilustram a utilização dessa ferramenta de regressão.

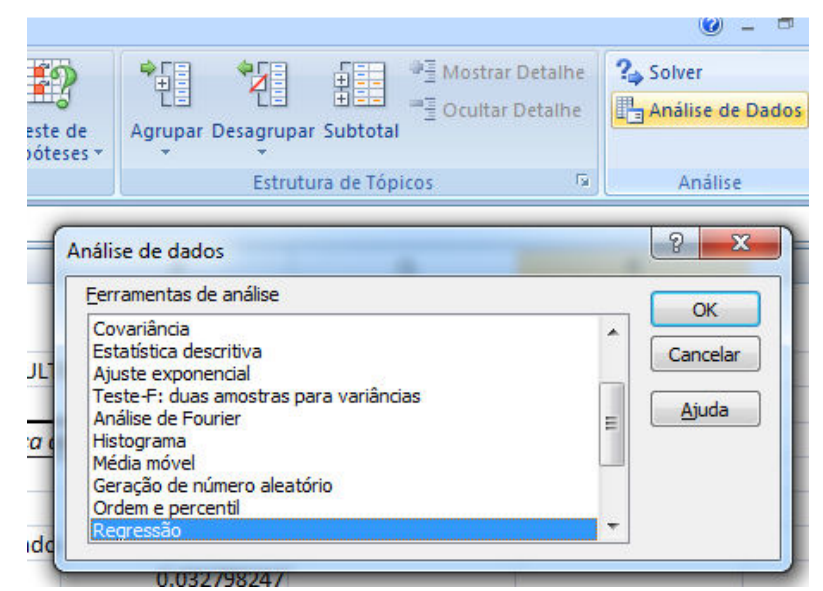

Figura 87: Ferramenta de regressão disponível em "Análise de Dados" do Excel 2007. 


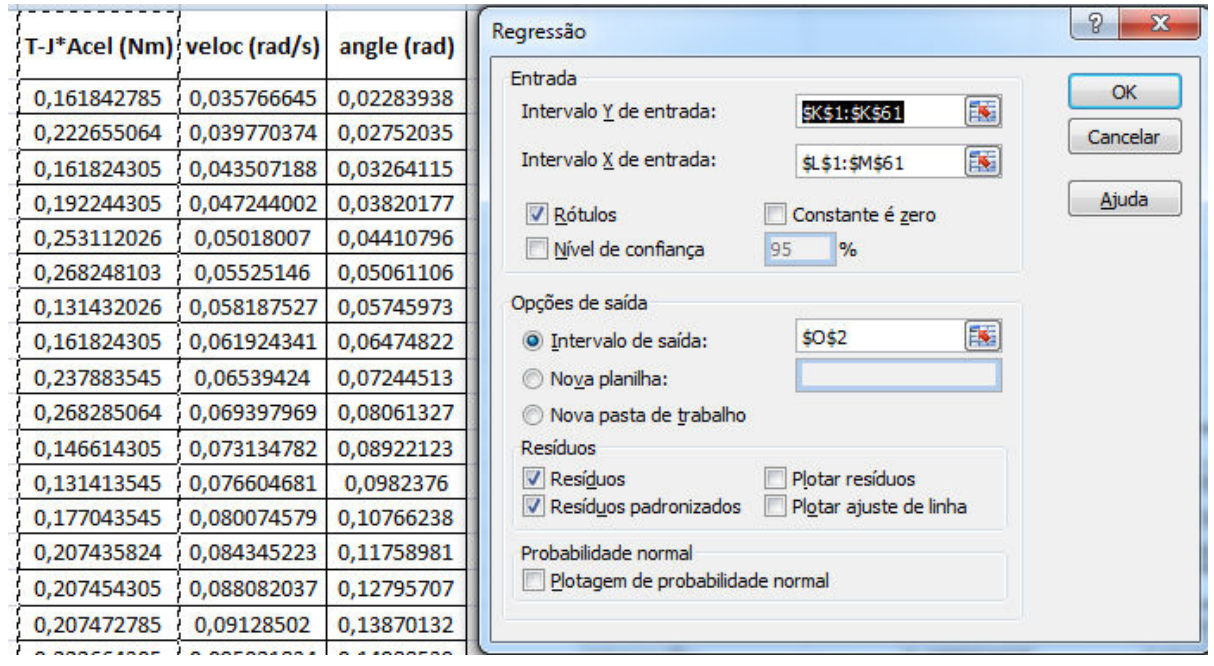

Figura 88: Seleção dos dados para o cálculo da regressão.

\begin{tabular}{|c|c|c|c|c|c|}
\hline \multicolumn{6}{|c|}{ RESUMO DOS RESULTADOS } \\
\hline \multicolumn{6}{|c|}{ Estatistica de regressão } \\
\hline R múltiplo & 0,700847261 & & & & \\
\hline R-Quadrado & 0,491186883 & & & & \\
\hline R-quadrado ajustado & 0,473333791 & & & & \\
\hline Erro padrão & 0,032798247 & & & & \\
\hline Observações & 60 & & & & \\
\hline \multicolumn{6}{|l|}{ ANOVA } \\
\hline & $g l$ & $S Q$ & $M Q$ & $F$ & Fde significação \\
\hline Regressão & 2 & 0,059192214 & 0,029596107 & 27,51270693 & $4,33423 \mathrm{E}-09$ \\
\hline Resíduo & 57 & 0,061316326 & 0,001075725 & & \\
\hline \multirow[t]{2}{*}{ Total } & 59 & 0,12050854 & & & \\
\hline & Coeficientes & Erro padrão & Stat $t$ & valor- $P$ & $95 \%$ inferiores \\
\hline Interseção & 0,188952428 & 0,01468308 & 12,86871905 & $1,66563 \mathrm{E}-18$ & 0,159550069 \\
\hline $\operatorname{veloc}(\mathrm{rad} / \mathrm{s})$ & 0,255736005 & 0,132264042 & 1,933526308 & 0,058143004 & $-0,009118169$ \\
\hline angle (rad) & $-0,151636217$ & 0,0235118 & $-6,449366467$ & 2,61567E-08 & $-0,198717784$ \\
\hline
\end{tabular}

Figura 89: Formato da apresentação dos resultados da regressão. 
Anexos - Desenhos Técnicos 

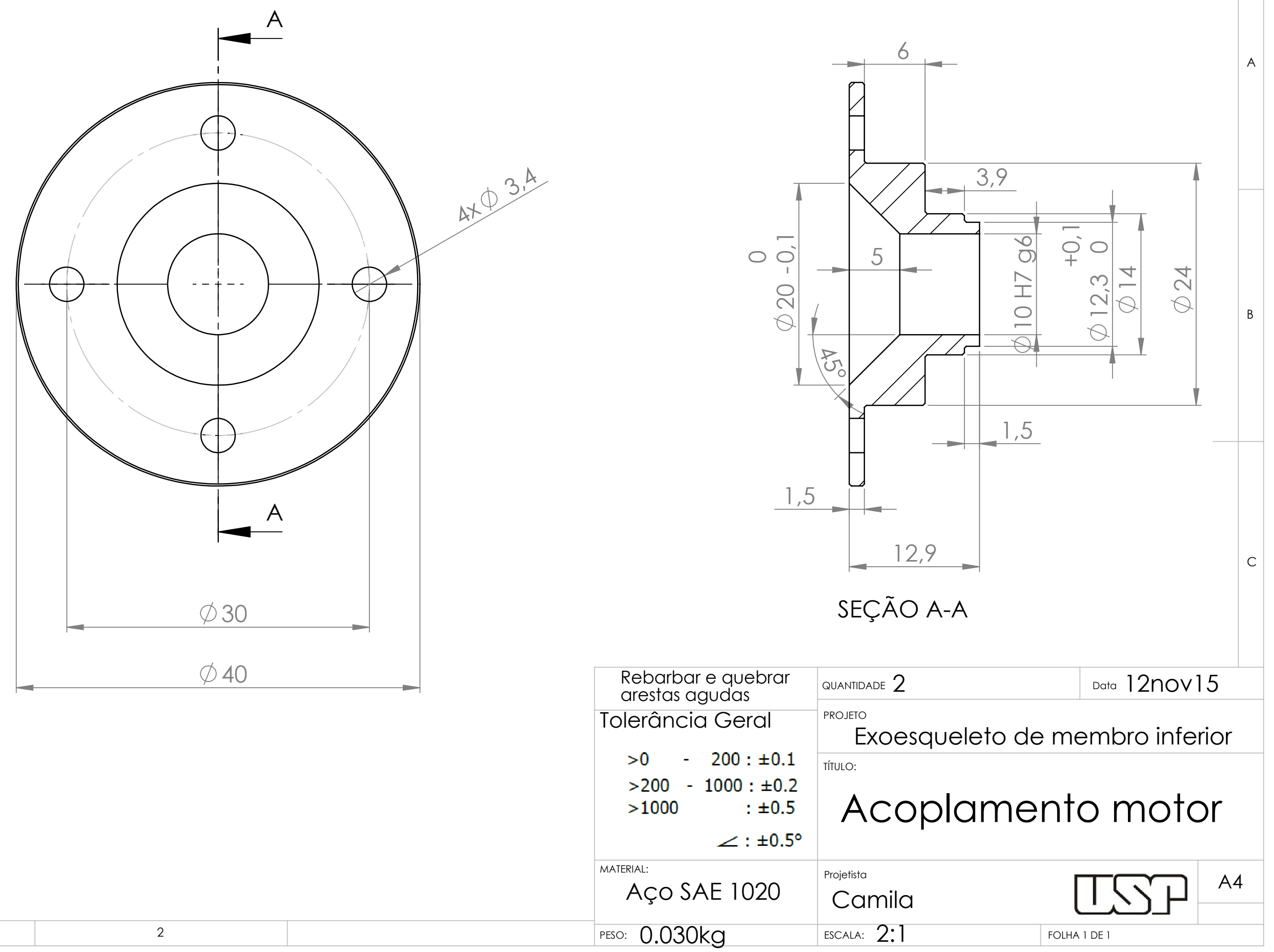

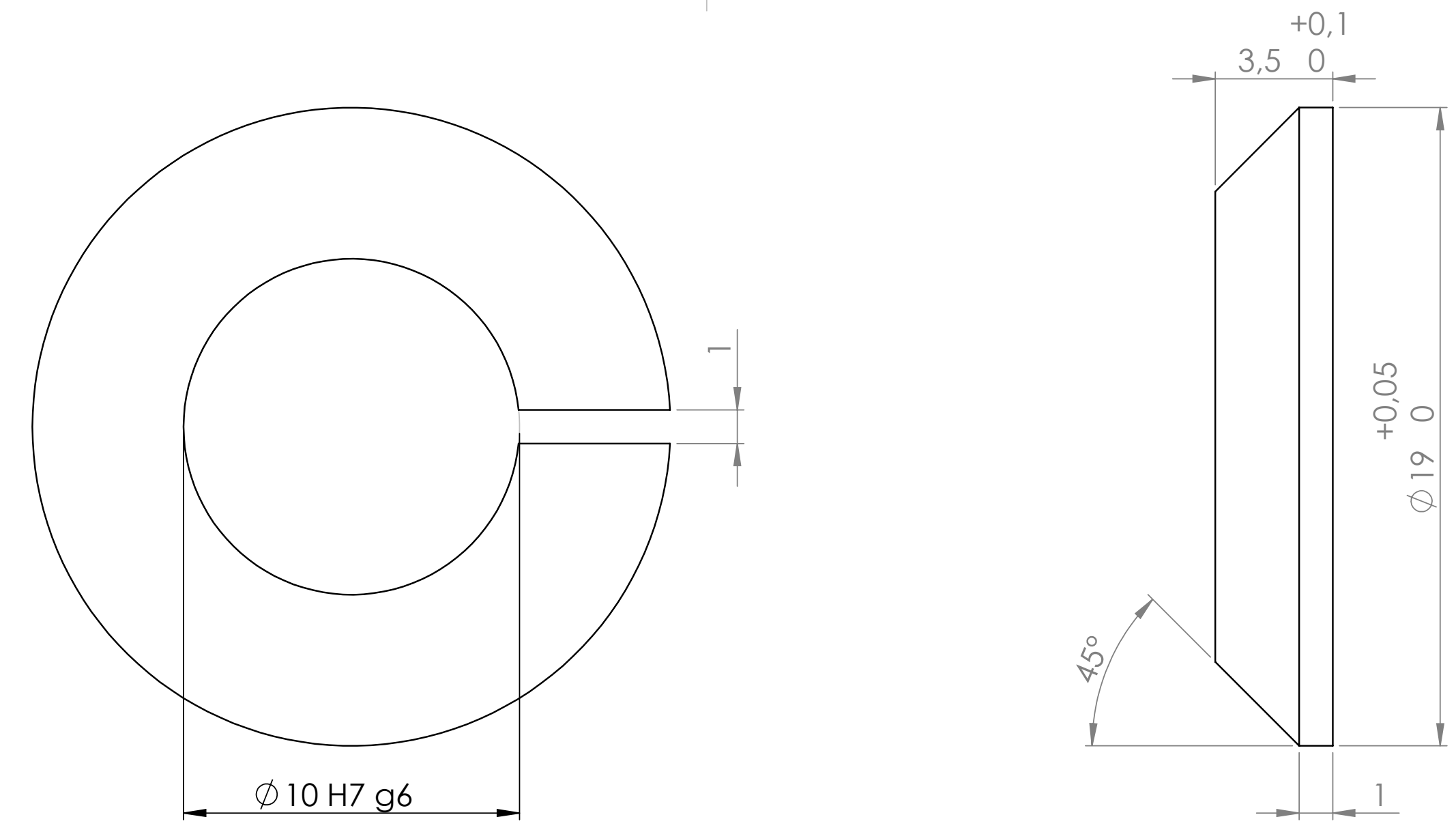

Rebarbar e quebrar

arestas agudas

Tolerância Gera

$>0$

$>200-1000: \pm 0.2$

$>1000 \quad: \pm 0.5$

$\angle: \pm 0.5^{\circ}$

MATERIAL:

Aluminio 6351 T6

PESO: $\quad 0.002 \mathrm{~kg}$
QUANTIDADE 2

PROJETO

Exoesqueleto de membro inferior Tíบบ:

AnelDePressao

Projetista

Camila

ESCALA: 5:1 
B

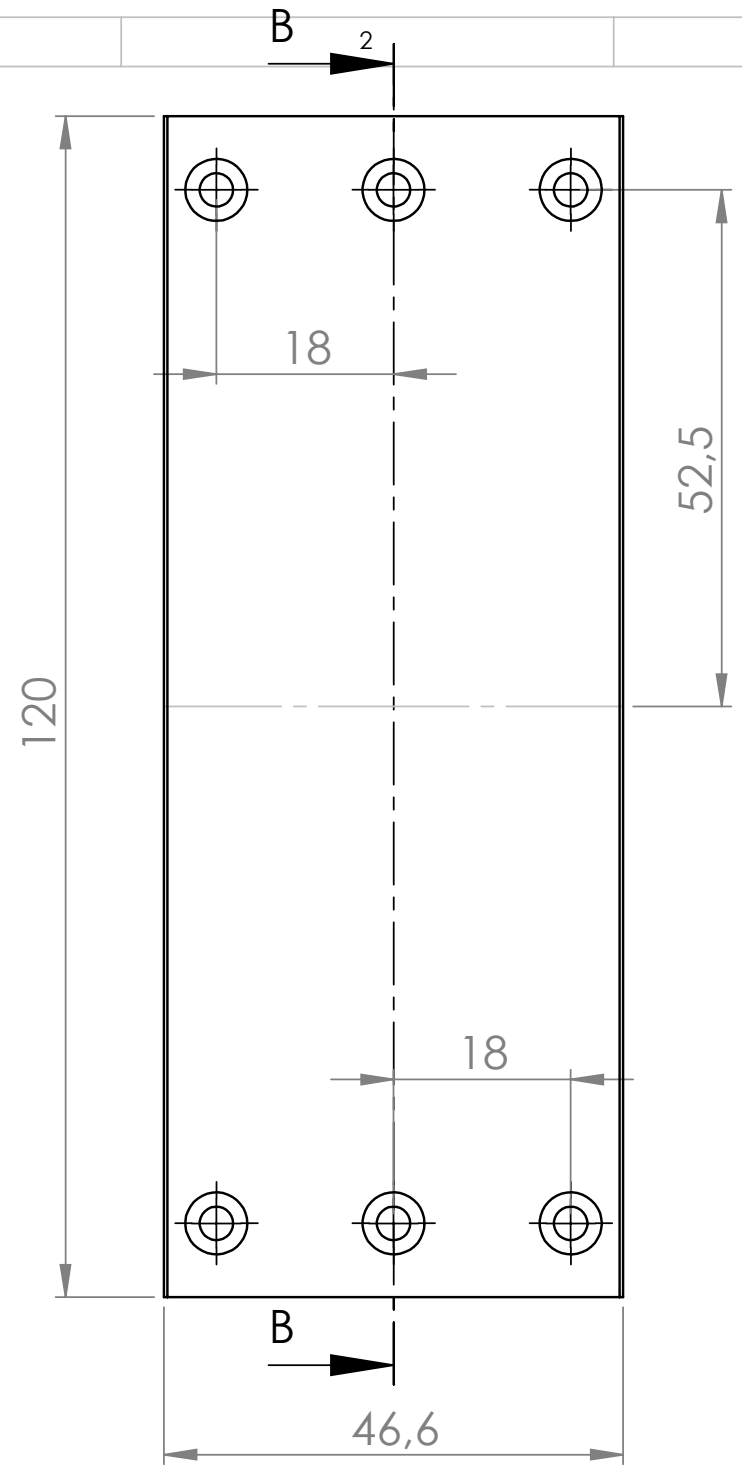

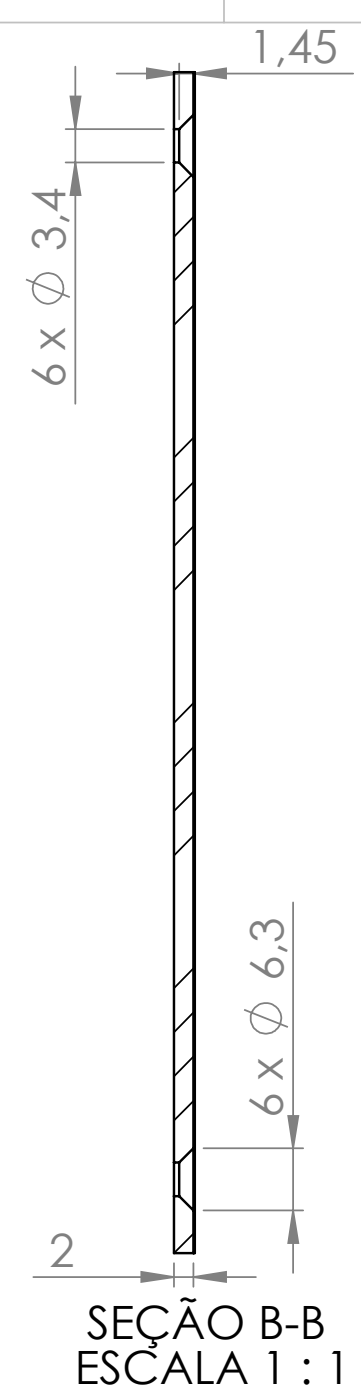

Rebarbar e quebrar

Tolerância Geral

$$
>0
$$

$>200-1000: \pm 0.2$

$>1000$

$: \pm 0.5$

$<: \pm 0.5^{\circ}$ PROJETO

Exoesqueleto de membro inferior ApoioCanela

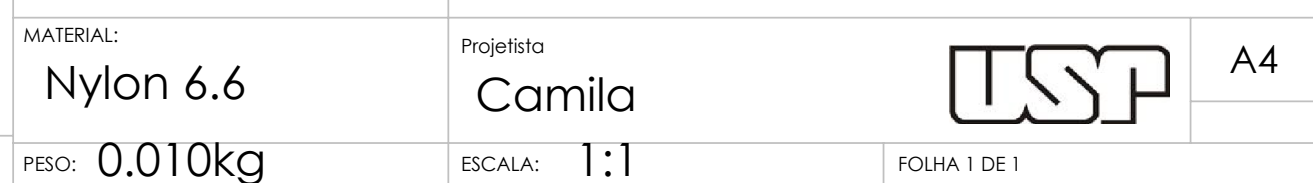




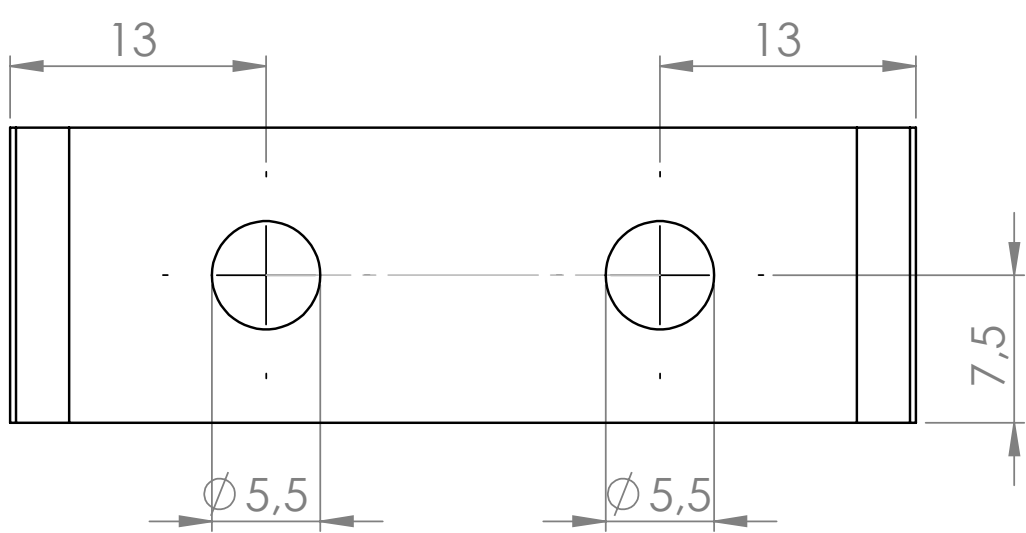

B

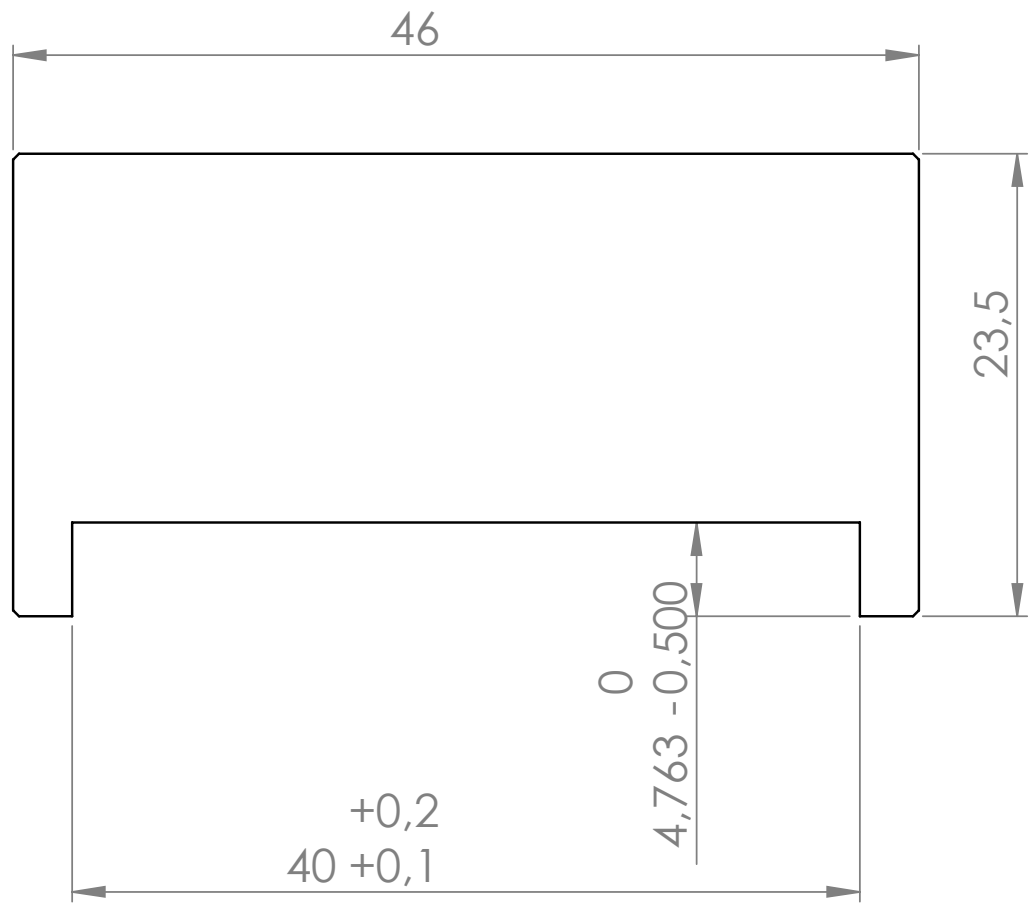

Chanfro: $0.3 \mathrm{~mm} \times 45$

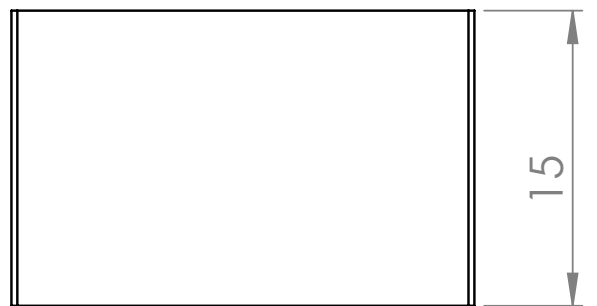

B

C

Rebarbar e quebrar

arestas agudas

Tolerância Geral

$>0 \quad-200: \pm 0.1$

$>200-1000: \pm 0.2$

$>1000 \quad: \pm 0.5$

$\angle: \pm 0.5^{\circ}$

MATERIAL: Aluminio

6063 T5

PESO: $0.035 \mathrm{~kg}$
QUANTIDADE 2

PROJETO

Exoesqueleto de membro inferior Tíulo:

ApoioModulo

Projetisto

Camila

ESCALA: $2: 1$
TSP

A4 


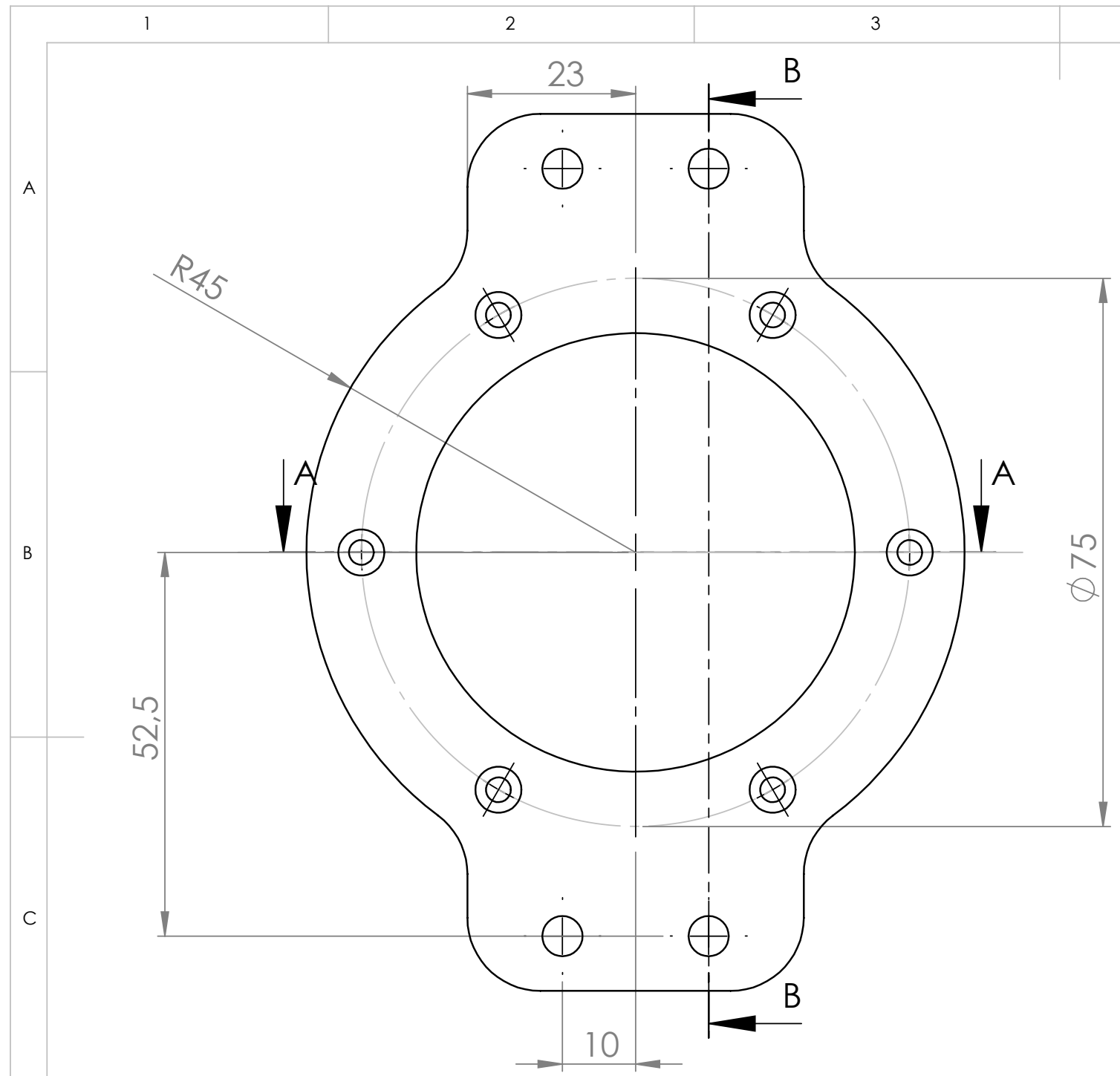

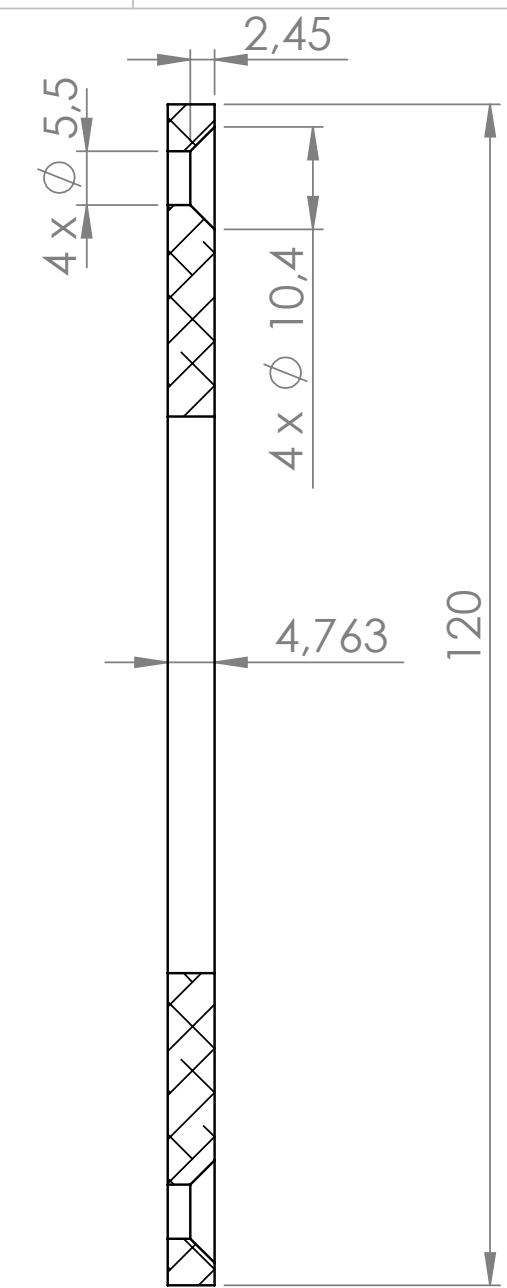

SEÇÃO B-B

ESCALA 1:1

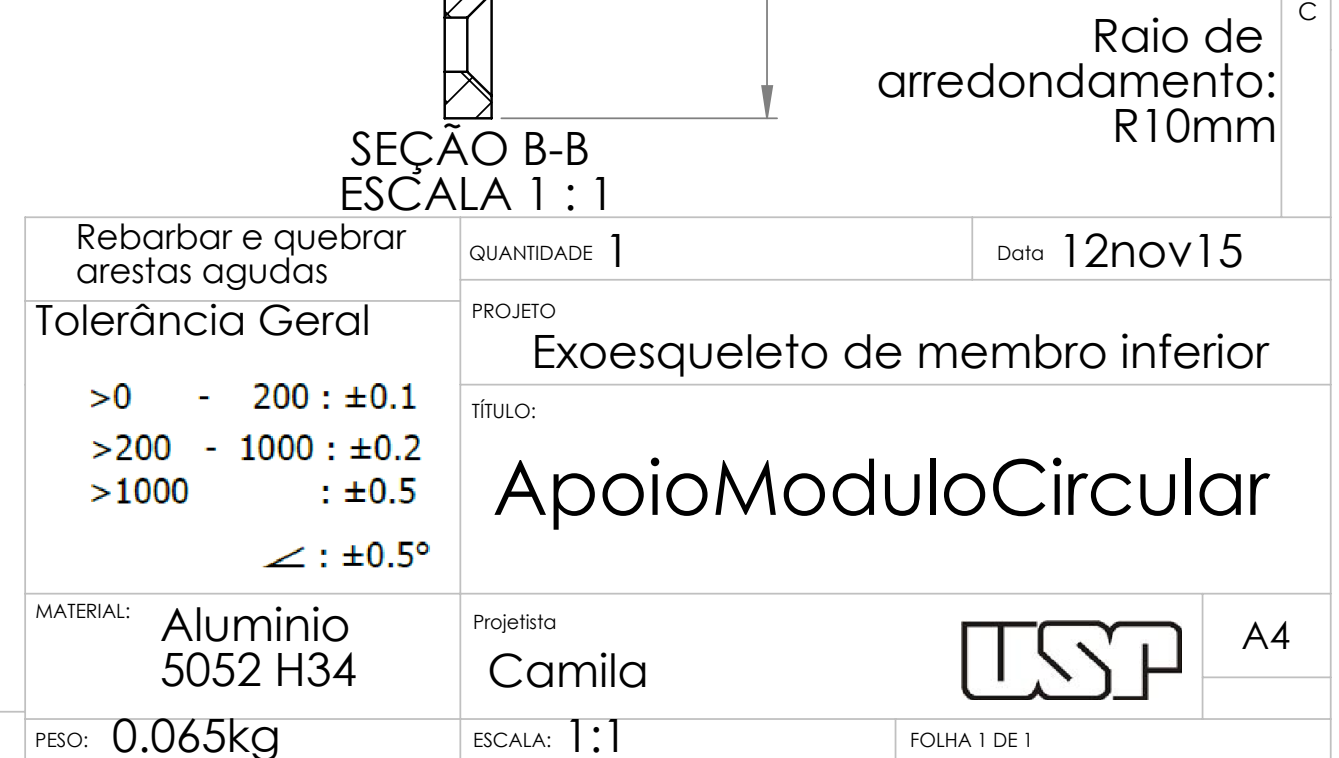

ESCALA: $1: 1$

FOLHA I DE 1

2 


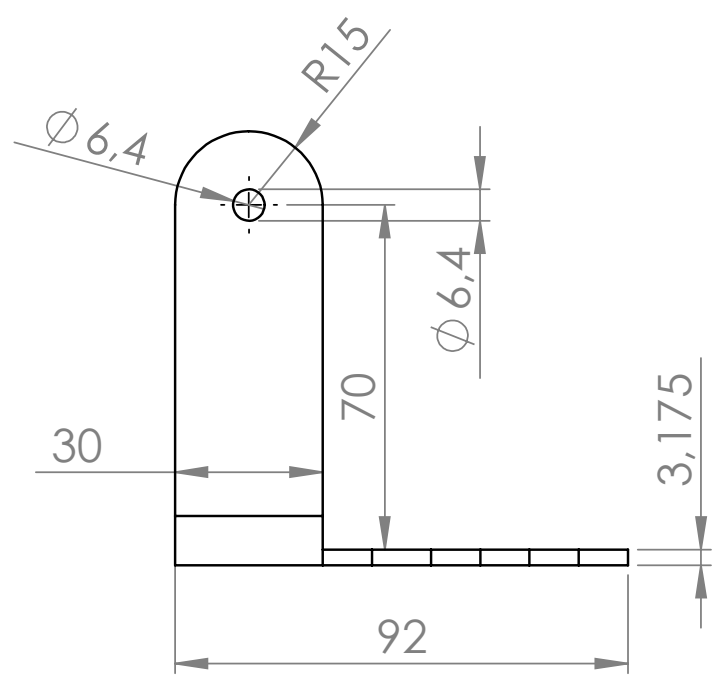

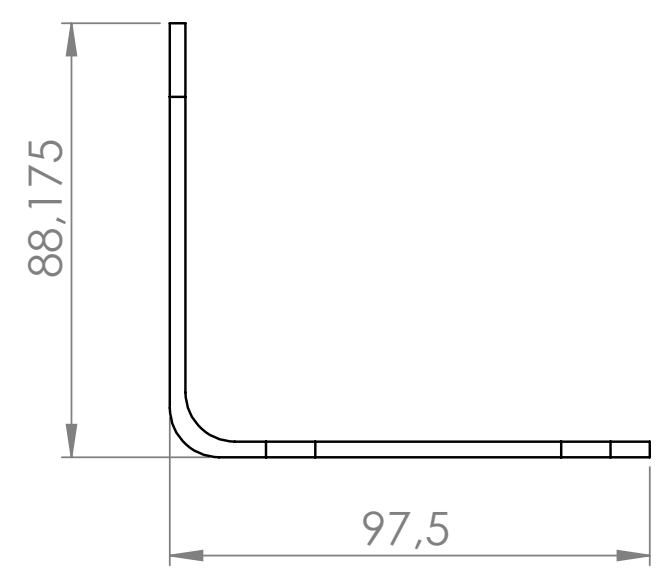

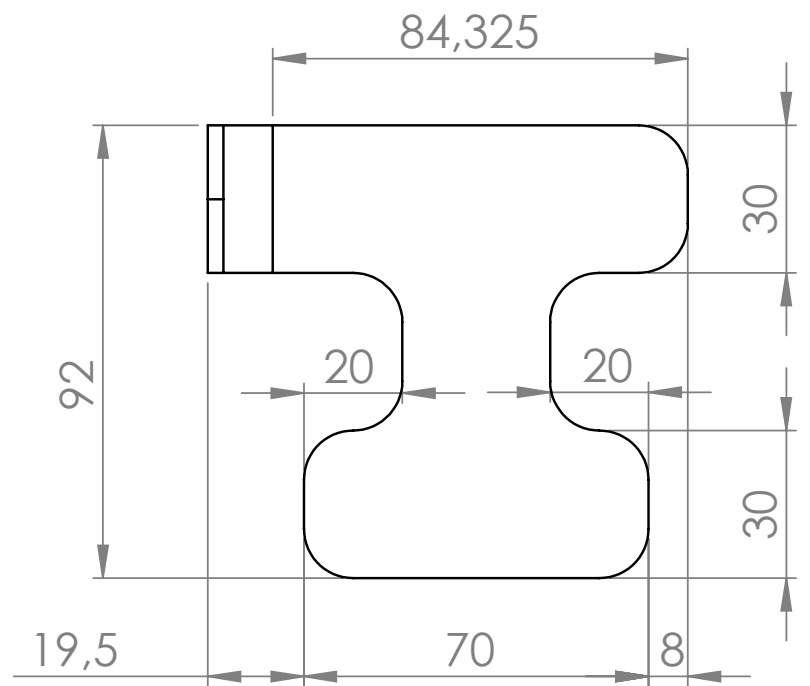

Raio de arredondamento: R10mm
Rebarbar e quebrar

arestas agudas Tolerância Gera

$>0 \quad-\quad 200: \pm 0.1$

$>200-1000: \pm 0.2$

$>1000:: \pm 0.5$

$\angle: \pm 0.5^{\circ}$

MATERIAL: Aluminio

$5052 \mathrm{H} 34$

PESO: $0.210 \mathrm{~kg}$
QUANTIDADE 1

Data 12 nov 15

PROJETO

Exoesqueleto de membro inferior Tí́TLO:

\section{BasePe2}

Projetista

Camila ESCALA: $1: 2$

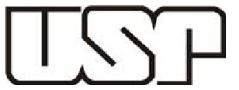

A4 


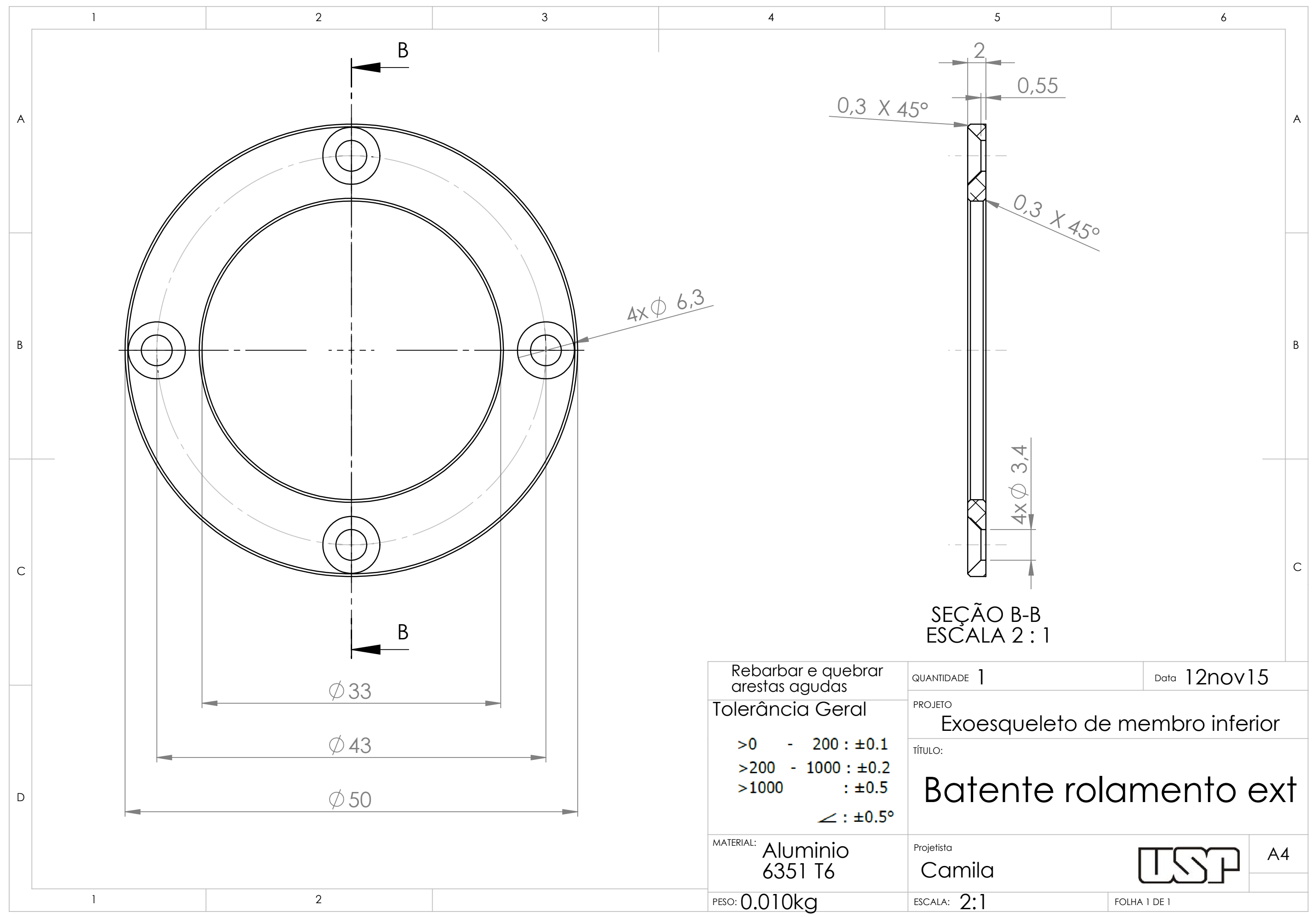




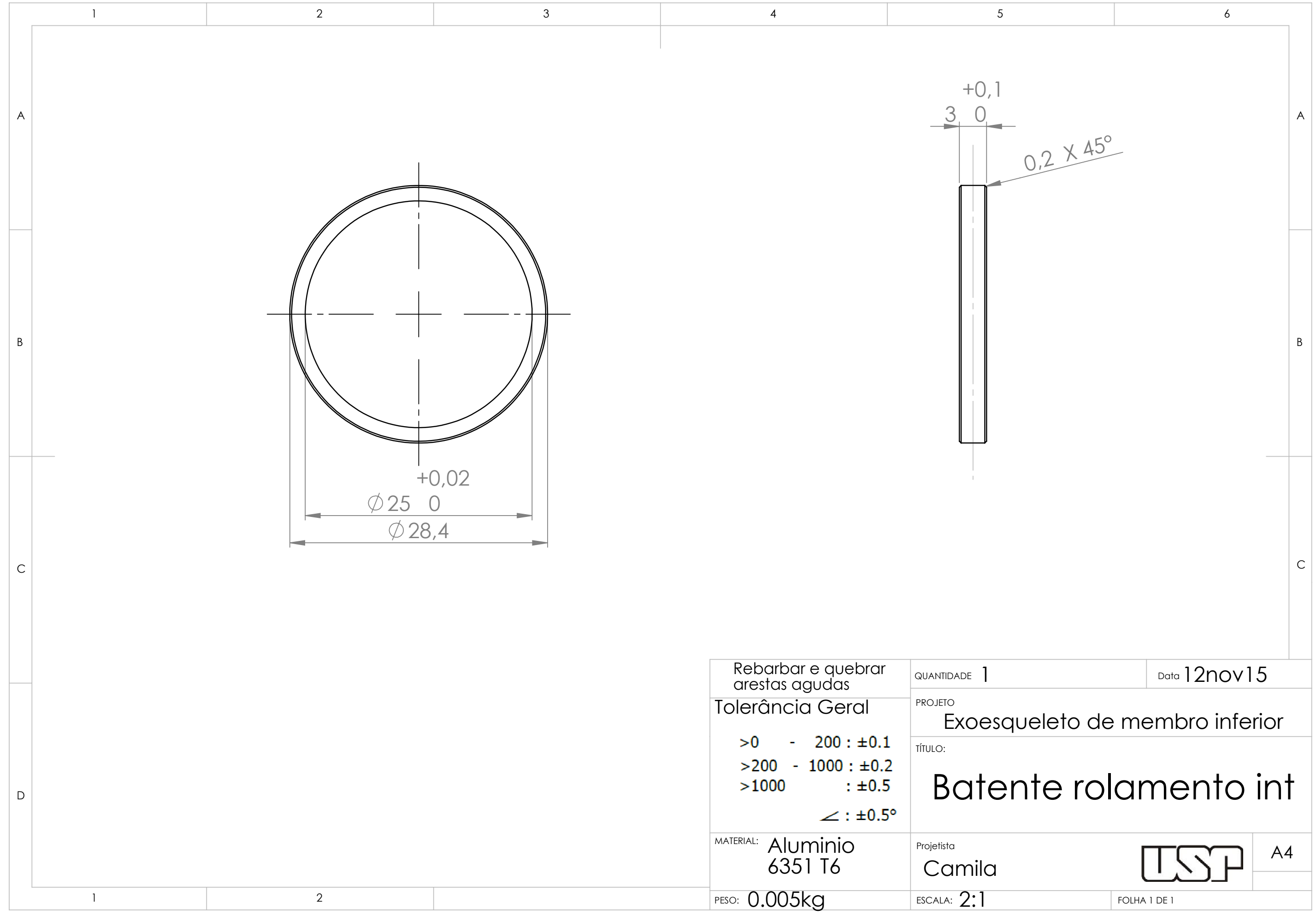



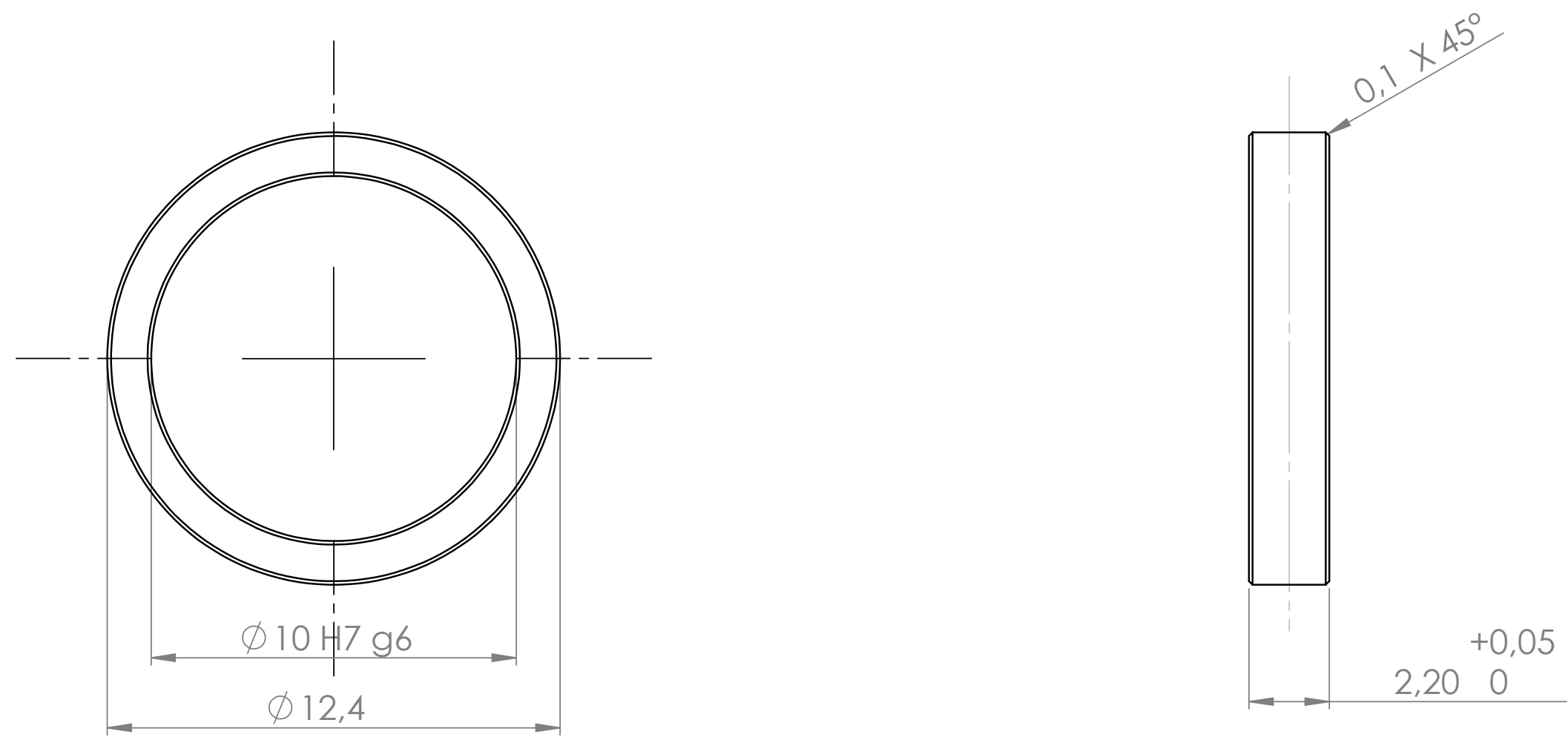

A
Rebarbar e quebrar

arestas agudas

Tolerância Gera

$>0$

$>200-1000: \pm 0.2$

$>1000 \quad: \pm 0.5$

$<: \pm 0.5^{\circ}$

MATERIAL:

Aço Inox 304

PESO:

BatRollntMotor

ojetista

Camila

TSP ${ }^{A 4}$ ESCALA: $5: 1$ 

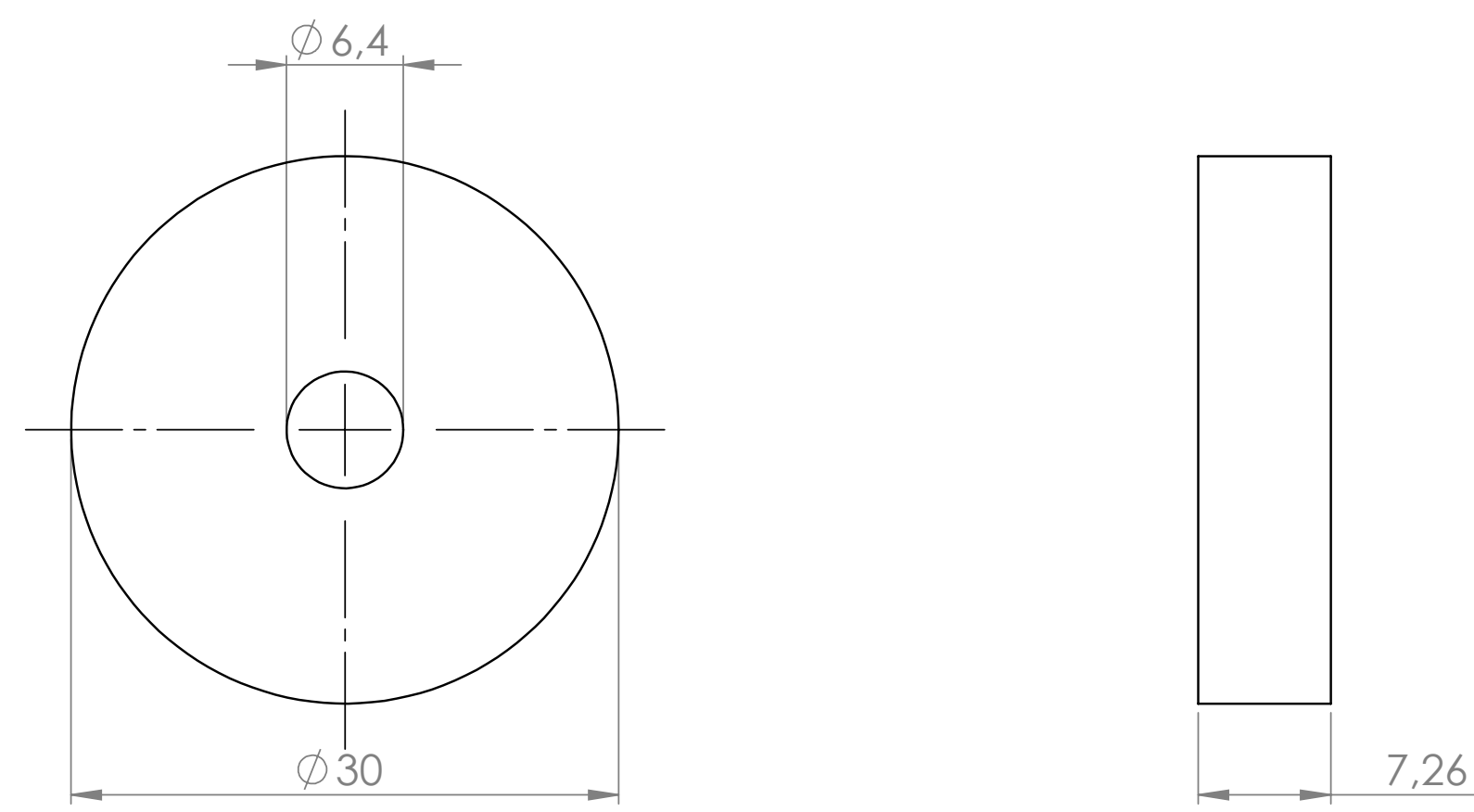

Rebarbar e quebrar

arestas agudas Tolerância Geral

$>0$$$
>0
$$

$-1000: \pm 0.2$

$>1000$

$$
: \pm 0.5
$$$$
\angle: \pm 0.5^{\circ}
$$

MATERIAL:

Nylon 6.6

PESO: $0.001 \mathrm{~kg}$
QUANIIDADE 2

PROJETO

Exoesqueleto de membro inferior TíTuLO:

\section{Bucha}

Projetista

Camila

ESCALA: 2:1 

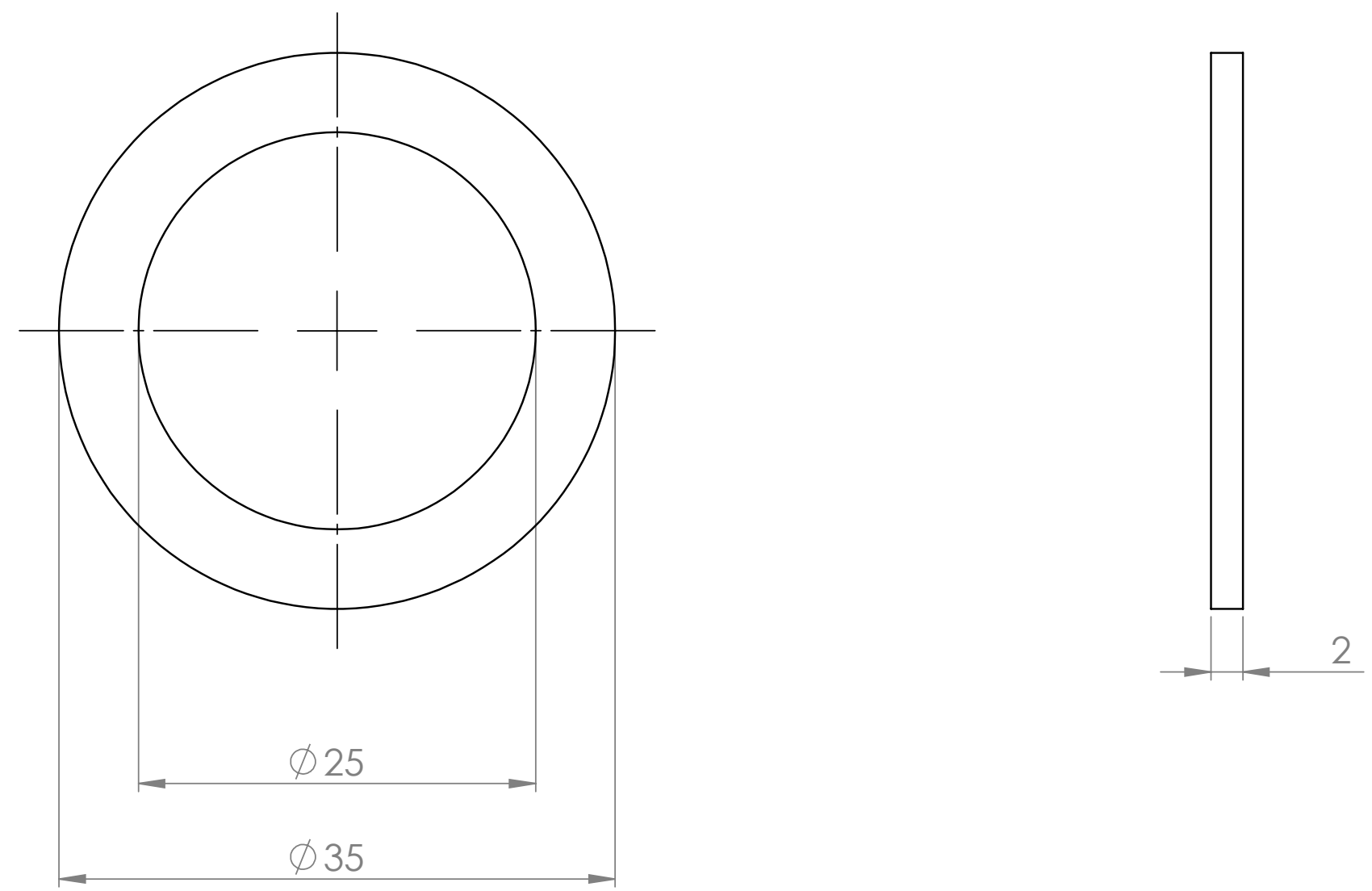

Rebarbar e quebrar

arestas agudas

Tolerância Gera

$>0$

$>200-1000: \pm 0.2$

$>1000 \quad: \pm 0.5$

$\angle: \pm 0.5^{\circ}$

MATERIAL:

Nylon 6.6

PESO: $0.001 \mathrm{~kg}$
QUANTIDADE 2 PROJETO

Exoesqueleto de membro inferior Título:

BuchaJoelho

rojetista

Camila ESCALA: $2: 1$ 

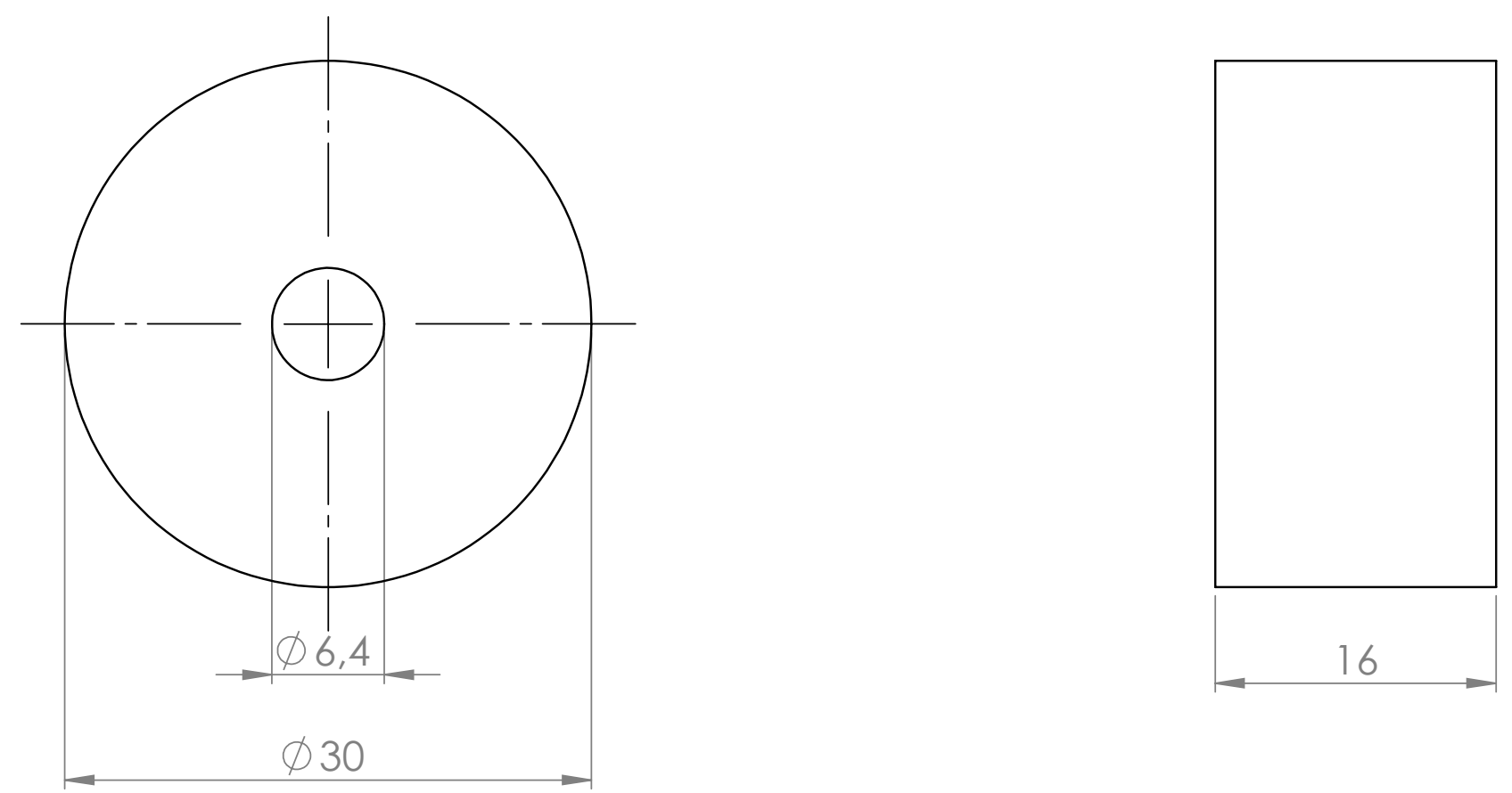

\section{Tolerância Geral}

$>0$

$>200-1000: \pm 0.2$

$>1000 \quad: \pm 0.5$

$\angle: \pm 0.5^{\circ}$

MATERIAL:

Nylon 6.6 PESO: $0.010 \mathrm{~kg}$
PROJETO

Exoesqueleto de membro inferior Título:

\section{BuchaTornozelo}

Projetista

TSP ${ }^{A 4}$ 

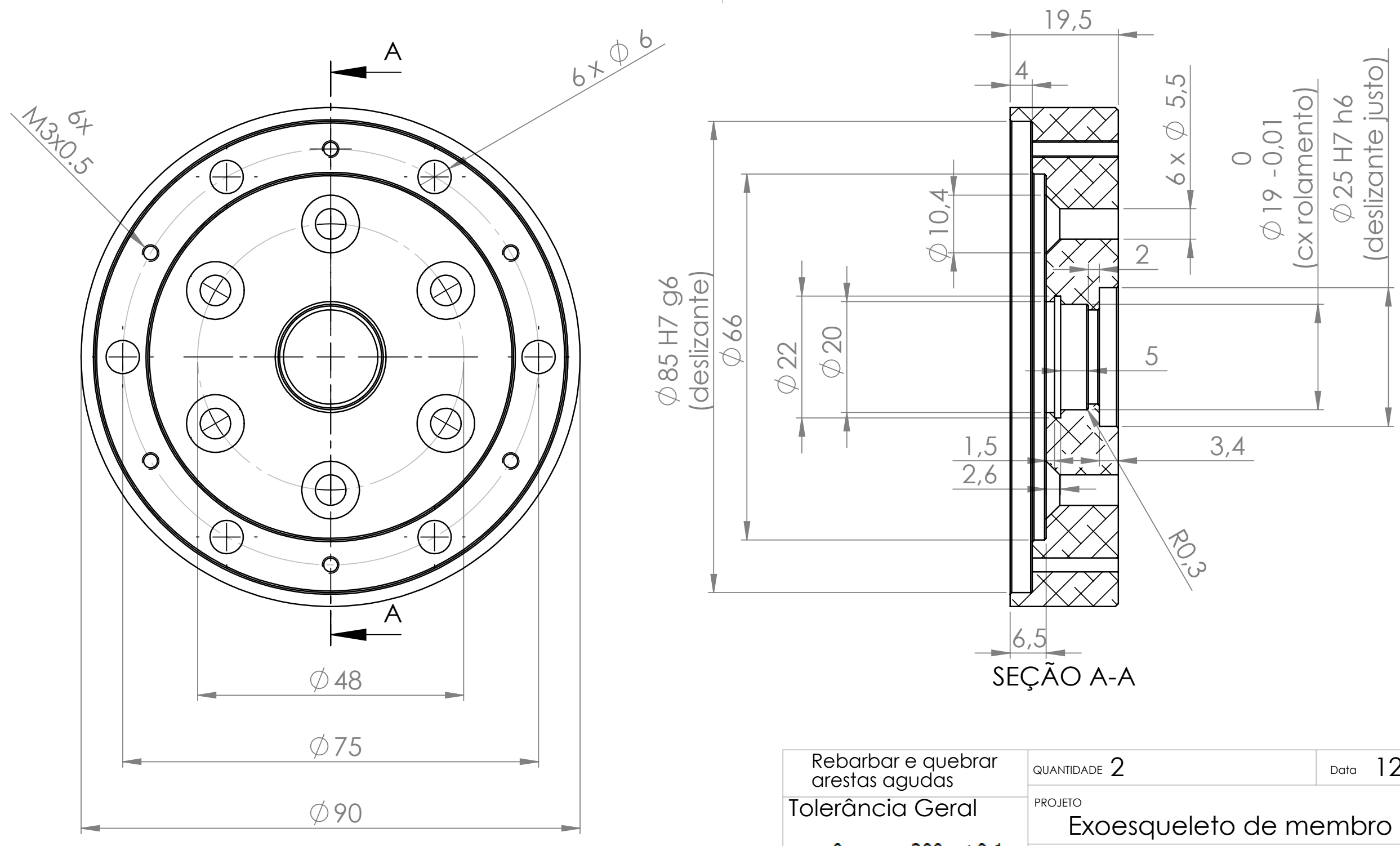

A

Rebarbar e quebrar arestas agudas Tolerância Geral

$>0 \quad-200: \pm 0$

$>200-1000: \pm 0.2$

$>1000 \quad: \pm 0.5$ $<: \pm 0.5^{\circ}$

\section{Aluminio} $6351 \mathrm{T6}$

QUANTIDADE 2

Data 12 nov 15

PROJETO

Exoesqueleto de membro inferior TíTULO:

Caixa de reducao 1 

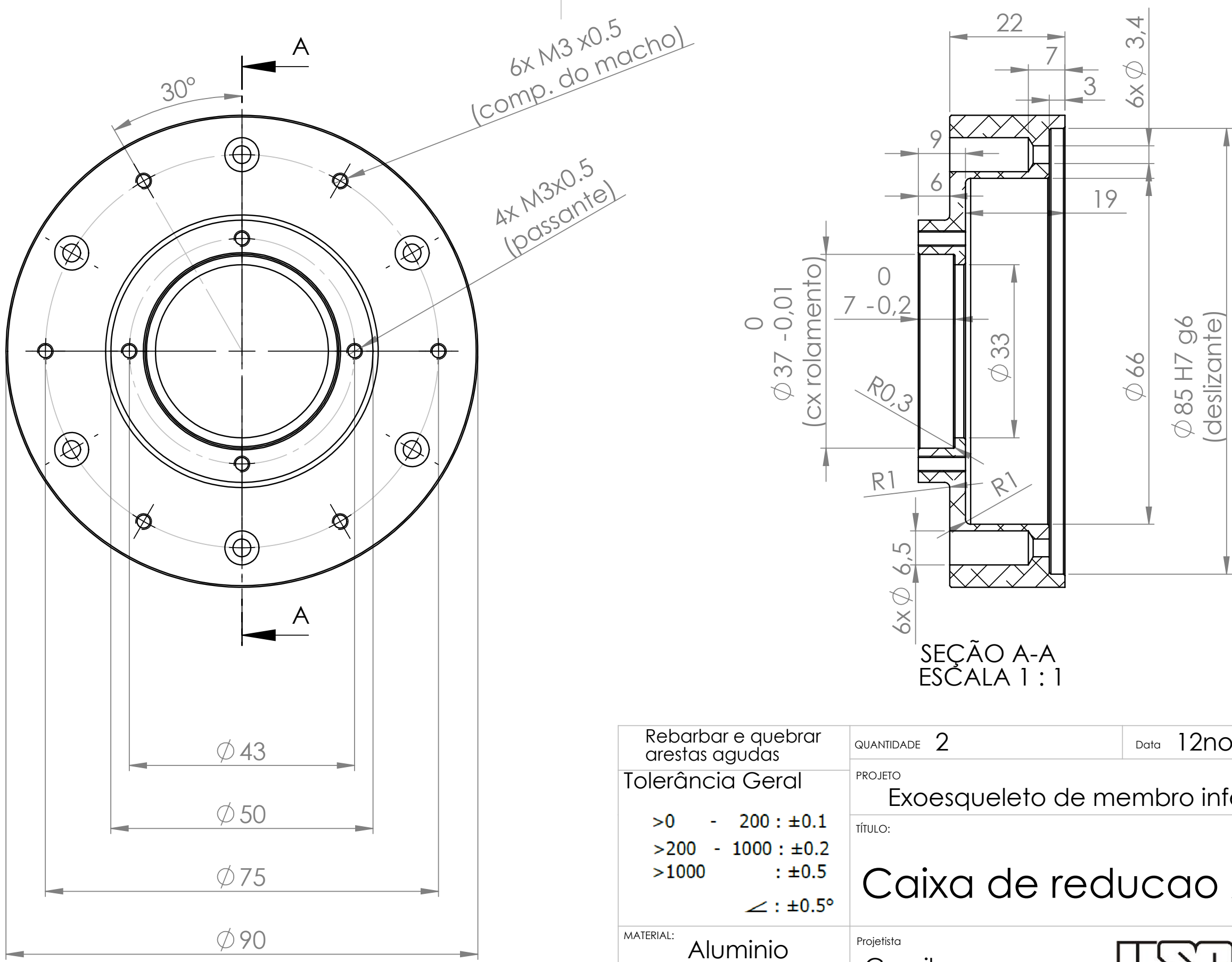

A

Rebarbar e quebrar arestas agudas Tolerância Geral

$$
>0
$$

$$
>200
$$$$
>1000
$$$$
200: \pm 0.1
$$$$
00: \pm 0.2
$$$$
: \pm 0.5
$$$$
\angle: \pm 0.5^{\circ}
$$

MATERIAL: Aluminio $6351 \mathrm{T6}$
QUANTIDADE 2

Data 12 nov 15 PROJETO

Exoesqueleto de membro inferior TíuL:

Caixa de reducao 2

Projetista

Camila ESCALA: $1: 1$ 


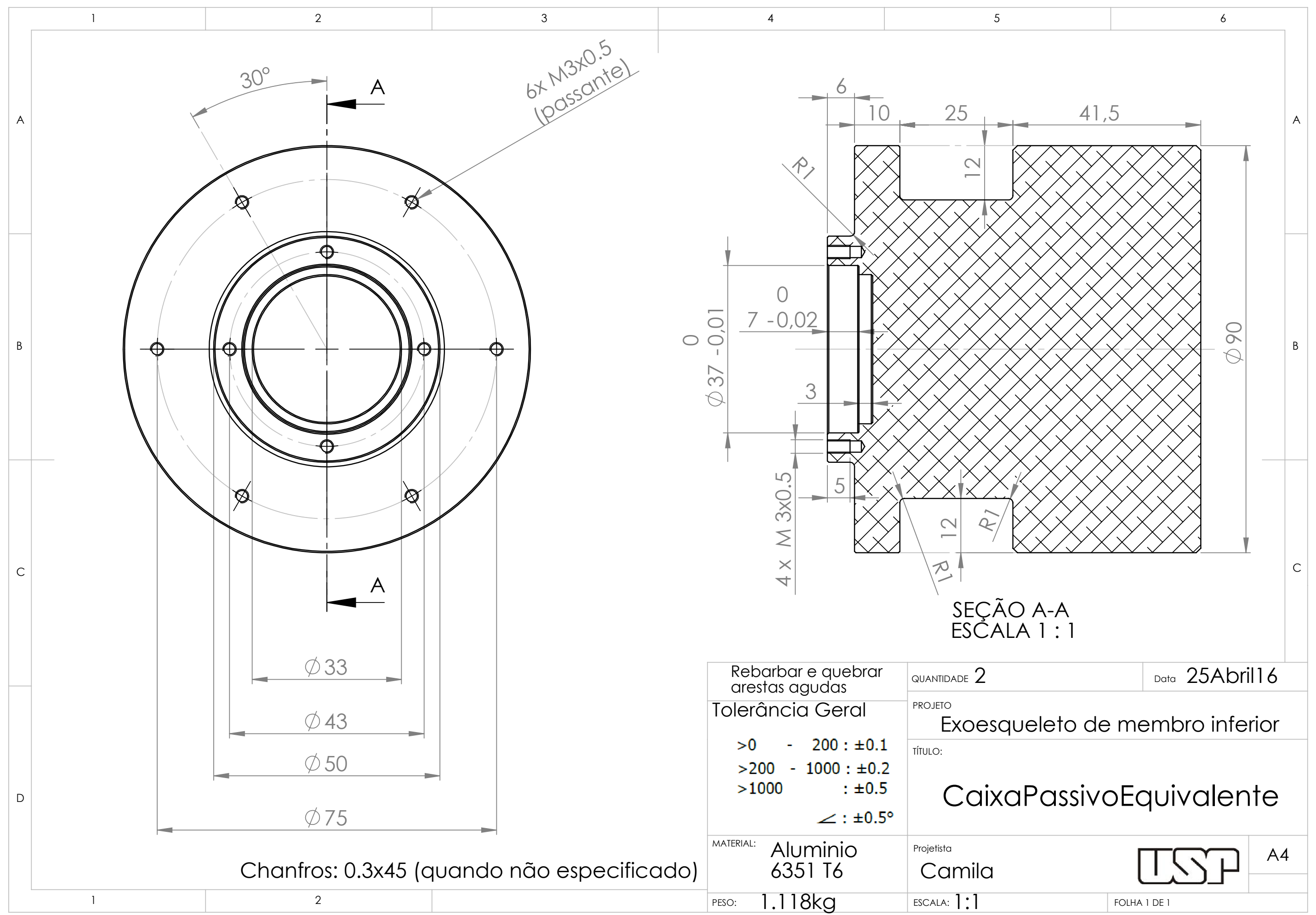



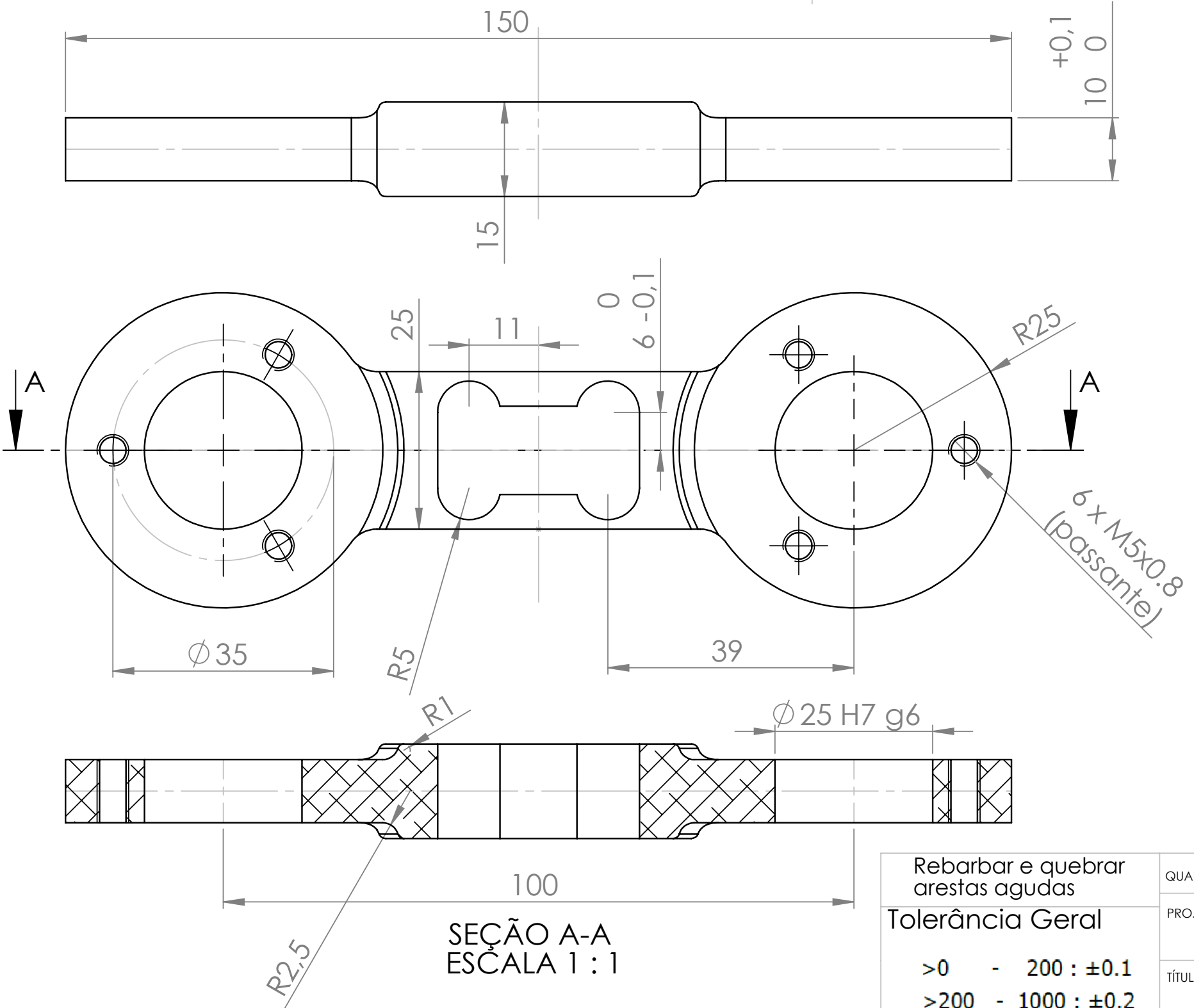

$\varnothing 25 \mathrm{H7} 96$

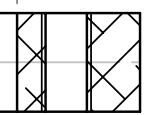

Rebarbar e quebrar arestas agudas Tolerância Geral

$>0 \quad-200: \pm 0.1$ $>200-1000: \pm 0.2$ $>1000 \quad: \pm 0.5$ $\angle: \pm 0.5^{\circ}$

MATERIAL: Aluminio $6351 \mathrm{T6}$
QUANTIDADE 4 Data 12 nov 15 PROJETO Exoesqueleto de membro inferior TíTULO:

CelulaDeCarga Projetisto Camila ESCALA: $1: 1$ 


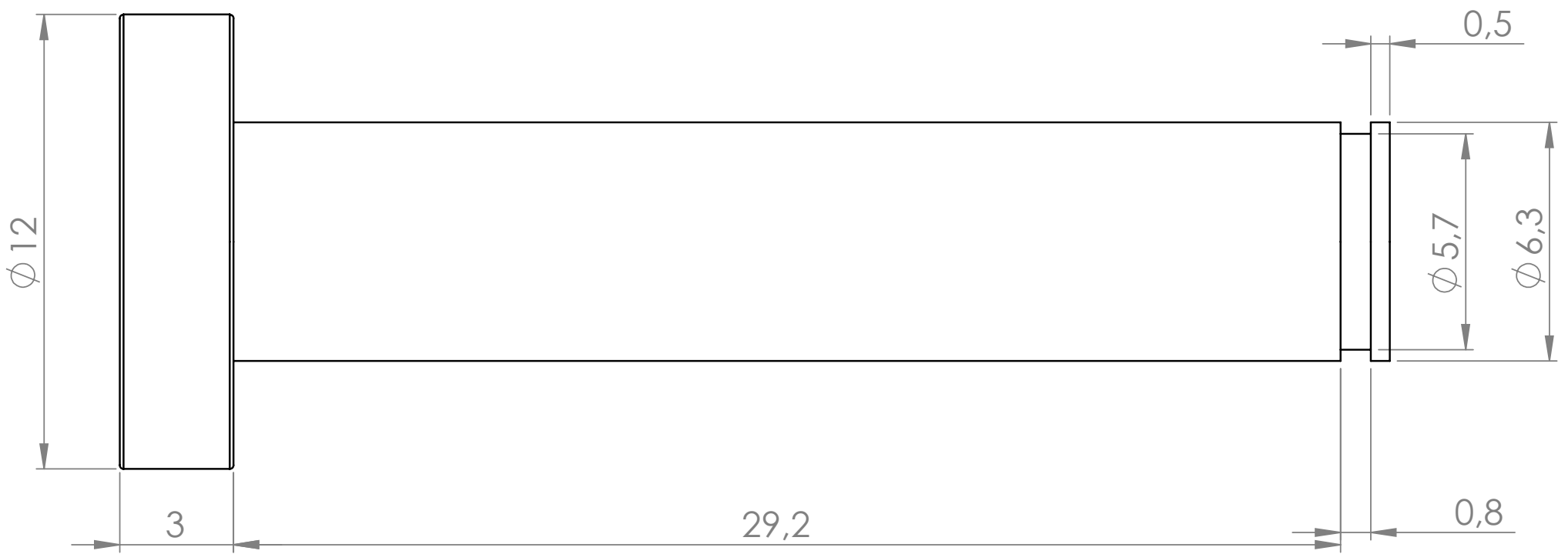

Tolerância Geral

$$
>0
$$

$>200-1000: \pm 0.2$

$>1000$

$$
: \pm 0.5
$$$$
\angle: \pm 0.5^{\circ}
$$

PROJeTO

Exoesqueleto de membro inferior TíTULO:

\section{EixoBucha}

\begin{tabular}{|c|c|}
\hline MAterIAL: & Projetista \\
Cço Inox 304 & Camila \\
\hline PESO: $0.010 \mathrm{~kg}$ & ESCALA: $5: 1$
\end{tabular}




\section{$\varnothing 20 \mathrm{H7} g 6$}

C

D
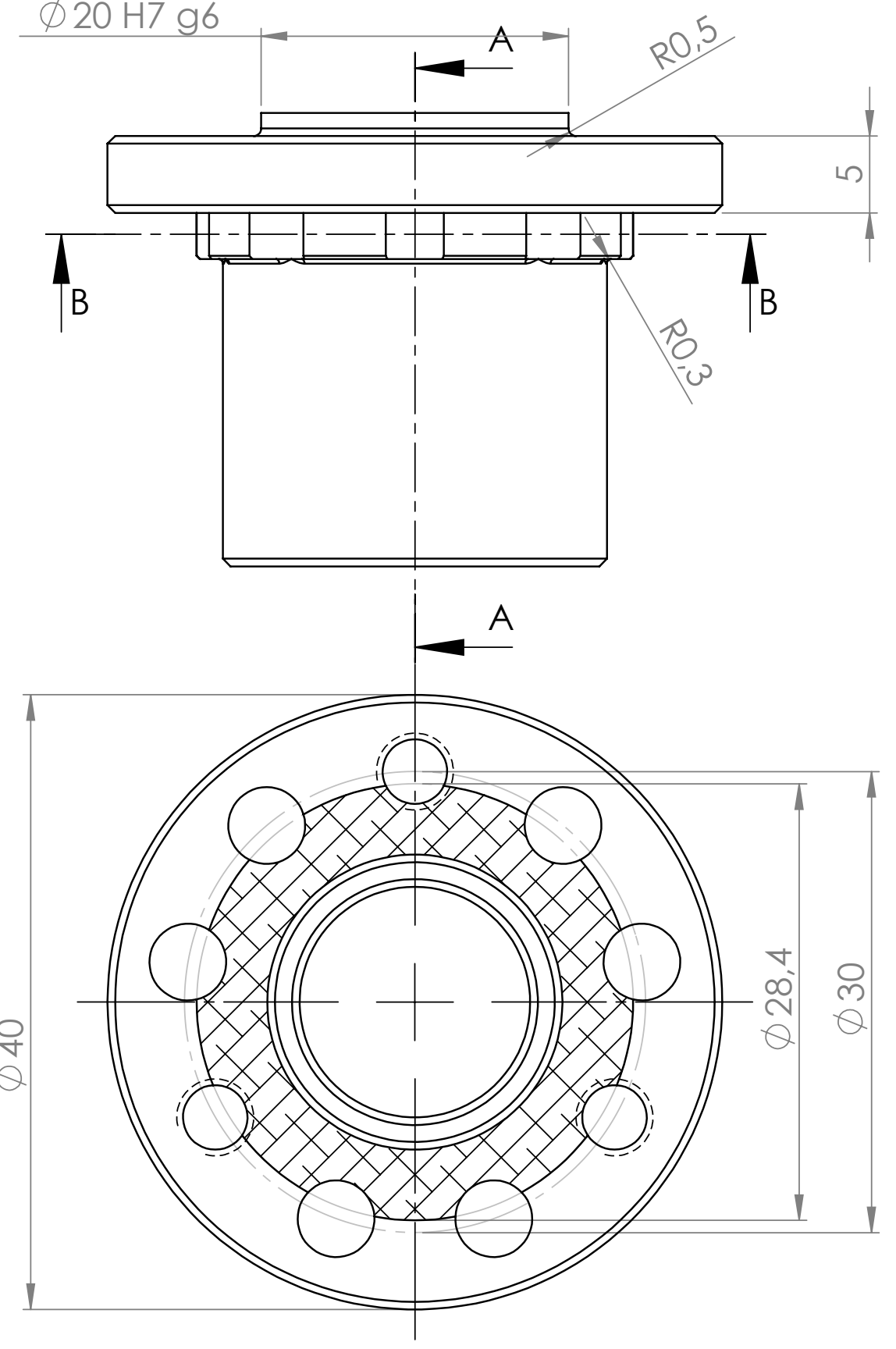

SECÃO B-B

1

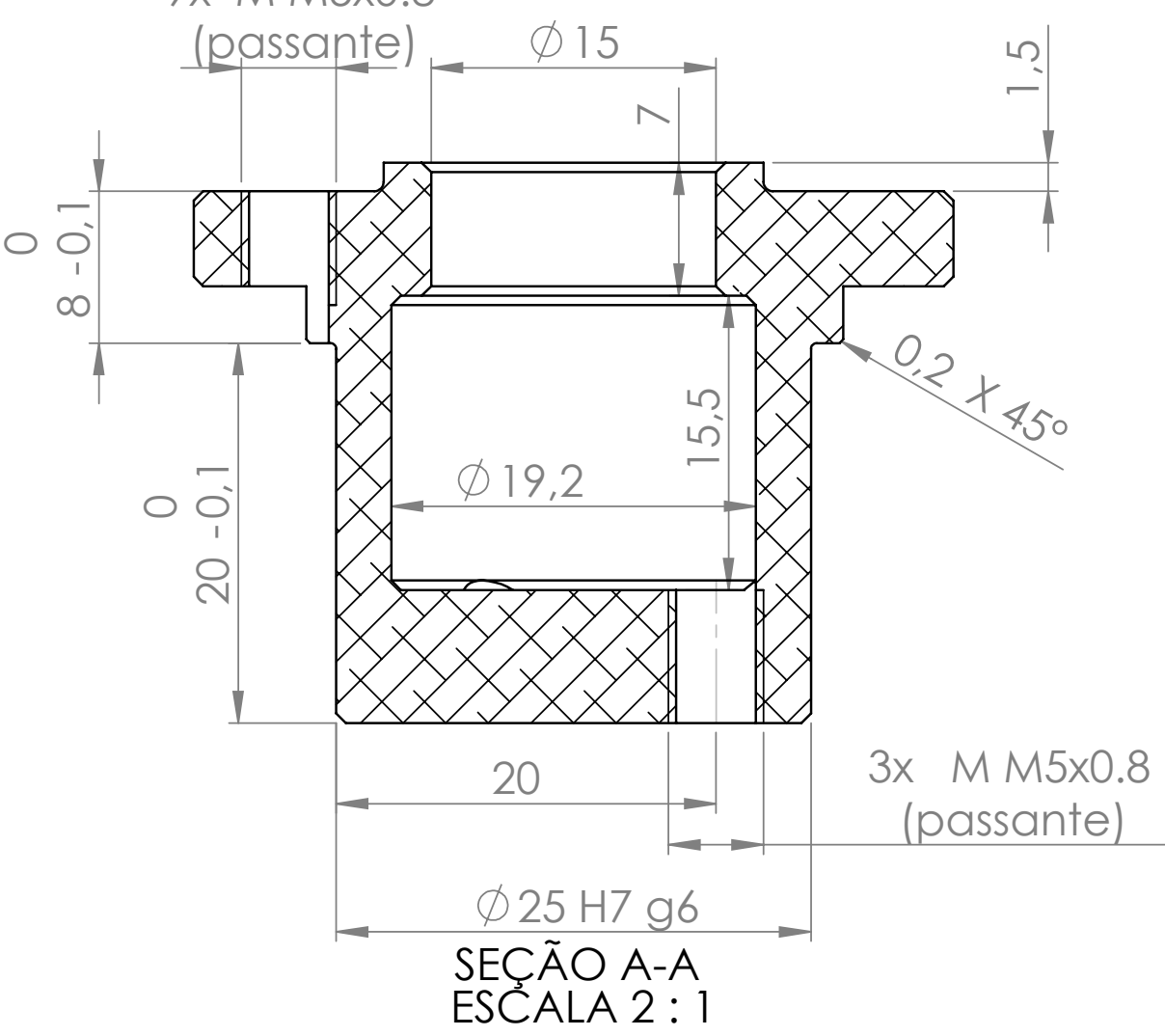

Chanfros: $0.5 \times 45$ (quando não especificado)

Rebarbar e quebrar arestas agudas Quantidade 2 Data 12nov 15

Tolerância Geral

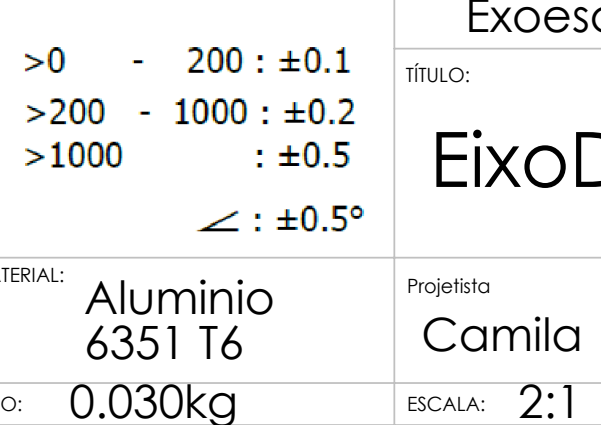



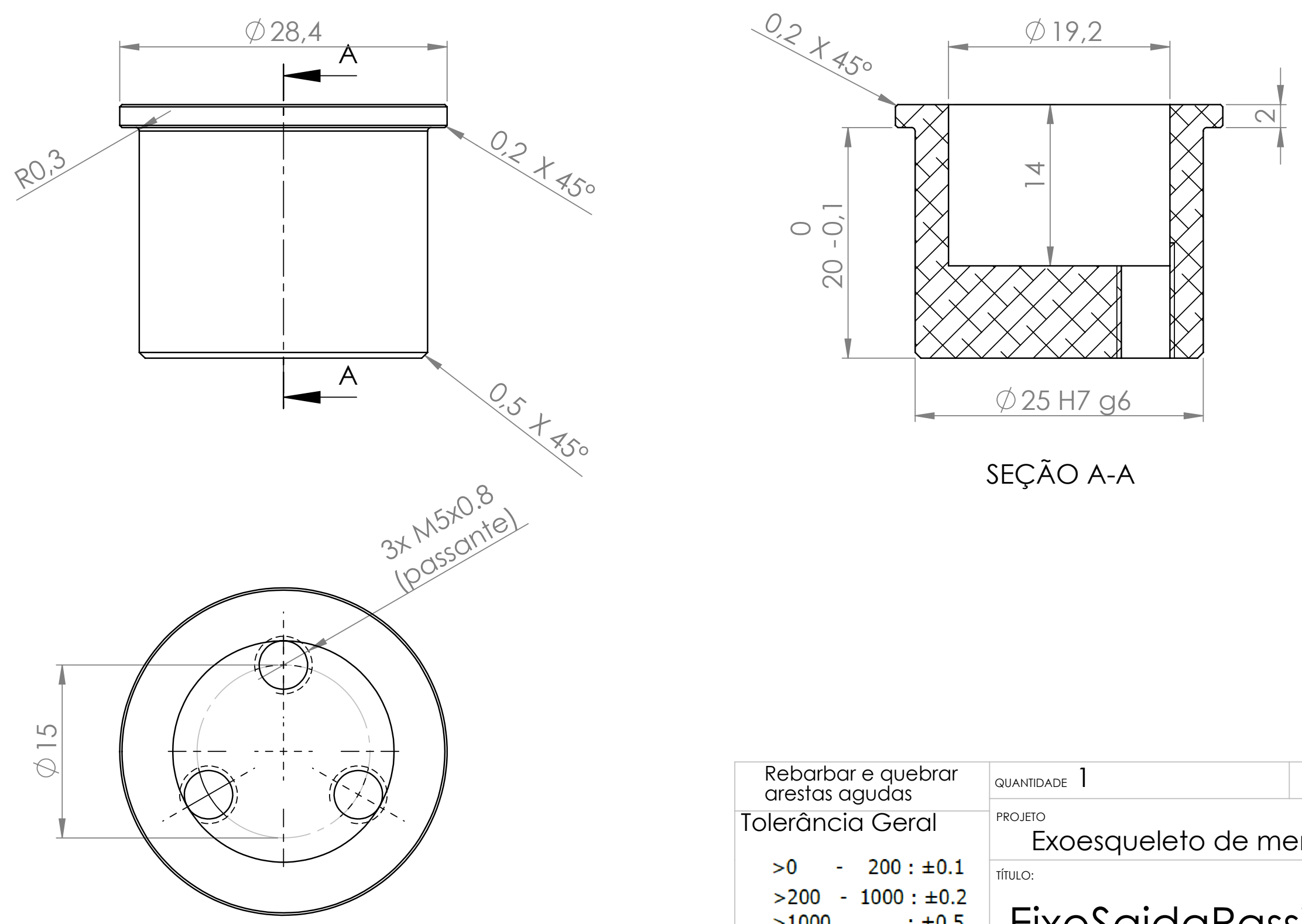

SEÇÃO A-A

Rebarbar e quebrar

arestas agudas

Tolerância Gera$$
200: \pm 0.1
$$

$>0 \quad-\quad 200: \pm 0.1$

$>200-1000: \pm 0.2$

$>1000 \quad: \pm 0.5$

$<: \pm 0.5^{\circ}$

Aluminio

6351 T6

PESO: $0.020 \mathrm{~kg}$
QUANTIDADE 1

PROJETO

Exoesqueleto de membro inferior Tí́TLO:

\section{EixoSaidaPassivo}

rojetisto

Camila ESCALA: $2: 1$ 


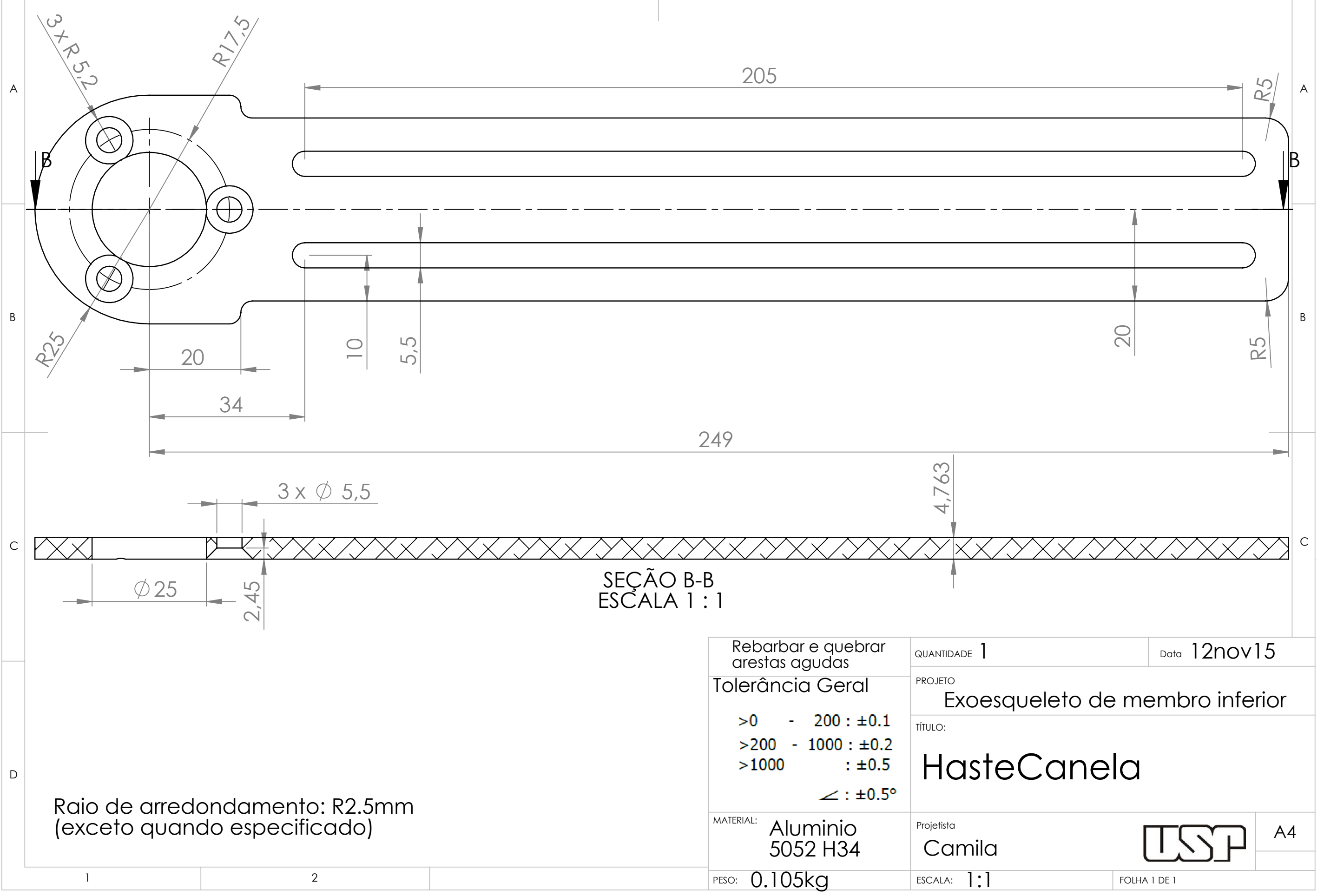


192,5
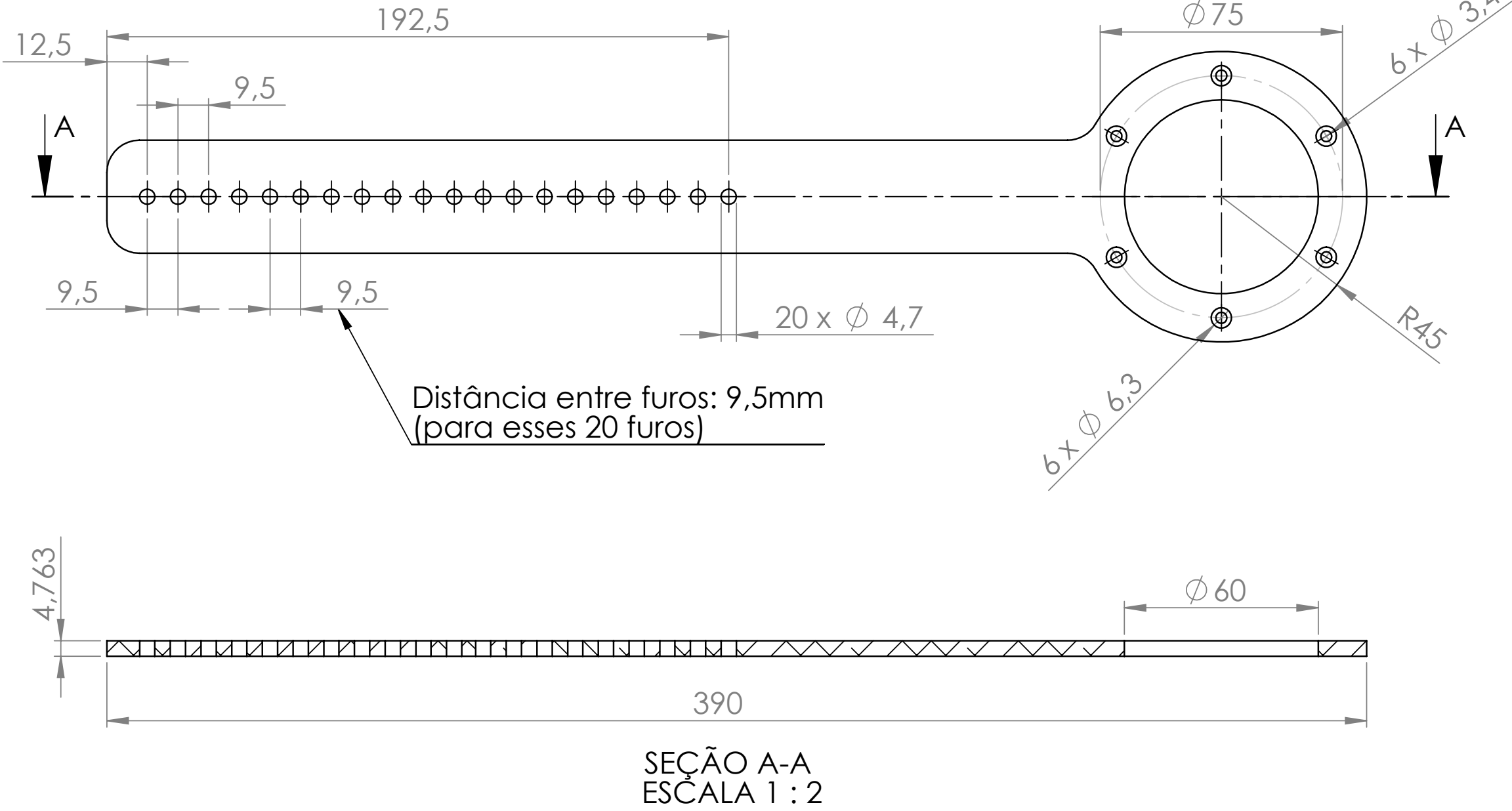

Rebarbar e quebrar arestas agudas Tolerância Geral

$>0 \quad-200: \pm 0.1$

$>200-1000: \pm 0.2$

$>1000 \quad: \pm 0.5$ $<: \pm 0.5^{\circ}$

MATERIAL: Aluminio $5052 \mathrm{H} 34$ PESO: $0.180 \mathrm{~kg}$
QUANTIDADE 1 Data 12 nov 15 PROJETO Exoesqueleto de membro inferior Tí́TLO:

HasteCoxa

Projetista

Camila ESCALA: $1: 2$

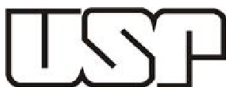

A4 

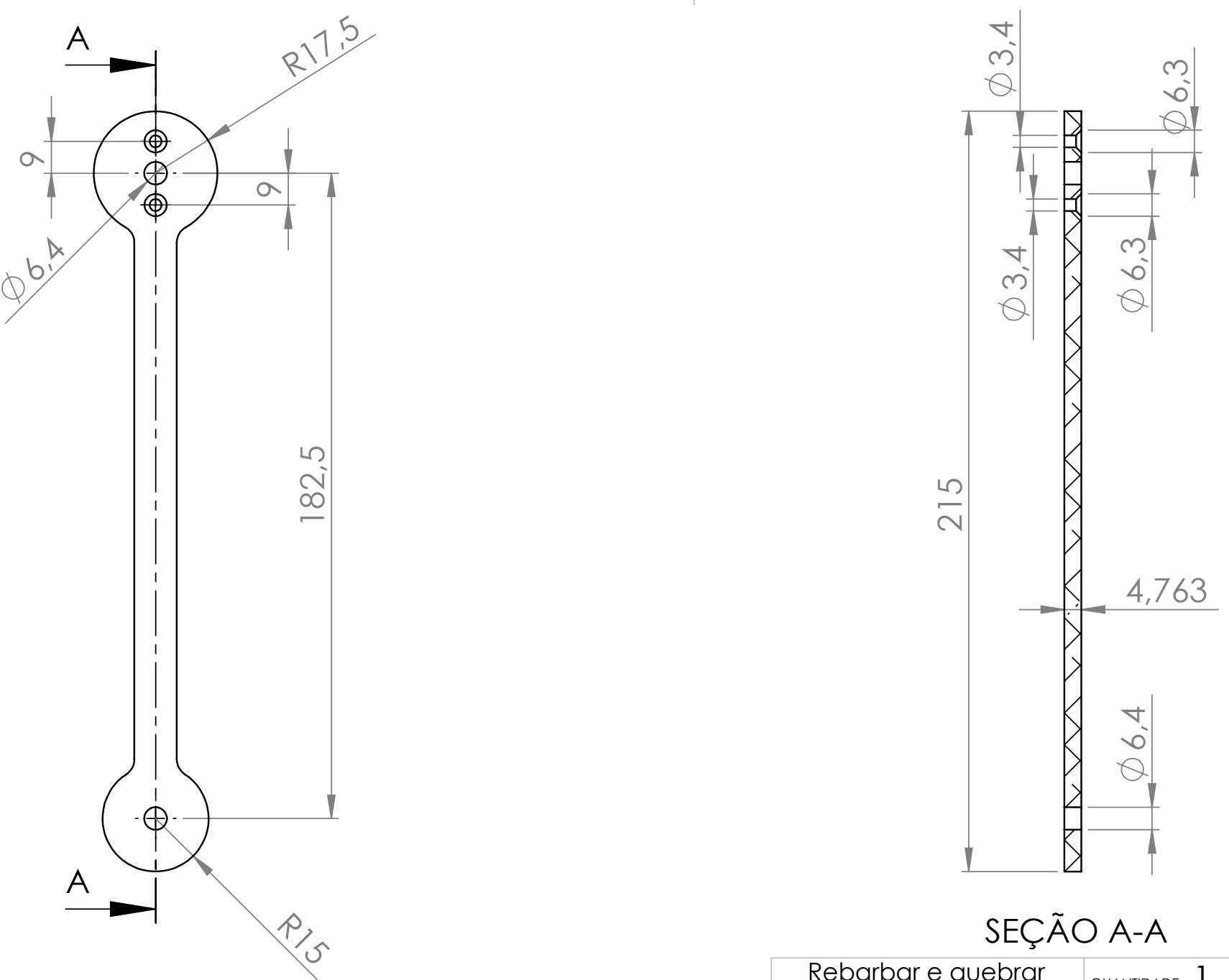

SEÇÃO A-A

\begin{tabular}{|c|c|c|c|}
\hline \multirow{2}{*}{$\begin{array}{l}\text { Rebarbar e quebrar } \\
\text { arestas agudas } \\
\text { olerância Geral }\end{array}$} & QUANTIDADE 1 & \multicolumn{2}{|c|}{ Data 12 nov 15} \\
\hline & \multicolumn{3}{|c|}{$\begin{array}{l}\text { PRoJeto } \\
\text { Exoesqueleto de membro inferior }\end{array}$} \\
\hline$>0-200: \pm 0.1$ & \multirow{3}{*}{\multicolumn{3}{|c|}{ HasteTornozelo }} \\
\hline $\begin{aligned}>200-1000 & : \pm 0.2 \\
>1000 & : \pm 0.5\end{aligned}$ & & & \\
\hline$\angle: \pm 0.5^{\circ}$ & & & \\
\hline $\begin{array}{l}\text { Aluminio } \\
5052 \mathrm{H} 34\end{array}$ & Carjetista & تــ & A4 \\
\hline
\end{tabular}




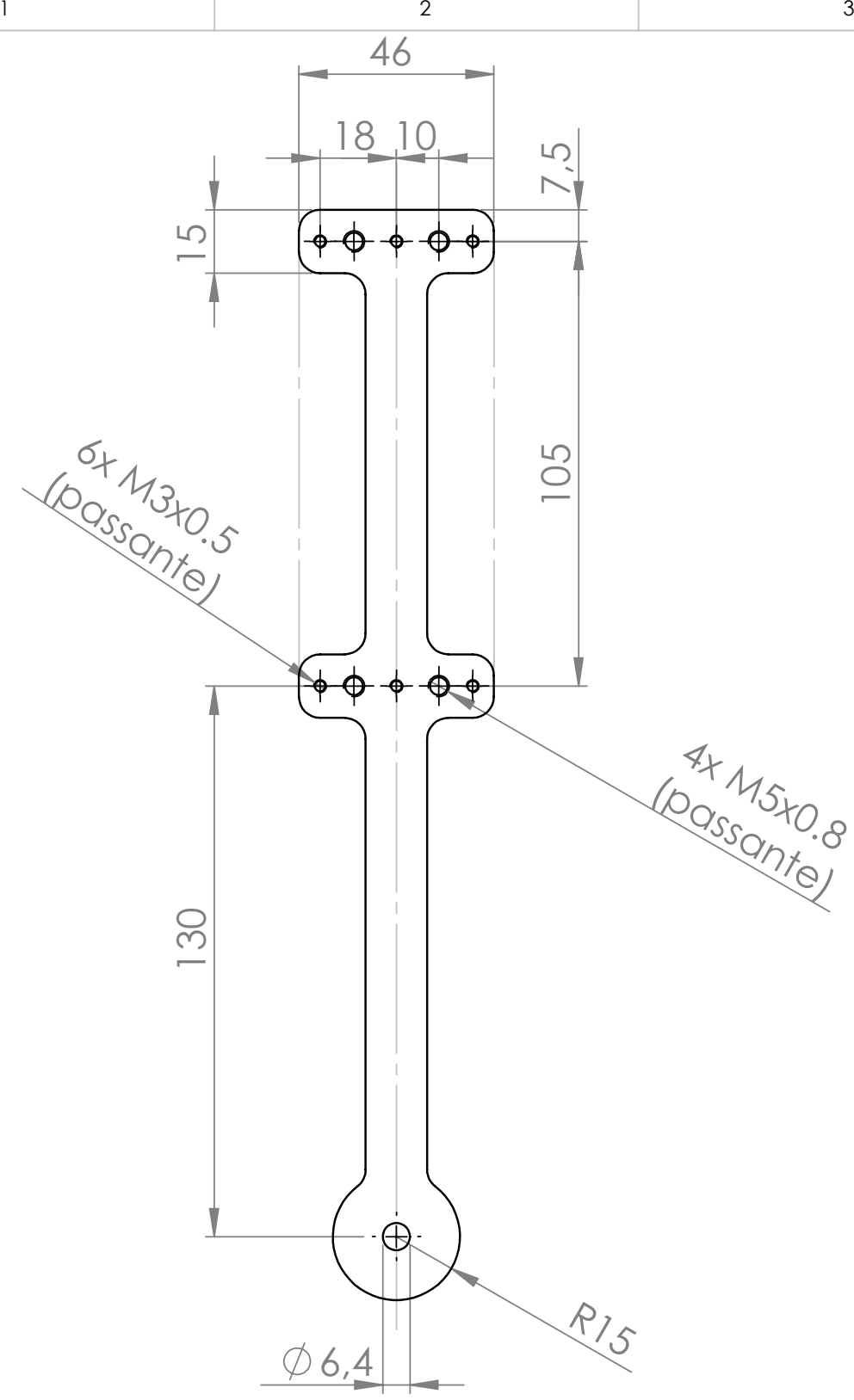

Rebarbar e quebrar arestas agudas Tolerância Gera

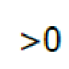

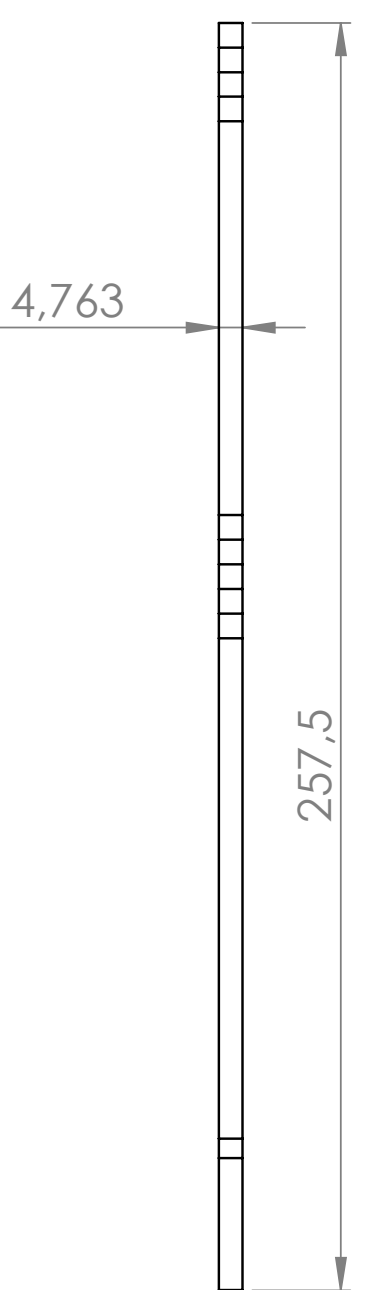

A

QUANTIDADE 1 Data 12 nov 15 PROJETO

Exoesqueleto de membro inferior TíTULO:

HasteTornozelo2

Projetist

Camila

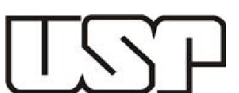

A4 


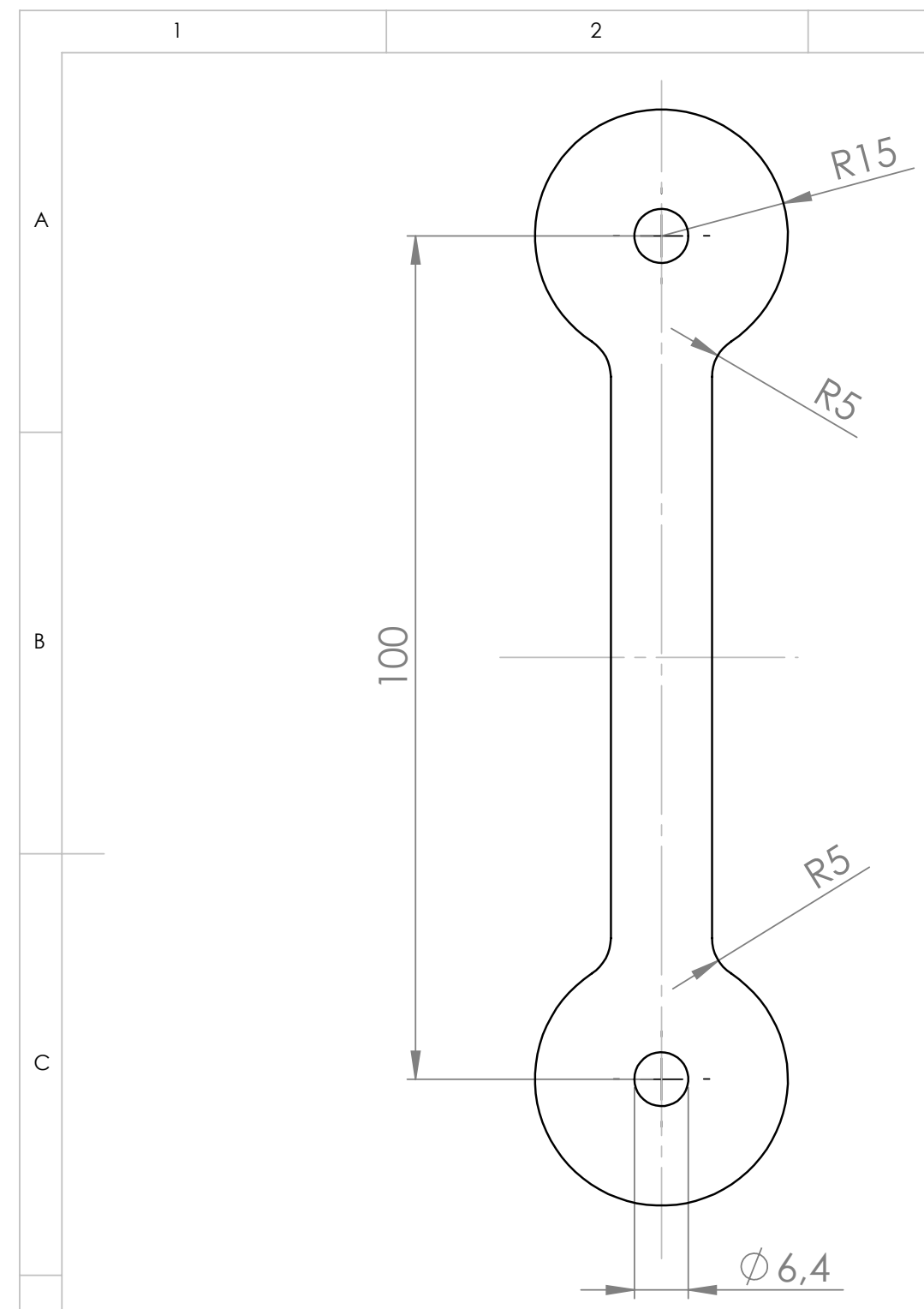




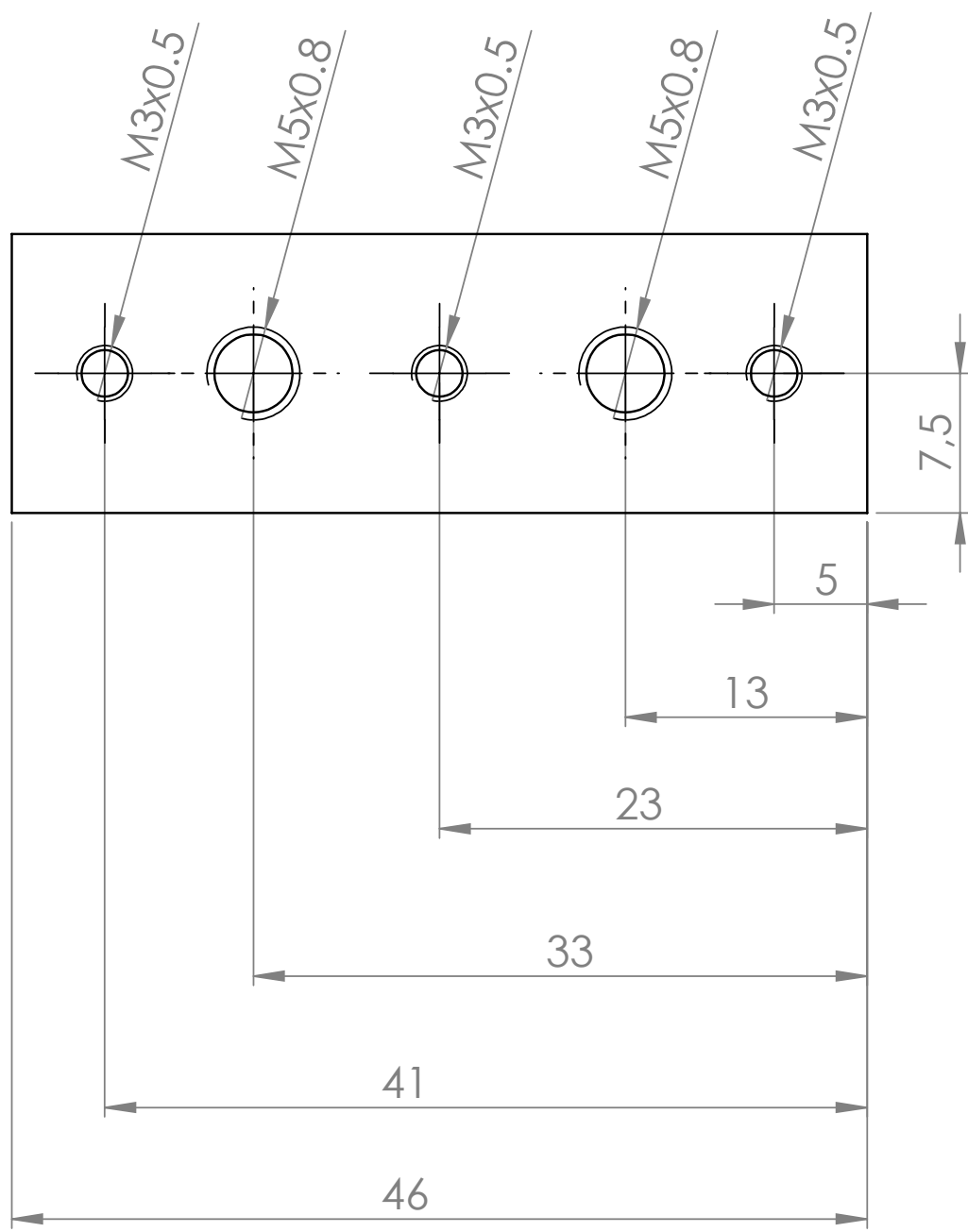

Rebarbar e quebrar

arestas agudas Tolerância Gera

$$
>0
$$

$>200-1000: \pm 0.2$

$>1000:: \pm 0.5$ $<: \pm 0.5^{\circ}$

Aluminio $5052 \mathrm{H} 34$

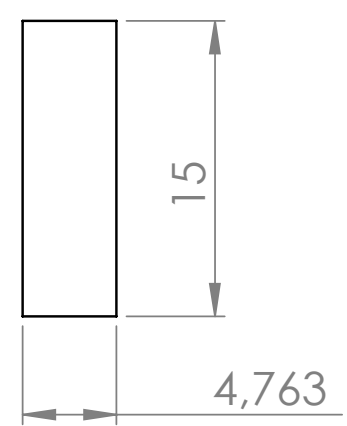

QuANTIDADE 2

Data 12 nov 15 PROJETO

Exoesqueleto de membro inferior Tíบบ:

SupApoioCanela

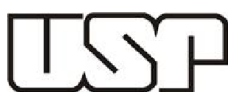

A4 


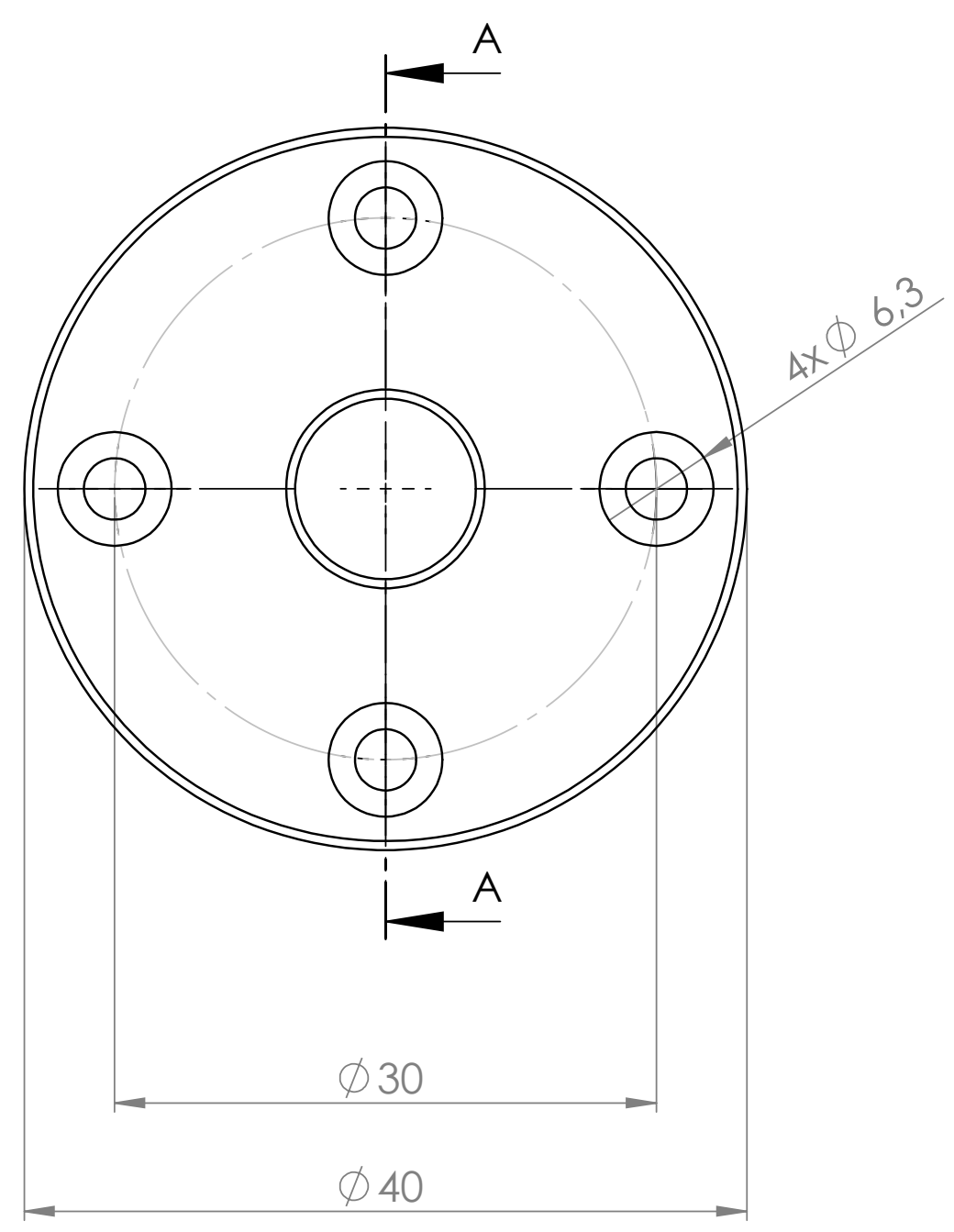

Rebarbar e quebrar

arestas agudas

Tolerância Geral

$>0$

$>200-1000: \pm 0.2$

$>1000 \quad: \pm 0.5$

$\angle: \pm 0.5^{\circ}$

MATERIAL:

Aço SAE 1020 PESO: $0.022 \mathrm{~kg}$

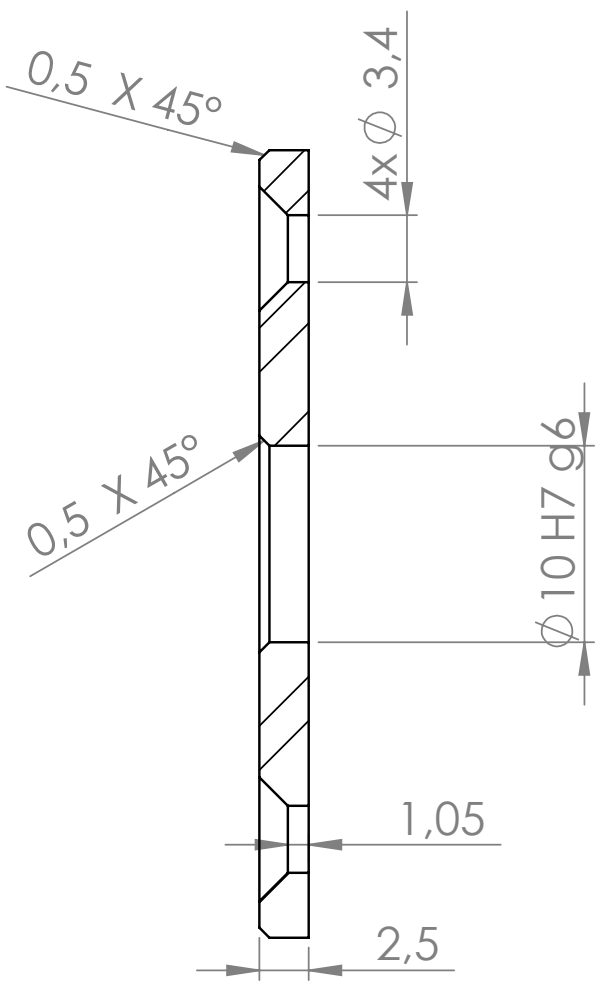

SEÇÃO A-A

QUANTIDADE 2

Data 12nov 15 PROJETO

Exoesqueleto de membro inferior TíTULO:

TampaAnelPressao Projetista

TSP A4 

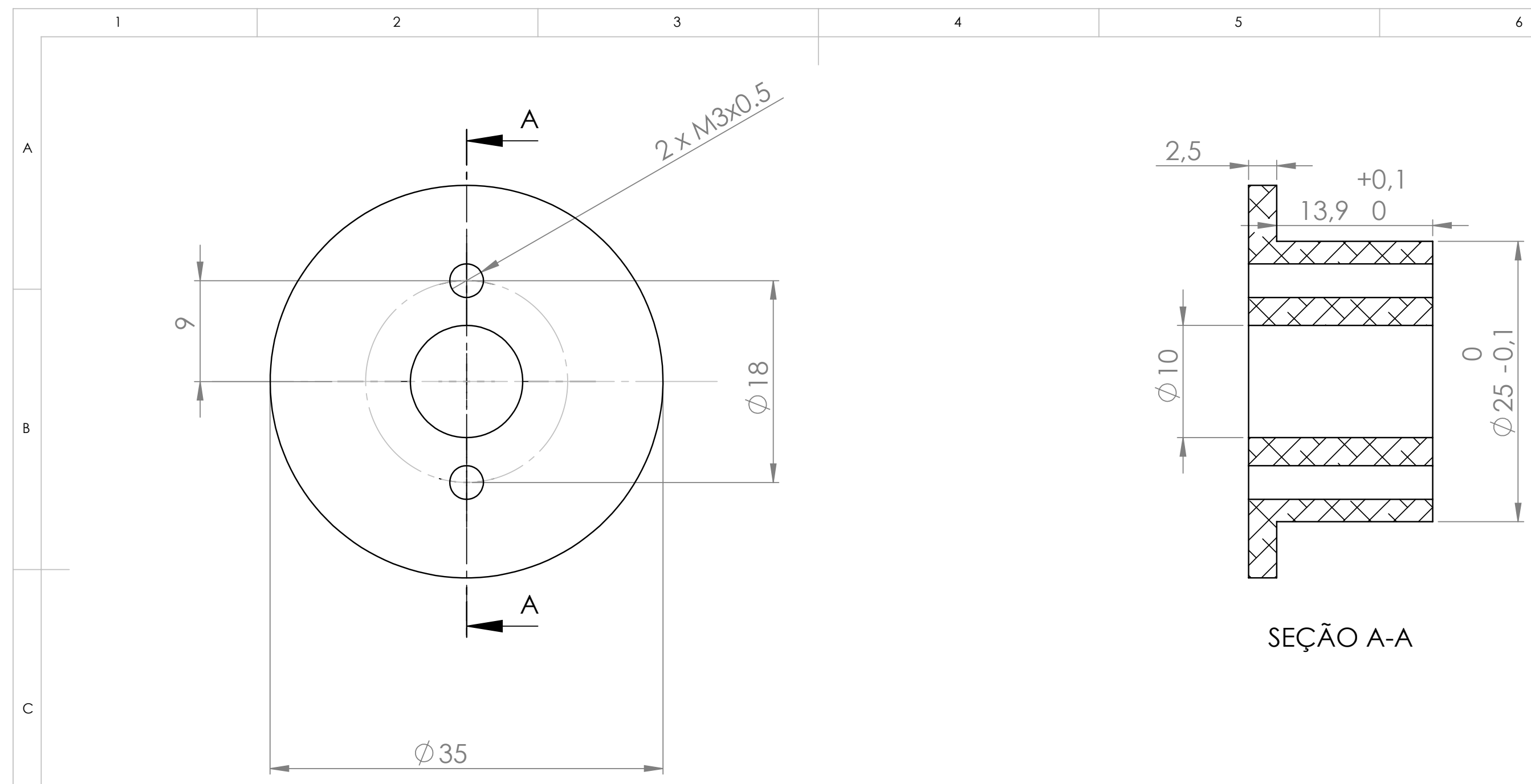

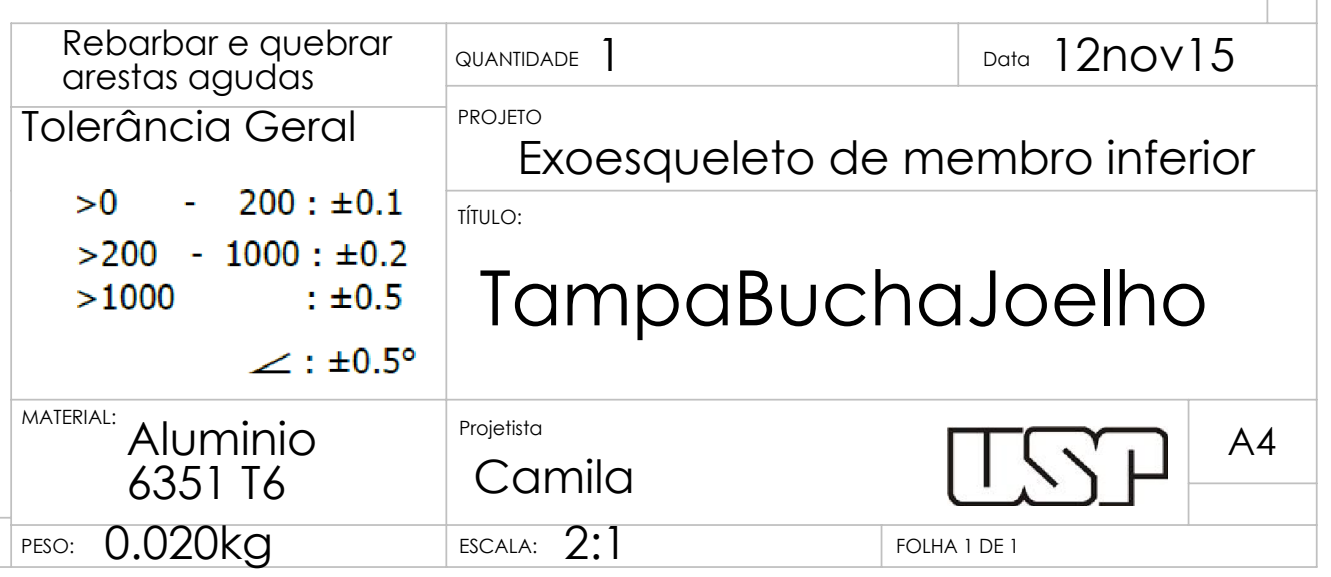




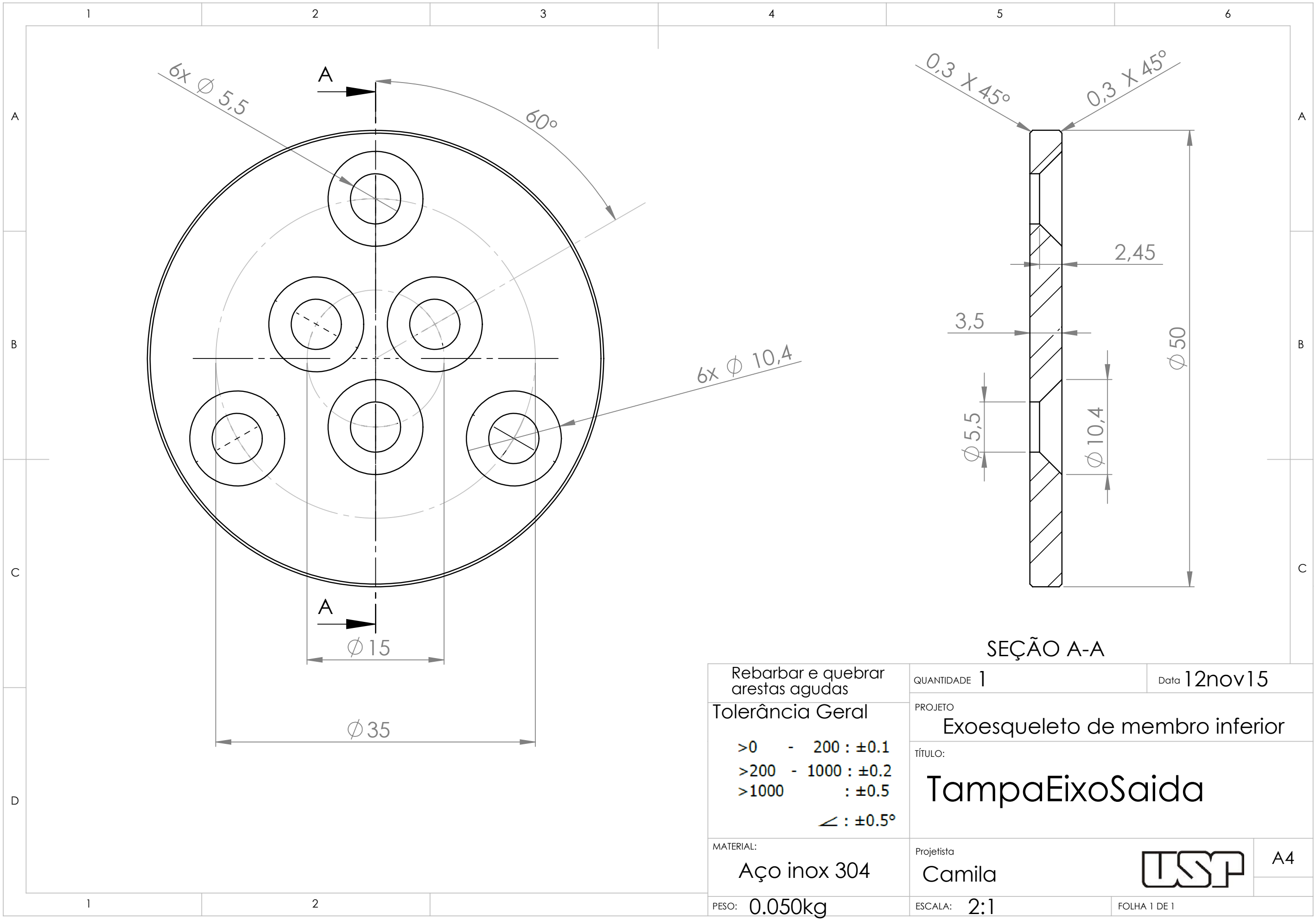

